Portland State University

PDXScholar

\title{
Bike-Ped Portal: Development of an Online Nonmotorized Traffic Count Archive
}

\author{
Krista Nordback \\ Portland State University, nordback@pdx.edu \\ Kristin A. Tufte \\ Portland State University, tufte@pdx.edu \\ Nathan McNeil \\ Portland State University \\ Morgan Harvey \\ Portland State University \\ Michelle Watkins \\ Portland State University
}

Follow this and additional works at: https://pdxscholar.library.pdx.edu/trec_reports

Part of the Transportation Commons, Urban Studies Commons, and the Urban Studies and Planning Commons

Let us know how access to this document benefits you.

\section{Recommended Citation}

Norback, K., Tufte, K., McNeil, N., Harvey, M., Watkins, M. (2017). Bike-Ped Portal: Development of an Online Nonmotorized Traffic Count Archive. NITC-RR-817. Portland, OR: Transportation Research and Education Center (TREC). https://doi.org/10.15760/trec.170

This Report is brought to you for free and open access. It has been accepted for inclusion in TREC Final Reports by an authorized administrator of PDXScholar. Please contact us if we can make this document more accessible: pdxscholar@pdx.edu. 


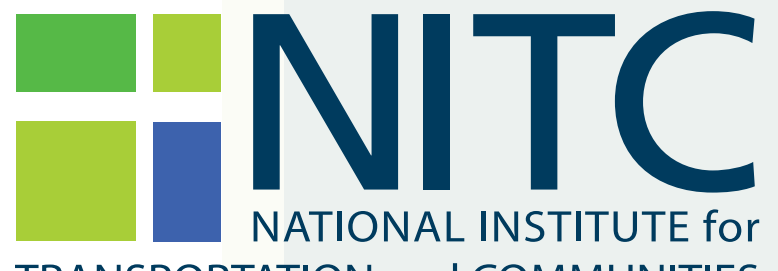

TRANSPORTATION and COMMUNITIES

FINAL REPORT

Bike-Ped Portal:

Development of an Online

Nonmotorized Traffic Count Archive

NITC-RR-817 May 2017

NITC is a U.S. Department of Transportation

national university transportation center.

HI! TREC 


\section{BIKE-PED PORTAL \\ Development of an Online \\ Nonmotorized Traffic Count Archive}

FINAL REPORT

NITC-RR-817

by

Krista Nordback

Kristin Tufte

Nathan McNeil

Morgan Harvey

Michelle Watkins

Portland State University

for

National Institute for Transportation and Communities (NITC)

P.O. Box 751

Portland, OR 97207
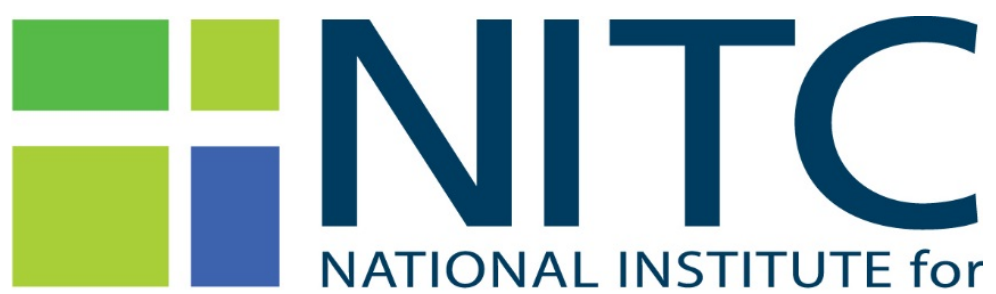

TRANSPORTATION and COMMUNITIES

May 2017 



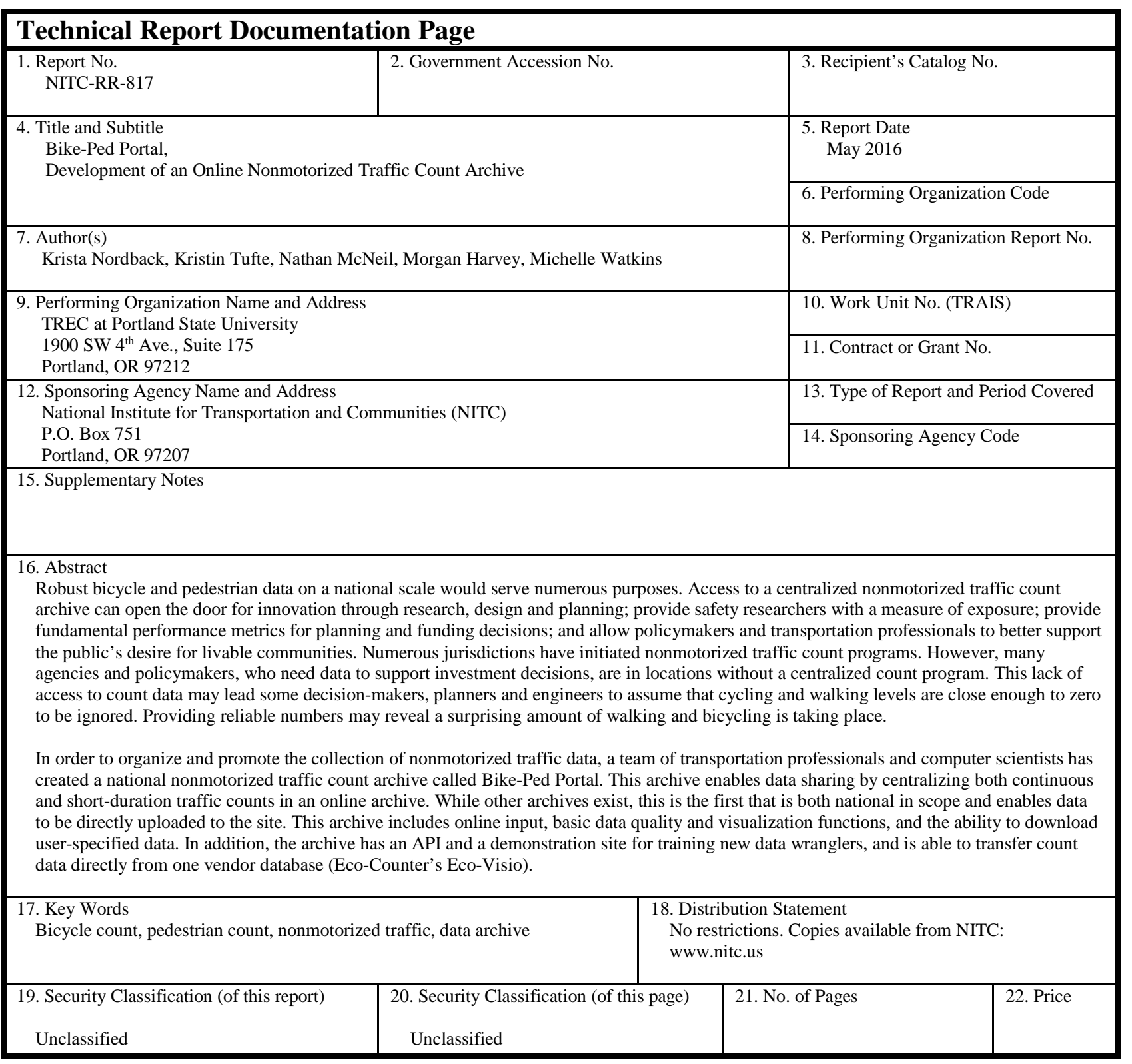





\section{Acknowledgements}

This project was funded by a pooled fund organized by the National Institute for Transportation and Communities (NITC), which also provided matching funds. We would like to thank the following sponsors for their contribution to the pooled fund: NITC; Oregon Department of Transportation; City of Bend/Bend Metropolitan Planning Organization (MPO); City of Austin, TX; City of Boulder, CO; Lane Council of Governments, Central Lane MPO, and City of Eugene, OR; Oregon Community Foundation and Cycle Oregon; Metro (Portland, OR); and the U.S. Department of Transportation Federal Highway Administration Office of Planning. Many people have contributed to make this work possible. We are very grateful for our outstanding Technical Advisory Committee members: Susan Payne and Josh Roll of LCOG; Aleksiina Chapman of Austin; Don Crownover and Sheila Lyons of ODOT; Jeremy Raw of FHWA; Jovi Anderson of Bend MPO; Mike Gardner-Sweeney of Boulder; Lake McTighe and John Mermin of Metro; Mike Sellinger of Alta Planning and Design; Matt Berkow of NelsonNygaard; Ray Jackson of Mid-Willamette Valley Council of Governments; and Hau Hagedorn of NITC. We are also deeply grateful for the work of Susan Payne at LCOG; Jon Makler and Tara Weidner at ODOT; Marjorie Bradway at the City of Portland; Elizabeth Stolz who consulted on the project; and Jennifer Dill, Hau Hagedorn, and Susan Peithman at NITC, who got the project off the ground. We'd like to recognize the support of the Modeling Program Coordination (MPC) subcommittee of the Oregon Modeling Steering Committee (OMSC), which includes representatives from all of the Metropolitan Planning Organizations within Oregon, including Rogue Valley Council of Governments (Medford, OR), Corvallis Area Metropolitan Planning Organization (Corvallis, OR), and Mid-Willamette Valley Council of Governments (Salem, OR). Thanks also to NITC, IBM and the Saturday Academy for funding internships for area high school students who worked on the project: Jolene Liu, Tomas Ramirez, Tara Sengupta, Gautam Singh, Max Fajardo, Kim Le, Kimberly Kuhn, and James Lindsey. The data wrangler team continues with a team of students, including Lynn Tran, Carlynn de Joya, Will Hahn, Dennis Nguyen, Devin Roth, and Dylan Johnstone (data wranglers); Michelle Watkins (data wrangler coordinator); Siming Chang (statistician); and Tejaswini Vibhute and Will Brown (software development).

\section{Disclaimer}

The contents of this report reflect the views of the authors, who are solely responsible for the facts and the accuracy of the material and information presented herein. This document is disseminated under the sponsorship of the U.S. Department of Transportation University Transportation Centers Program the National Institute for Transportation and Communities in the interest of information exchange. The U.S. Government the National Institute for Transportation and Communities assume no liability for the contents or use thereof. The contents do not necessarily reflect the official views of the U.S. Government the National Institute for Transportation and Communities. This report does not constitute a standard, specification, or regulation.

\section{Recommended Citation}

Nordback, Krista, Kristin Tufte, Nathan McNeil, Morgan Harvey, and Michelle Watkins. BikePed Portal: Development of an Online Nonmotorized Traffic Count Archive. NITC-RR-817. Portland, OR: Transportation Research and Education Center (TREC), 2017. 



\section{TABLE OF CONTENTS}

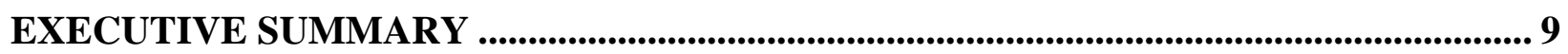

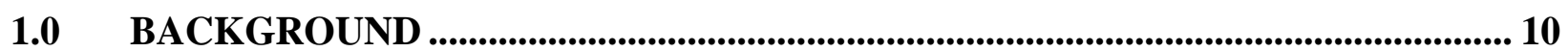

1.1 INCREASING COLLECTION OF BICYCLE AND PEDESTRIAN COUNT DATA .. 10

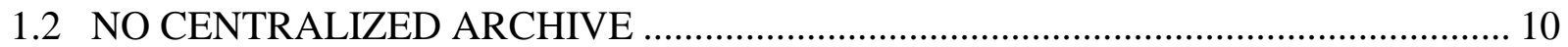

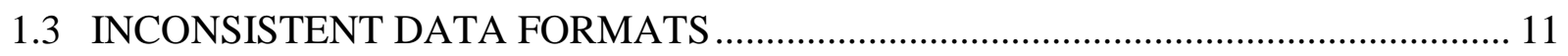

1.4 NEED FOR QUALITY DATA THAT IS ACCESSIBLE ................................................ 12

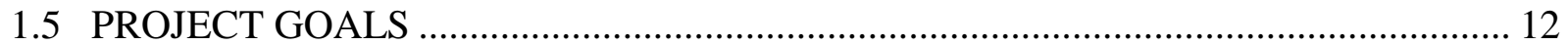

1.6 DEVELOPMENT AND PROJECT MANAGEMENT............................................... 12

1.6.1 Pooled Fund Mechanism................................................................................... 12

1.6.2 Team Composition.............................................................................................. 12

1.6.3 Technical Advisory Committee .............................................................................. 13

2.0 EXISTING DATA FORMATS AND WAREHOUSES ........................................... 14

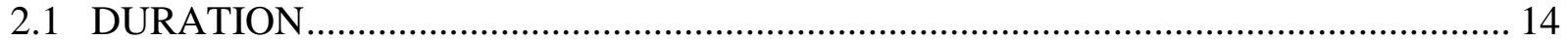

2.1.1 Classification by Duration and Data Collection Method ........................................ 14

2.1.2 Intersection vs. Segment Counts....................................................................... 15

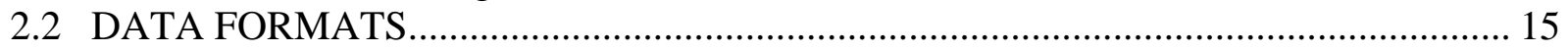

2.2.1 Raw Data Formats.............................................................................................. 16

2.2.1.1 Manual Counts: Intersection Turning Movements ............................................. 17

2.2.1.2 Automated Counts: Eco-Counter .................................................................. 18

2.2.1.3 Automated Counts: TRAFx .................................................................... 19

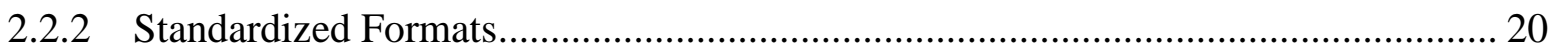

2.2.2.1 National Bicycle and Pedestrian Documentation Project..................................... 21

2.2.2.2 Los Angeles County Bike Count Data Clearinghouse .......................................... 21

2.2.2.3 Traffic Monitoring Guide ........................................................................... 22

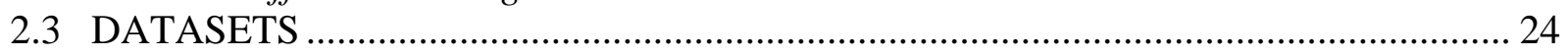

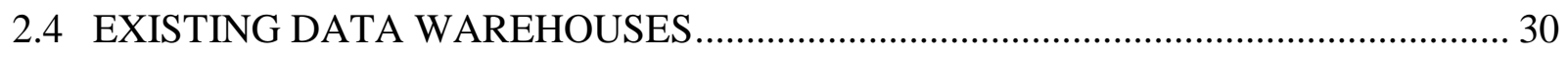

3.0 BIKE-PED PORTAL ARCHITECTURE ............................................................ 33

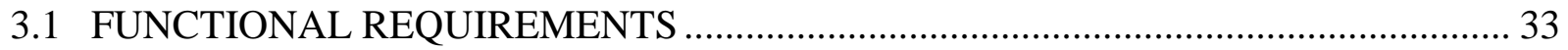

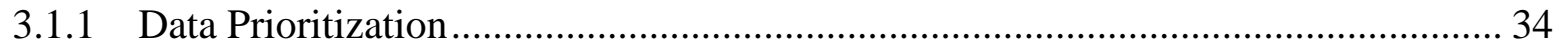

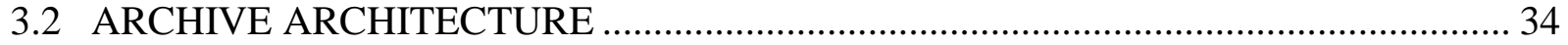

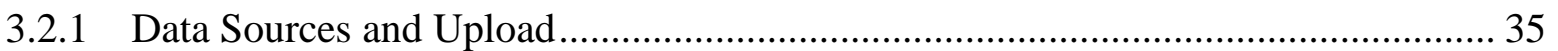

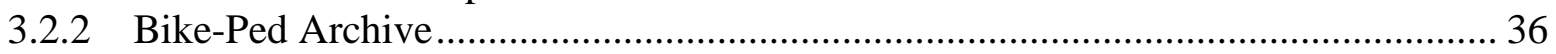

3.2.3 Data Quality Process ................................................................................................. 36

3.2.4 Bike-Ped Portal Web Interface ................................................................................. 36

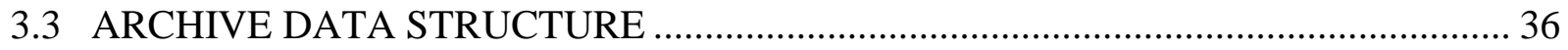

4.0 TOOL DEVELOPMENT ............................................................................................. 39

4.1 USERS AND AUTHENTICATION ……………................................................. 39

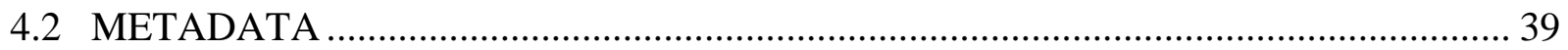

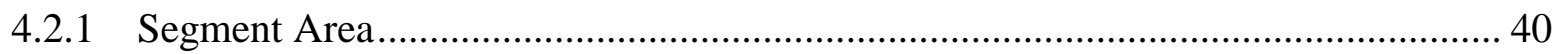

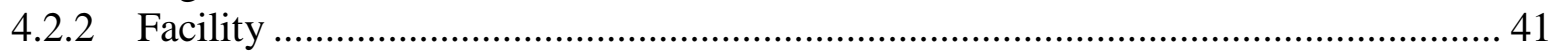

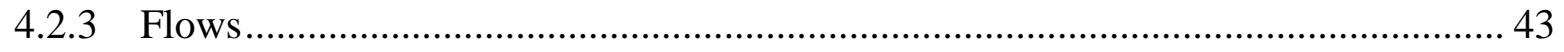

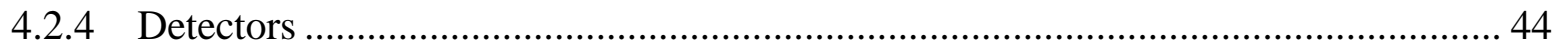

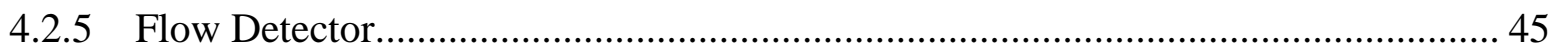




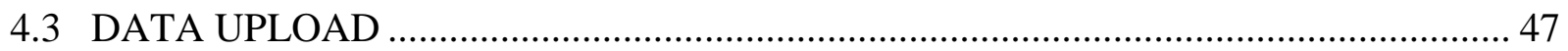

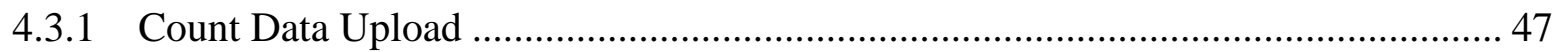

4.3.2 Count Data Format................................................................................................ 52

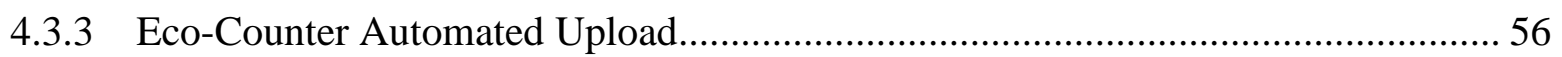

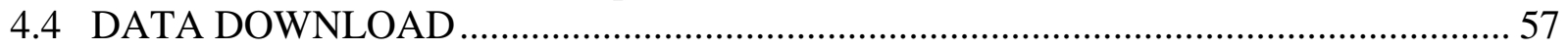

4.4.1 Data Download User Interface............................................................................ 57

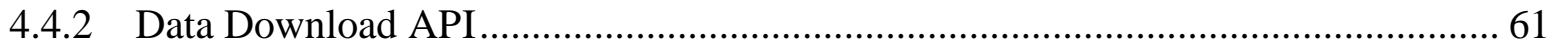

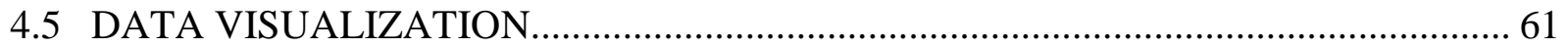

5.0 DATA QUALITY............................................................................................................. 64

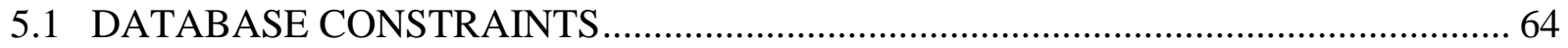

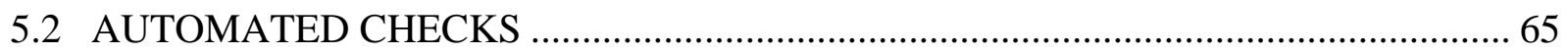

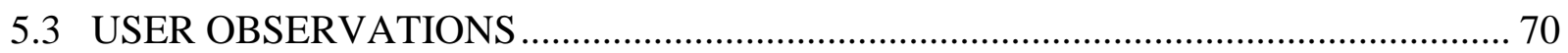

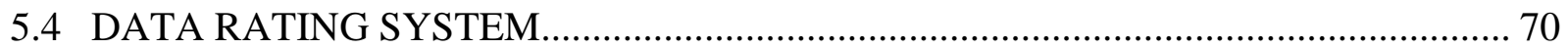

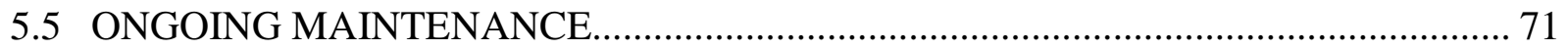

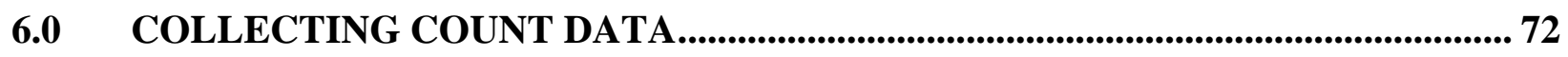

6.1 GETTING DATA FROM TAC PARTNERS AND OTHER PARTNERS ....................... 72

6.2 UPLOADING COUNT DATA - INTERNS ………………………………………….... 72

6.3 ANALYSIS OF TIME AND EFFORT TO UPLOAD ................................................... 75

7.0 CONCLUSIONS AND NEXT STEPS .......................................................................... 76

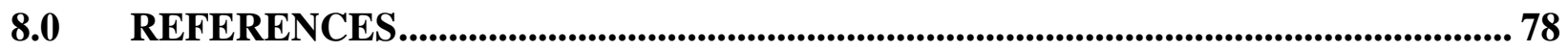

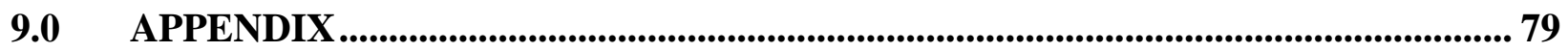

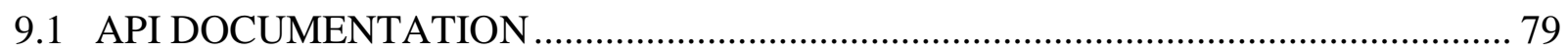

9.2 QUALITY ASSURANCE/QUALITY CONTROL SUPPORTING DOCUMENTATION

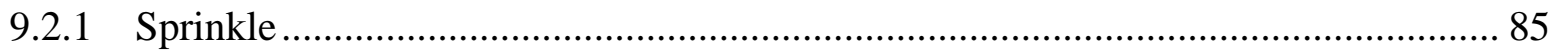

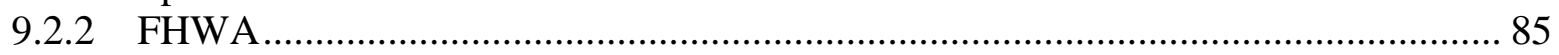

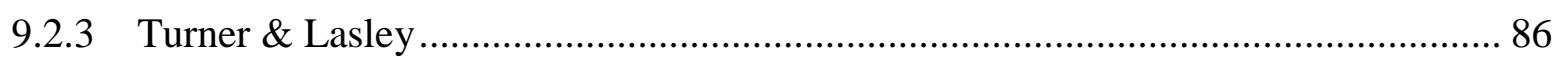

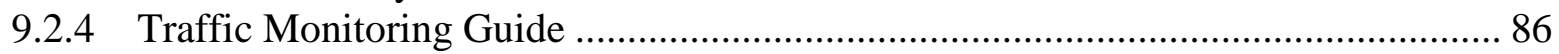

9.2.5 References for QA/QC Supporting Documentation .................................................... 88

9.3 ENTITY RELATIONSHIP DIAGRAMS (ERDS) ……………………………............ 89

9.4 EXAMPLES OF OTHER ONLINE NONMOTORIZED COUNT DATABASES.......... 98

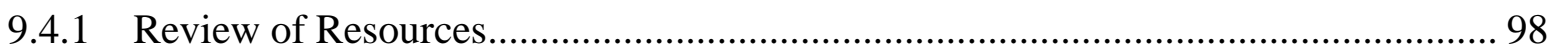

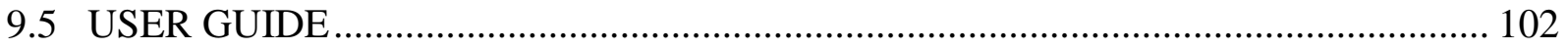

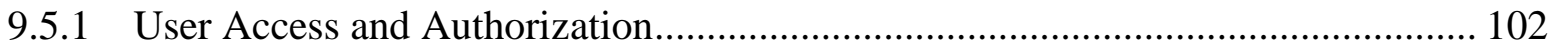

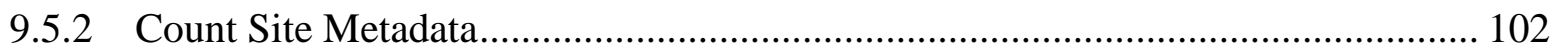

\section{LIST OF TABLES}

Table 1.1 Technical Advisory Committee Membership....................................................... 13

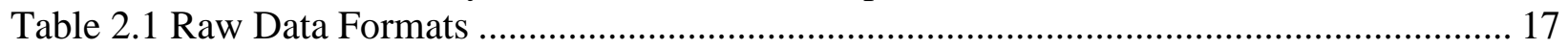

Table 2.2 Summary of Data Fields Included in Standard Data Formats ......................................... 22

Table 2.3 Datasets Available To Be Added To Archive and Status of Upload.............................. 26

Table 2.4 Matrix of Data Warehouse Types .................................................................................... 30

Table 2.5 Examples of Public, Online, Nonmotorized Traffic Count Databases and Tools ......... 31 
Table 3.1 Basic Functional Requirements for Phase I................................................................ 33

Table 4.1 Examples of Possible Headers ....................................................................................... 54

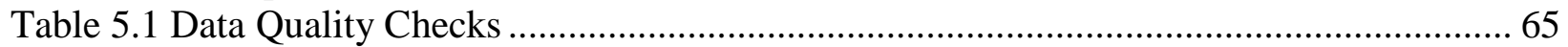

Table 10 Potential Bike/Ped Travel Monitoring Data - Quality Assurance and Quality Control

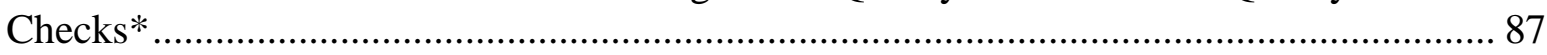

\section{LIST OF FIGURES}

Figure 1.1 Basic Features of the Data Archive.......................................................................... 11 Figure 2.1 Example Manual Turning Movement Count Using JAMAR Count Board (Source:

City and County of Denver)............................................................................................... 18

Figure 2.2. Eco-Counter Pedestrian Count Output ………........................................................... 19

Figure 2.3 TRAFx Raw Data Format (Source: Metro)............................................................. 20

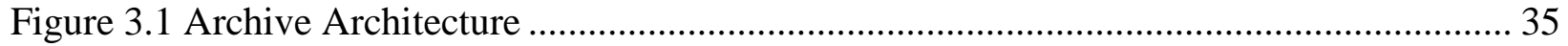

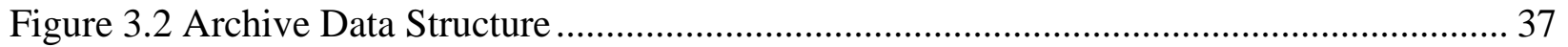

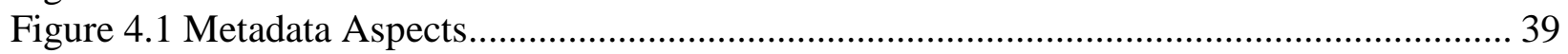

Figure 4.2 Segment Area Illustration................................................................................. 40

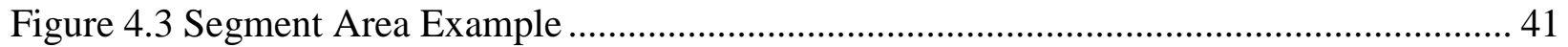

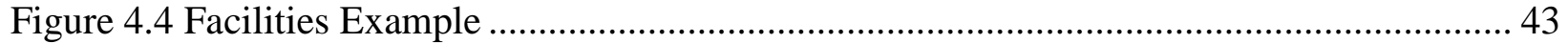

Figure 4.5 Flows Example .................................................................................................. 45

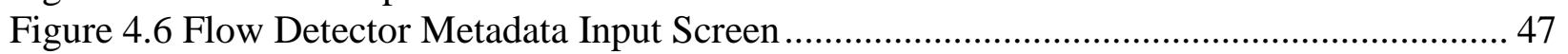

Figure 4.7 Data Upload Organization Selection Screen ............................................................. 49

Figure 4.8 Data Upload Detector and Flow Selection ................................................................. 50

Figure 4.9 Data Upload File Selection............................................................................. 51

Figure 4.10 Data Uploaded Visualization..................................................................................... 52

Figure 4.11 Preferred Data Format Example .............................................................................. 53

Figure 4.12 Start Time Format Selection in Excel …………..................................................... 55

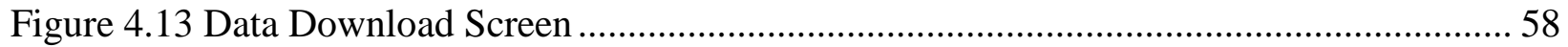

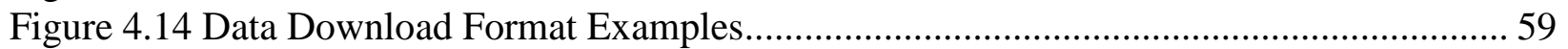

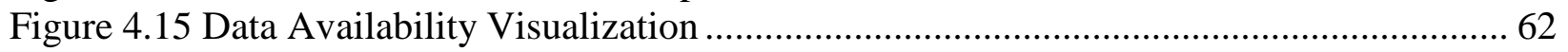

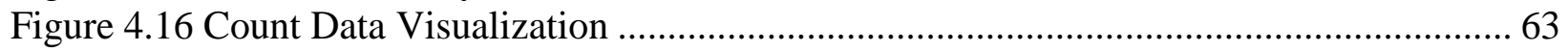

Figure 5.1 Number of Consecutive Hours with Zero Counts .......................................................... 67

Figure 5.2 Number of Hours with Duplicated Non-zero Counts..................................................... 67

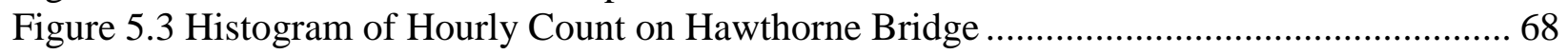

Figure 5.4 Histogram of Daily Count on Hawthorne Bridge …………….................................. 69

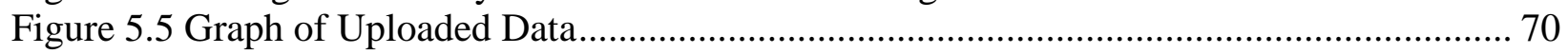

Figure 6.1 Data Records in Bike-Ped Portal by Year …………................................................... 73

Figure 6.2 Segment Areas by State in Bike-Ped Portal ............................................................... 74

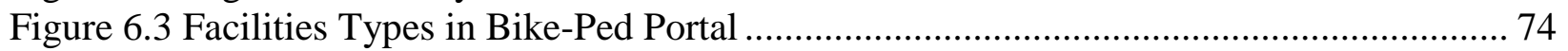

Figure 6.4 Modes of Travel by Percent of Records in Bike-Ped Portal ....................................... 75

Figure 9.1 DVRPC Pedestrian and Bicycle Counts Website (DVRPC, 2014).............................. 99

Figure 9.2 Map View from Bike Arlington Bicycle and Pedestrian Counters Website (Bike

Arlington, 2014) ...................................................................................................... 100

Figure 9.3 Data View from Bike Arlington Bicycle and Pedestrian Counters Website (Bike

Arlington, 2014) .................................................................................................................. 101 


\section{EXECUTIVE SUMMARY}

Robust bicycle and pedestrian data on a national scale would help promote effective planning and engineering of walking and bicycling facilities, build the evidence-based case for funding such projects, and dispel notions that walking and cycling are not occurring. In order to organize and promote the collection of nonmotorized traffic data, a team of transportation professionals and computer scientists has created a national bicycle and pedestrian count archive called Bike-Ped Portal. This archive enables data sharing by centralizing continuous and short-duration traffic counts in an online archive. While other archives exist, this is the first archive that is both national in scope and enables data to be directly uploaded to the site. This archive includes online input, data quality checking, data visualization functions and the ability to download user-specified data. In addition, the archive is able to transfer count data directly from one vendor database (Eco-Counter's Eco-Visio).

This report details how the archive was created, including a review of count types, standard formats, existing online archives, a list of primary functional requirements, a description of archive architecture and diagrams of archive data structure. The archive's versatile data structure allows for both automated and manual counts and both mobile counters and validation counts of the same traffic flow, an innovation in design which greatly expands the usefulness of the archive.

In addition, this report documents the user interface and data checks, summarizes count data uploaded to the archive, and provides a user guide in the Appendix. Approximately five million data records from 1998 to the present have been uploaded to the archive as of May 2016. These data currently come from five states: Colorado, Oregon, Texas, Virginia, and Washington. Data includes bicyclist, pedestrian, equestrian and "other" counts collected both manually and via automated equipment. Most of the data currently available is from Oregon, since ODOT is one of our key project partners. For sites where data are uploaded daily to the vendor's (Eco-Counter's) database (Eco-Visio) and permission has been obtained from both the data owner and equipment vendor, data are uploaded daily.

The main product of the project is the actual online Nonmotorized Traffic Count Archive, which is accessible at http://bp.its.pdx.edu/. This report documents the process of developing the archive, along with how to use the archive. 


\subsection{BACKGROUND}

Robust bicycle and pedestrian data on a national scale would serve numerous purposes. Access to a centralized nonmotorized traffic count archive will open the door for innovation through research, design and planning; provide safety researchers with a measure of exposure; provide fundamental performance metrics for planning and funding decisions; and allow policymakers and transportation professionals to better support the public's desire for livable communities. Numerous jurisdictions have initiated nonmotorized traffic count programs. However, many agencies and policymakers, who need data to support investment decisions, are in locations without a centralized count program. This lack of access to count data may lead some decision-makers, planners and engineers to assume that cycling and walking levels are close enough to zero to be ignored. Providing reliable numbers may reveal a surprising amount of walking and bicycling is taking place.

\subsection{INCREASING COLLECTION OF BICYCLE AND PEDESTRIAN COUNT DATA}

Travel monitoring is an established field, complete with guidelines, methods and requirements for practice, but including bicyclists and pedestrians in such monitoring programs is new and developing. Only a handful of states have bicycle and pedestrian count programs, and the Traffic Monitoring Guide (TMG) only recently added instructions for collecting nonmotorized traffic counts in 2013. Despite the lack of a comprehensive methodology, local and regional agencies have been collecting bicycle and pedestrian count data for decades and such data collection is intensifying, especially with the greater availability of automated bicycle and pedestrian count technologies. This has resulted in a plethora of data formats and count program designs, and a lack of coordination. Multiple agencies within the same metropolitan area may conduct counts without knowledge of the others, wasting resources in a field already constrained by limited means.

\subsection{NO CENTRALIZED ARCHIVE}

The lack of a centralized data archive and common data formatting inhibits data sharing and access, thereby greatly reducing the utility of this growing, but dispersed, dataset. While other online bicycle and pedestrian traffic count archives exist (2), this is the first that is both national in scope and enables data to be directly uploaded to the site. This archive includes online input, data quality checking and data visualization, as well as data 
storage and the ability to download user-specified data. These basic elements of a data archive are illustrated in Figure 1.1. This archive addresses the need for a national nonmotorized traffic data one-stop location that provides multiagency data access, distribution and archiving.

In addition to promoting data sharing between agencies, the archive preserves these data and can provide them back to the agencies that provided them in the event that personnel change and the original data are misplaced or deleted.

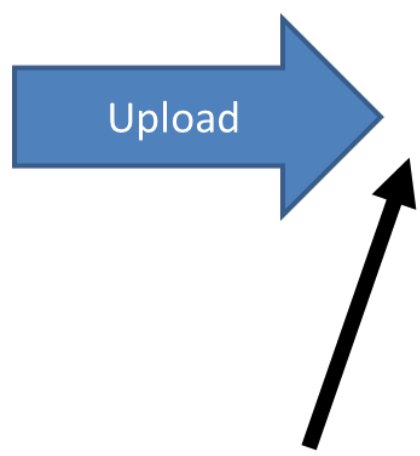

Data Checking (QA/QC)
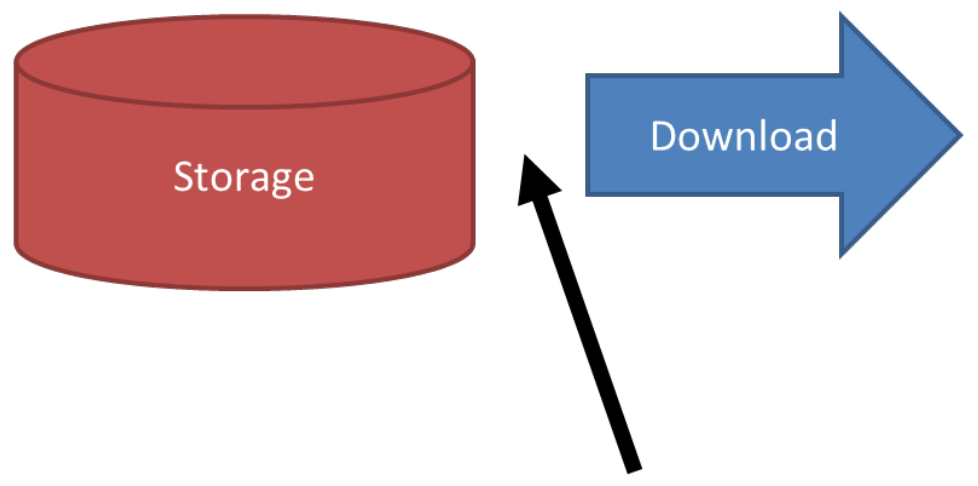

Data Visualization

Figure 1.1 Basic Features of the Data Archive

\subsection{INCONSISTENT DATA FORMATS}

The need for a centralized archive is demonstrated by the current state of bicycle and pedestrian counts in which many counts never leave the hard drives and servers of the agencies collecting them and many such data are lost.

For example, when compiling continuous count data for the state of Oregon, the team identified data from at least six local agencies in addition to that collected by the state department of transportation. This finding is similar to that found by the project team for Colorado (3). None of these data had been included in a centralized archive and were thus difficult to share with other agencies that might be searching for them. 


\subsection{NEED FOR QUALITY DATA THAT IS ACCESSIBLE}

Access to a centralized nonmotorized traffic data archive will open the door for innovation through research, design and planning; provide fundamental performance metrics for planning and funding decisions; and allow policymakers and transportation professionals to better support the public's desire for livable communities. While the National Bicycle and Pedestrian Documentation Project (4) does provide a standard count data collection format and invites participants to submit their counts, these data are not available to the public and are not compiled into a database.

\subsection{PROJECT GOALS}

Our methodology divides this challenge into several discrete pieces. The first part is to unify data in a common format. This requires software that can determine if a dataset conforms or translates it if it doesn't. The second part is to validate the data. This requires software that can recognize potentially invalid data and prompt the data supplier to verify, adjust or exclude them. The third part is to archive the data, which requires stability and security. The fourth and final part is to release the data through online output tools, which requires an effective website that serves a variety of user types.

\subsection{DEVELOPMENT AND PROJECT MANAGEMENT}

\subsubsection{Pooled Fund Mechanism}

This project was funded through the Pooled Fund program of the National Institute for Transportation and Communities (NITC), the U.S. Department of Transportation's national center for livable communities and one of five U.S. DOT national university transportation centers. The NITC fund matched funding provided by the Oregon Department of Transportation (ODOT); the Federal Highway Administration (FHWA); the City of Boulder, CO; the City of Eugene, OR; Lane Council of Governments (LCOG) in Lane County, OR; the City of Austin, TX; the City of Bend, OR; Jackson County; Cycle Oregon; and Metro (Portland's regional MPO).

\subsubsection{Team Composition}

The project team is an interdisciplinary group with expertise in software development, transportation planning and engineering. It includes program and management staff with expertise in nonmotorized facilities and counting, and technical and development staff with expertise in software, web and database development and extensive experience with 
transportation data (particularly through the development and operation of PORTAL). The team is assisted by a team of data wranglers which include undergraduate and graduate students and a team of interns from the Saturday Academy's Apprenticeship in Science and Engineering program, which has connected us with some of the best and brightest high school students in the metropolitan area.

\subsubsection{Technical Advisory Committee}

The Technical Advisory Committee represented funders and data providers and advised the project team as a resource for building a robust, useful and practical online data archive. The TAC met every three to four months in Salem, OR (with one meeting occurring in Portland). Remote attendance was also enabled. Technical Advisory Meeting dates included:

- March 20, 2014

- July 25, 2014

- November 4, 2014

- February 24, 2015

- June 26, 2015

- December 8, 2015

Table 1.1 Technical Advisory Committee Membership

\begin{tabular}{ll}
\hline Name & Organization \\
\hline Susan Payne & Lane Council of Governments \\
Josh Roll & Lane Council of Governments \\
Aleksiina Chapman & City of Austin \\
Don Crownover & Oregon Department of Transportation \\
Jeremy Raw & Federal Highway Administration \\
Jovi Anderson & Bend Metropolitan Planning Organization (BMPO) \\
Mike Sweeney & City of Boulder \\
Sheila Lyons & Oregon Department of Transportation \\
Hau Hagedorn & Portland State University \\
Lake McTighe & Metro \\
John Mermin & Metro \\
Mike Sellinger & ALTA Planning + Design \\
Matt Berkow & Formerly of ALTA Planning + Design \\
Ray Jackson & Mid-Willamette Valley Council of Governments \\
\hline
\end{tabular}




\subsection{EXISTING DATA FORMATS AND WAREHOUSES}

\subsection{DURATION}

With a data archiving system, it is critical to understand how data that will populate the archiving system is gathered. This is important because an archiving system's back-end functionality is dependent on how data suppliers will provide information. In an effort to understand the back-end data suppliers of nonmotorized traffic volume data, a review of the nonmotorized count duration and data types is offered below.

Traffic count data, in general, are diverse, and nonmotorized traffic count data are especially so because nonmotorized travel is more complex (e.g., pedestrians may cross a road or intersection in a variety of ways) and because these data have lacked an effective central organizing mandate. However, there are some important function-based distinctions that inform data classifications. Bicycle and pedestrian count data can be classified by method of collection into several categories.

\subsubsection{Classification by Duration and Data Collection Method}

First, manual counts are counts conducted by individuals. Generally they consist of an individual, often an agency staff member, volunteer or intern manually counting people walking or bicycling. These counts may be taken on location in the field or while reviewing video recordings or feeds on a computer. They may be taken by hand by jotting lines on a paper schematic of the count location, with a handheld electronic counting board, by using a smartphone, or various other ways. Manual counts are often conducted over a short duration (e.g., two hours) at infrequent intervals (e.g., once annually). Because they are short in duration, these counts are also biased by weather conditions, events, and weekly and seasonal variation.

Next, short-duration automated counts are distinct from manual counts in that they are collected by machine and typically have a longer duration than manual counts (24 hours to multiple weeks). They are collected by mobile automated counters. Because they are short in duration, they are also subject to biases such as seasonality and weather.

Finally, continuous automated counts may provide the best data about a location. Continuous automated counts are collected continuously, 24 hours per day, seven days per week, 365 days a year, by counters that are permanently installed at a location. Continuous automated counts do not need to be adjusted for seasonality and, in contrast 
with a 48-hour count, which could be affected by an unusual weather pattern, the long duration of continuous counts limits the impact of special events and unusual weather. However, they are still susceptible to under- or overcounting due to occlusion, improper set up, or other technical issues related to the specific technology, site and traffic flow.

Each type of count may contain bias. Manual counts are often conducted by volunteers or otherwise non-full-time counters and may be subject to counter bias. Automated counters require appropriate installation and maintenance and need validation. While such counts are not subject to human bias, they may have substantial biases due to occlusion, improper installation or setup, and other systematic errors depending on the specific technology, site and traffic flow (5). However they also allow for much longer-duration counts than are possible with manual counting and thus provide a valuable source of count data. With such count records, one can study hourly, daily and monthly traffic patterns, which would be impossible to study with only manual counts.

\subsubsection{Intersection vs. Segment Counts}

Another important way to classify count data is by whether the count is collected at an intersection and/or on a road or path segment. Intersection counts are sometimes broken out into turning movements. Segment counts are also known as screenline counts because they count every bicyclist or pedestrian who crosses an imaginary line drawn perpendicular to the facility. Many manual counts are collected at intersections, and most automated counts are collected on segments. Recent developments in video image processing are making intersection counts feasible for longer durations.

Intersection counts can be much more complex than segment counts because traffic turns at intersections. The paths of nonmotorized traffic flow at intersections are not as channelized as it is for motor vehicles. For example, bicyclists may either act as on-street vehicles or use crosswalks like pedestrians. This leads to a greater degree of complexity in nonmotorized intersection counts than is required for motor vehicle counts.

\subsection{DATA FORMATS}

This section provides an overview of current standard data formats. The project team reviewed these formats, in addition to the formats of data provided by our partner agencies, to inform our database structure design and, where possible, to be compatible with other count archives. Our goal is to create a robust data structure that can handle data from a variety of input sources, including manual, short-duration and continuous automated counts. For this reason, an understanding of existing standard data formats is important. 
Nonmotorized count data formats vary by jurisdiction in the case of manual counts and by counter manufacturer in the case of automated counts. To standardize these data, there are at least three main ongoing efforts in the U.S. The oldest is that offered by the National Bicycle and Pedestrian Documentation Project (NBPDP) (4). The other two have only been established in the last two years: the Los Angeles Bike Count Data Clearinghouse (2) and FHWA's Traffic Monitoring Guide (TMG) (6) data format. The NBPDP and Los Angeles formats are designed for manual counts. The TMG format includes the ability to adapt to both manual and automated counts, but is best adapted to automated count data.

\subsubsection{Raw Data Formats}

Despite efforts by the NBPDP and others to standardize manual counts, they are collected in many formats. The forms provided by NBPDP are often modified to suit the needs of local jurisdictions, which can lead to lack of compatibility both in the raw data themselves and in the formats in which the data are stored. For example, the NBPDP intersection form is specific for bicycle counts only, but some jurisdictions have modified it to collect pedestrian counts as well. Similarly, the NBPDP intersection form does not record gender or helmet use, but has been modified by some jurisdictions to include these fields, adding to the complexity of the data produced.

For automated counts, the data formats used by different equipment manufacturers can vary and are often not interoperable. These raw data usually consist of a date and time followed by a count, counts for directional counts, or equipment which counts multiple locations or modes. However, even minor differences between data files require modifications to the loading script for each raw file type to be added to an archive. Once such a script is created, uploading future data can be automatic, unless the manufacturer changes the data output file format even slightly. This becomes more problematic the more raw data formats an archive supports and the more often manufacturers make format changes.

For this reason, standardized formats are desirable in order to archive data. If all data were always produced in one standard format, adding them to an archive would be significantly easier. The TMG offers a standard format for nonmotorized count data, which includes metadata. Unfortunately, the fixed-width format is difficult to interpret for those unfamiliar with it.

Data formats are diverse. They vary by jurisdiction in the case of manual counts and by counter manufacturer in the case of automated counts. Below is a list of data formats by manufacturer name and example agencies that use these formats. 
Table 2.1 Raw Data Formats

\begin{tabular}{|l|l|}
\hline Data format by vendor & Locations where format has been used \\
\hline Eco-Counter & $\begin{array}{l}\text { Portland, OR; Eugene, OR; Boulder, CO; } \\
\text { Austin, TX; San Francisco, CA; Seattle, WA; } \\
\text { Arlington, VA; San Diego, CA; North Carolina; } \\
\text { and many more }\end{array}$ \\
\hline TRAFx & $\begin{array}{l}\text { Portland metro area, Pitkin \& Summit counties } \\
\text { in Colorado, and many more }\end{array}$ \\
\hline GTT Canoga & Boulder, CO \\
\hline TimeMark & Olympia, WA \\
\hline Miovision & Boulder, CO \\
\hline Iteris & Denver, CO \\
\hline MetroCount & Boulder County, CO; Hennepin County, MN \\
\hline Trail Master & Minneapolis, MN; Redmond, WA \\
\hline JAMAR & Portland, OR; Boulder, CO; San Diego, CA \\
\hline Sensys & Seattle, WA \\
\hline Ivan Technologies & Longmont, CO \\
\hline Chambers Electronics & Blacksburg, VA \\
\hline 2070 signal controller software & Portland, OR \\
\hline $\begin{array}{l}\text { Manual counts (NBPDP, turning } \\
\text { movement counts and other) }\end{array}$ & $\begin{array}{l}\text { Portland and Bend, OR; Oregon and Washington } \\
\text { State; Milwaukee, WI; and many more }\end{array}$ \\
\hline
\end{tabular}

This list is not exhaustive, but gives an example of the diversity of such data types. Examples of some prominent vendor formats are provided below.

\subsubsection{Manual Counts: Intersection Turning Movements}

Intersection turning movement counts are a common data type. While the exact format of the data varies by vendor, by intersection and by jurisdiction, the basic concept is the same. Data can be collected directly in the field or entered from videos. Counts can be collected by volunteers, staff or traffic monitoring firms, and data are often entered in electronic count boards and output in spreadsheet format. Figure 2.2 shows an example of the spreadsheet format. 


\begin{tabular}{|c|c|c|c|c|c|c|c|c|c|c|c|c|c|c|c|c|}
\hline \multirow{2}{*}{\multicolumn{2}{|c|}{$\begin{array}{l}\text { File Name: } \\
\text { Start Date: }\end{array}$}} & \multicolumn{15}{|c|}{ C:IProgram FilesIJAMARIPetraProlData FilesIHNTBICCD TIMINGI1I14TH\&ARAPAHOEPM.p } \\
\hline & & \multicolumn{15}{|c|}{$11 / 6 / 2007$} \\
\hline \multicolumn{2}{|c|}{ Start Time: } & 4:00:0 & PM & & & & & & & & & & & & & \\
\hline \multicolumn{17}{|c|}{ Site Code: 00000000} \\
\hline \multicolumn{17}{|c|}{ Comment 1: Default Comments } \\
\hline \multicolumn{2}{|c|}{ Comment 2: } & \multicolumn{15}{|c|}{ Change These in The Preferences Window } \\
\hline \multicolumn{2}{|c|}{ Comment 3: } & \multicolumn{15}{|c|}{ Select File/Preference in the Main Scree } \\
\hline \multicolumn{2}{|c|}{ Comment 4: } & \multicolumn{15}{|c|}{ Then Click the Comments Tab } \\
\hline & & \multicolumn{3}{|c|}{$\begin{array}{l}\text { ARAPAHOE } \\
\text { Southbound }\end{array}$} & \multicolumn{4}{|c|}{$\begin{array}{c}14 T H \text { ST } \\
\text { Westbound }\end{array}$} & \multicolumn{4}{|c|}{$\begin{array}{l}\text { ARAPAHOE } \\
\text { Northbound }\end{array}$} & \multicolumn{4}{|c|}{$\begin{array}{l}\text { 14TH ST } \\
\text { Eastbound }\end{array}$} \\
\hline Start & Left & Thru & Right & Peds & Left & Thru & Right & Peds & Left & Thru & Right & Peds & Left & Thru & Right & \begin{tabular}{|l|} 
Peds \\
\end{tabular} \\
\hline 16:00 & 41 & 56 & 0 & 16 & 0 & 0 & 0 & 33 & 0 & 0 & 20 & 4 & 0 & 95 & 2 & 4 \\
\hline $16: 15$ & 47 & 60 & 0 & 0 & 0 & 0 & 0 & 28 & 0 & 0 & 21 & 3 & 0 & 91 & 4 & 1 \\
\hline $16: 30$ & 42 & 78 & 0 & 4 & 0 & 0 & 0 & 19 & 0 & 0 & 19 & 4 & 0 & 82 & 5 & 1 \\
\hline $16: 45$ & 51 & 79 & 0 & 11 & 0 & 0 & 0 & 33 & 0 & 0 & 18 & 11 & 0 & 80 & 10 & 3 \\
\hline $17: 00$ & 54 & 116 & 0 & 13 & 0 & 0 & 0 & 51 & 0 & 0 & 11 & 30 & 0 & 103 & 13 & 5 \\
\hline $17: 15$ & 33 & 72 & 0 & 11 & 0 & 0 & 0 & 37 & 0 & 0 & 29 & 31 & 0 & 123 & 18 & 0 \\
\hline $17: 30$ & 45 & 81 & 0 & 18 & 0 & 0 & 0 & 46 & 0 & 0 & 40 & 26 & 0 & 96 & 16 & 14 \\
\hline $17: 45$ & 41 & 82 & 0 & 31 & 0 & 0 & 0 & 45 & 0 & 0 & 22 & 26 & 0 & 117 & 16 & 0 \\
\hline
\end{tabular}

Figure 2.1 Example Manual Turning Movement Count Using JAMAR Count Board (Source: City and County of Denver)

Though apps are available to support manual pedestrian counts, many agencies still use paper and clipboards to do pedestrian intersection counts. However, in some cases, such as Washington State's Bicycle and Pedestrian Documentation Program, volunteers enter count data from their paper forms used in the field directly into an online database. This avoids additional staff time to aggregate this data.

\subsubsection{Automated Counts: Eco-Counter}

Eco-Counter is a manufacturer of bicycle and pedestrian counting equipment including inductive loops (ZELT), pneumatic tubes (TUBES), passive infrared (PYRO), and a combination of loops and infrared (MULTI). Figure 2.3 shows an example of the standard data format for Eco-Counter devices. The example shown is from their PYRO model, a passive infrared device that counts warm bodies. The first and second columns list the start date and time of the count period. The third column lists the total volume and the fourth and fifth column list the pedestrians counted in each direction. The output count format for their other detectors is similar. 


\begin{tabular}{|l|r|r|r|r|}
\hline & & TREC & Pyrobox_H-9_IN & Pyrobox_H-9_OUT \\
\hline $17 / 06 / 2014$ & $14: 00$ & 0 & 0 & 0 \\
\hline $17 / 06 / 2014$ & $14: 15$ & 0 & 0 & 0 \\
\hline $17 / 06 / 2014$ & $14: 30$ & 0 & 0 & 0 \\
\hline $17 / 06 / 2014$ & $14: 45$ & 2 & 1 & 1 \\
\hline $17 / 06 / 2014$ & $15: 00$ & 0 & 0 & 0 \\
\hline $17 / 06 / 2014$ & $15: 15$ & 67 & 44 & 23 \\
\hline $17 / 06 / 2014$ & $15: 30$ & 77 & 46 & 31 \\
\hline $17 / 06 / 2014$ & $15: 45$ & 5 & 3 & 2 \\
\hline $17 / 06 / 2014$ & $16: 00$ & 4 & 4 & 0 \\
\hline $17 / 06 / 2014$ & $16: 15$ & 2 & 1 & 1 \\
\hline $17 / 06 / 2014$ & $16: 30$ & 1 & 1 & 0 \\
\hline $17 / 06 / 2014$ & $16: 45$ & 3 & 1 & 2 \\
\hline $17 / 06 / 2014$ & $17: 00$ & 0 & 0 & 0 \\
\hline $17 / 06 / 2014$ & $17: 15$ & 2 & 1 & 3 \\
\hline $17 / 06 / 2014$ & $17: 30$ & 4 & 1 & 0 \\
\hline $17 / 06 / 2014$ & $17: 45$ & 0 & 0 & 0 \\
\hline $17 / 06 / 2014$ & $18: 00$ & 0 & 0 & \\
\hline
\end{tabular}

\section{Figure 2.2. Eco-Counter Pedestrian Count Output}

\subsubsection{Automated Counts: TRAFX}

TRAFx is a manufacturer of bicycle and pedestrian counting equipment including passive infrared and radar units. Figure 2.3 shows an example of a TRAFx raw count data, which is supplied by the vendor in CSV format. The first two columns indicate the start date (yy-mm-dd) and time, and the third indicates the total pedestrian traffic volume. This example comes from a non-directional counter. 


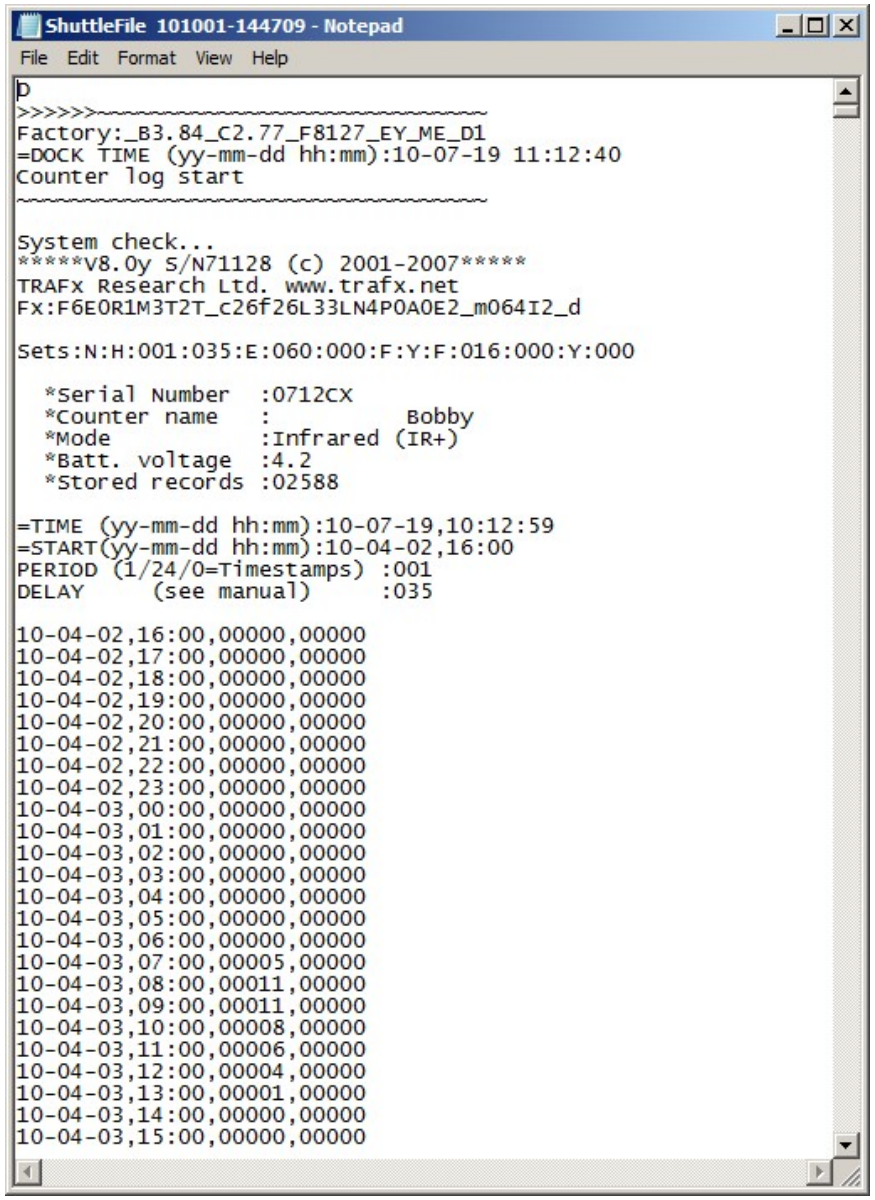

Figure 2.3 TRAFx Raw Data Format (Source: Metro)

\subsubsection{Standardized Formats}

For this work we are drawing from three main standardized formats for the U.S.:

- National Bicycle and Pedestrian Documentation Project (NBPDP) format

- Los Angeles Data Clearinghouse format

- Federal Highway Administration (FHWA)’s Traffic Monitoring Guide (TMG) format 


\subsubsection{National Bicycle and Pedestrian Documentation Project}

The first effort on the national level to create a standard format for bicycle and pedestrian counts was the National Bicycle and Pedestrian Documentation Project (NBPDP). The NBPDP was initiated by a joint effort between the Institute of Transportation Engineers (ITE) and Alta Planning and Design in 2004 as a response to the lack of available bicycle and pedestrian data for use in analysis, estimation and other purposes (7). The NBPDP website provides standard forms, instructions and other information for agencies interested in counting nonmotorized traffic. The NBPDP has helped and encouraged many jurisdictions around the nation to start bicycle and pedestrian counting programs.

The NBPDP accepts and stores data files submitted by email to the project's administrators. It encourages submitters to use its standard data format for such submissions but does not require it. The format includes contact information for the person responsible for data as well as data fields summarized in Table 1. The format asks for general information on the area in which the count is collected and count-locationspecific information as well as count data. While these fields would provide helpful metadata for those studying the area, they can sometimes be found in other databases and may not be readily accessible to the count data provider. This can lead to few data providers submitting data such as population density or number of visitors to an area.

While the NBPDP data collection methodology is meant to provide guidance on data collection methods, it does not address the need for electronically managing the data in an organized, standardized, easily accessible database and associated archiving system. Access to data collected using the NBPDP method is found by request only, which does not yield an electronically efficient way to access data in a practice-ready format. BikePed Portal may partner with NBPDP in the future to address some of these concerns.

\subsubsection{Los Angeles County Bike Count Data Clearinghouse}

Another effort to standardize and collect bicycle count data comes from the Los Angeles area. The University of California Los Angeles (UCLA) Luskin School of Public Affairs' Bike Count Data Clearinghouse project began in 2012 with the goal of housing bike volume data from the Los Angeles County region (8). The project was co-sponsored by Southern California Association of Governments and the Los Angeles County Metropolitan Transportation Authority. This data archive offers a user-friendly interface featuring a web-GIS tool to make housed data accessible for use. Data are standardized for municipalities in Los Angeles County. To the authors' knowledge, this archive is the only publicly available, online bicycle count archive that also enables no-cost online data uploads from agencies within a region. 
While the Los Angeles Data Clearinghouse provides access to data electronically, the project database structure is focused on handling primarily two-hour count data. Data handling and uploading of data are restricted, and data suppliers must first obtain approval to upload data to the system.

\subsubsection{Traffic Monitoring Guide}

The FHWA's Traffic Monitoring Guide (TMG) is “intended to provide the most up to date guidance to State highway agencies in the policies, standards, procedures, and equipment typically used in a traffic monitoring program" (6). Chapter 7 of the recently updated TMG gives instructions for coding and entering collected nonmotorized traffic count data in the TMG format. The TMG's main goal is to help states manage and improve their traffic monitoring programs, including all related business processes, technology and equipment. Unlike the previously discussed data formats, the TMG format has precise requirements for the number and type of characters in each field in a data file.

The TMG format includes two types of data files: nonmotorized station description records and nonmotorized count records. Data fields in the station description include state and county codes, station identification code (Station ID), functional classification of road (including two new categories for trails and general area counts), and other specifics listed in Table 1 . The count record includes 24 hours of data per record and optional weather information, and repeats some of the same fields also included in the station description.

Each of these have suggested and required fields. Because the NBPDP does not have a place to upload data and data is to be sent in the form of a summary spreadsheet, this data format is more flexible than the other two.

Table 2.2 Summary of Data Fields Included in Standard Data Formats

\begin{tabular}{|c|lll|}
\hline $\begin{array}{c}\text { Information } \\
\text { Type }\end{array}$ & NBPDP & Los Angeles & TMG \\
\hline Identification & Location description & $\begin{array}{l}\text { Location ID } \\
\text { Dataset name }\end{array}$ & Station ID \\
\hline Locational & $\begin{array}{l}\text { Land uses (1 to 2 miles) } \\
\text { Jurisdiction } \\
\text { Population density } \\
\text { Bike/ped mode share } \\
\text { Median age and income }\end{array}$ & Land use & State; County \\
\hline
\end{tabular}




\begin{tabular}{|c|c|c|c|}
\hline $\begin{array}{c}\text { Information } \\
\text { Type }\end{array}$ & $\begin{array}{l}\text { NBPDP } \\
\text { Number of visitors to area } \\
\text { Type of setting } \\
\text { Scenic quality } \\
\text { Visitor destinations (1 } \\
\text { mile) }\end{array}$ & Los Angeles & TMG \\
\hline Route & $\begin{array}{l}\text { Motor traffic volumes } \\
\text { Posted speed limit } \\
\text { Intersecting traffic volume } \\
\text { Crossing protection } \\
\text { Topography }\end{array}$ & $\begin{array}{l}\text { Road class } \\
\text { Speed limit }\end{array}$ & $\begin{array}{l}\text { Functional class } \\
\text { National highway } \\
\text { Direction of route } \\
\text { Posted speed limit, route } \\
\text { signing, route number } \\
\text { Intersection } \\
\text { Crosswalk }\end{array}$ \\
\hline Facility & $\begin{array}{l}\text { Facility type } \\
\text { Length of facility }\end{array}$ & $\begin{array}{l}\text { Bikeway type } \\
\text { Type of other users }\end{array}$ & $\begin{array}{l}\text { Exclusive facility } \\
\text { Sidewalk }\end{array}$ \\
\hline Network & $\begin{array}{l}\text { Connecting facility quality } \\
\text { Quality of network }\end{array}$ & None & None \\
\hline Counter & None & None & $\begin{array}{l}\text { Year established } \\
\text { Year discontinued } \\
\text { Latitude \& longitude } \\
\text { Type of sensor } \\
\text { LRS ID } \\
\text { LRS location point } \\
\text { Station location } \\
\text { Location relative to road }\end{array}$ \\
\hline $\begin{array}{c}\text { Count } \\
\text { Description }\end{array}$ & None & $\begin{array}{l}\text { Count method } \\
\text { Direction }\end{array}$ & $\begin{array}{l}\text { Count type (walk/cycle) } \\
\text { Direction of travel } \\
\text { Method of counting } \\
\text { Factor groups } \\
\text { Count purpose } \\
\text { Notes }\end{array}$ \\
\hline Temporal & $\begin{array}{l}\text { Date } \\
\text { Time }\end{array}$ & $\begin{array}{l}\text { Date } \\
\text { Day } \\
\text { Period } \\
\text { Interval Begin }\end{array}$ & $\begin{array}{l}\text { Year, month and day } \\
\text { Count start time } \\
\text { Count interval (min.) }\end{array}$ \\
\hline
\end{tabular}




\begin{tabular}{|c|lll|}
\hline $\begin{array}{c}\text { Information } \\
\text { Type }\end{array}$ & NBPDP & Los Angeles & TMG \\
\hline Weather & Weather & Raining (yes/no) & $\begin{array}{l}\text { Precipitation (yes/no) } \\
\text { High and low } \\
\text { temperature }\end{array}$ \\
\hline \multirow{3}{*}{ Count } & Count of bicyclists & $\begin{array}{l}\text { Count of bicyclists } \\
\text { Female bicyclists } \\
\text { Sidewalk bicyclists }\end{array}$ & Count per interval \\
& $\begin{array}{l}\text { Count of pedestrians } \\
\text { Count of other non- } \\
\text { motorized traffic }\end{array}$ & $\begin{array}{l}\text { Wrong way cyclists } \\
\text { Count of other }\end{array}$ \\
\hline
\end{tabular}

Abbreviations: min. = minutes, ID = Identification, $L R S=$ Linear Referencing System

\subsection{DATASETS}

There are a multitude of existing online archives of bicycle and pedestrian count data in the U.S. and abroad. They fall into four categories as described in the matrix in Table 5, depending on if the source code is publicly or privately owned and if the data are available to the public or if access is restricted.

This review focuses on those archives which are both publicly available and publicagency owned with open-source code because they are most similar to the scope of this project. Examples are listed in Table 2. These are usually managed by local or regional agencies who desire multiagency data sharing. With the exception of the Los Angeles Bike Count Data Clearinghouse (2), these sites do not allow users to upload data to the system, but only allow users to view or download data. The project team found no states with an easily accessible, public, online bicycle and pedestrian count database. This illustrates, once again, the need for a nationally accessible system that can provide publicly available, online, nonmotorized traffic volume data.

The Travel Monitoring Analysis System (TMAS) operated by FHWA is an archive of motor vehicle traffic data, the new version of which is being designed to include nonmotorized traffic counts (6). While this database is operated by a public agency, it currently does not include nonmotorized count data and is not available to the public. For these reasons, it is not included in Table 2.

The NBPDP provides a standard data format and encourages participants to send in data files. However, it does not archive these data into one database and does not make these data available publicly. For this reason, it is not included in Table 2. 
In addition to the publicly available data archives listed in Table 2, there are also many privately available data archives and online tools. Most of these data management products cater primarily to motor vehicle traffic, but some include bicycle and pedestrian traffic. Traffic count database products are available through detector manufacturers and traffic data software providers. These proprietary software products provide data analysis tools and often produce reports, and some are able to export the data for use in other software.

Nonmotorized traffic count data can be categorized many ways. Below are some helpful classifications.

Bicycle and pedestrian count data can be classified by method of collection into three categories:

- Short-duration manual (including non-automated video counts) (<24-hours)

- Short-duration automated counts (24 hours to one year)

- Continuous automated counts (one year or more)

Data collection sites can be classified into two categories:

- Intersection counts (including turning movement counts)

- Road or path segment counts (also known as screenline counts)

Most automated counts are collected on segments because this is an easier environment to count nonmotorized road users with equipment and many manual counts are collected at intersections.

Table 2.3 lists datasets available from TAC member agencies and some others for the archive. This is not an exhaustive list of all count data available in the U.S., but a list of the data sources considered for addition into Bike-Ped Portal during this first phase of the project. Automated count data in this table are the highest priority to be included in the archive. Data that were uploaded to Bike-Ped Portal are indicated by checkmarks in the last column of the table. 
Table 2.3 Datasets Available To Be Added To Archive and Status of Upload

\begin{tabular}{|c|c|c|c|c|c|c|}
\hline Jurisdiction & Dataset & Locations & $\begin{array}{l}\text { Inter- } \\
\text { sec- } \\
\text { tions? }\end{array}$ & $\begin{array}{l}\text { Manual/ } \\
\text { Automated }\end{array}$ & $\begin{array}{l}\text { Short/ } \\
\text { Continuou } \\
\text { s }\end{array}$ & $\begin{array}{l}\text { Loaded } \\
\text { in Bike- } \\
\text { Ped } \\
\text { Portal? }\end{array}$ \\
\hline \multicolumn{7}{|l|}{ Oregon } \\
\hline \multirow{3}{*}{$\begin{array}{l}\text { Oregon } \\
\text { Department of } \\
\text { Transportation }\end{array}$} & Turning movement counts & $\begin{array}{l}\text { various locations in } \\
\text { Oregon }\end{array}$ & $\checkmark$ & $\begin{array}{l}\text { Manual } \\
\text { Video }\end{array}$ & Short & \\
\hline & Eco MULTI & $\begin{array}{l}\text { Columbia River } \\
\text { Highway }\end{array}$ & & Automated & Continuous & \\
\hline & ZELT & $\begin{array}{l}\text { Bullards Bridge - Coast } \\
\text { Highway }\end{array}$ & & Automated & Continuous & \\
\hline $\begin{array}{l}\text { Oregon State } \\
\text { Parks }\end{array}$ & PYRO & $\begin{array}{l}\text { West Gorge Trail and } \\
\text { Mosier Twin Tunnels }\end{array}$ & & Automated & Continuous & \\
\hline \multirow[t]{2}{*}{ Metro } & TRAFx & various & & Automated & $\begin{array}{l}\text { Continuous } \\
\text { and Short }\end{array}$ & $\checkmark$ \\
\hline & EcoMULTI & Wilsonville & & Automated & Continuous & $\checkmark$ \\
\hline $\begin{array}{l}\text { Tualatin Hills } \\
\text { Park and } \\
\text { Recreation } \\
\text { District }\end{array}$ & TRAFx & Metro Area & & Automated & Continuous & $\checkmark$ \\
\hline \multirow{2}{*}{ City of Portland } & Trail Counts & various & & Manual & Short & \\
\hline & Hawthorne Bridge & Hawthorne Bridge & & Automated & Continuous & $\checkmark$ \\
\hline
\end{tabular}




\begin{tabular}{|c|c|c|c|c|c|c|}
\hline Jurisdiction & Dataset & Locations & $\begin{array}{l}\text { Inter- } \\
\text { sec- } \\
\text { tions? }\end{array}$ & $\begin{array}{l}\text { Manual/ } \\
\text { Automated }\end{array}$ & $\begin{array}{l}\text { Short/ } \\
\text { Continuou } \\
\text { s }\end{array}$ & $\begin{array}{l}\text { Loaded } \\
\text { in Bike- } \\
\text { Ped } \\
\text { Portal? }\end{array}$ \\
\hline & EcoTUBE counts & various & & Automated & Short & \\
\hline & $\begin{array}{l}\text { Inductive loop counts on } \\
\text { Portal }\end{array}$ & & & Automated & Continuous & \\
\hline & Bicycle intersection counts & various intersections & $\checkmark$ & Manual & Short & \\
\hline & Turning movement counts & various intersections & $\checkmark$ & Manual & Short & \\
\hline & JAMAR piezo electric & East Bank Esplanade & & Automated & Continuous & \\
\hline $\begin{array}{l}\text { City of } \\
\text { Portland/Metro }\end{array}$ & PYRO & Steel Bridge Riverwalk & & Automated & Continuous & \\
\hline TriMet & EcoZelts (loops) & Tilikum Crossing & & Automated & Continuous & \\
\hline $\begin{array}{l}\text { Washington } \\
\text { Park }\end{array}$ & TRAFx & trails in Portland park & & Automated & Continuous & $\checkmark$ \\
\hline Washington & Turning movement counts & intersection counts & $\checkmark$ & Manual & Short & \\
\hline County & & On-street counts & & & & \\
\hline $\begin{array}{l}\text { Mid-Willamette } \\
\text { Valley Council } \\
\text { of Governments }\end{array}$ & Turning movement counts & Salem, Corvallis & $\checkmark$ & $\begin{array}{l}\text { Manual } \\
\text { Video }\end{array}$ & Short & \\
\hline $\begin{array}{l}\text { Lane Council of } \\
\text { Governments }\end{array}$ & Tube counts & Eugene & & Automated & Short & $\checkmark$ \\
\hline \multirow{2}{*}{$\begin{array}{l}\text { Deschutes } \\
\text { County }\end{array}$} & Manual counts - intersection & Bend & $\checkmark$ & Manual & Short & \\
\hline & Manual counts - segment & Bend & & Manual & Short & $\checkmark$ \\
\hline
\end{tabular}




\begin{tabular}{|c|c|c|c|c|c|c|}
\hline Jurisdiction & Dataset & Locations & $\begin{array}{l}\text { Inter- } \\
\text { sec- } \\
\text { tions? }\end{array}$ & $\begin{array}{l}\text { Manual/ } \\
\text { Automated }\end{array}$ & $\begin{array}{l}\text { Short/ } \\
\text { Continuou } \\
\text { s }\end{array}$ & $\begin{array}{l}\text { Loaded } \\
\text { in Bike- } \\
\text { Ped } \\
\text { Portal? }\end{array}$ \\
\hline \multicolumn{7}{|l|}{$\begin{array}{l}\text { Washington } \\
\text { State }\end{array}$} \\
\hline Olympia & TimeMark tube counts & various & & Automated & Short & \\
\hline \multirow{4}{*}{ Seattle } & & intersection counts & $\checkmark$ & Manual & Short & \\
\hline & Eco MULTI \& Zelts & various & & Automated & Continuous & \\
\hline & & Sensys & & Automated & Continuous & \\
\hline & Eco-Counter TUBES & tube & & Automated & Short & \\
\hline \multirow{2}{*}{$\begin{array}{l}\text { Washington } \\
\text { State } \\
\text { Department of } \\
\text { Transportation } \\
\end{array}$} & Eco MULTI \& Zelts & various & & Automated & Continuous & \\
\hline & & intersection counts & $\checkmark$ & Manual & Short & \\
\hline \multicolumn{7}{|l|}{ Texas } \\
\hline \multirow{2}{*}{ Austin } & Eco-Counter TUBES & tube & & Automated & Short & \\
\hline & Eco-Counter MULTI & 2 sites & & Automated & Continuous & \\
\hline \multicolumn{7}{|l|}{ Colorado } \\
\hline \multirow{3}{*}{ Boulder } & Canoga GTT & paths & & Automated & Continuous & $\checkmark$ \\
\hline & Eco-Counter ZELT & Folsom, 13th St & & Automated & Continuous & \\
\hline & turning movement counts & intersection counts & $\checkmark$ & Manual & Short & \\
\hline \multicolumn{7}{|l|}{ Virginia } \\
\hline Arlington & Eco-Counter and MetroCount & various & & Automated & Continuous & $\checkmark$ \\
\hline
\end{tabular}




\begin{tabular}{|c|c|c|c|c|c|c|}
\hline Jurisdiction & Dataset & Locations & $\begin{array}{l}\text { Inter- } \\
\text { sec- } \\
\text { tions? }\end{array}$ & $\begin{array}{l}\text { Manual/ } \\
\text { Automated }\end{array}$ & $\begin{array}{l}\text { Short/ } \\
\text { Continuou } \\
\text { s }\end{array}$ & $\begin{array}{l}\text { Loaded } \\
\text { in Bike- } \\
\text { Ped } \\
\text { Portal? }\end{array}$ \\
\hline & $\begin{array}{l}\text { Hard copies in box from } \\
\text { Arlington }\end{array}$ & various & & Manual & Short & \\
\hline \multicolumn{7}{|l|}{ Minnesota } \\
\hline $\begin{array}{l}\text { University of } \\
\text { Minnesota }\end{array}$ & $\begin{array}{l}\text { Trail Master infrared event- } \\
\text { based }\end{array}$ & 6 trail sites & & Automated & Continuous & \\
\hline \multirow{3}{*}{$\begin{array}{l}\text { Minnesota } \\
\text { Department of } \\
\text { Transportation }\end{array}$} & Eco-Counter & 5 continuous & & Automated & Continuous & \\
\hline & one week each & $80+$ trail sites & & Automated & Short & \\
\hline & 48 hrs to 3-week duration & $12+$ & & Automated & Short & \\
\hline Minneapolis & & intersection counts & $\checkmark$ & Manual & Short & \\
\hline \multicolumn{7}{|l|}{ California } \\
\hline San Diego & $\begin{array}{l}\text { Eco-Counter ZELT and } \\
\text { MULTI }\end{array}$ & 38 continuous sites & & Automated & Continuous & \\
\hline
\end{tabular}




\subsection{EXISTING DATA WAREHOUSES}

There are a multitude of existing public online databases of bicycle and pedestrian count data in the U.S. and abroad. They fall into four categories as described in the matrix below, depending on if they are publicly or privately owned and if the data is available to the public or if access is restricted. Examples of each type are provided in the matrix, but these by no means constitute all such data warehouses. The appendix contains screenshots of some of the examples listed in the matrix for publicly available (not password protected) and public-agency owned and operated nonmotorized traffic count archives.

Table 2.4 Matrix of Data Warehouse Types

\begin{tabular}{lll} 
OWNER & \multicolumn{1}{l}{ PUBLICLY } & ACCESS RESTRICTED \\
\multicolumn{1}{l}{ AVUILABLE } & \\
NON-PROFIT & $\begin{array}{l}\text { DVRPC, Portal, Arlington, } \\
\text { LCOG, Boulder, Seattle, }\end{array}$ & FHWA, CDOT \\
PRIVATE FIRM & $\begin{array}{l}\text { LA Metro, Austin } \\
\text { WayCount, EcoCounter }\end{array}$ & Eco-Visio, DataNet
\end{tabular}

This review will focus on those data warehouses which are publicly available and publicagency owned because they are most similar to the scope of this project. These are usually run by local or regional agencies who want to share their count data with others. With the exception of the Los Angeles Bike Count Data Clearinghouse, these sites do not allow users to upload data to the sites, but only allow users to view or download data. Table 2.5 lists example sites by category. Currently we found no states with an easily accessible, public, online bicycle and pedestrian count database, though Colorado and Washington State have been working on one. Some of the sites include weather data.

Databases under development: UC Berkeley SafeTREC, a research center at the University of California, Berkeley, focused on transportation safety, has designed a database that inventories infrastructure as well as including nonmotorized traffic volume counts, and includes both a facility inventory and volume data (Proulx et al., 2015). For this reason, it has the most exhaustive list of metadata related to pedestrian and bicycle infrastructure of any of the databases reviewed. The volume database can store both intersection and segment pedestrian count data, and includes metadata such as whether the count is on an intersection approach or in a crosswalk; whether the count is manual or automated; the approach ID for crosswalks; the node and approach IDs; the volume by direction of travel; duration of count; start time; and weather as a text description. We did not include it in Table 2.5 because it does not appear to be publicly available at this time. 
Table 2.5 Examples of Public, Online, Nonmotorized Traffic Count Databases and Tools

\begin{tabular}{|c|c|c|c|c|c|c|c|}
\hline \multirow[t]{2}{*}{ Agency } & \multirow[t]{2}{*}{ URL } & \multicolumn{2}{|c|}{ Data Types } & \multirow[t]{2}{*}{ Map? } & \multirow[t]{2}{*}{ Graph? } & \multirow{2}{*}{$\begin{array}{l}\text { Allows } \\
\text { Data } \\
\text { Download } \\
\end{array}$} & \multirow[t]{2}{*}{ Other } \\
\hline & & Duration & Automated? & & & & \\
\hline $\begin{array}{l}\text { Delaware } \\
\text { Valley } \\
\text { Regional } \\
\text { Planning } \\
\text { Commission }\end{array}$ & $\begin{array}{l}\text { http://www.dvrpc.org/webma } \\
\text { ps/pedbikecounts/ }\end{array}$ & One week & $\checkmark$ & $\checkmark$ & $\checkmark$ & $\checkmark$ & $\begin{array}{l}\text { Now includes } \\
\text { weather }\end{array}$ \\
\hline Arlington, VA & $\begin{array}{l}\text { http://www.bikearlington.com } \\
\text { /pages/biking-in- } \\
\text { arlington/counter-dashboard/ }\end{array}$ & Continuous & $\checkmark$ & $\checkmark$ & $\checkmark$ & $\checkmark$ & $\begin{array}{l}\text { Includes } \\
\text { weather }\end{array}$ \\
\hline $\begin{array}{l}\text { Portal (Olson } \\
\text { et al., 2012) }\end{array}$ & $\begin{array}{l}\text { http://demo.portal.its.pdx.edu/ } \\
\text { Portal/index.php/pedbike }\end{array}$ & Continuous & $\checkmark$ & $\checkmark$ & $\checkmark$ & & \\
\hline $\begin{array}{l}\text { Lane Council } \\
\text { of } \\
\text { Governments }\end{array}$ & $\begin{array}{l}\text { http://www.thempo.org/what_ } \\
\text { we_do/bicycle_counts_web_a } \\
\text {.cfm }\end{array}$ & $>24 \mathrm{hr}$ & $\checkmark$ & $\sqrt{ }$ & & $\checkmark$ & $\begin{array}{l}\text { Weather in } \\
\text { output file, } \\
\text { includes } \\
\text { photos }\end{array}$ \\
\hline LA Metro & $\begin{array}{l}\text { http://www.bikecounts.luskin. } \\
\text { ucla.edu/ }\end{array}$ & Two hour & & $\checkmark$ & & $\checkmark$ & $\begin{array}{l}\text { Allows data } \\
\text { input }\end{array}$ \\
\hline Seattle, WA & $\begin{array}{l}\text { http://www.seattle.gov/transp } \\
\text { ortation/bikecounter_fremont. } \\
\text { htm\#detail }\end{array}$ & Continuous & $\checkmark$ & $\checkmark$ & $\checkmark$ & & $\begin{array}{l}\text { Only two } \\
\text { sites, but } \\
\text { includes } \\
\text { weather }\end{array}$ \\
\hline
\end{tabular}


Proprietary software: In addition to the publicly available data warehouses listed in Table 2.4, there are also many privately available data warehouses and online tools. Most of these data management products cater primarily to motor vehicle traffic but some include bicycle and pedestrian traffic, such as EcoCounter's EcoVisio and TRAFx's DataNet. Data warehousing products are available through detector manufacturers and traffic data software providers. These proprietary software products provide data analysis tools and often produce reports. The data interfaces often include maps with count locations listed as points and can also house photos of count locations. The analysis tools include various graphs and summary tables which can be sorted, filtered and exported in various formats. These products store the data remotely and make it available to users through password-protected online tools (information on two example software products: EcoCounter’s EcoVisio and TRAFx's DataNet). 


\subsection{BIKE-PED PORTAL ARCHITECTURE}

\subsection{FUNCTIONAL REQUIREMENTS}

One of the first steps in building any national archiving system or data warehouse is to develop functional requirements. Building this national archiving system has included obtaining funding for the basic creation of a bicycle and pedestrian count data clearinghouse. With this initial project, a basic nonmotorized traffic count clearinghouse has been established as part of Portal, an existing transportation data archive operated at Portland State University (9). The new archive is referred to as the Bike-Ped Portal. The basic functions that the Bike-Ped Portal includes after the first phase of work are listed in Table 3.1.

Table 3.1 Basic Functional Requirements for Phase I

\begin{tabular}{|c|c|}
\hline Requirement & Phase 1 Priority \\
\hline Input Tool & $\begin{array}{l}\text { Provide user accounts so they can upload data } \\
\text { Ability to upload count files online } \\
\text { User input tool for counts on road or path segments }\end{array}$ \\
\hline $\begin{array}{l}\text { Quality Assurance/ } \\
\text { Quality Control } \\
\text { (QA/QC) Tool }\end{array}$ & $\begin{array}{l}\text { Automated check for database constraints } \\
\text { User fixes errors and resubmits } \\
\text { Basic automated data quality checks }\end{array}$ \\
\hline $\begin{array}{l}\text { Archive } \\
\text { Documentation and } \\
\text { Metadata }\end{array}$ & $\begin{array}{l}\text { Flexible architecture to expand to future uses and allow mobile counters } \\
\text { and multiple counts of the same traffic flow } \\
\text { A set of required and optional fields for locations, detectors and data } \\
\text { records }\end{array}$ \\
\hline Output Tool & $\begin{array}{l}\text { Map of count locations } \\
\text { Data visualization with two basic graphs for a user-chosen time period: } \\
\text { data availability and volume by record } \\
\text { Export: Allow data to be exported in CSV format } \\
\text { Basic application programming interface (API) }\end{array}$ \\
\hline Data to Include & Prioritize segment count sites \\
\hline
\end{tabular}




\subsubsection{Data Prioritization}

Managing the development of a data archiving system requires careful thought and prioritization to produce a working product within a given budget and time frame. While the vision for the project is to include all types of count data, in order to produce a working data archive within the budget and time frame of the project, some data types are prioritized over others.

The priorities, listed below, were made based on the recommendations of the project's Technical Advisory Committee (TAC) and are based on their desire to focus on the most complete, qualitydriven and manageable data first.

- Datasets with 24 hours of consecutively collected hourly counts or greater per location are a first priority. Shorter duration counts are a second priority.

- Data collected on segments are a first priority. Data collected at intersections are a second priority.

Counts longer than 24 hours are prioritized because they provide views of travel patterns over the course of the day that cannot be known with shorter-duration counts. Traffic statistics can be calculated with 24-hour counts and continuous count volume data can provide conclusions about time of day, day of week, month of year, and year-to-year travel volume trend patterns.

Counts at intersections are inherently more complex and are usually associated with counts collected for less than 24 hours. For the first phase of work, if automated count data are collected at intersections each approach to the intersection will be treated as a separate road or path segment. The ability to archive individual turning movements is a task left for future phases of work.

While data greater than 24 hours are prioritized, numerous manual count data of two-hour duration have been added to Bike-Ped Portal. These data can be uploaded via CSV files, just as readily as automated count data, if properly formatted.

\subsection{ARCHIVE ARCHITECTURE}

The diagram shown in Figure 3.1 illustrates the system architecture for the Bike-Ped Portal. The Bike-Ped Portal has two primary components - the Bike-Ped Portal web interface and the BikePed Portal archive.

When building any archiving system, developing a strategic database architecture that is solid, sustainable and maintainable is critical. For this project, a system architecture that provides front-end, back-end and middle-ware database functionality is required. Below are system architecture components with descriptions of the existing and anticipated functionality. Anticipated functionality is shown in grey. Currently all data is raw, no validated data exists within the archive and the visual validation interface has not been created, nor has the email 
approval functionality. Instead, the narrow red arrow in the figure indicates that raw data is displayed directly to the user.

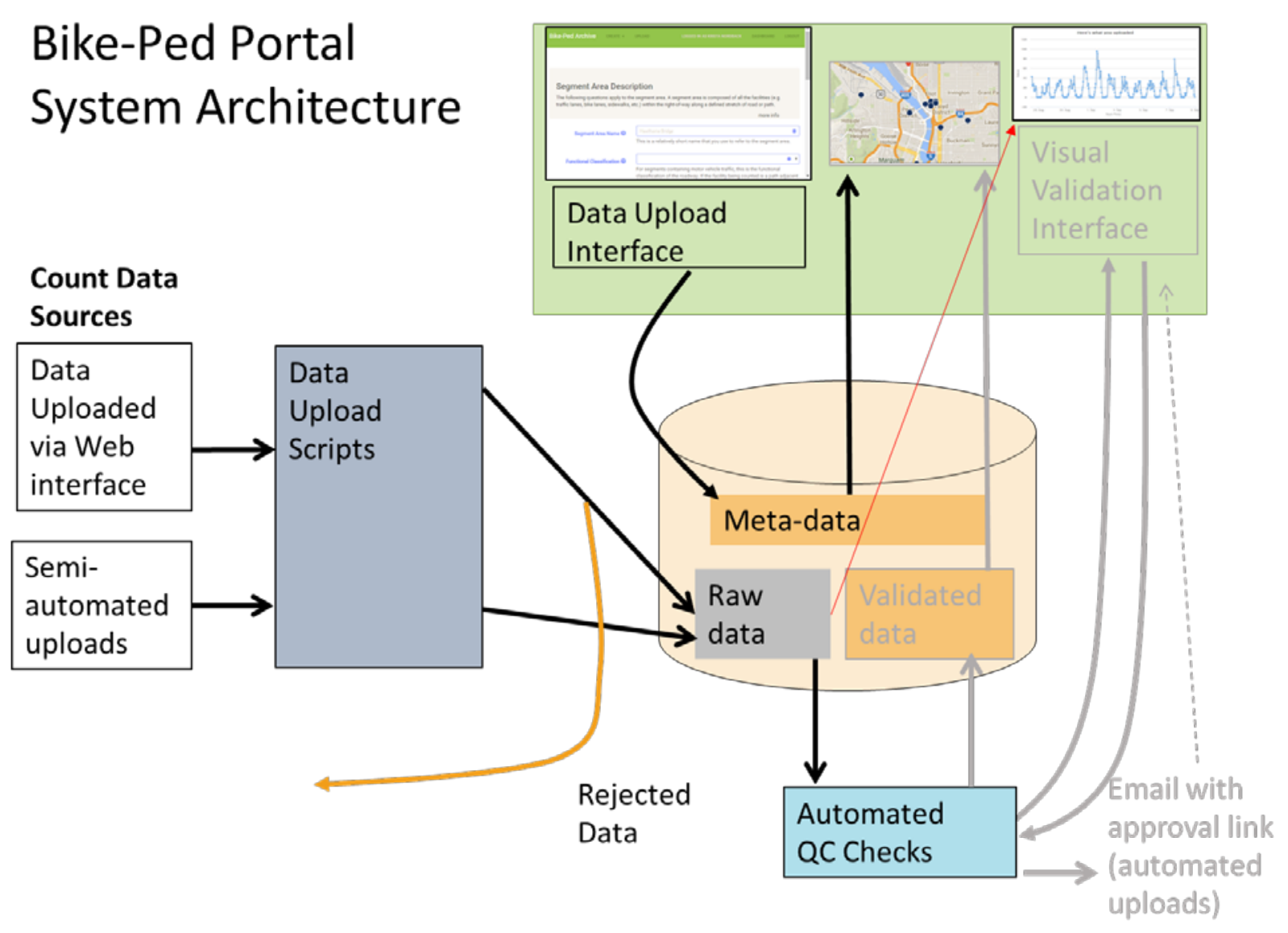

Figure 3.1 Archive Architecture

\subsubsection{Data Sources and Upload}

Count data arrive into the archive from two primary sources: files uploaded by agencies through the web interface and files automatically uploaded to a vendor's API. The count data are accompanied by metadata that describes the count segments and detectors. All metadata are uploaded through the web interface. As part of the upload process, the data are checked to ensure it meets basic formatting criteria and "sanity checks," such as verifying the start date of the file precedes the end date and that required data fields are not null. If the data pass these initial checks, the data are loaded into the "raw data" portion of the Bike-Ped Portal archive. If the data do not pass the check and the data are rejected, the user is notified that either the data have been submitted or the data have been rejected. 


\subsubsection{Bike-Ped Archive}

The Bike-Ped Portal uses a PostgreSQL database that is shared with the existing Portal traffic data archive. The archive stores both the raw uploaded data and the validated data.

\subsubsection{Data Quality Process}

The data uploaded to the Bike-Ped Portal are checked through a simple quality control (QC) process. The diagram in Figure 3.1 shows some important features of the QC process. The QC process is being created to identify suspect data based on simple flags such as counts that are unusually high for a given hour or day and unusually high numbers of consecutive identical counts. Data arrives to the archive either through the web interface or through automated upload to an ftp site.

In Phase II improvements to Bike-Ped Portal, the user would be notified of the suspect data. The notification would be either directly through the web-upload process for data being uploaded through the website or through an email for data that are uploaded to the ftp site. The process for validation would be the same for datasets uploaded through the website or through the semiautomatic ftp upload. In either case, the user would be asked to investigate and validate suspicious data. The user would be provided with information about the data quality tests that fail and will be able to view simple plots of the data.

Also, in future versions of Bike-Ped Portal, the user would be given the ability to add notes to the data. Each note would be associated with a count detector and a range of time. The notes would give the user a chance to record information about events or other things that affect the counts; particularly of interest are observations that may not be available from other sources. After the user has reviewed the data and QC information, the count data would be accepted into the validated data in the archive or may be included but marked as invalid data which will be hidden from public use.

\subsubsection{Bike-Ped Portal Web Interface}

The Bike-Ped Portal has a web interface which supports adding metadata, data upload, simple QC, graph of uploaded data, and data download.

\subsection{ARCHIVE DATA STRUCTURE}

As with all data archiving systems, the archive data structure describes how the metadata and validated data are stored within the archive. The data are stored with an eye toward minimizing redundancy while preserving as much detail as available in the raw data. The data structure was designed to allow easy access to the data for querying and easy and efficient future data processing.

As shown in Figure 3.2, the data structure consists of the following basic elements: Segment Areas, Detectors, Facilities, Flows, Count Descriptors, and the Data records themselves. While 
the specific fields included in these basic elements may be adjusted, the elements themselves and their relationship to one another have been finalized and represent a novel and versatile approach to archiving bicycle and pedestrian count data. Each element is described below. Detailed entity relationship diagrams are included in the Appendix.
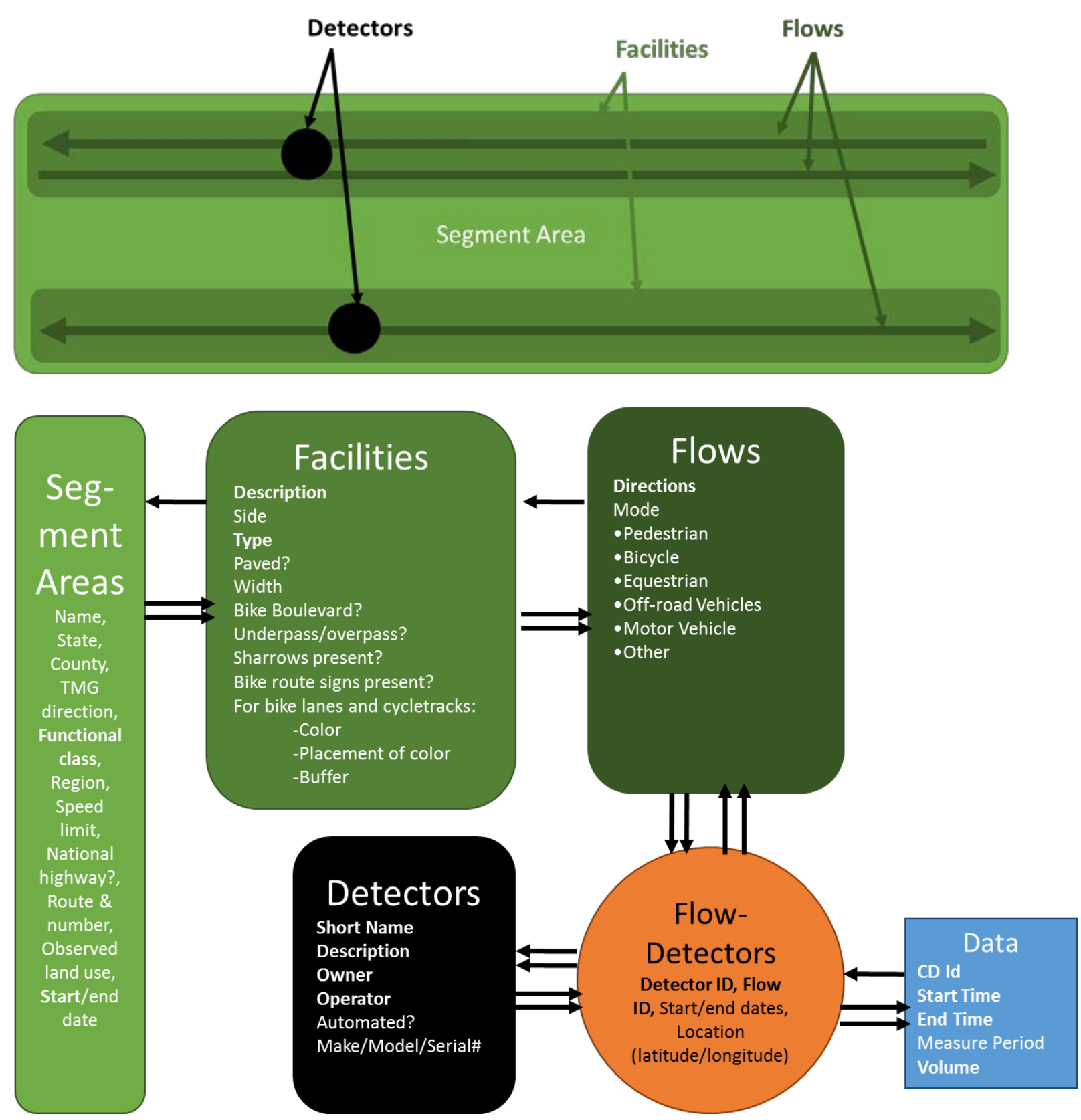

Figure 3.2 Archive Data Structure

The Segment Area represents the section of roadway or path on which the count is collected, including all associated transportation facilities. In the upper portion of Figure 3, the largest rounded rectangle represents the Segment Area. For example, if the count were conducted on a 
bridge, the segment area would include the entire bridge, roadway, sidewalks and paths. This area will be input by the user and used for future efforts to combine count data with various linebased datasets. The Segment Area has high-level attributes such as name, state, county and observed land use. In addition, TMG attributes were included in the data structure for the purpose of exporting to TMG format. Finally, for the geographic attribute, Segment Area is spatially represented as a polygon in the archive.

In this data structure, the Detector element represents the device that is used to collect counts. A Detector may be a pneumatic tube for bicycle counts, an inductive loop bicycle detector, an infrared device, or a person. The Detectors are shown as large dots in Figure 3.2. Multiple Detectors may to be associated with one Segment Area. The attributes of the Detector device include a description and information about the device, such as if it is automated or continuous and its make, model and serial number. As with Segment Area, TMG fields have been included to support output to TMG format.

The Facility represents the facility on which traffic is being counted. For example, a Facility might represent the north sidewalk of a roadway or a bicycle lane on the roadway. Facilities are shown as two boxes, one for each sidewalk on either side of the roadway represented by the Segment Area in Figure 3.2. Facility data include information describing the type of facility, its width and pavement type.

The Flow represents the traffic flow that is being counted. A single Detector may count multiple Flows. For example, a single Detector may count both bicycles and pedestrians, or a single Detector may count both northbound and southbound traffic. Thus there are typically multiple Flows associated with each Detector. There can also be multiple Detectors associated with a given Flow. The Flow includes the travel direction and mode of travel.

In order to accommodate multiple Detectors for a given Flow and multiple Flows for a given Detector, a table was created to link a given Detector to a given Flow, called the Count Descriptor. The Count Descriptor table also includes the location of the Detector, which is represented as a point.

The final item in the data structure is the Data records themselves. These records contain simply the time interval of the count and the counts recorded in that time period. A file to be uploaded to the site is likely to contain many Data records.

The Data structure is currently focused on counts collected on road or path segments. However, in the future phases of work, the team plans to expand the basic Data structure to include intersection-specific data. This can be accomplished by making modifications to Segment Area to define an intersection area instead of a segment, minor modifications to Detector, and expansion of Flows and Facilities to include specific movements and crosswalk counts. This illustrates the inherent flexibility in the archive Data structure. 


\subsection{TOOL DEVELOPMENT}

The archive is accessible at http://bp.its.pdx.edu/. A demo site is available at http://bpdemo.its.pdx.edu to allow users to practice creating new sites and upload data without contaminating the database.

\subsection{USERS AND AUTHENTICATION}

An add-user-page was created so that the administrator can create accounts for new users. The administrator can then associate each user with a group or groups. A group is usually an organization or jurisdiction, such as a department of transportation, university, company or nonprofit. Users are limited to only upload data for their group but can view data for all groups.

\subsection{METADATA}

The first time a user enters a new count site, they must first provide some detailed information about the site. This metadata can be saved and, in the future, they only need to select and confirm the count site before entering the count data. Metadata entry requires entering information about four aspects of the counting:

- Segment Area - the section of roadway and/or path on which the count is collected INCLUDING all associated transportation facilities.

- Facility - the specific facility on which the count was collected, such as a bike lane or a sidewalk.

- Flow - the traffic flow being counted, such as southbound pedestrians.

- Detector - the person or machine doing the counting.

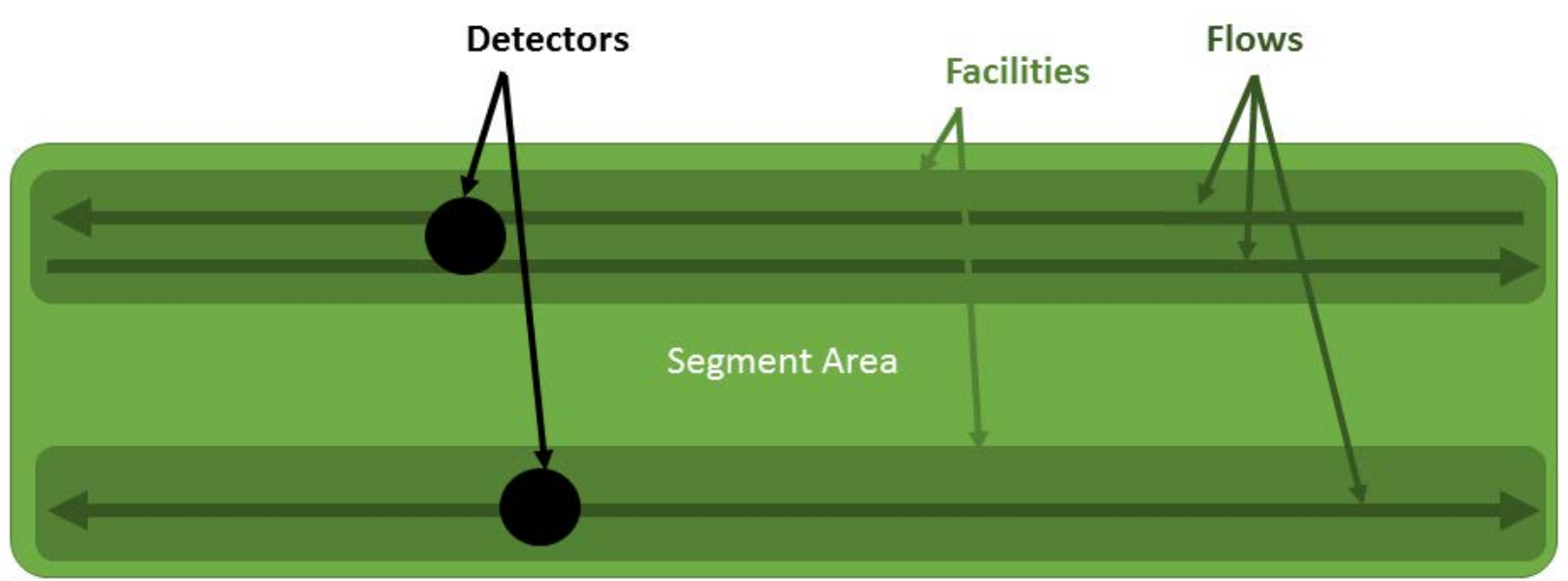

Figure 4.1 Metadata Aspects 


\subsubsection{Segment Area}

A Segment Area includes all transportation-related facilities within the right-of-way, such as sidewalks, motor vehicle lanes, bicycle lanes, and shared-use paths. A Segment Area generally should not include intersections or other places where nonmotorized traffic enters or exits the segment. In other words, expected nonmotorized traffic remains relatively constant over the length of the Segment Area.
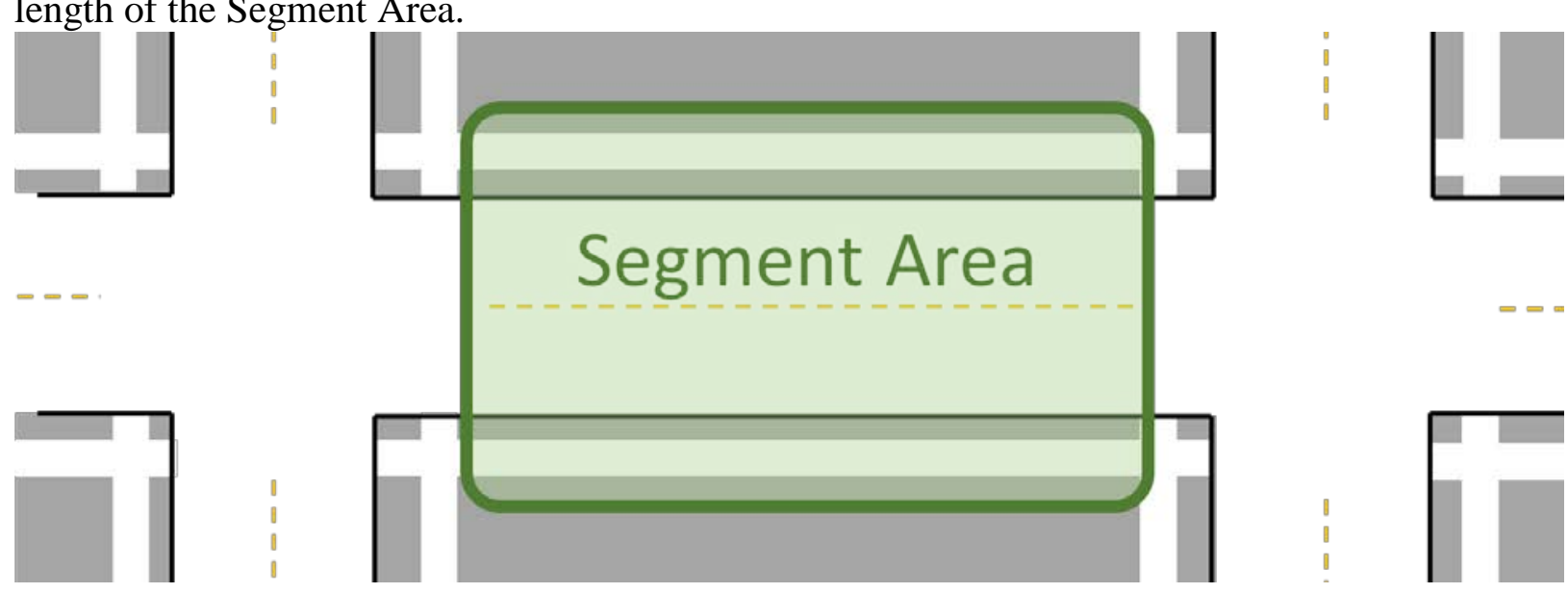

Figure 4.2 Segment Area Illustration

Segment Area fields include:

- Segment Area Name: This is a relatively short name that you use to refer to the Segment Area. The Segment Area name is user-defined and should be descriptive but concise. If the segment includes a roadway the segment name might include the roadway name, for example, "Broadway, Center Blvd to Westbank Ave.” Alternatively, some jurisdictions have predefined names for count stations such as "Bellview4" that may be appropriate Segment Area names. Details of the count station can be added later in the Facility or Detector description field.

- Functional Classification: For segments containing motor vehicle traffic, this is the functional classification of the roadway. If the facility being counted is a path adjacent to a road (and within the right-of-way), the characteristics of the road (not the path) should be entered here. For segments without motorized traffic, choose "Trail or Shared Use Path” or "General Activity Count.” General Activity Counts are described in FHWA's Traffic Monitoring Guide 2013 Section 7.9 as "for pedestrian counts in an open area like the Mall in Washington, D.C."

- State: In which state is the Detector located?

- County: In which county is the Detector located?

- Speed Limit: The posted speed limit along the segment in miles per hour.

- Is the Segment Area part of the National Highway System: Yes/No.

- Route Type: The type of route as indicated by the posted sign. For example, for a highway marked as US 92, select "U.S." 
- Route Sign Number: If the count is taken on a facility with a posted route number (for US 92, this would be "92") indicate that number. Otherwise leave it blank.

- Observed Land Use: Select all that apply (options include residential, school, agricultural, water, office, university, park, bridge, retail, industrial, mixed-use, transit center).

Segment Area Example: For the Hawthorne Bridge, the Segment Area would be the area between the entrances and exits on either side of the bridge. A Segment Area is composed of all the facilities (e.g., traffic lanes, bike lanes, sidewalks, etc.) within the right-of-way along a defined stretch of road or path. In a more typical city block, the Segment Area might extend the length of a block, but would not include the intersections (where traffic might enter or exit the Segment Area).

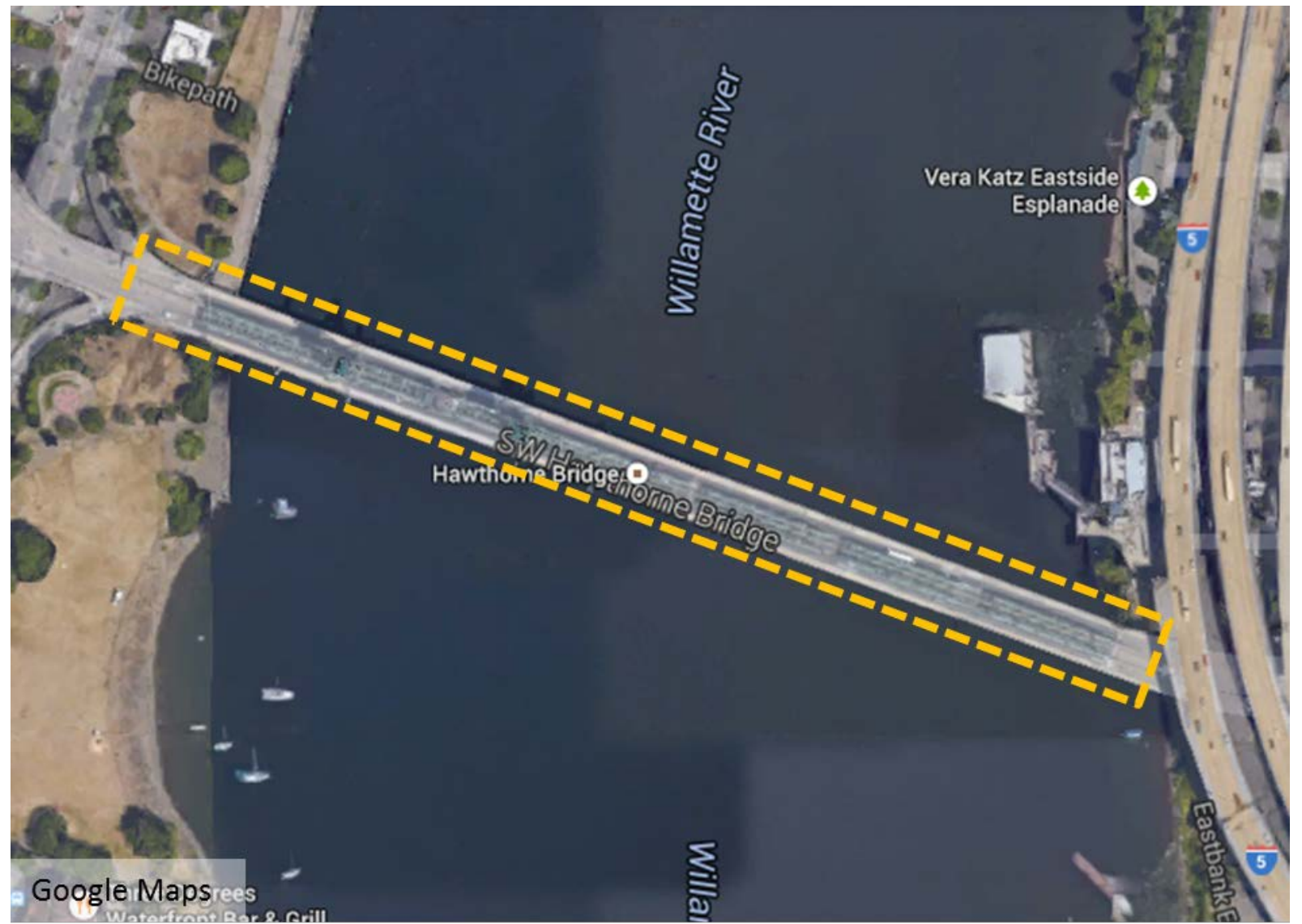

Figure 4.3 Segment Area Example

\subsubsection{Facility}

The Facility, such as a sidewalk or bike lane, is within a Segment Area. For example, the eastbound bike lane is a separate Facility from the westbound bike lane, and the south sidewalk 
is a separate Facility from the north sidewalk. If the count is taken in the roadway, the Facility is the roadway.

Facility fields include:

- Description: Please provide a brief description of the Facility on which the count was taken. The purpose of this field is to differentiate this Facility from others in the Segment Area or vicinity. The description might reference the Facility type, side of the street, name (if one exists), or other key information (e.g., north-side bike lane or south-side sidewalk). If the Facility is a path which has a specific name, please indicate the name here (e.g., the Springwater Corridor Trail or the Burke-Gilman Trail). Any other information about the Facility, such as nearby cross streets or proximity to destinations of interest, is also useful.

- Facility Type: If the Facility is the shoulder of a roadway, indicate "roadway" as the Facility type.

- Paved: Is the Facility paved?

- Side: On which side of the roadway is the sidewalk, bike lane, path or cycle track that is being counted? For example, if the sidewalk is on the north side of an east-west roadway, choose "North." If the path is located in the center of a roadway between motor vehicle travel lanes, choose "Median."

- Facility Width: Estimate the width of the Facility (sidewalk, bike lane, cycle track, roadway shoulder, or path) at the point at which the count was taken (in feet). Round to the nearest foot. For cycle tracks and bike lanes, do not include the width of the buffer between motorists and cyclists, just the width of the bicycle travel lane. For shared paths, include the full width of the path, even if the path is painted with dividing lines between pedestrians and cyclists.

- Buffer: What type of buffer, if any, is present between the bike lane or cycle track and motorized traffic? Select all that apply.

- Overpass: Was the count taken at a Facility designed to allow nonmotorized traffic to pass over the top of a roadway (e.g., a pedestrian bridge)?

- Underpass: Was the count taken at a Facility designed to allow nonmotorized traffic to cross underneath a roadway (e.g., a pedestrian undercrossing)?

Facilities Example: Zooming in on a cross section of the Hawthorne Bridge Segment Area, we see the individual Facilities that make it up. In our context, a Facility is a demarcated portion of the roadway, such as a traffic lane, bike lane or sidewalk. On the Hawthorne Bridge, the Facilities include a north-side, shared-use path, two westbound traffic lanes, two eastbound traffic lanes, and a south-side, shared-use path. 


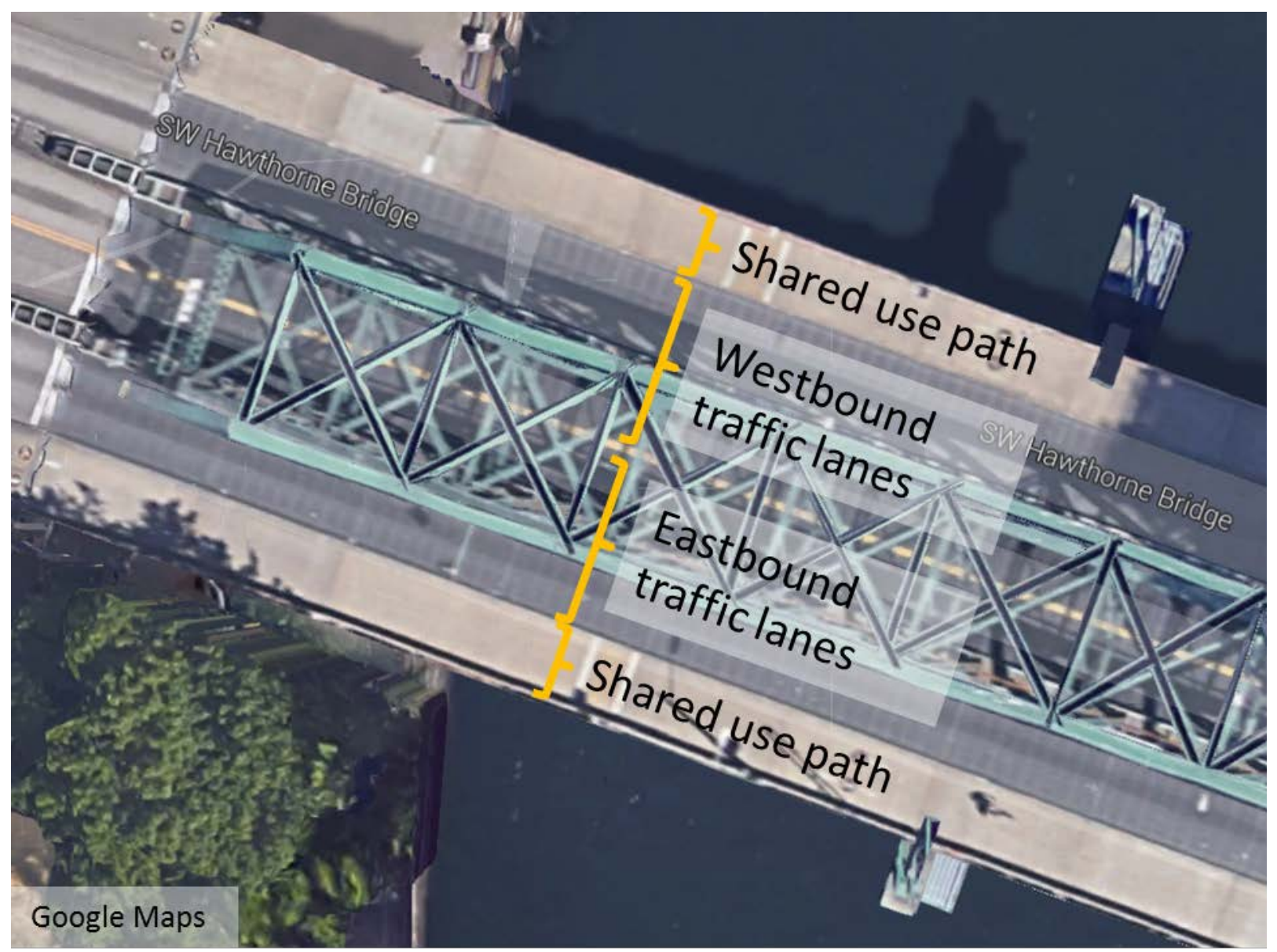

Figure 4.4 Facilities Example

\subsubsection{Flows}

A Flow is information about a specific type or types of measured activity along a path. For example, eastbound pedestrian traffic or combined southbound and northbound bicycle traffic.

\section{Flow fields include:}

- Flow Type: Choose the type of traffic counted. Choose all types included in the count. Options include bicycle, pedestrian, equestrian, off-road, motor vehicles, and other. Flow types should correspond to the capability and intended use of the Detector/counter. For example, if only bicyclists will be counted, only "bicycle" should be selected as a Flow type. If the Detector will count both bicyclists and pedestrians (and cannot or will not distinguish between them), both "Bicycle" and "Pedestrian" should be selected as Flow types. However, if the Detector is able to distinguish bicyclists and pedestrians AND you intend to upload counts for each, THEN you should add independent Flows for each type (e.g., add a "Bicycle" Flow first, press save and continue, and then come back and add a "Pedestrian” Flow as a separate Flow). Off-road motor vehicles refer to vehicles not permitted on roadways, such as snowmobiles, motorized dirt bikes, and motorized allterrain vehicles (ATVs). 
- Flow Directions: Flow directions should correspond to the capability and intended use of the Detector/counter. For example, if only Northbound traffic will be counted, only "Northbound" should be selected as a Flow direction. If the detector will count both Northbound and Southbound traffic (and cannot or will not distinguish between them), both "Northbound" and "Southbound" should be selected as Flow directions. However, if the Detector is able to distinguish Northbound and Southbound traffic AND you intend to upload counts for each, THEN you should add independent Flows for each direction (e.g., add a "Northbound" Flow first, and then come back and add a "Southbound" Flow as a separate Flow).

\subsubsection{Detectors}

This is information about a single detection device.

Fields for Detector include:

- Organization

- Jurisdiction

- Description

- Short Name

- Serial Number

- Make

- Model

Flows and Detectors Example: A facility may have one or more "Flows" that you are measuring - each Flow is a measurable type of activity that generally specifies "who" and "in what direction." On the Hawthorne Bridge, the south-side, shared-use path (pictured below) might be expected to have eastbound bicyclists, and pedestrians travelling both east- and westbound. The "Detector" measures the Flow on the Facility. On the Hawthorne Bridge, the pneumatic tube counter pictured measures the eastbound bicyclist traffic separate from westbound bicycle traffic.

Notes:

1. It is only necessary to add a "Flow" if it will be measured by the Detector. Because pedestrians are not measured by the Detector in our example, and therefore no pedestrian counts would be associated with the Facility, it would not be necessary to add them as a Flow. However, if a new Detector were added that could capture pedestrian traffic, you might then want to add a pedestrian Flow.

2. It is important to recognize the limitations of the Detector when inputting Flow information - for example, if the Flow cannot distinguish direction of travel, then the Flow should include all expected directions of travel. As another example, if a Detector were installed that could identify pedestrian traffic, but could not distinguish directionality, a Flow might be added that included pedestrians travelling both in the eastbound AND westbound directions. 


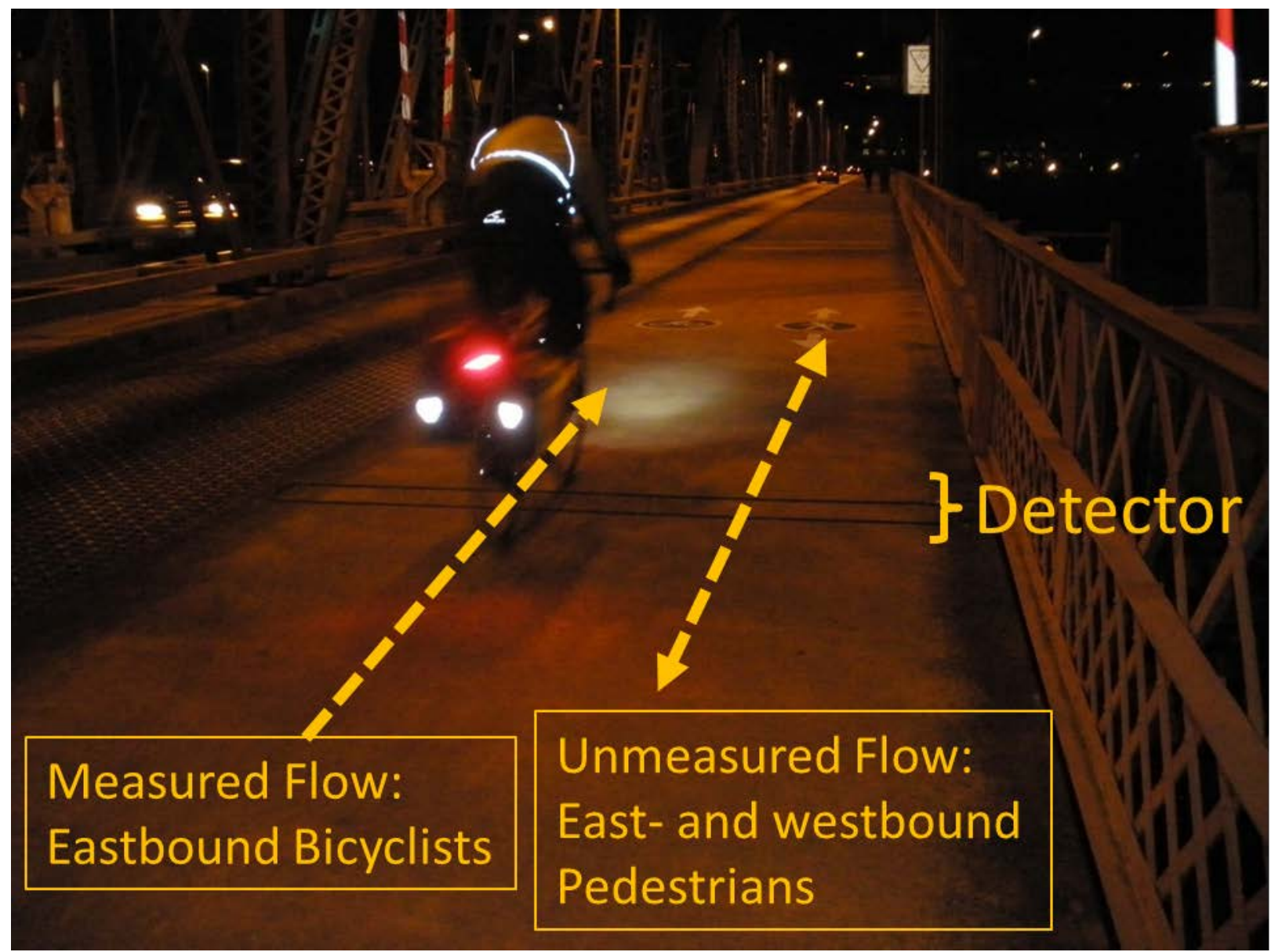

Figure 4.5 Flows Example

\subsubsection{Flow Detector}

Select an organization then select a Detector and a Flow associated with that Detector.

Creating Flow Detectors: A map has been added to pinpoint the location of the Detector when creating a Flow Detector for data input. 


\section{Flow Detector}

Select an organization then select a detector and a flow associated with that detector

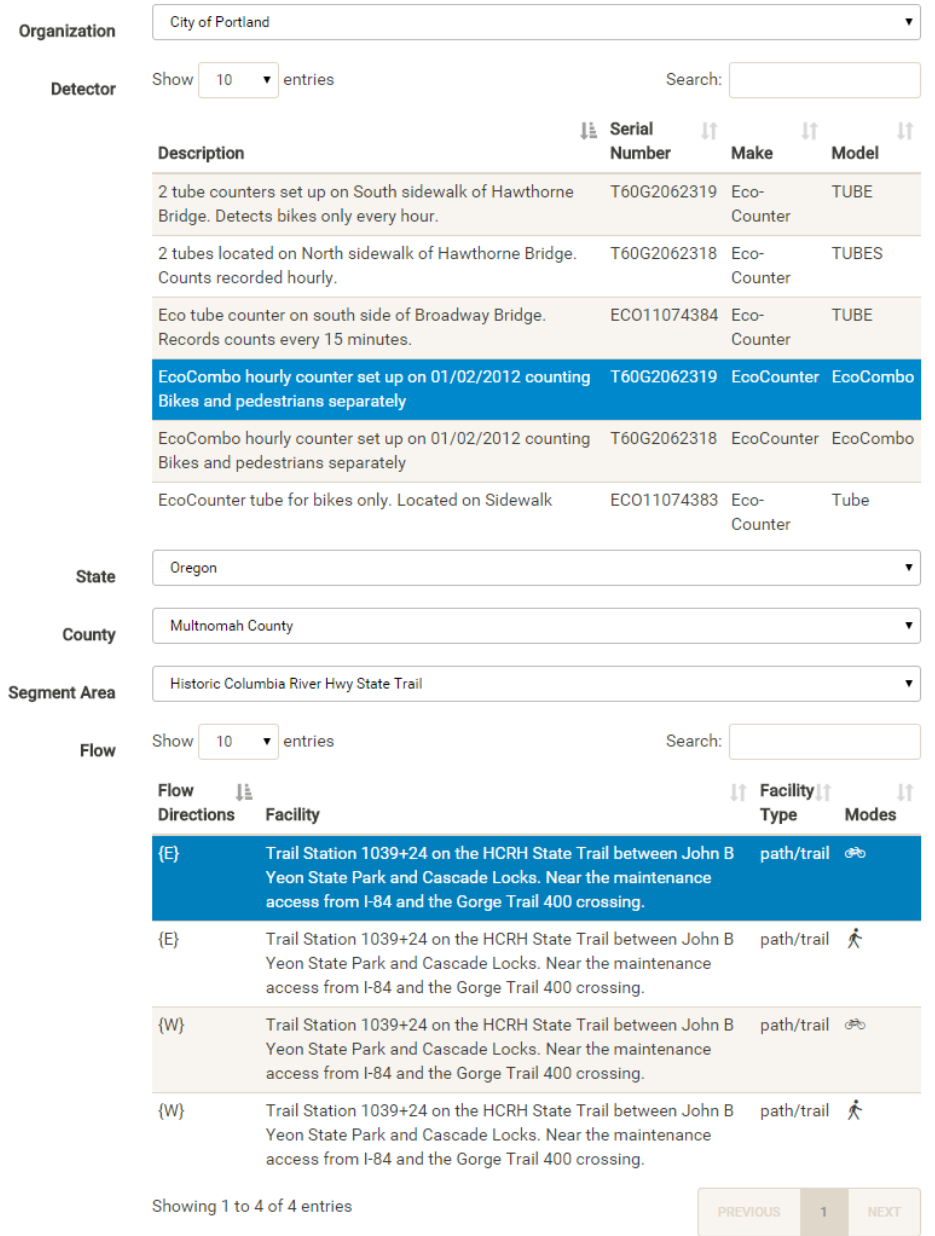




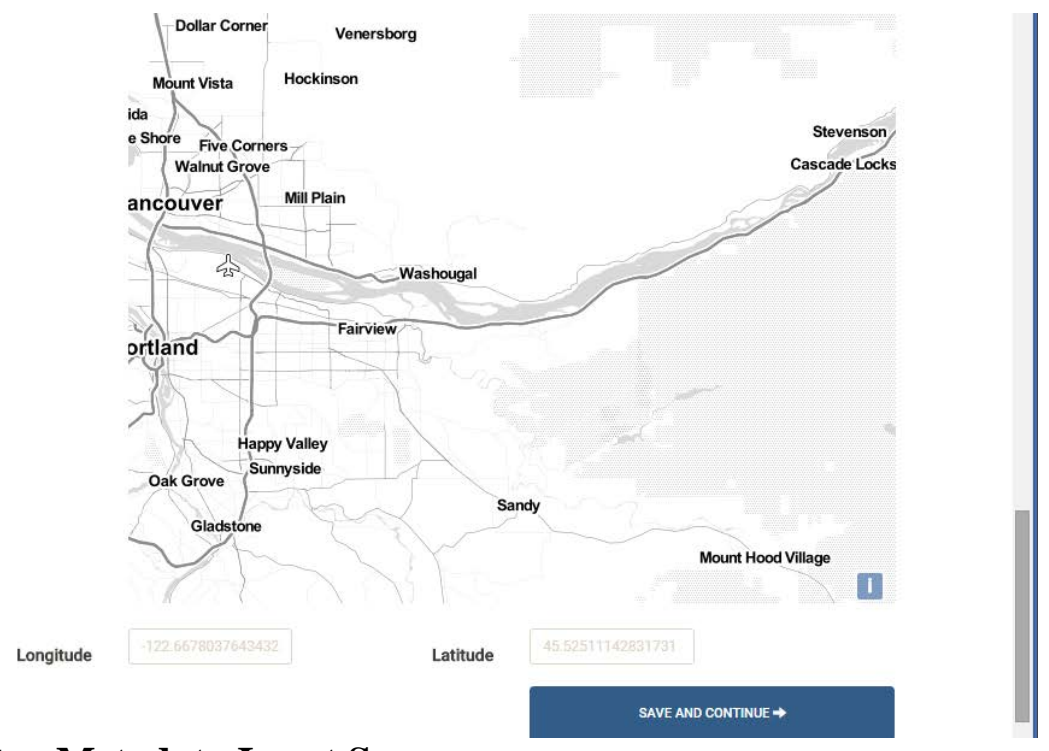

Figure 4.6 Flow Detector Metadata Input Screen

\subsection{DATA UPLOAD}

All count data records are uploaded in comma-separated values (CSV) files for a given previously created Flow Detector. Even if there is only one count record (for example, a count record could be from 5-6 p.m. on March 16, 2014, there were 10 pedestrians observed walking north on the east sidewalk of SW $4^{\text {th }}$ Avenue in Portland), a CSV file must be created and uploaded to the Flow Detector in order for the count to be added to the archive. Section 4.3.1 describes how to upload the file, and the process of formatting the CSV file is explained in Section 4.3.2.

\subsubsection{Count Data Upload}

The first step in the count upload process is to establish the organization (Figure 4.7) and Detector and Flow (Figure 4.8) for which the count data is being uploaded. After the Detector and Flow Detectors are selected, the user may either browse to find the file or files to upload or drag and drop the file or files to be uploaded. As shown in Figure 4.9, multiple files may be uploaded at the same time.

During upload, a green bar shows progress toward full upload. The upload process is not instantaneous because data checks must be made to determine if the files are properly formatted. If there is a problem in data upload, the user may be shown an error message. If data upload is successful, a message to that effect is presented and a graph of the data volumes is presented to the user, as shown in Figure 4.10. By default the full data set uploaded are presented.

Example screenshots for these steps are provided in the figure for a TRAFx infrared counter located on a trail near Portland's International Rose Test Garden, which is managed and owned by Washington Park Transportation Management Association (also known as Explore Washington Park). 


\section{Data Upload}

Select an organization then select a detector and a flow associated with that detector

\begin{tabular}{|l|}
\multicolumn{1}{|c|}{ Organization } \\
\hline Washington Park TMA \\
\hline Bend MPO \\
Central Lane MPO \\
City of Austin \\
City of Bend \\
City of Boulder \\
City of Eugene \\
City of Portland \\
Cycle Oregon \\
Jackson County \\
LCOG \\
Metro \\
MWVCOG \\
Oregon Department of Transportation \\
Portland State University \\
Arlington_Virginia \\
Olympia_Washington \\
City of Seattle \\
Minneapolis \\
THPRD \\
Washington Park TMA \\
\hline
\end{tabular}

Figure 4.7 Data Upload Organization Selection Screen 


\section{Data Upload}

Select an organization then select a detector and a flow associated with that detector

\section{Organization}

Washington Park TMA

Detector Show $10 \quad$ entries
Search:

\begin{tabular}{|c|c|c|c|}
\hline Description & Serial Number & Make & Model \\
\hline Washington Park IR counters & unknown & TRAFx & Infrared Trail Counter \\
\hline
\end{tabular}

Showing 1 to 1 of 1 entries

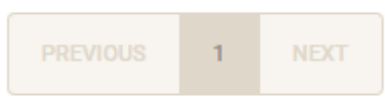

Flow Show $10 \quad \mathbf{v}$ entries
Search:

\begin{tabular}{|c|c|c|c|c|}
\hline $\begin{array}{l}\text { Segment } \downarrow I E \\
\text { Area }\end{array}$ & $\begin{array}{l}\text { Flow } \\
\text { Directions }\end{array}$ & Facility & $\begin{array}{l}\text { Facility } \\
\text { Type }\end{array}$ & Modes \\
\hline $\begin{array}{l}\text { Marquam @ } \\
\text { Hwy } 26 \text { (Site } \\
\text { ID: 32) }\end{array}$ & $\{\mathrm{NW}, \mathrm{SE}\}$ & $\begin{array}{l}\text { Marquam Trail not far off of Highway } 26 \text {. Deep in trees, likely not } \\
\text { paved. Across from Washington Park. Connects park to residential } \\
\text { area. }\end{array}$ & path/trail & $\dot{x}$ \\
\hline $\begin{array}{l}\text { Rose Garden } \\
\text { Ped Trail (Site } \\
\text { ID: 43) }\end{array}$ & $\{W, E\}$ & $\begin{array}{l}\text { Entrance to the SW Pedestrian Trail off of Sacajawea Blvd. Leads } \\
\text { to the Rose Garden and Amphitheater. Paved, well-maintained. } \\
\text { Open to bikes and pedestrians. }\end{array}$ & path/trail & $\kappa^{2}$ \\
\hline
\end{tabular}

\section{Figure 4.8 Data Upload Detector and Flow Selection}


Search:

\begin{tabular}{l} 
Segment \\
Area \\
\hline Marquam @ \\
Hwy 26 (Site \\
ID: 32)
\end{tabular}

Rose Garden $\quad\{W, E\}$

Ped Trail (Site ID: 43)

\begin{tabular}{|c|c|}
\hline $\begin{array}{l}\text { Upper } \\
\text { Madison Trail } \\
\text { (Site ID: } 52 \text { ) }\end{array}$ & $\{\mathrm{SW}, \mathrm{NE}$ \\
\hline $\begin{array}{l}\text { Wildwood@ } \\
\text { MAC (Site ID: } \\
60)\end{array}$ & $\{\mathrm{NW}, \mathrm{SE}$ \\
\hline $\begin{array}{l}\text { Wildwood at } \\
\text { Burnside (Site } \\
\text { ID: } 61 \text { ) }\end{array}$ & $\{\mathrm{N}, \mathrm{S}\}$ \\
\hline
\end{tabular}

Showing 1 to 5 of 5 entries

\begin{tabular}{|c|c|c|}
\hline $\begin{array}{l}\text { Flow } \\
\text { Directions }\end{array}$ & Facility & $\begin{array}{l}\text { Facility } \\
\text { Type }\end{array}$ \\
\hline$\{\mathrm{NW}, \mathrm{SE}\}$ & $\begin{array}{l}\text { Marquam Trail not far off of Highway } 26 \text {. Deep in trees, likely not } \\
\text { paved. Across from Washington Park. Connects park to residential } \\
\text { area. }\end{array}$ & path/trail \\
\hline$\{W, E\}$ & $\begin{array}{l}\text { Entrance to the SW Pedestrian Trail off of Sacajawea Blvd. Leads } \\
\text { to the Rose Garden and Amphitheater. Paved, well-maintained. } \\
\text { Open to bikes and pedestrians. }\end{array}$ & path/trail \\
\hline
\end{tabular}

Gated road that leads up to the Portland Reservoir. Paved and roadway $\dot{\kappa}$ well-maintained, few road markings. Plenty of greenery and trees. Close to residential area in Washington Park.

Thin unpaved trail running throughout Washington Park, heavily path/trail $\dot{\kappa}$ forested. Counter is located where Wildwood Trail follows Kingston Dr in a U. Popular hiking trail.

Thin unpaved trail running throughout Washington Park, heavily path/trail $\dot{\kappa}$ forested. Counter is located S of Burnside where Wildwood Trail runs parallel to Fischer Ln. Popular hiking trail.

Modes

$\dot{\kappa}$

א




\section{Data Upload}

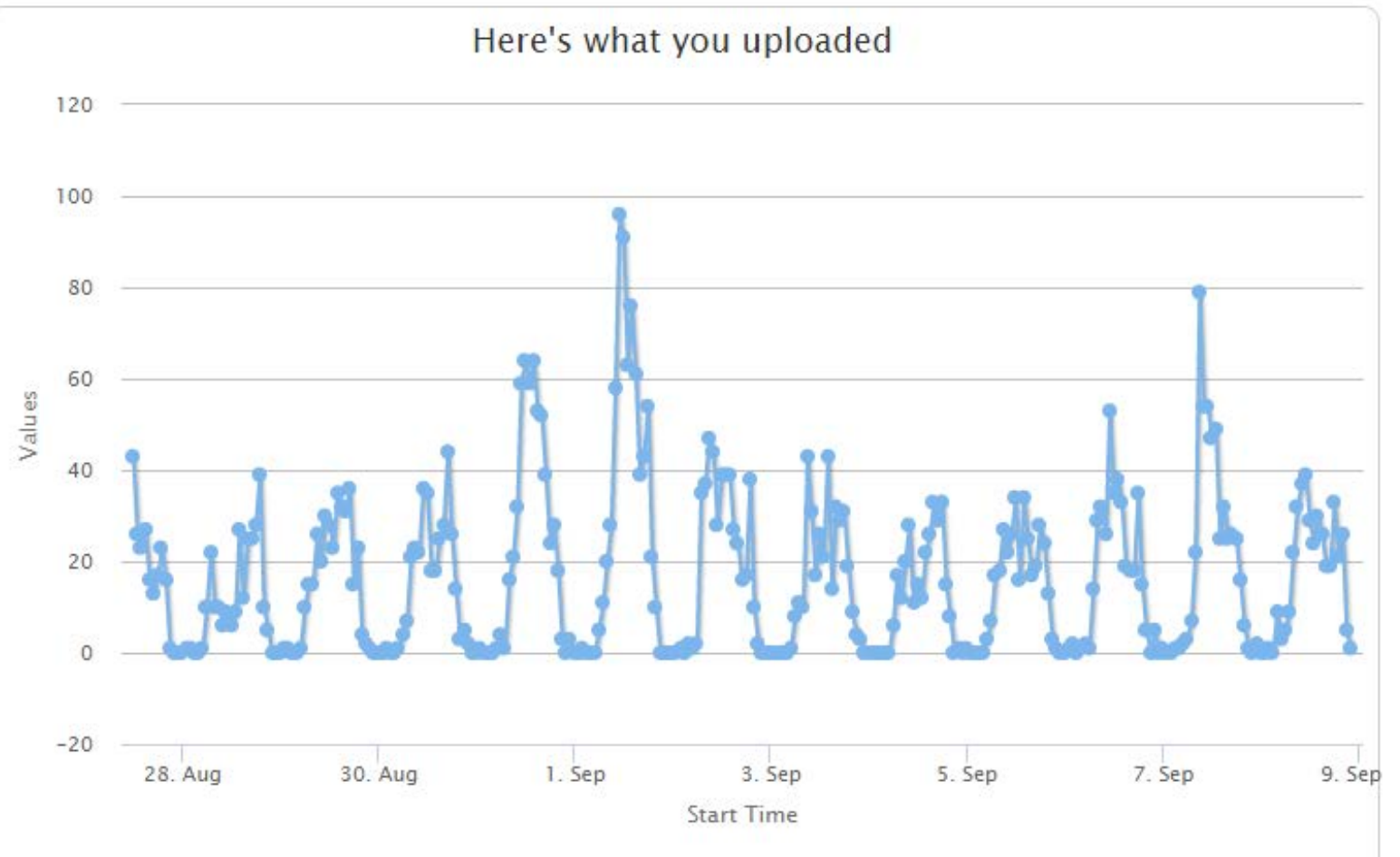

Figure 4.10 Data Uploaded Visualization

\subsubsection{Count Data Format}

The data input files submitted to Bike-Ped Portal must be in CSV files. Each Flow Detector's count data must be in a separate file. Below is an example. 


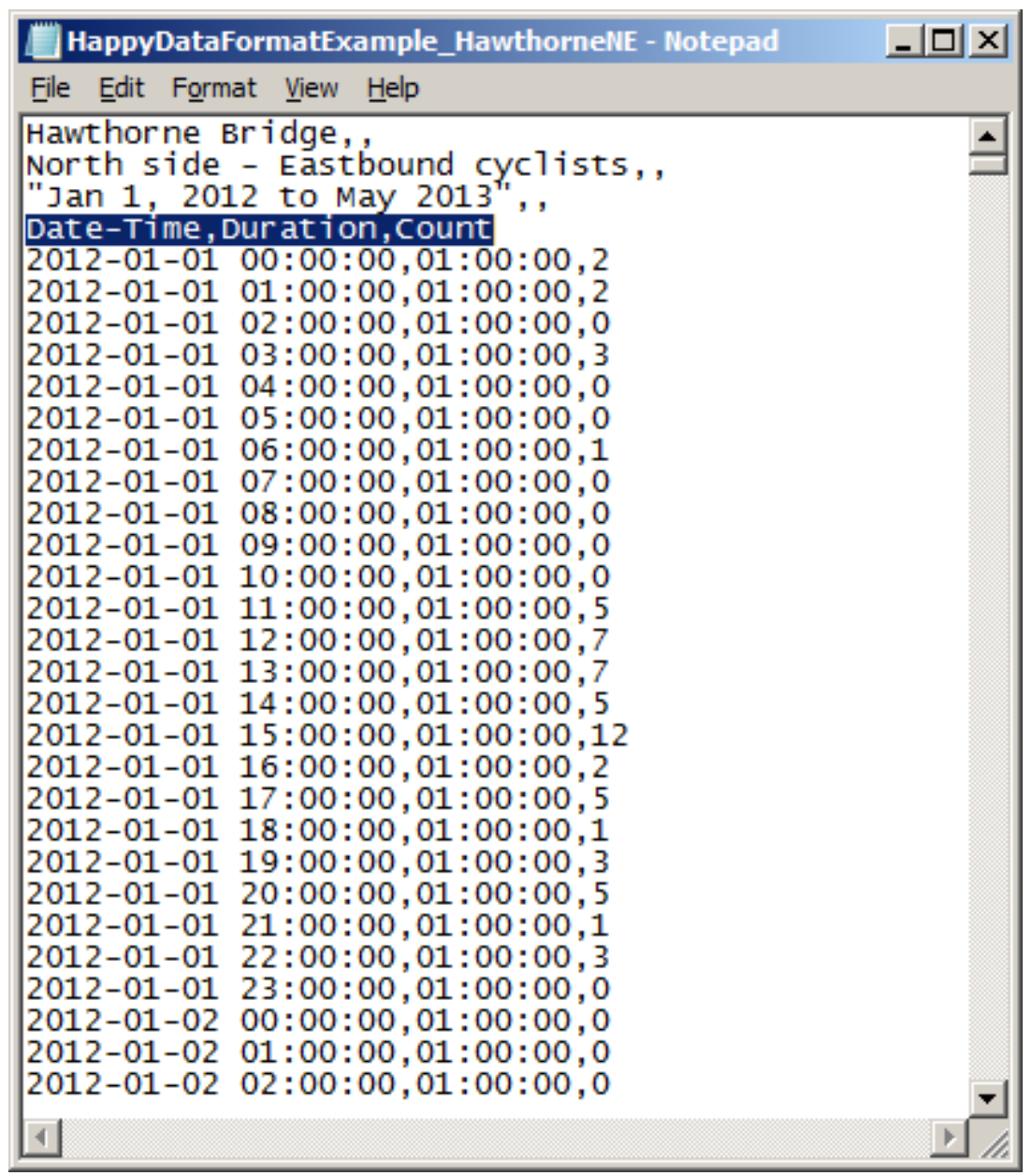

Figure 4.11 Preferred Data Format Example

Reference Lines: The first three lines can be any text up to 1,024 characters per line. These can be any text. It will be saved in the archive with the record of the upload.

Header Row: The fourth row is the header row, which must read one of the following: start time,duration,count start time,endtime,count

In the first column of the header line, the word "start" followed by the word "time" with an optional space, underscore, or hyphen between both words are all valid. Similarly, in the second column of the header line, the word "end" followed by the word "time" with an optional space, underscore, hyphen or no space between the words are all valid. If desired, the second column may also be called “duration" or "measure period.” If "measure period” is used, an optional space, underscore, hyphen or no space between the words are all valid. The third column may be called either "count" or "volume." This is case insensitive, so all examples listed in Table 4.1 are valid headers. 
Table 4.1 Examples of Possible Headers

\begin{tabular}{|l|l|l|}
\hline 1st column & 2nd column & 3rd column \\
\hline STARTTIME & END-TIME & Count \\
Start-Time & endtime & COUNT \\
Start_time & duration & VOLUME \\
start time & Duration & voLUme \\
& MeasurePeriod & \\
& Measure-Period & \\
& period & \\
\hline
\end{tabular}

The remaining lines are composed of the data itself. Each row contains three data fields separated by commas: Start Time, Duration, and Count. Each are detailed below.

Start Time: The "Start Time" is the start time for the time period during which counting occurred. Start Time must be in the following format: YYYY-MM-DD HH:MM:SS

- For example, if 12 cyclists were counted between 5:30-6 p.m. on Tuesday, January 6, 2015, the Start Time would be 2015-01-06 17:30:00. This can be done in Excel by selecting "Format Cells." "More Numbers Formats," "Custom” and choosing or creating the code: "yyyy-mm-dd hh:mm:ss" 


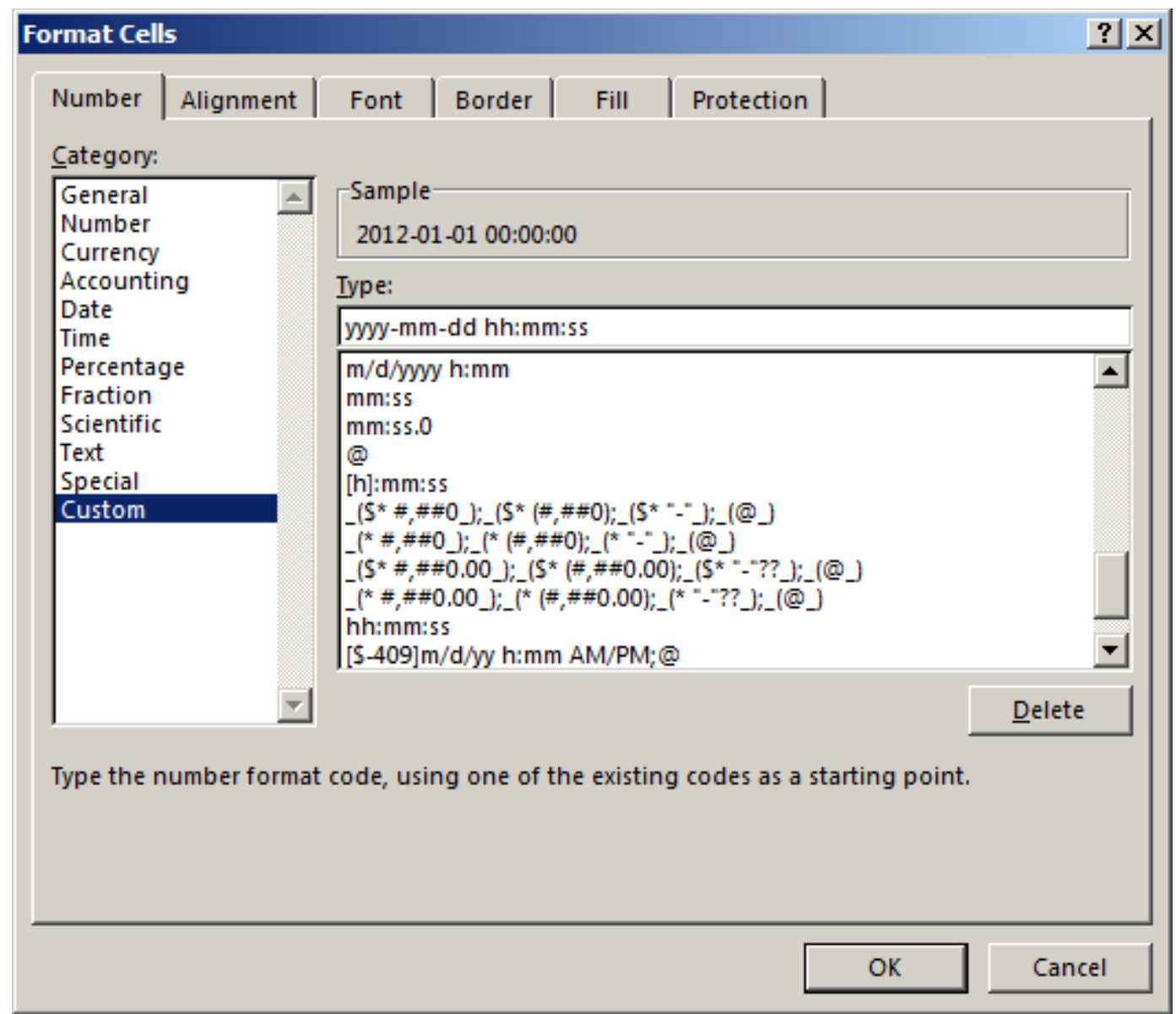

Figure 4.12 Start Time Format Selection in Excel

AM/PM: Do not include a.m. and p.m., but use the 24 hour time.

Correct 17:30:00

Incorrect 5:30 p.m.

Time Zone: The time zone will be selected in a drop-down menu prior to uploading the file.

Daylight Savings: Daylight savings time can be dealt with in one of two ways:

- Option 1 - Separate a year of data into two parts: one with all the counts collected during standard time and the other with all of the counts collected during daylight savings time.

- Option 2 - Delete the data record for the one hour of time in the spring 2 a.m. on March _ that is redundant (when we spring forward). While this does result in a loss of data, it is an hour when little usually happens.

Duration: Duration is the length of the time period during which counts occurred. For example, if 25 cyclists were counted between 5:30-6 p.m., the Duration would be 00:30:00. Duration is a time field in the following format: $\mathrm{HH}: \mathrm{MM}: \mathrm{SS}$ 
Count: The Count is the number of road users of the type defined as the traffic Flow which are counted by the Detector during the given Duration after the given Start Time.

The Count is an integer. It cannot be left blank.

\section{Other Information:}

- The name of the Count file can be anything the user chooses.

- If data are in an incorrect format, the file will be rejected. If the file duplicates any data already in the Bike-Ped Portal, it will be rejected. Contact us in order to delete the data before importing the new data. (We are looking for funding sources to allow editing of the data. If you would like to support this effort, please let us know.)

- The file is saved in the archive along with the date of upload and header information. Currently the data are stored as raw data.

\subsubsection{Eco-Counter Automated Upload}

Eco-Counter, a major manufacturer of bicycle and pedestrian counting equipment, has provided the team with access to automated count data from partner count sites via their API. This allows daily upload to Bike-Ped Portal from partner Detectors with modem connections, which upload to the Eco-Visio Eco-Counters database each night. 


\subsection{DATA DOWNLOAD}

Data can be downloaded as a CSV file using a download page. The download page allows users to select the location's state, county and Segment Area from drop-down menus and then the Flow Detector from a list. Once a Flow Detector has been selected, the page displays data availability for that site in terms of a graph of records available per week. From this page, a CSV file can be downloaded for the dates selected by the user.

\subsubsection{Data Download User Interface}

Users will be able to view Detectors and download count data by entering in the state and county and selecting the Segment Area: 


\section{Download}

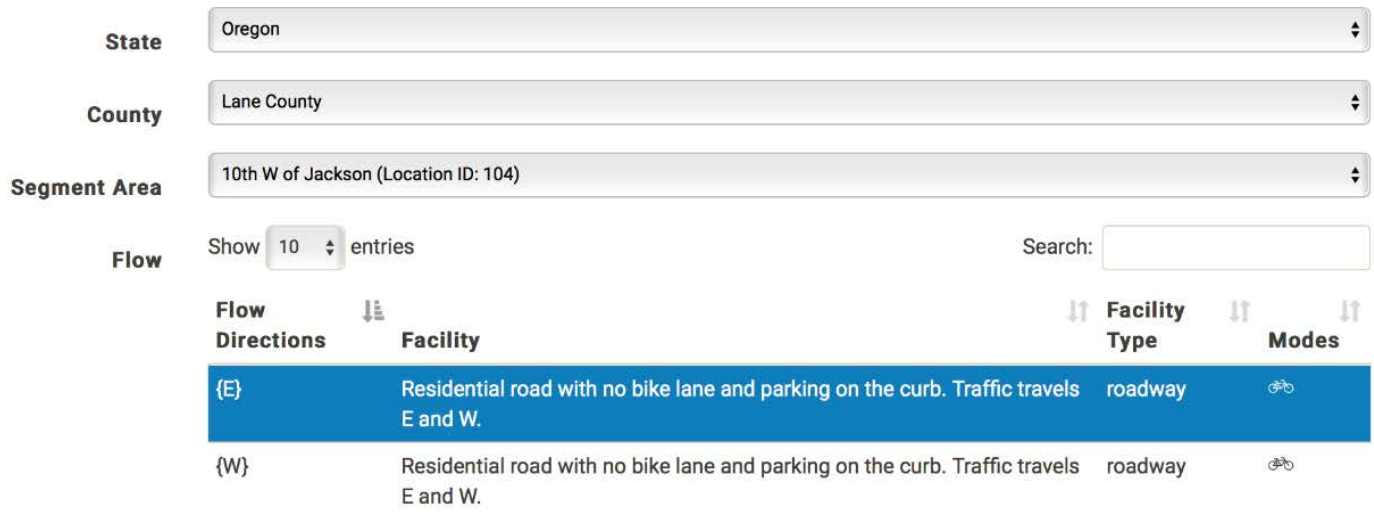

Showing 1 to 2 of 2 entries

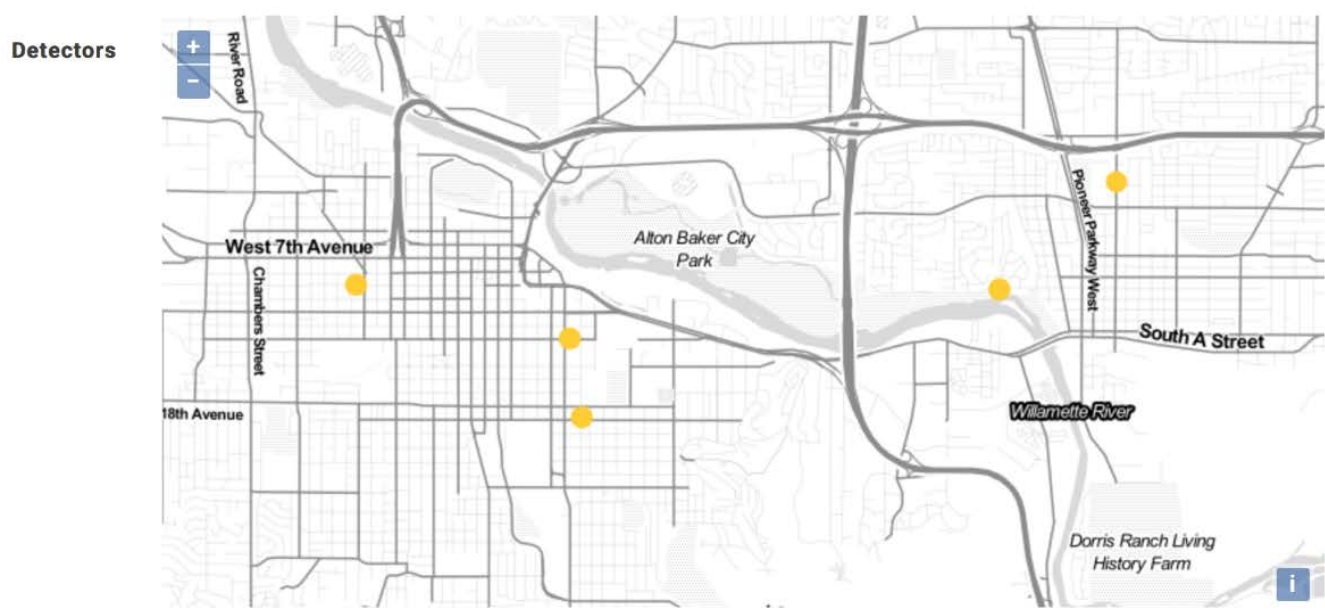

Figure 4.13 Data Download Screen 
Example CSV opened in WordPad:

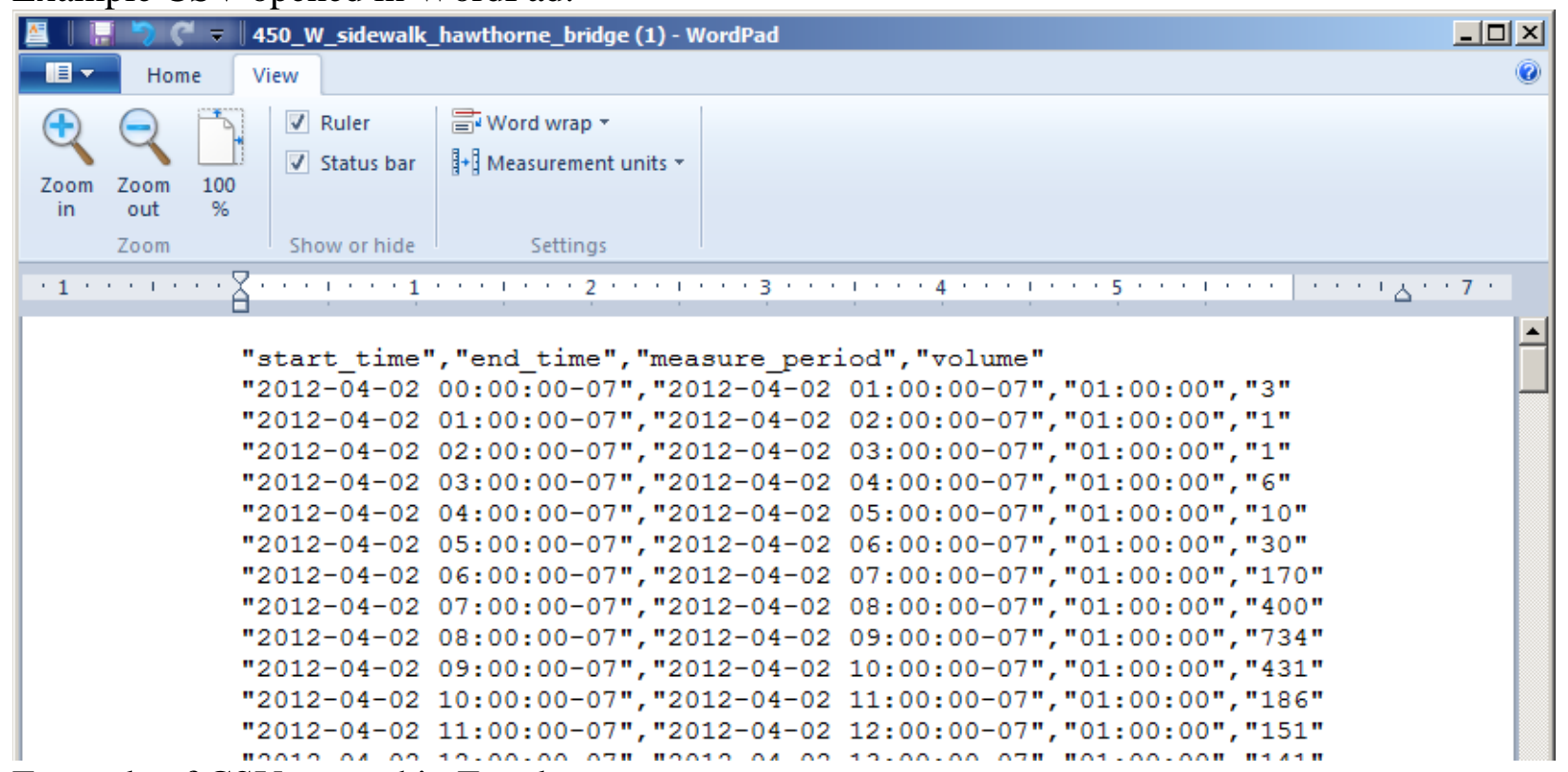
Example of CSV opened in Excel.

\begin{tabular}{|c|c|c|}
\hline $2-\overline{0} 4-02$ & $00: 00: 00-07 ", " 2012-0 \overline{4}-02$ & $01: 00: 00-07 ", " 01: 00: 00 ", " 3 "$ \\
\hline $2-04-02$ & $01: 00: 00-07 ", " 2012-04-02$ & $02: 00: 00-07 ", " 01: 00: 00 ", " 1 "$ \\
\hline $2-04-02$ & $02: 00: 00-07 "$, & $03: 00: 00-07 "$, \\
\hline $012-04-02$ & $03: 00: 00-07 "$, & $04: 00: 00-07 "$, \\
\hline $012-04-02$ & $04: 00: 00-07 "$, & $05: 00: 00-07 "$, \\
\hline $012-04-02$ & $05: 00: 00-07 "$, & $06: 00: 00-07 "$, \\
\hline $012-04-02$ & $06: 00: 00-07 "$, & $07: 00: 00-07 "$, \\
\hline $012-04-02$ & $07: 00: 00-07 "$, & $08: 00: 00-07 ", " 01: 00: 00 "$, \\
\hline $012-04-02$ & $08: 00: 00-07 "$, & $09: 00: 00-07 ", " 01: 00: 00 "$, \\
\hline $012-04-02$ & $09: 00: 00-07 "$, & $10: 00: 00-07 ", " 01: 00: 00 "$, \\
\hline $012-04-02$ & $10: 00: 00-07 "$, & $11: 00: 00-07 ", " 01: 00: 00 "$, \\
\hline $012-04-02$ & $11: 00: 00-07 ", "$ & $12: 00: 00-07 ", " 01: 00: 00 "$, \\
\hline
\end{tabular}

\begin{tabular}{|c|c|c|c|c|c|c|c|c|c|}
\hline \multicolumn{2}{|c|}{ G10 } & $\times \vee f_{x}$ & \multirow[b]{2}{*}{ C } & \multirow[b]{2}{*}{ D } & \multirow[b]{2}{*}{$\mathrm{E}$} & \multirow[b]{2}{*}{$\mathrm{F}$} & \multirow[b]{2}{*}{$\mathbf{G}$} & \multicolumn{2}{|c|}{$\mathbf{v}$} \\
\hline 4 & $\mathrm{~A}$ & $\mathrm{~B}$ & & & & & & $\mathrm{H}$ & $\Delta$ \\
\hline 1 & start_time & end_time & measure_ & volume & & & & & \\
\hline 2 & $4 / 2 / 20120: 00$ & $4 / 2 / 20121: 00$ & $1: 00: 00$ & 3 & & & & & \\
\hline 3 & $4 / 2 / 20121: 00$ & $4 / 2 / 20122: 00$ & $1: 00: 00$ & 1 & & & & & \\
\hline 4 & $4 / 2 / 20122: 00$ & $4 / 2 / 20123: 00$ & $1: 00: 00$ & 1 & & & & & \\
\hline 5 & 4/2/2012 3:00 & $4 / 2 / 20124: 00$ & 1:00:00 & 6 & & & & & \\
\hline 6 & $4 / 2 / 20124: 00$ & $4 / 2 / 20125: 00$ & 1:00:00 & 10 & & & & & \\
\hline 7 & $4 / 2 / 20125: 00$ & $4 / 2 / 20126: 00$ & $1: 00: 00$ & 30 & & & & & \\
\hline 8 & $4 / 2 / 20126: 00$ & $4 / 2 / 20127: 00$ & $1: 00: 00$ & 170 & & & & & \\
\hline 9 & $4 / 2 / 20127: 00$ & $4 / 2 / 20128: 00$ & 1:00:00 & 400 & & & & & \\
\hline 10 & $4 / 2 / 20128: 00$ & 4/2/2012 9:00 & 1:00:00 & 734 & & & & & \\
\hline 11 & $4 / 2 / 20129: 00$ & $4 / 2 / 201210: 00$ & $1: 00: 00$ & 431 & & & & & \\
\hline 12 & $4 / 2 / 201210: 00$ & $4 / 2 / 201211: 00$ & $1: 00: 00$ & 186 & & & & & \\
\hline 13 & $4 / 2 / 201211: 00$ & $4 / 2 / 201212: 00$ & $1: 00: 00$ & 151 & & & & & \\
\hline 14 & $4 / 2 / 201212: 00$ & $4 / 2 / 201213: 00$ & 1:00:00 & 141 & & & & & \\
\hline 15 & $4 / 2 / 201213: 00$ & $4 / 2 / 201214: 00$ & $1: 00: 00$ & 188 & & & & & \\
\hline 16 & $4 / 2 / 201214: 00$ & $4 / 2 / 201215: 00$ & 1:00:00 & 146 & & & & & \\
\hline 17 & $4 / 2 / 201215: 00$ & $4 / 2 / 201216: 00$ & $1: 00: 00$ & 121 & & & & & \\
\hline 18 & $4 / 2 / 201216: 00$ & $4 / 2 / 201217: 00$ & $1: 00: 00$ & 154 & & & & & \\
\hline 19 & $4 / 2 / 201217: 00$ & $4 / 2 / 201218: 00$ & 1:00:00 & 137 & & & & & \\
\hline
\end{tabular}

Figure 4.14 Data Download Format Examples 


\subsubsection{Data Download API}

A full-featured download API is included in the website. Users are required to have an account prior to using the API. The username and password is used to obtain an authentication token which must used with subsequent requests.

\subsection{DATA VISUALIZATION}

At this time the archive provides two views of data uploaded. One is a graph of data availability as show in Figure 4.15. The other graph shows the raw counts by time for each record (Figure 4.16). A record could be a minute, an hour or a day, depending on the record length of the raw data. Both graphs' default time period shown is the first and last record stored in the archive, which is very useful for understanding the time period covered by the data. However, the date range can be changed to a date range selected by the user either using the "Start Date" and "End Date" selection tools or by using the mouse to select the data of interest on the graph itself. These data visualizations give the user basic information on traffic volumes during the time period of interest. The graphs are generated using Highcharts (Highcharts, 2016). 


\section{Bike-Ped Archive}

\section{$\{\mathrm{W}, \mathrm{E}\}$}

Entrance to the SW Pedestrian Trail off of Sacajawea Blvd. Leads to the Rose

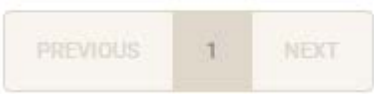

Start Date

2014-06-09

豆

End Date

2016-02-22

Data availability

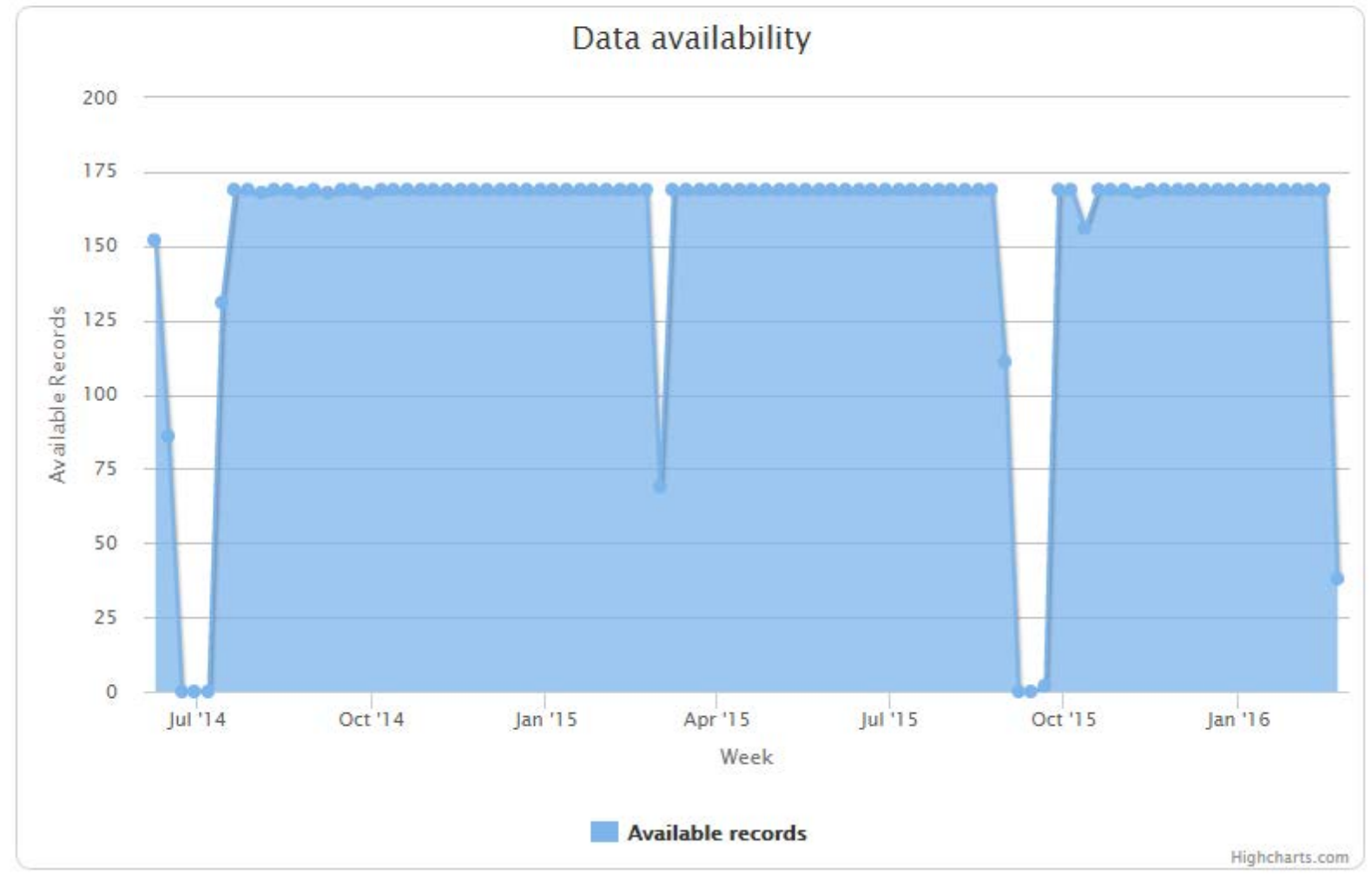

Figure 4.15 Data Availability Visualization 


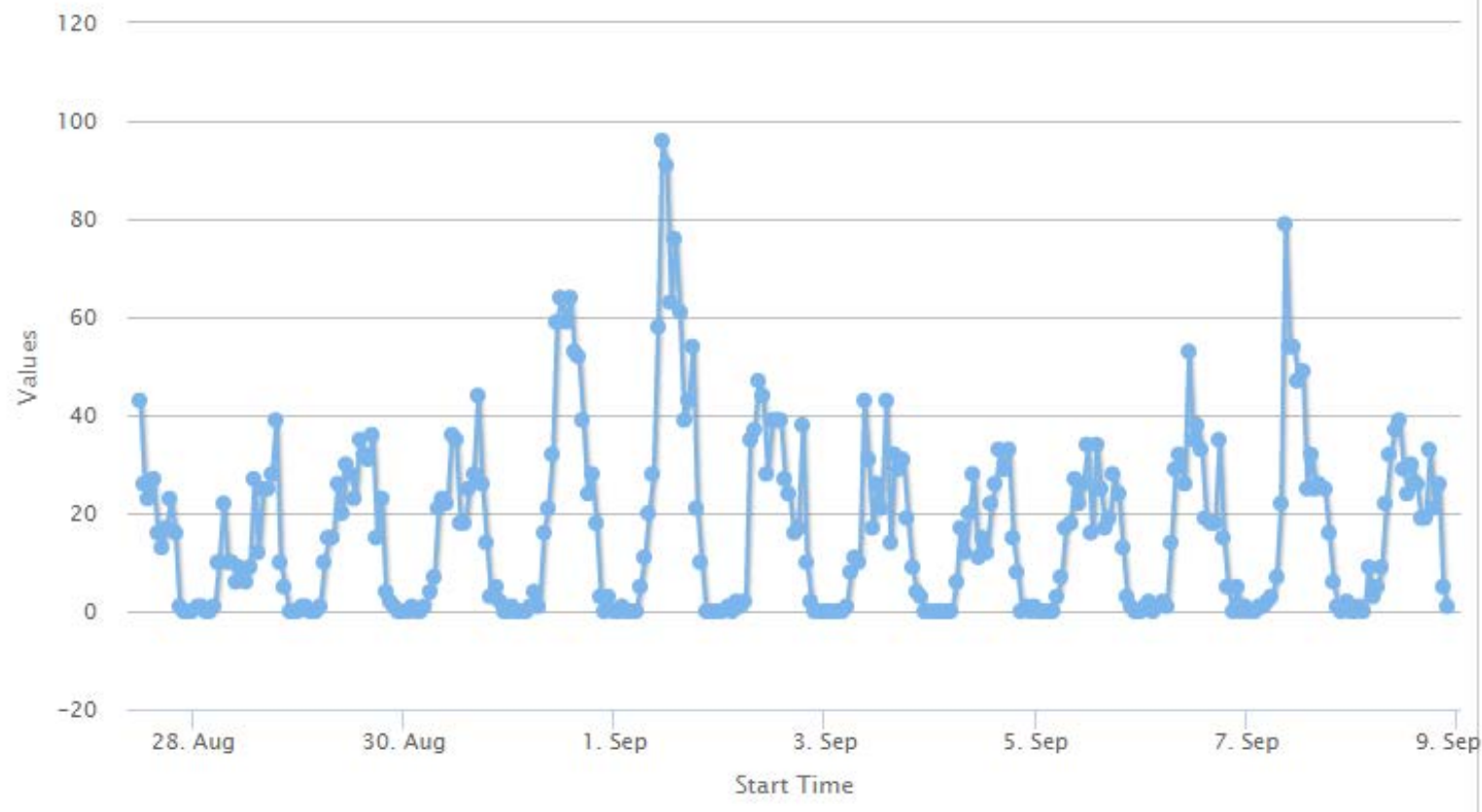

Figure 4.16 Count Data Visualization

Additional data visualizations are planned to be designed and implemented as part of Phase II work. These would be based on the needs of transportation planners. 


\subsection{DATA QUALITY}

The goal of Bike-Ped Portal is to have several layers of quality assurance and quality control (QA/QC) that aim to improve the quality of data. The QA/QC measures will either act to a) automatically reject certain data (while providing feedback as to why the data was rejected so that the uploader may correct the problem); b) alert the uploader about an issue observed in the data and require affirmation before allowing the upload; or c) trigger an alert on the back end while allowing the data to be uploaded, though not yet accepted until an archive representative approves the data. QA/QC measures are implemented to various degrees during metadata upload (e.g., inputting information about the count detectors, location, etc.) and during the count data upload process (i.e., uploading the actual count numbers).

Three levels of QA/QC will be discussed in this document:

1. Database constraints

2. Automated checks

3. User observation

Each level of QA/QC is detailed below. The Appendix reviews the background material on this subject including Appendix J of the Federal Highway Administration's Traffic Monitoring Guide (TMG)(1). In this memo the term "user" refers to the person who is inputting the data. These three steps apply to data directly uploaded to the website and data that are automatically uploaded. For automatically uploaded data, users will need to log in to the site to QA/QC the data and will be emailed if more than a month of data has been left unchecked. Unchecked data stays in a holding area and is not accepted into the database.

While the above text describes the goal of Bike-Ped Portal, at the time of this report only the first (database constraints) and part of the second (automated checks) levels of QA/QC have been implemented. At this time, Bike-Ped Portal rejects data that is not in the correct format or violates database constraints, and provides the user with an error message. In addition, basic QC tests described below are being implemented in the database, but the flagged data are not communicated to the user.

\subsection{DATABASE CONSTRAINTS}

The first layer of control on data quality begins with data validation according to the field constraints imposed on both the metadata and count data. The field constraints limit the acceptable data to appropriate formats, lengths, etc.

1. Database constraints:

- Required fields must be non-null.

- If there is a route type indicated (interstate, US hwy, state hwy, county road, etc.), there must also be a route number associated with it. If there is no route type indicated, there also can't be a route number.

- End time must be after the start time, or the end time can be null.

- Speed limit is blank by default, and must be between 0 and 100 if specified. 
- The pavement color, prevalence of color through intersections and driveways, and buffer are specific to cycle tracks and bike lanes, and must be blank for other types of facilities.

- Overlapping counts (counts for the same detector of the same flow at the same time) will not be allowed. Feedback will be provided so that the uploader may edit the data appropriately. To replace data already in the database, users will need to contact Portal staff to first delete the old data before they attempt to add new counts for that detector/flow/time period.

- If no detector is specified, no data can be uploaded.

- Each count must include either the start and end date/time or the start date/time and the duration. If start and end date/time and duration are all included the start date/time plus the duration is required to equal the end time.

- Counts must be integers greater than or equal to zero, not NULL with default zero.

Some constraints will be added in future phases of work as additional funding becomes available.

Constraints for future phases:

- Ability to identify data for which daylight savings time is in the wrong place.

- Missing data (gaps in the timestamps). One- and two-hour gaps could be associated with false timestamps and incorrect or correct daylight savings times.

\subsection{AUTOMATED CHECKS}

Once count data have passed initial constraint validation (including having the appropriate fields, having a valid timestamp, etc.), a set of automated checks are being created to examine if the dataset includes unusually high or low counts, and other checks as listed in Table 5.1. The checks are for the raw data, which are usually directional values.

Table 5.1 Data Quality Checks

\begin{tabular}{|l|l|l|l|}
\hline Flag & $\begin{array}{l}\text { Accept } \\
\text { as } \\
\text { valid }\end{array}$ & $\begin{array}{l}\text { Accept } \\
\text { but } \\
\text { keep } \\
\text { flag }\end{array}$ & $\begin{array}{l}\text { Invalid } \\
\text { data, } \\
\text { accept } \\
\text { but } \\
\text { hide }\end{array}$ \\
\hline On the record level & \multicolumn{2}{l|}{} \\
\hline Flag data with $>6$ identical non-zero values & & \\
\hline On the hourly level & & & \\
\hline Flag if $>15$ consecutive zeros & & & \\
\hline Flag hours $>1,500$ & & & \\
\hline On the daily level & & & \\
\hline Flag days $>10,000$ & & & \\
\hline Flag days with zero counts (if hourly counts not provided) & & & \\
\hline
\end{tabular}


In the future additional functionality may be implemented. Below describes what might be included:

For each flag, the user could be asked if the data should be accepted as valid; if the data should be accepted but kept flagged; or if the data are invalid. Invalid data can still be included in the archive, but will be marked as invalid and will be hidden from the general public.

The numbers supplied in the flags listed in Table 5.1 are default, placeholder values. They can be easily changed in the software, but for now we are not allowing the user to change them and we are not using the data in the database to determine them because there is not enough test data yet available. However, we have used some of the test data we have to verify that these are reasonable for the first phase, and expect that future experience will allow us to modify them in future phases of the work.

Each default flag value was evaluated based on test data. For flag values of lower bound thresholds two datasets were examined:

- A set of 10 years of test data from eastbound bicycle counts from an inductive loop detector operated by the City of Boulder at a low-volume location with Annual Average Daily Bicyclists (AADB) of 164 in suburban Boulder on a wide sidewalk, shared-use path on the north side of a six-lane highway (Arapahoe Blvd.). The test data have already been validated and checked so they represent a correct dataset, although the location is known to consistently undercount cyclists. Of the 10 years of data only $73 \%$ of it is present in the test data. The rest was either not collected or rejected.

- A set of bicycle counts from inductive loops in Aurora, CO, was collected by the Colorado Department of Transportation on a residential street near a school in a suburban area for a four-year period (October 2010 to October 2014). While these data have not been validated or cleaned, they do represent a site with very low counts (AADB=27 in 2011). For this reason, these data are a good test case for low-volume thresholds.

When more than 15 consecutive hours with zero counts are present, these data will be flagged. The value, 15, was chosen because for less than 15 consecutive zeros the percent of flagged hours in the test data increased sharply. This default threshold of 15 consecutive zeros represents $0.2 \%$ of the Arapahoe data and $1.1 \%$ of the Aurora data, which seems reasonable in both cases as shown in Figure 5.1. 

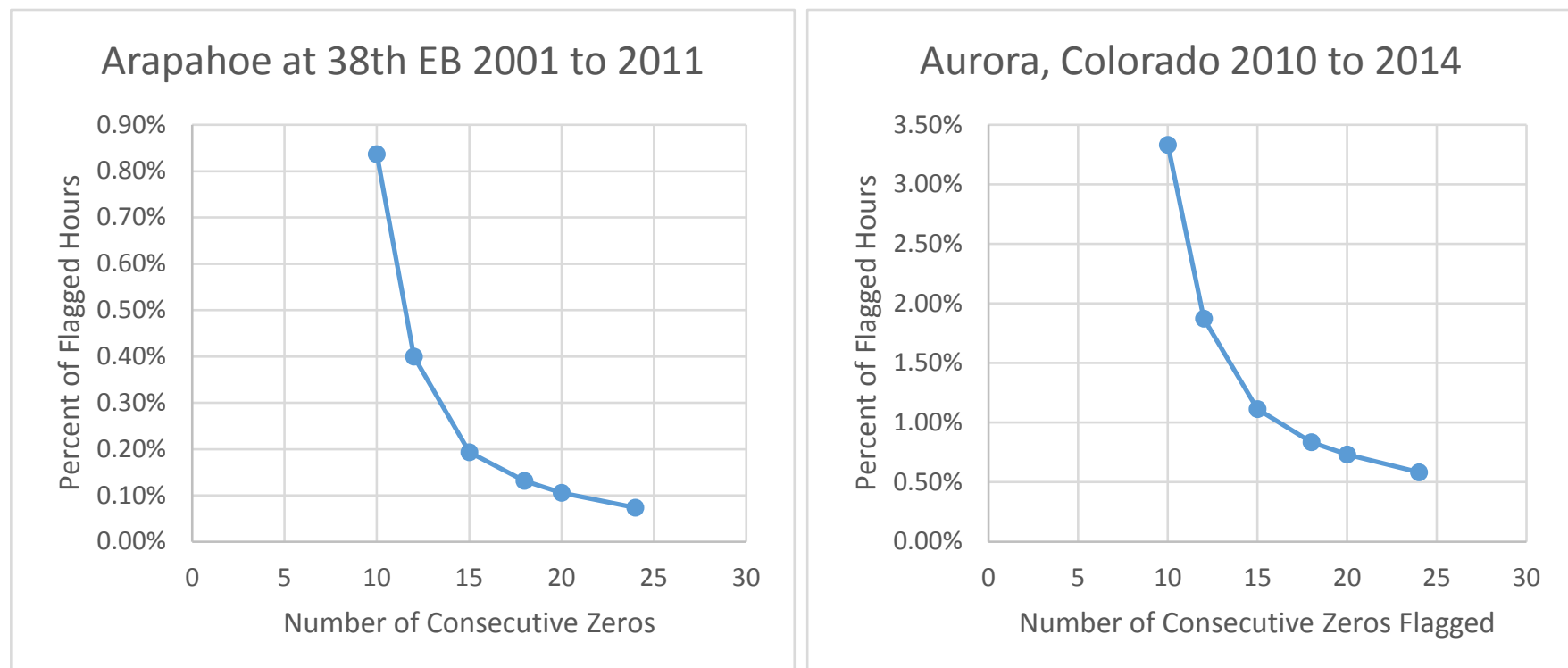

Figure 5.1 Number of Consecutive Hours with Zero Counts

The value, 6, consecutive non-zero values was chosen based on the percent of data flagged, as shown in Figure 5.2. This threshold was chosen, because for fewer than six consecutive nonzeros the percent of flagged hours rose sharply. At the threshold of 6 consecutive non-zero values $0.2 \%$ of the Arapahoe test data and $0.3 \%$ of the Aurora test data were flagged. This seems reasonable in both cases.
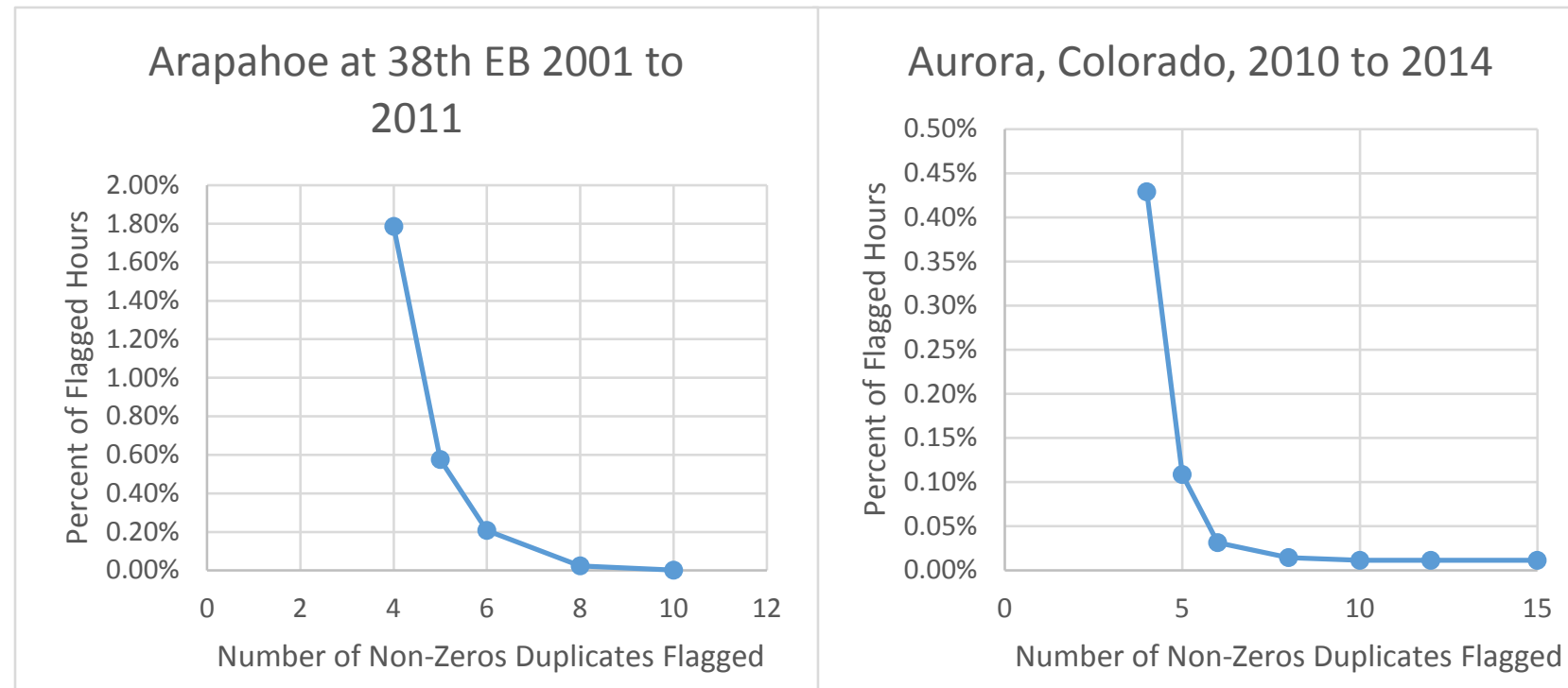

Figure 5.2 Number of Hours with Duplicated Non-zero Counts

The maximum hourly value, 1,500, was chosen based on data from Portland's Hawthorne Bridge (Figure 5.3), one of the locations in the U.S. with the highest bicycle volumes, for the period of January 2012 to October 2014. The highest count recorded on the bridge during that time period was 1,697 (both directions) bicycles on Saturday, June 8, at 9 p.m., the date of the World Naked 
Bike Ride. The next highest hours were 1,535 on Sunday, August 11, 2013, and 1,502 on Sunday, August 12, 2012, both at 8 a.m. and corresponding to Portland's annual Bridge Pedal. The choice of an hourly volume that would result in flagging these exceptional hours seemed appropriate, as it would allow users to identify hours with particularly high volumes and note them appropriately in the comments.

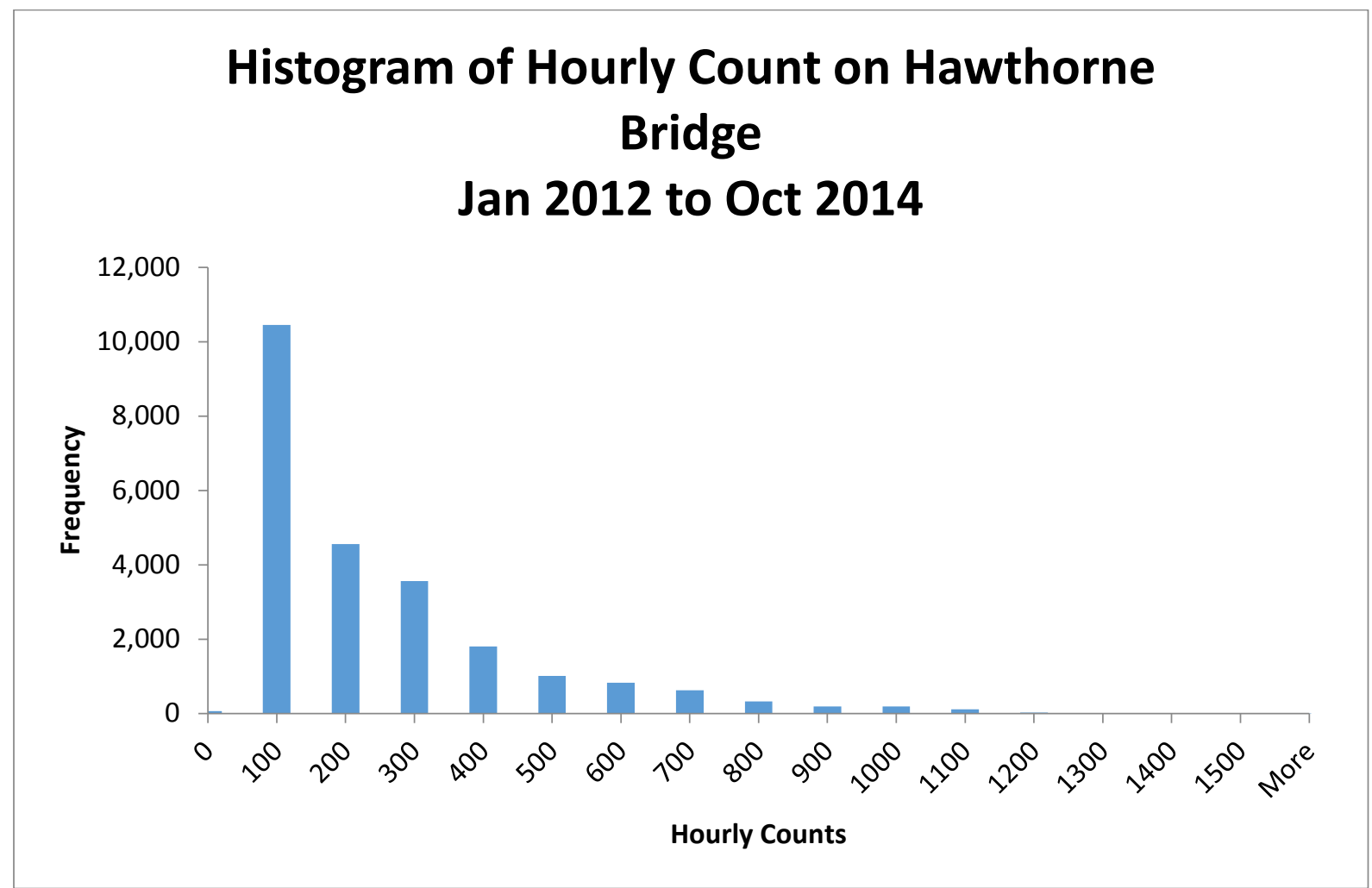

Figure 5.3 Histogram of Hourly Count on Hawthorne Bridge

The maximum daily value, 10,000 count per day, was again chosen based on data from Portland's Hawthorne Bridge (Figure 5.4), which recorded the highest daily count of 9,834 on Saturday, June 8, 2013, (2), the date of the World Naked Bike Ride. Here we chose a value above the maximum to prevent flagging too much. The hourly counts should already flag most events, and this additional check serves to flag events that are either exceptional or that represent technical problems. 


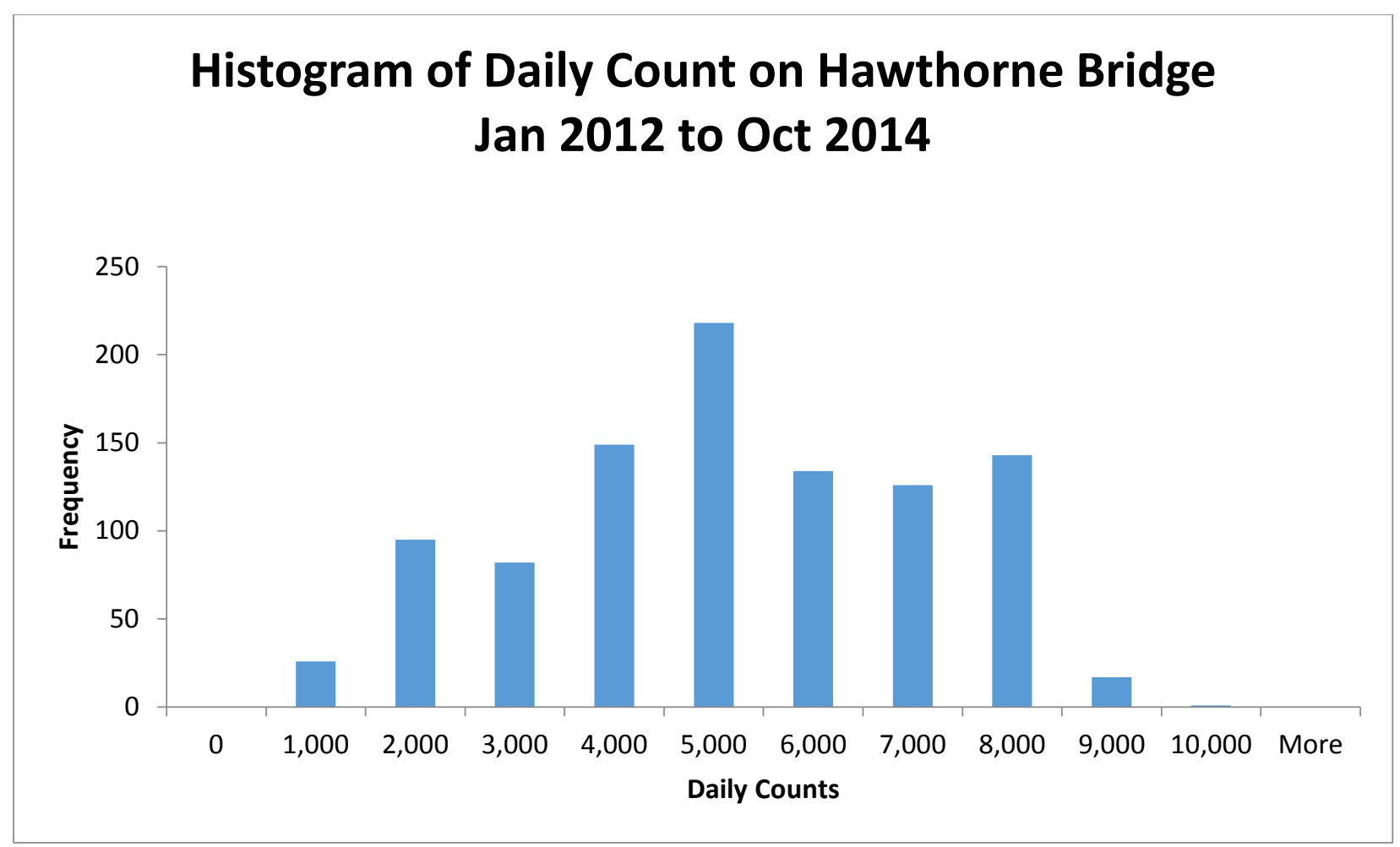

Figure 5.4 Histogram of Daily Count on Hawthorne Bridge

Flagging days with zero counts is redundant with flagging over 15 consecutive zeros, but is appropriate when the data is only provided at the daily level and no hourly values are available. These checks do not include all the checks desired. Some potentially useful checks could be included in future phases of work as additional funds become available.

Potential automated checks to be implemented in future phases:

- Direction Distribution Check: For data with separated, two-directional traffic flows, flag data with too much of a directional bias.

- Comparison of Counts: Where counts are collected for the same flow, at the same time, but by different detectors, check if the percent difference is above a given threshold.

- Repeating Counts: Check for count patterns that repeat in order to identify if data has been copied from one time period and pasted to a different time period.

- Inconsistent Counts: When counts jump or decline precipitously, there may be a problem. As more test data become available we can better study this to understand how best to identify such jumps and if a generalized threshold can or should be established.

- Global, State, Regional, Equipment-specific, User-specified, or Location-specific Thresholds: Future phases of work could examine how thresholds should be set and allow them to be set by jurisdiction, by individual location, by users, or based on historic data at the site. Future research is needed to identify how to set thresholds. 


\subsection{USER OBSERVATIONS}

In future phases of work, Bike-Ped Portal may include a feature to allow users to provide comments about their data. Specifically, the user would be shown a graph (Figure 5.5) of the total counts over time. The original design was to then ask users to identify problem data as either questionable or incorrect, and allow users to add comments to the data for specified time periods. The user would indicate if the comment refers to counts which the archive will "accept" or to "invalid data" which would be hidden from the public web interface. This work is planned to be completed as part of Bike-Ped Portal Phase II.

\section{Bike-Ped Archive}

\section{Data Upload}

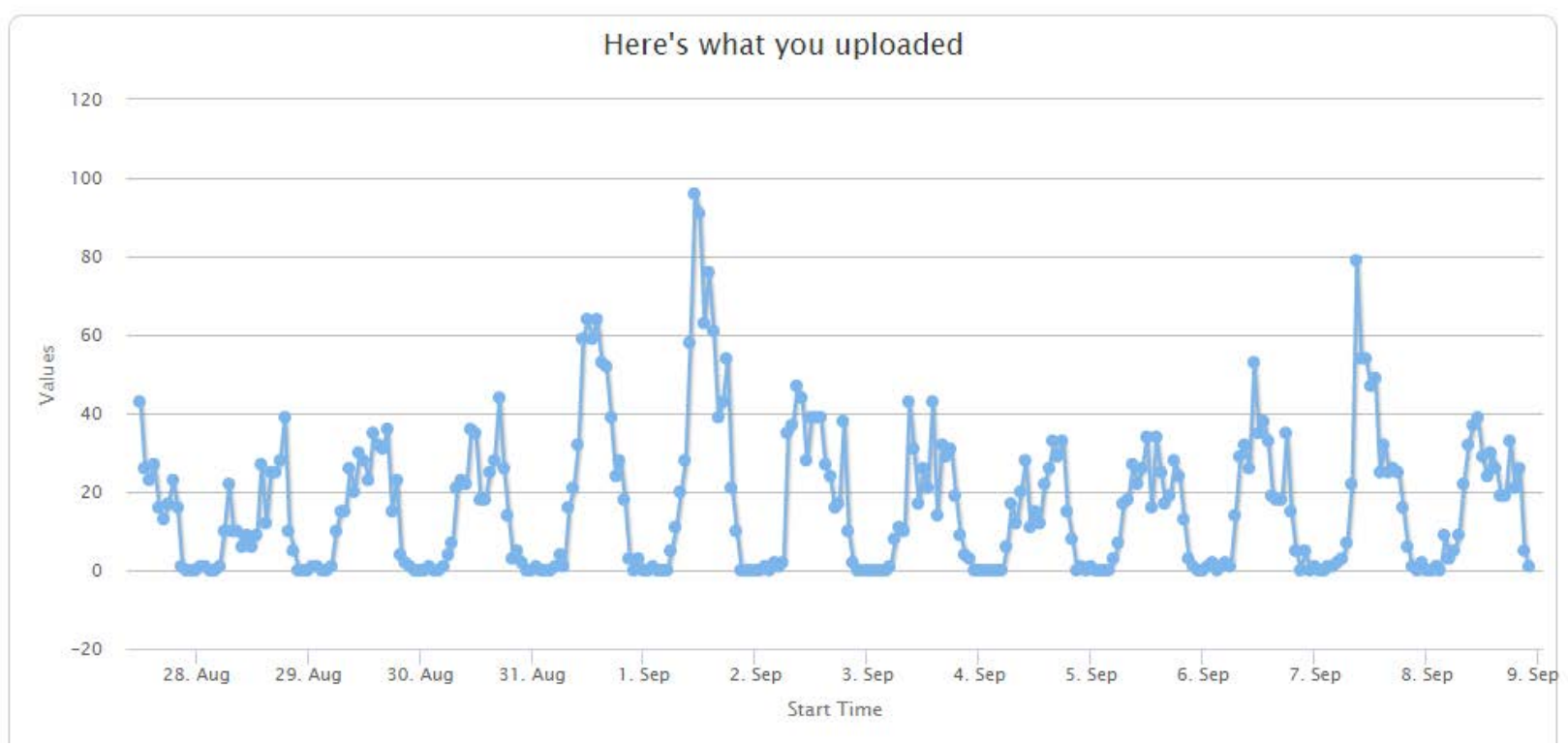

Figure 5.5 Graph of Uploaded Data

\subsection{DATA RATING SYSTEM}

At this time it is not feasible to develop a comprehensive data rating system. Such a system can be developed in the next phase of work when more data are available to be evaluated. As a potential intermediary next step, we suggest the following simplistic system. 
- If the user has identified any of the data as "invalid" either through the automated checking or visual inspection processes, the data would not be available to anyone except official users of the system; in other words, it will be hidden from the general public.

- All of the data quality information, both automated flags that have not been indicated as “accept as valid" by the user and user-specified comments, would be supplied when data are accessed.

- The data will obtain a gold-star rating if it has no automated flags, except those for which the user has indicated "accept as valid," and no user-specified "invalid data.” For example, gold-star data may contain user comments such as "heavy snow caused path to close" or "cycling event passed by counter."

At this time, no data rating system is in place. All Bike-Ped Portal data are raw and available to those with Bike-Ped Portal accounts. A rating system will be easier to develop in the next phase of work when sufficient data have been uploaded to the system to test such ratings.

\subsection{ONGOING MAINTENANCE}

In future phases of the project, maintenance checks can be added for the metadata as well. For example, as a means of confirming that metadata is current for each detector, the user who inputs the metadata could be asking to confirm the station data annually. 


\subsection{COLLECTING COUNT DATA}

\subsection{GETTING DATA FROM TAC PARTNERS AND OTHER PARTNERS}

Partner agencies provided data in one of the following ways: by emailing files, by providing the project team a username and password in order to access their equipment vendor's database (Eco-Visio or DataNet), or by posting their data on a public webpage. One interested agency has sent a cardboard box of data which has yet to be processed. Data provided in electronic formats are much preferred. Currently, all data must be formatted in Bike-Ped Data format in order to be entered. See the User Guide in the Appendix for details.

For manual counts, even when summary spreadsheets are available, PDFs of the original data collection forms are often needed since the project team desires to preserve the data in its most detailed form, if possible, and the original sheets sometimes have useful information missing in the summary document.

\subsection{UPLOADING COUNT DATA - INTERNS}

In the summer of 2015, seven high school interns from Saturday Academy’s Apprenticeships in Science and Engineering program spent two months adding data to Bike-Ped Portal. They wrote Python scripts, cleaned data, formatted data, learned about sites and even collected some of their own data.

Thanks to their dedicated and detailed work, Bike-Ped Portal contains counts from

- Five states

- 12 counties

- 44 jurisdictions

- 36 users

- 343 road or path segments of which 278 are in Oregon

- 355 detectors (both human and machine)

- 1,325 uploaded files

- 4.8 million count records

- 38 million trips

During the 2015-2016 school year, two students worked to add data to the archive from Boulder, Arlington and San Diego as part of a related project funded primarily by FHWA to study how to annualize bicycle and pedestrian short-duration counts and implement a software tool for creating such a metric. Their work is ongoing, and they are joined by a third student who will 
focus on Washington State and Portland data, funded through a Washington State Department of Transportation research project on optimizing bicycle and pedestrian short-duration counting.

Figure 6.1 shows the number of records by year and the total volume of counts by year. As shown, there is little data prior to 2010. The year 2013 appears to have a large number of count records. The highest total volume is for the recent data in 2015.

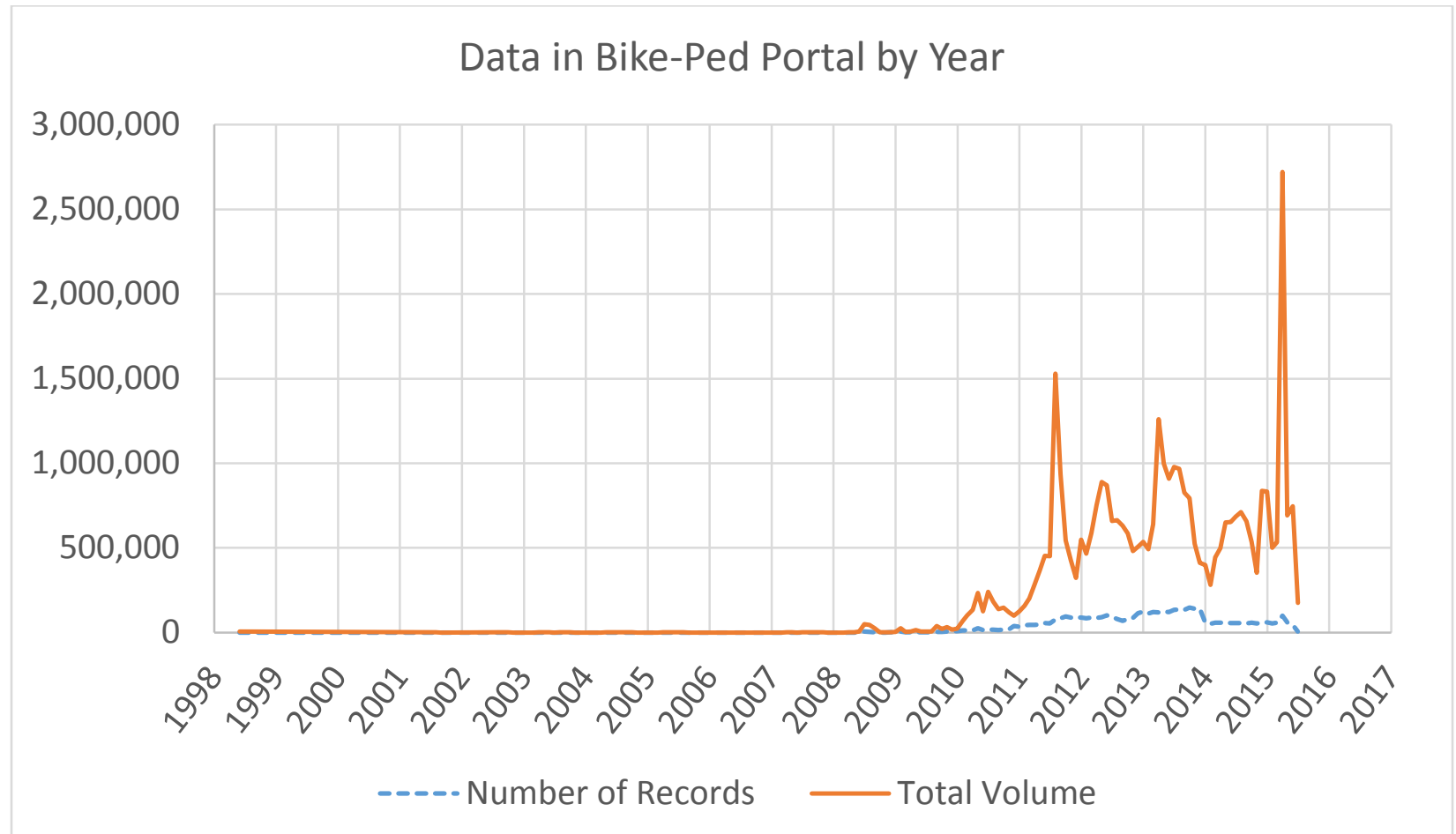

\section{Figure 6.1 Data Records in Bike-Ped Portal by Year}

Figure 6.2 shows that for the 343 segment areas in the archive most are from Oregon, with a minority from Colorado, Washington, Texas and Virginia. Figure 6.3 shows that paths are the most common facility type on which archive data were collected, followed by bike lanes and roadways. Sidewalks were not as common. Figure 6.4 shows that the majority of count sites count cyclists (65\%), with about a quarter counting pedestrians and less than $10 \%$ counting other types of nonmotorized users. 


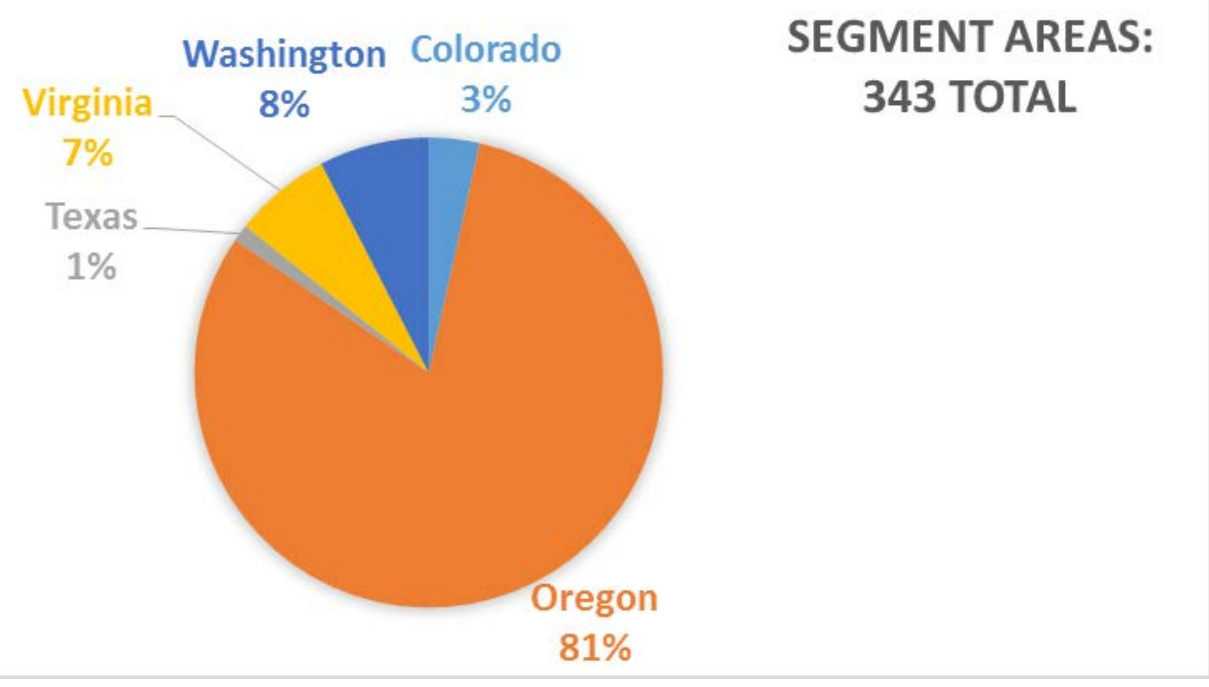

Figure 6.2 Segment Areas by State in Bike-Ped Portal

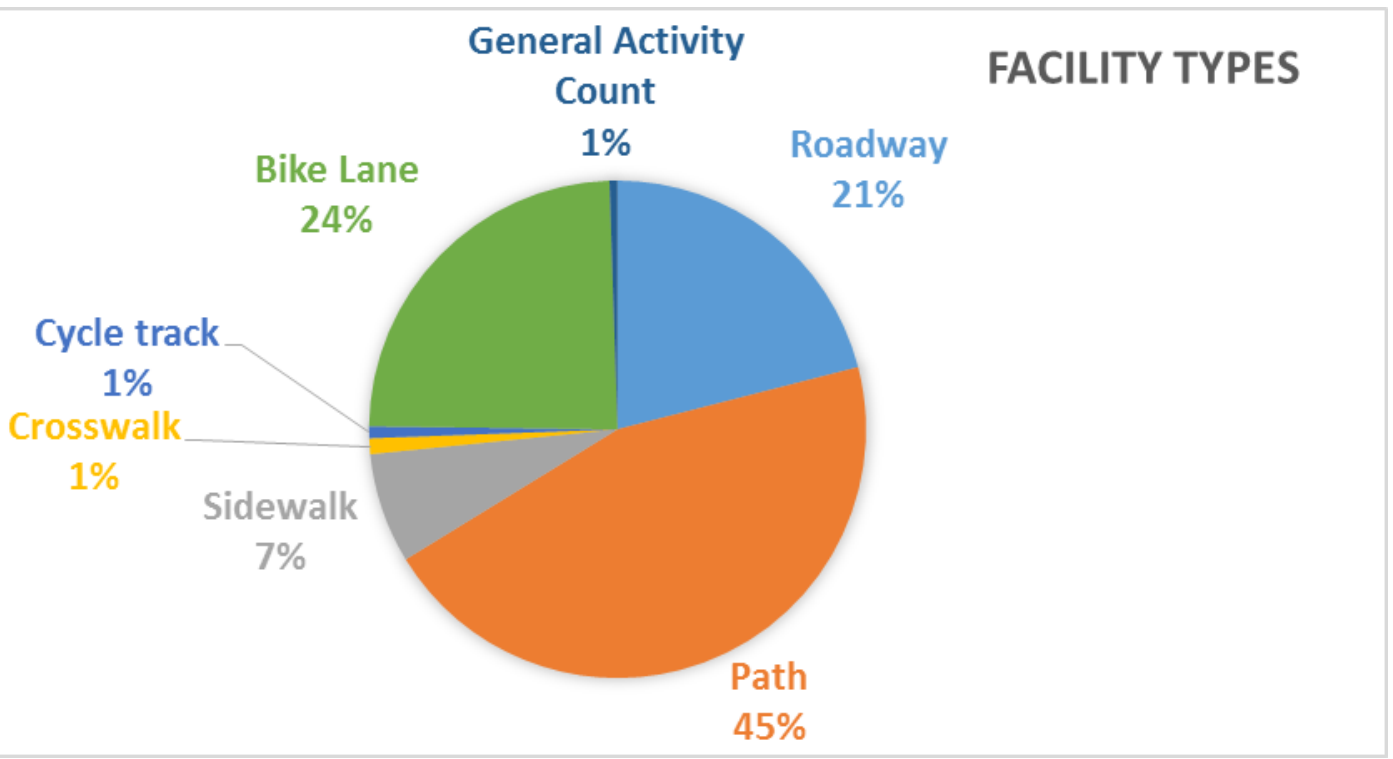

Figure 6.3 Facilities Types in Bike-Ped Portal 


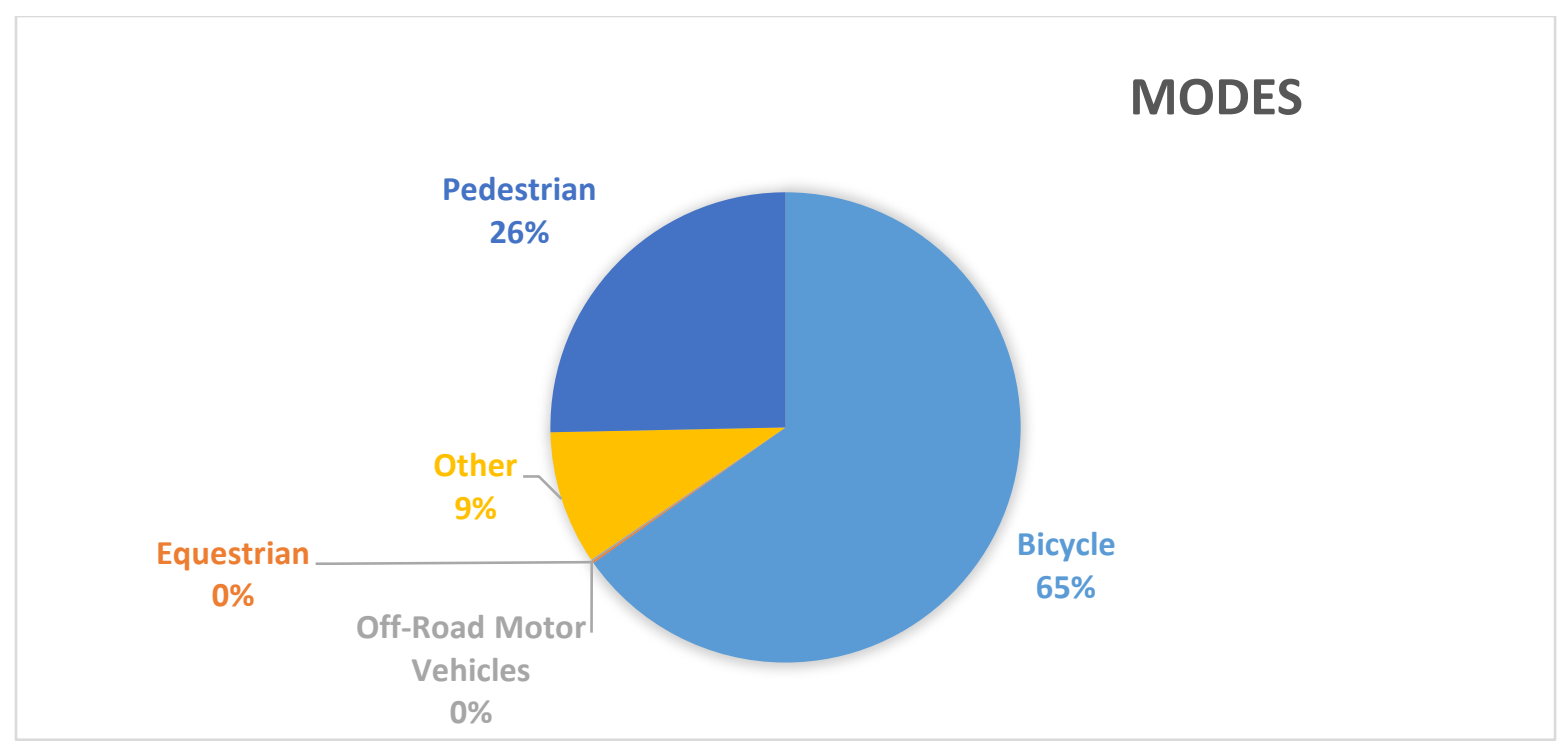

Figure 6.4 Modes of Travel by Percent of Records in Bike-Ped Portal

\subsection{ANALYSIS OF TIME AND EFFORT TO UPLOAD}

The seven high school interns worked full time on uploading count data to Bike-Ped Portal during the summer of 2015. Two specialized in writing Python scripts to facilitate data upload, especially of the older Boulder data which were in XML files. The other five worked on creating the metadata associated with the count data and uploading the count data.

The interns report spending 1,652 hours on Bike-Ped Portal during that summer, of which about 200 hours were spent adding metadata and uploading files. During this time, the interns reported adding 414 segment areas and uploading 961 CSV files. On average, this means that it took four hours to completely prepare, create and upload data for a given segment area. However, it only took half an hour, on average, to upload the files and add the metadata to Bike-Ped Portal. This indicates that data preparation was a time-consuming task.

Of the two students who measured their time uploading data and adding metadata specifically, one estimated it took $13 \%$ of her time and the other $39 \%$ of her time. The task of recording metadata in a spreadsheet before adding it to the archive took $67 \%$ of one student's time while the other reported that this task only required $6 \%$ of her time. Formatting data files into proper CSV format took one student $20 \%$ of her time and the other $55 \%$ of her time. This illustrates how these tasks vary by dataset and by individual. Some jurisdictions had well-organized metadata, while others required more time to properly locate and describe the segment area, facility, flow and detector. Some datasets were easier than others to format in CSV format. 


\subsection{CONCLUSIONS AND NEXT STEPS}

Bike-Ped Portal is now a functional, online archive of nonmotorized traffic data which holds data from five states and includes five million count records, which documents over 38 million people counted.

As documented in this report, Bike-Ped Portal started as a NITC Pooled-Fund Project in the spring of 2014. Database and user interface design continued through the fall of 2014 as development began. By the summer of 2015 the archive was able to accept and download count data, and was thus ready for alpha testing. A substantial data loading process was conducted with the help of seven local high school interns. Improvements to the user interface were made during the summer of 2015 to improve functionality for the alpha testers.

Development continued in the fall of 2015 with the creation of a demo site to allow new users to practice creating metadata and uploading of the API, adding the ability to input flow-detector location on a map; automated upload of data directly from Eco-Counter's Eco-Visio database for sites with modem connections; exporting data as a CSV file; error messages to the users when files failed to upload; and a new data download page which allows users to download data for a selected time period. In the winter of 2016, development continued with adding the ability for some users to edit and delete metadata (segment areas, facilities, flows, detectors, and flow detectors); data visualization at upload; an improved download user interface which includes a graph of data availability which automatically displays available data for the site; and development of basic quality checks to identify potentially erroneous data such as too many zeros or unusually high counts.

Currently, the archive is being used for research purposes by two other research projects: One for the Washington State Department of Transportation to optimize manual counting programs, and the other for FHWA to understand how many continuous count locations are needed to estimate AADB and AADP with sufficient accuracy and how to best automate the estimation of these metrics. Proposals to use the archive for other research purposes have been submitted. This shows the utility of the archive to answer research questions important to state and national agencies.

The next phase of work aims to expand the utility of Bike-Ped Portal for practicing transportation professionals, especially transportation planners, by creating an "Explore Data" page to provide users with basic metrics from the database. Other plans include partnership with Alta Planning and Design to explore and process some of the data in the National Bicycle and Pedestrian Documentation Project. Future projects for the archive may include research to improve the quality checks for bicycle and pedestrian count data and implement the findings in Bike-Ped Portal, and working with FHWA to export metadata and count data in the finalized version of TMG format.

As the archive continues to grow and develop, it is step by step fulfilling its mission to safely store and aggregate the nation's bicycle and pedestrian count data. Currently, it is mostly used for research purposes, but in the coming years improvements in the user interface and data 
quality checks will widen the group of potential users. Future directions may include creating a smartphone app to allow manual counters to collect data in the field and send it directly to BikePed Portal, the expansion of the archive into intersection turning movement count data, and connection of the archive to other datasets such as GPS traces from smartphone apps, facility inventories, and crash data.

Jurisdictions around the country continue to count cycling and walking using an ever-growing variety of equipment, people and approaches. As they seek to use, share and analyze this data, Bike-Ped Portal is well positioned to meet these needs and play a unique and central role in data sharing and preservation. Bike-Ped Portal's success will be a national asset that can improve bicycle and pedestrian safety analysis, transportation system operations and maintenance, regional planning, facility design, economic and environmental impact studies, and the study of public health benefits from active travel. 


\subsection{REFERENCES}

Alta Planning and Design and ITE. (2009). "National Bicycle and Pedestrian Documentation Project." Retrieved November 22, 2011, from bikepeddocumentation.org.

Bike Arlington. "Bicycle and Pedestrian Counters." Retrieved August 1, 2014, 2014, from http://www.bikearlington.com/pages/biking-in-arlington/counter-dashboard/

Delaware Valley Regional Planning Commission. "Pedestrian and Bicycle Counts." Retrieved August 1, 2014, 2014, from http://www.dvrpc.org/webmaps/pedbikecounts/.

Federal Highway Administration (2013). Traffic Monitoring Guide. Washington, DC, U.S. Department of Transportation.

Highcharts. (2016). Retrieved May 1, 2016, from http://www.highcharts.com/.

Huff, H. and M. Brozen (2014). Creating the Bicycle Count Data Clearinghouse for Los Angeles County, California. 93rd Annual Meeting of the Transportation Research Board. Washington, D.C., Transportation Research Board of the National Academies.

Nordback, K., K. Tufte, et al. (2015). "Creating a National Non-Motorized Traffic Count Archive: Process and Progress." Transportation Research Record(2527): 90-98.

Olson, C. S., S. M. Kothuri, et al. (2012). A Framework for Multimodal Arterial Data Archiving 91st Annual Meeting of the Transportation Research Board. Washington, D.C., Transportation Research Board of the National Academies.

Proulx, F., Y. Zhang, and O. Grembek (2015). "A Database for Active Transportation Infrastructure and Volume." Transportation Research Record, no. 2527: 99-106.

Turner, S. and P. Lasley (2013). Quality Counts for Pedestrians and Bicyclists: Quality Assurance Procedures for Non-Motorized Traffic Count Data. 92nd Annual Meeting of the Transportation Research Board. Washington, D.C., Transportation Research Board of the National Academies.

Turner, S., T. Qu, et al. (2012). Strategic Plan for Non-Motorized Traffic Monitoring in Colorado. College Station, TX, Texas Transportation Institute: 99. 


\subsection{APPENDIX}

\subsection{API DOCUMENTATION}

\section{Get Key}

Returns an authentication token to be used in subsequent requests. Tokens expire when unused for over an hour. The key must be sent as a cookie value called bp_auth with subsequent requests.

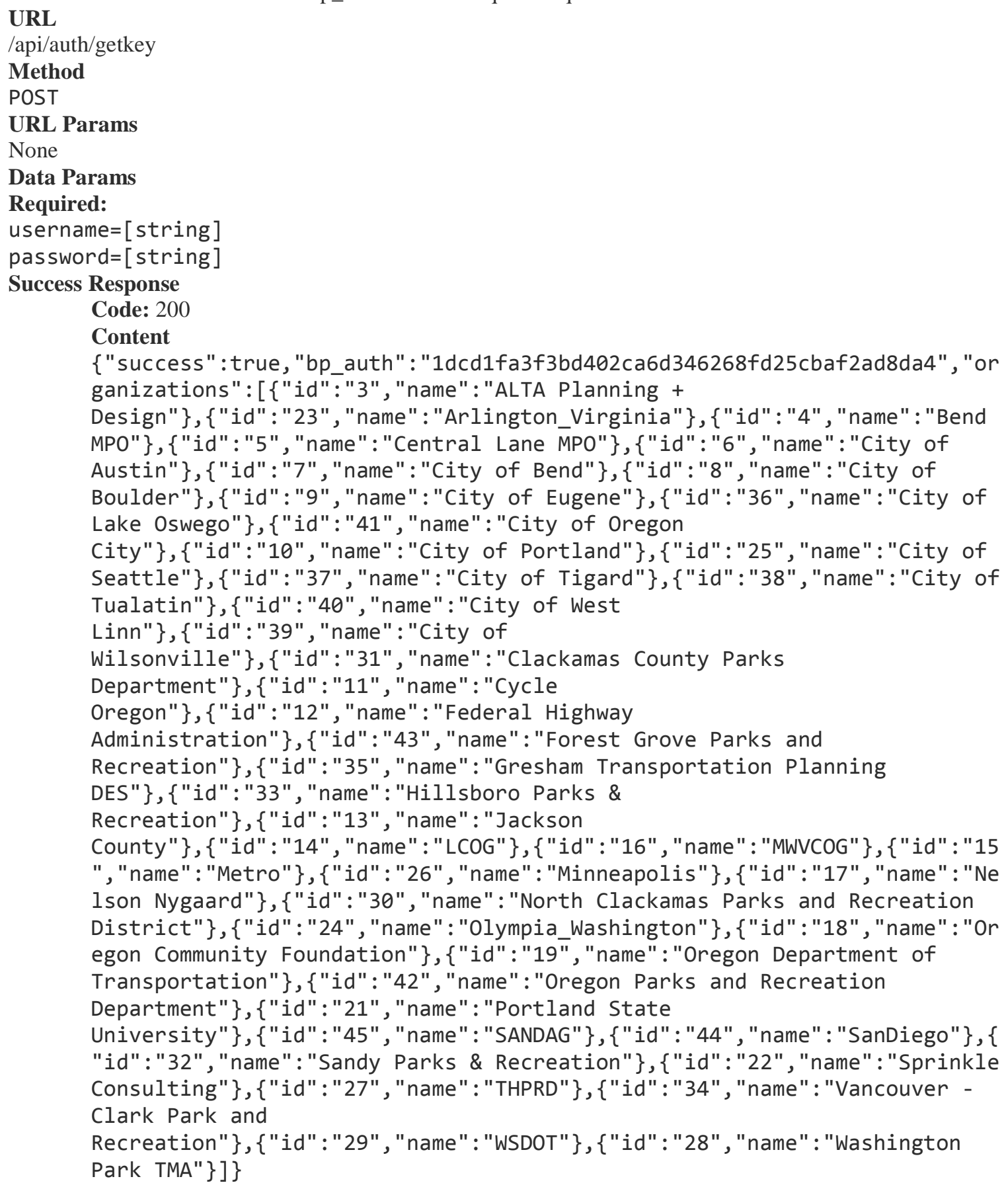

Error Response 
Code: 401 Unauthorized

\section{Content}

OR

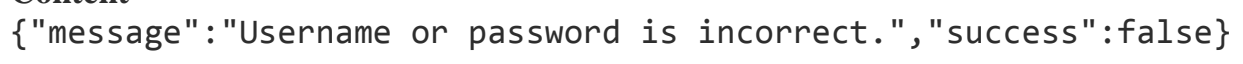

Code: 401 Unauthorized

Content

Sample Call

\{"message":"Must supply both a username and password.","success":false\}

POST /api/auth/getkey HTTP/1.1

Host: bp.local

Content-Type: application/x-www-form-urlencoded

Content-Length:41

Connection: Keep-Alive

username=user@example.com\&password=secret

\section{States}

Returns list of states optionally filtered to those in which a segment area exists.

URL

/api/bpmetadata/states[/:filter]

Method

GET

URL Params

Optional:

filter $=$ [true $\mid$ false $]$

Whether to filter to only those states with segment areas

Data Params

None

Success Response

Code: 200

Content

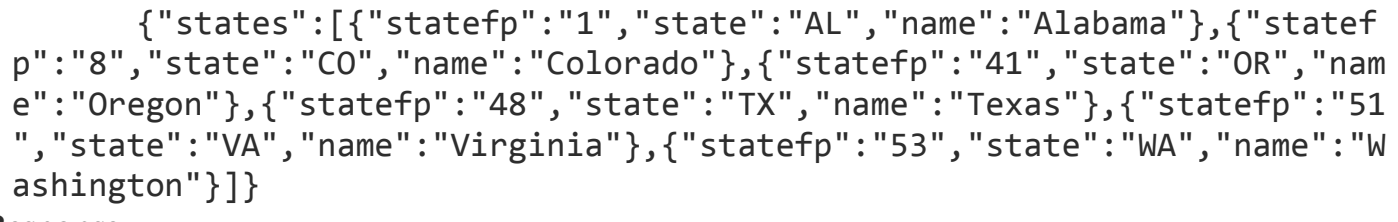

None

Sample Call

GET /api/bpmetadata/states/true HTTP/1.1

Host: bp.local

Connection: Keep-Alive

Cookie: bp_auth=40e93133b287477aaf46f7042e446cc657b41457

\section{Counties}

Returns list of counties in a given state optionally filtered to those in which a segment area exists.

URL

/api/bpmetadata/counties/:state[/:filter]

Method

GET

URL Params

Required:

state $=$ [string $]$

The state for which to list counties

Optional:

filter $=[$ true $\mid$ false $]$

Whether to filter to only those counties with segment areas 


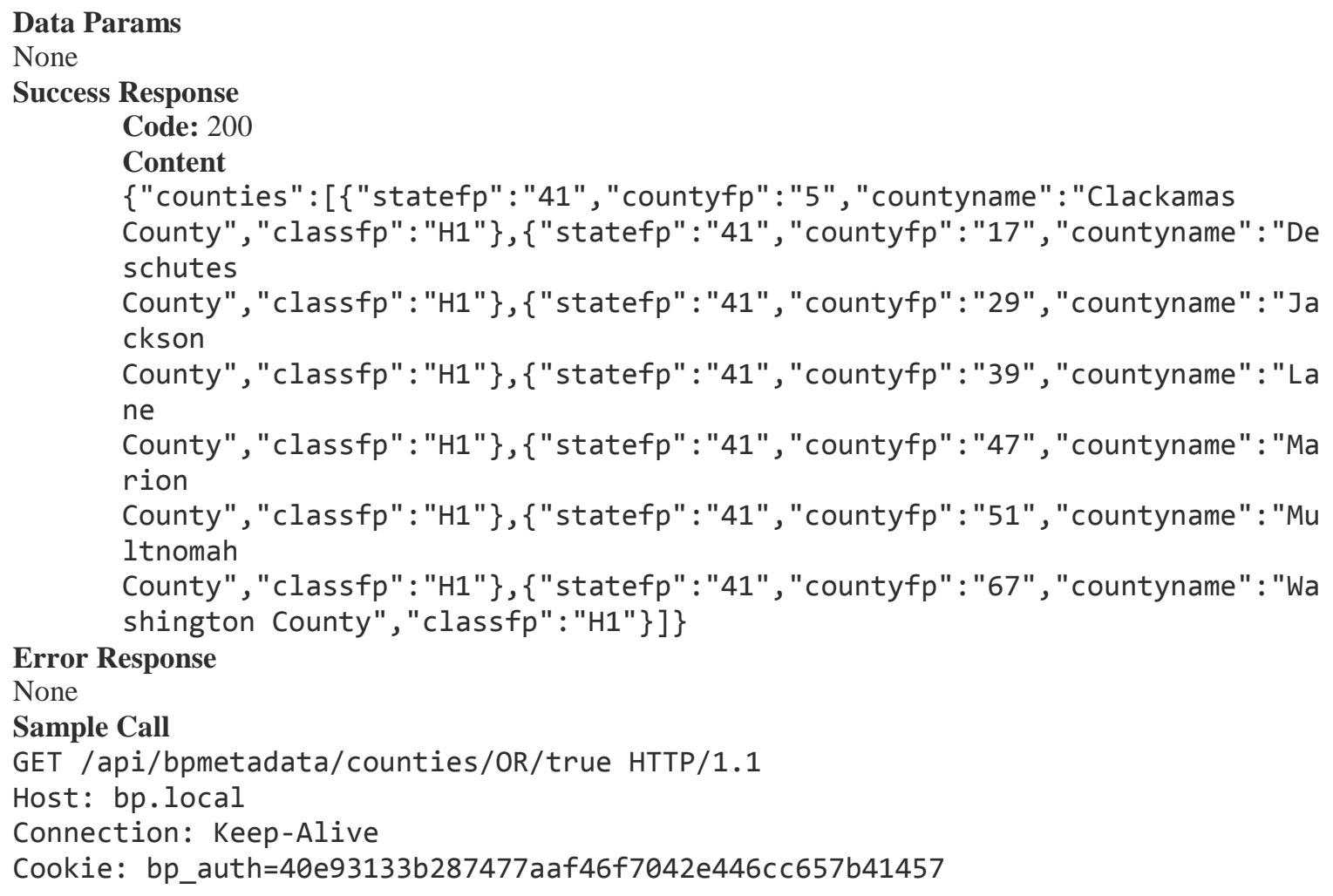

\section{Segment Areas}

Returns all segment areas in a given state and county.

URL

/api/bpmetadata/counties/:state/:countyfp

\section{Method}

GET

\section{URL Params}

Required:

state $=[$ string $]$

The state for which to list segment areas

county $\mathrm{fp}=$ [integer ]

The FP code for the county for which to list segment areas

\section{Data Params}

None

\section{Success Response}

Code: 200

Content

\{"segmentareas": [ \{"segment_area_id":"16", "segment_name":"8th@ Juniper

Park"\},\{"segment_area_id":" 23 ", "segment_name": "Colorado

Bridge"\},\{"segment_area_id": "19", "segment_name": "Columbia

Bridge"\},\{"segment_area_id":"12", "segment_name":"Deschutes River

Trail"\},\{"segment_area_id":"7", "segment_name":"Drake Park

Footbridge"\},\{"segment_area_id":"4", "segment_name" : "Galveston

Bridge"\}, \{"segment_area_id":"15", "segment_name": "Haul

Trail"\},\{"segment_area_id":"11","segment_name":"NE Franklin Ave

Pedestrian Tunnels" $\},\{$ "segment_area_id":"9", "segment_name": "NW Portland

Avenue Bridge"\},\{"segment_area_id":"10", "segment_name": "Newport

Bridge"\}, \{"segment_area_id":"13", "segment_name": "Reed Market

Bridge"\},\{"segment_area_id":"18","segment_name":"SE Reed Market Rd@ 


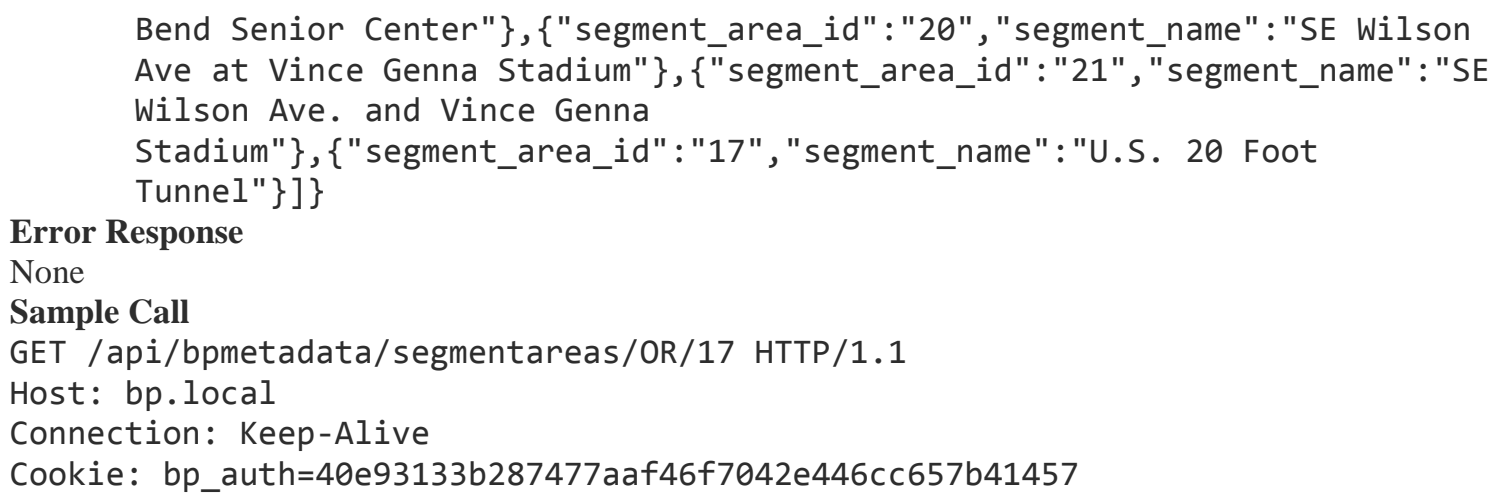

None

Sample Call

GET /api/bpmetadata/segmentareas/OR/17 HTTP/1.1

Host: bp.local

Connection: Keep-Alive

Cookie: bp_auth=40e93133b287477aaf46f7042e446cc657b41457

Facilities

Returns the facilities in a given segment area.

URL

/api/bpmetadata/facilities/:segment_area

\section{Method}

GET

URL Params

Required:

segment_area=[integer ]

The segment area for which to list facilities

Data Params

None

Success Response

Code: 200

Content

\{"facilities":[\{"facility_id":"15","description":"East and West Bound traffic across the Deschutes River and the side was unknown near the exit of Bend and into the wilderness"\}]\}

\section{Error Response}

None

Sample Call

GET /api/bpmetadata/facilities/13 HTTP/1.1

Host: bp.local

Connection: Keep-Alive

Cookie: bp_auth=40e93133b287477aaf46f7042e446cc657b41457

Flows

Returns the flows for a given facility.

URL

/api/bpmetadata/flows/:facility

Method

GET

URL Params

Required:

facility $=$ [integer ]

The facility for which to list flows

Data Params

None

Success Response

Code: 200

Content 
\{"data":[\{"flow_id":"42","description":"Haul Trail also known as the Colorado Pedestrian Bridge parallel to the Colorado Bridge across the Deschutes River with many differents sorts of traffic crossing traveling Northeast and Southwest

bound", "facility_type" : "path\/trail", "directions" : "\{SW,NE\}", "bicycle" : "t ", "pedestrian": "f", "equestrian": "f", "off_road": "f", "motor_vehicles": "f", "other":"f", "modes": "\&\#xe601; "\},\{"flow_id":"593", "description": "Haul

Trail also known as the Colorado Pedestrian Bridge parallel to the Colorado Bridge across the Deschutes River with many differents sorts of traffic crossing traveling Northeast and Southwest

bound", "facility_type" : "path\/trail", "directions": "\{SW, NE\}", "bicycle" : "f ", "pedestrian": " $t$ ", "equestrian": "f", "off_road": "f", "motor_vehicles": "f", "other":"f", "modes": "\&\#xe605; "\},\{"flow_id":"594", "description": "Haul Trail also known as the Colorado Pedestrian Bridge parallel to the Colorado Bridge across the Deschutes River with many differents sorts of traffic crossing traveling Northeast and Southwest

bound", "facility_type" : "path \/trail", "directions": "\{SW,NE\}", "bicycle" : "t ", "pedestrian": " $t$ ", "equestrian": "f", "off_road": "f", "motor_vehicles": "f", "other": "t", "modes":"\&\#xe601; \&\#xe605; \&\#xe607;

"\},\{"flow_id":"595","description": "Haul Trail also known as the Colorado Pedestrian Bridge parallel to the Colorado Bridge across the Deschutes River with many differents sorts of traffic crossing traveling Northeast and Southwest

bound", "facility_type" : "path \/trail", "directions": " $\{\mathrm{NW}, \mathrm{SE}\}$ ", "bicycle" : "f ", "pedestrian": "f", "equestrian": "f", "off_road": "f", "motor_vehicles": "f", Error Response

"other": "t", "modes": "\&\#xe607; "\}]\}

None

Sample Call

GET /api/bpmetadata/flows/15 HTTP/1.1

Host: bp.local

Connection: Keep-Alive

Cookie: bp_auth=40e93133b287477aaf46f7042e446cc657b41457

\section{Organization Detectors}

URL

/api/bpmetadata/orgdetectors/:organization

Method

GET

URL Params

Required:

organization=[integer ] The organization for which to list detectors

\section{Data Params}

None

Success Response

Code: 200

Content

\{"data":[\{"detector_id":"39","description":"Its an automatic sidewalk counter.","serial_num": "Unknown", "make" : "GTT", "model" : "Canoga"\}, \{ "detect or_id": "514", "description" : "arap38th", "serial_num": " ", "make": "GTT", "mode $1 ":$ "Canoga C900

Series"\}, \{"detector_id" : "507", "description": "bwybln", "serial_num" : "Unkno wn", "make": "GTT", "model": "Canoga C900 Series"\}]\}

\section{Error Response}

None 
Sample Call

GET /api/bpmetadata/orgdetectors/8 HTTP/1.1

Host: bp.local

Connection: Keep-Alive

Cookie: bp_auth=40e93133b287477aaf46f7042e446cc657b41457 


\subsection{QUALITY ASSURANCE/QUALITY CONTROL SUPPORTING DOCUMENTATION}

Prior to preparing the recommended QA/QC for the Technical Advisory Committee, the project team investigated similar QA/QC checks used by others for both nonmotorized and motorized traffic. This Appendix documents some of the tests used by others.

\subsubsection{Sprinkle}

Elizabeth Stolz with Sprinkle Consulting provided a list of potential checks based on her work with motor vehicle monitoring counts QA/QC. The table is provided in the following pages. Some of these checks were included in our QA/QC plan as indicated by the designation "M" for minimum requirement, and some are considered for future inclusion as indicated by the designation "P" for potential requirement.

\subsubsection{FHWA}

Federal Highway Administration's (FHWA’s) Traffic Monitoring Guide (TMG) Appendix J, includes details of the quality control checks used in the Travel Monitoring Analysis System (TMAS) 2.0. There are four types of errors: Fatal, Critical, Caution and Warning.

- Fatal errors occur when the data are in the wrong format (e.g., an unexpected data type is encountered in a given column).

- Critical errors occur when a field marked as "critical” in the TMG format is missing (left blank) in the input file. Critical errors for volume data also include:

o Seven or more consecutive hours with zero volume

0 One day of the week is not represented in a month for a given site in a given year

o Fewer than 24 hours for a given record

o Volume is over the maximum threshold per lane

o Directional splits greater than $10 \%$ variance from $50 \%$

o Monthly Average Daily Traffic (MADT) is not within $20 \%$ of previous year's MADT for that month

o State marks data as "restricted"

- Caution flags are used when the record is missing optional data or when odd or out-ofbound data are encountered. These include historical checks for a given day of week based on the previous six weeks for a given vehicle class. Caution flags are also used to indicate when there is insufficient historical data to run a test.

- Warning flags are given when exact duplicate records are submitted. One of the duplicates will be deleted. Users can abort or reject duplicate data.

In addition, Jeremy Raw from FHWA provided a draft document he is working on for the revised version of TMAS which will include nonmotorized traffic. The document included quality checks for fatal errors, critical errors, cautions and warnings. Since this document is still in draft form, it is not provided in this Appendix. 


\subsubsection{Turner \& Lasley}

Another useful document was a paper by Shawn Turner and Philip Lasley (2013) of the Texas Transportation Institute which examined data quality. They suggest six aspects of data quality: accuracy, validity, completeness, timeliness, coverage, and accessibility. Our QA/QC plan focuses on validity, although the purpose of the Bike-Ped Portal is to increase data accessibility. The paper lists three types of automated validity criteria:

- Quality control checks

- Validity checks

o Univariate and multivariate range criteria, such as maximum traffic counts per time period.

o Spatial and temporal consistency criteria, such as directional ratios should be less than $80 \%$ of traffic in one direction unless it is one way and percent deviation from previous hour, and maximum ratio of peak hour to daily volume.

o Detailed diagnostics which are technology specific.

- Business rules

The authors examine an example data set and use counts in one direction to check and adjust counts that were unusually high in the opposite direction.

\subsubsection{Traffic Monitoring Guide}

The Federal Highway Administration's TMG also includes guidance on data quality for motor vehicle monitoring data, which is not reproduced here but includes case studies (in TMG's Appendix E) from Virginia, Vermont, Pennsylvania, Washington State, and New York State (Federal Highway Administration, 2013). For example, Vermont includes monthly manual inspection of graphs of traffic over a 24-hour period from each day of the week for a given month to identify problems. Automated checks identify monthly volumes that are $10 \%$ different from the previous year. 
Table 2 Potential Bike/Ped Travel Monitoring Data - Quality Assurance and Quality Control Checks*

\begin{tabular}{|c|c|c|c|c|c|}
\hline $\begin{array}{l}\text { Valid } \\
\text { Check }\end{array}$ & $\#$ & & Check Type & Description & Comments \\
\hline \multicolumn{4}{|c|}{ Formatting Checks } & Description & \\
\hline$\checkmark$ & 1 & & Formatting & \multicolumn{2}{|l|}{ Data file contains numbers where numbers are expected } \\
\hline$\checkmark$ & 2 & & Formatting & Data file contains spaces where spaces are expected & Gaps Check \\
\hline \multicolumn{4}{|c|}{ Location and Classification Checks } & Description & \\
\hline$\checkmark$ & 3 & & Location & Data associated with correct site location & \\
\hline$\checkmark$ & 4 & & Location & Data is associated with correct road characteristics & example: roadway only, multi-use path, etc. \\
\hline$\checkmark$ & 5 & & Classification & Data associated with correct classification scheme & bike only, bike/ped combo, ped only, etc. \\
\hline$\checkmark$ & 6 & & Classification & Data are associated to the correct collection method & Automated, Manual, IR, Video, etc. \\
\hline$\checkmark$ & 7 & & Location & Data are associated with correct submitting Agency & ODOT, City of Eugene, etc. \\
\hline \multicolumn{4}{|c|}{ Data Validation Checks } & Description & \\
\hline $\mathbf{x}$ & 8 & & Data Validation & Directional Distribution & Data is too variable to set a threshold until a year of data is collected \\
\hline$x$ & 9 & & Data Validation & Hourly Directional Distribution & Data is too variable to set a threshold until a year of data is collected \\
\hline$\checkmark$ & 10 & $P$ & Data Validation & Interquartile (IQ) Range Check & Total Daily Volume upper limit \\
\hline $\mathbf{x}$ & 11 & & Data Validation & Ratio Check - Lane 1 to Lane 2 & No Sites with this type of Configuration / Instrumentation \\
\hline$\checkmark$ & 12 & $P$ & Data Validation & Ratio Check & Noon Volume to Midnight Volume Check \\
\hline$\checkmark$ & 13 & M & Data Validation & Number of Consecutive Zero's & Motorized is 7 but non-motorized might be 10 (KLN to use 24 ) \\
\hline$\checkmark$ & 14 & $\mathrm{P}$ & Data Validation & Number of Allowable Zero Intervals from 7am and 7pm & Need to set threshold \\
\hline$\checkmark$ & 15 & M & Data Validation & Number of Consecutive Identical Values Check & \\
\hline $\mathbf{x}$ & 16 & & Data Validation & Volume Interval & Data too variable from hour to hour to check volume interval changes \\
\hline $\mathbf{x}$ & 17 & & Data Validation & Continuous AADT Percent Difference check & Not enough data to run year to year AADT checks \\
\hline $\mathbf{x}$ & 18 & & Data Validation & Continuous MADT Percent Difference Check & Not enough Data to run year to year MADT checks \\
\hline $\mathbf{x}$ & 19 & & Data Validation & Short-term AADT Percent Difference Check & Need a full year of continuous count data to factor short duration count data \\
\hline $\mathbf{x}$ & 20 & & Data Validation & Classification Percent Threshold Checks & Not enough knowledge to set threshold for bike versus ped \\
\hline$x$ & 21 & & Data Validation & Ratio of Bike/Ped Check & Need to establish threshold \\
\hline $\mathbf{x}$ & 22 & & Data Validation & Total Vehicle Length Check & Need to set threshold \\
\hline $\mathbf{x}$ & 23 & & Data Validation & Vehicle Speed Check & Can speed data be acquired from collection equipment? \\
\hline$\checkmark$ & 24 & & Data Validation & All Bike Volumes Associated with Bike Volume data, etc. & \\
\hline $\mathbf{x}$ & 25 & & Data Validation & Minimum Number of Hours for a Short-term Count & Should be 24 hours \\
\hline$\checkmark$ & 26 & & Data Validation & Hourly Volume Math Check & Direction one + direction two $=$ Total Volume \\
\hline$\checkmark$ & 27 & & Data Validation & Count not Complete & Must have 24 hours of consecutive hourly data \\
\hline$\checkmark$ & 28 & M & Data Validation & Total Daily Volume Zero Check & Check daily volume equal to zero, throw this out for AADT creation purposes \\
\hline
\end{tabular}

M = Minimum QA/QC check; P = Potential for in future; *Table provided by Elizabeth Stolz with Sprinkle Consulting 


\subsubsection{References for QA/QC Supporting Documentation}

Federal Highway Administration. (2013). Traffic Monitoring Guide. Washington, DC: U.S. Department of Transportation.

Turner, S., \& Lasley, P. (2013). Quality Counts for Pedestrians and Bicyclists: Quality Assurance Procedures for Non-Motorized Traffic Count Data. Paper presented at the 92nd Annual Meeting of the Transportation Research Board, Washington, D.C. 


\subsection{ENTITY RELATIONSHIP DIAGRAMS (ERDS)}

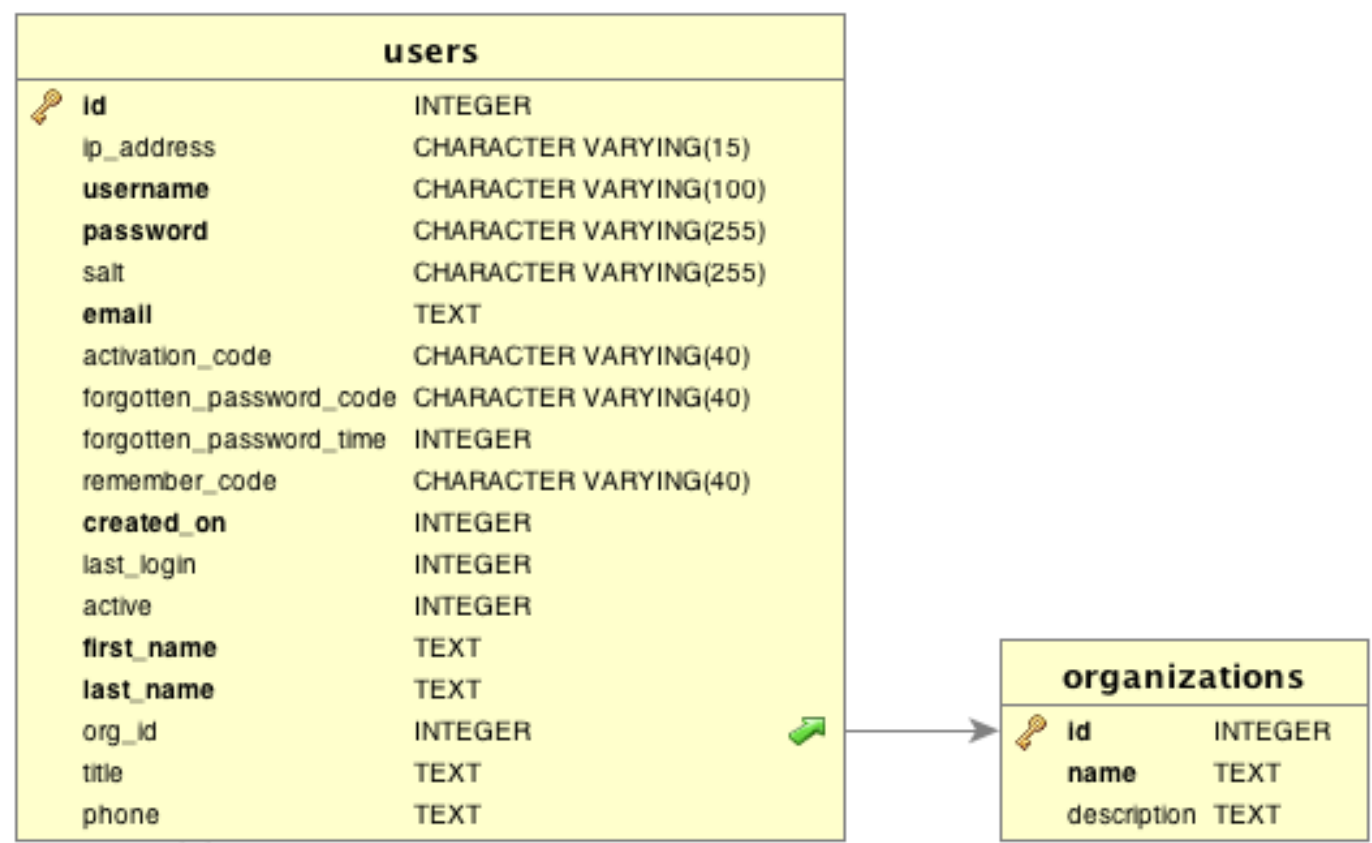




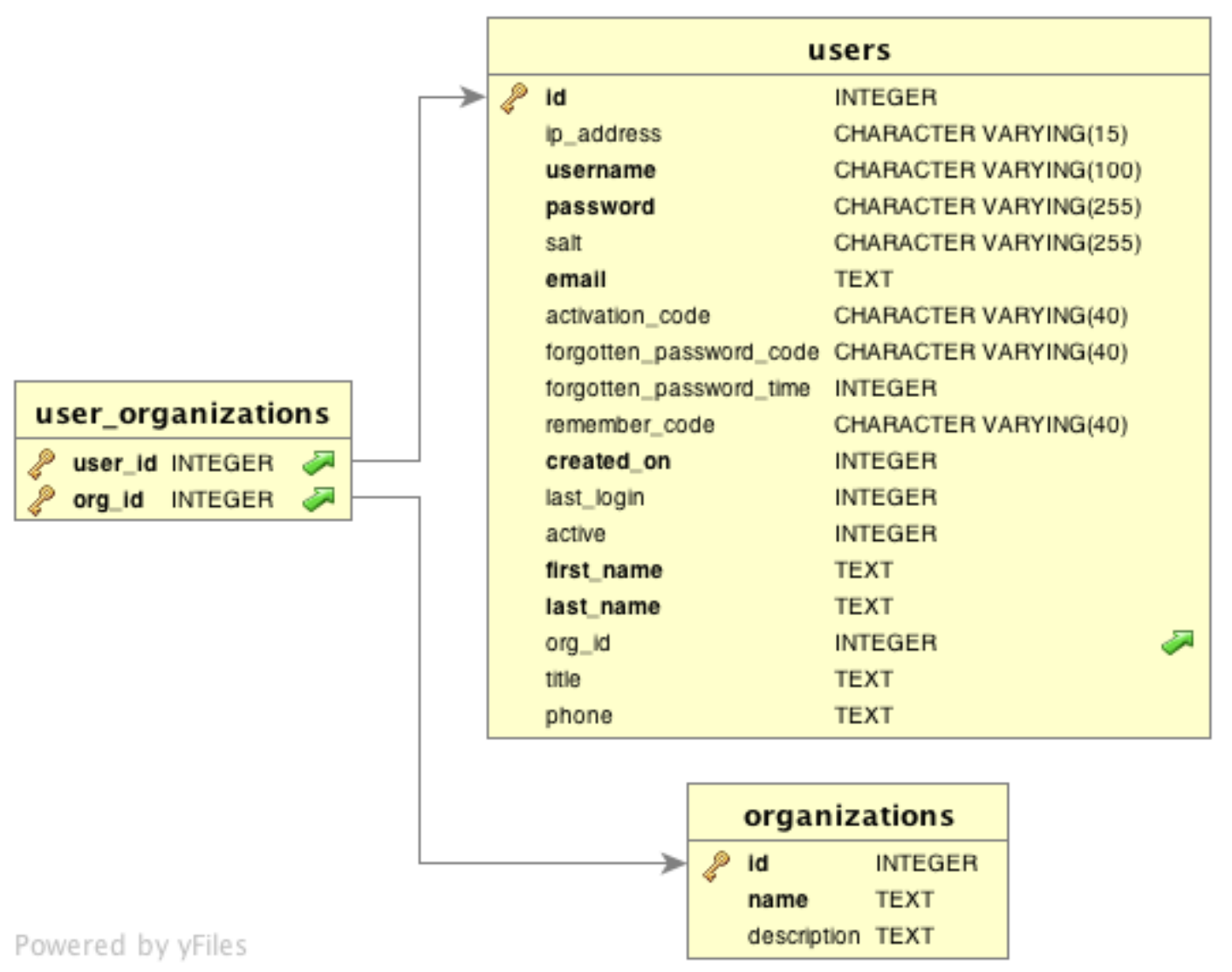




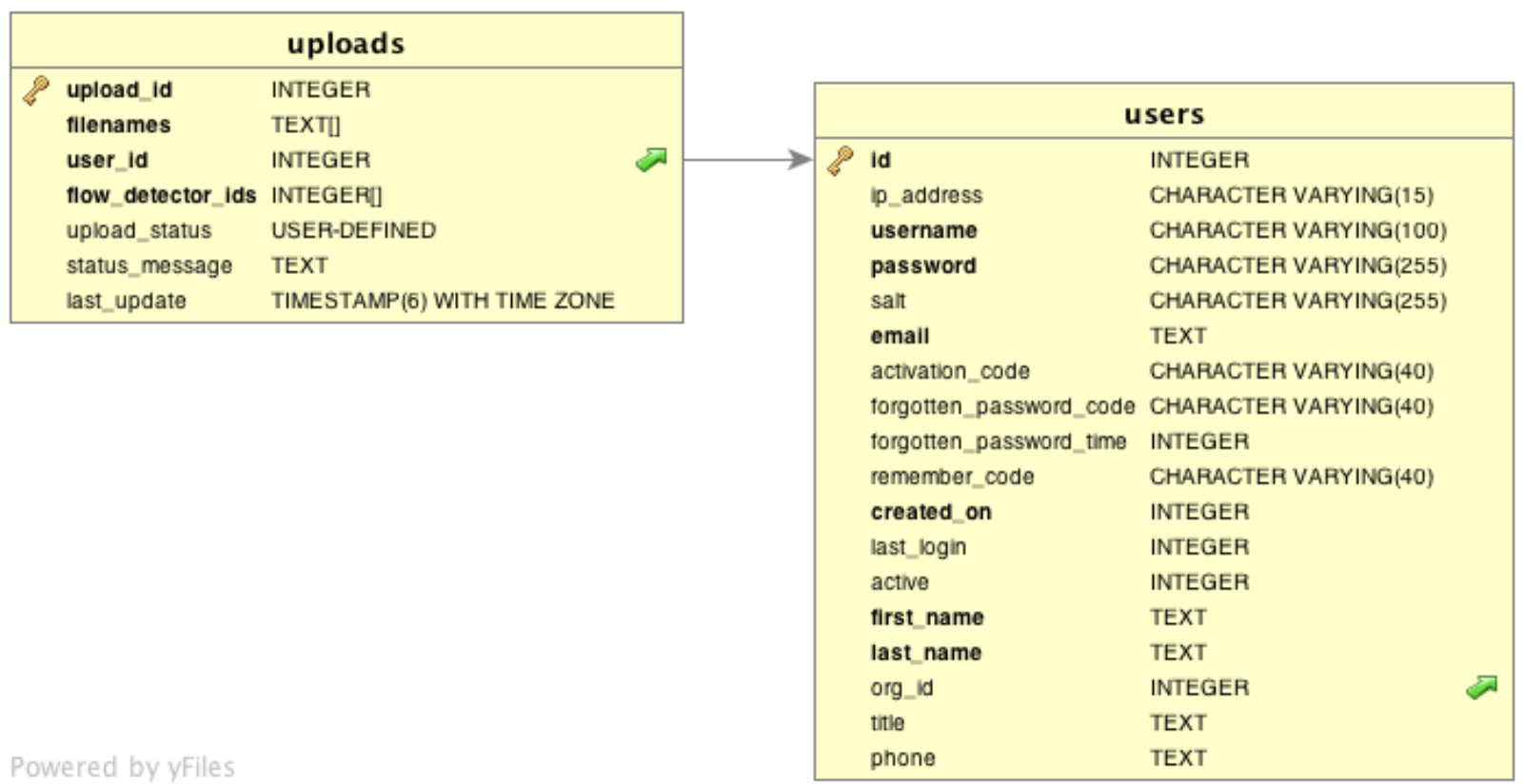




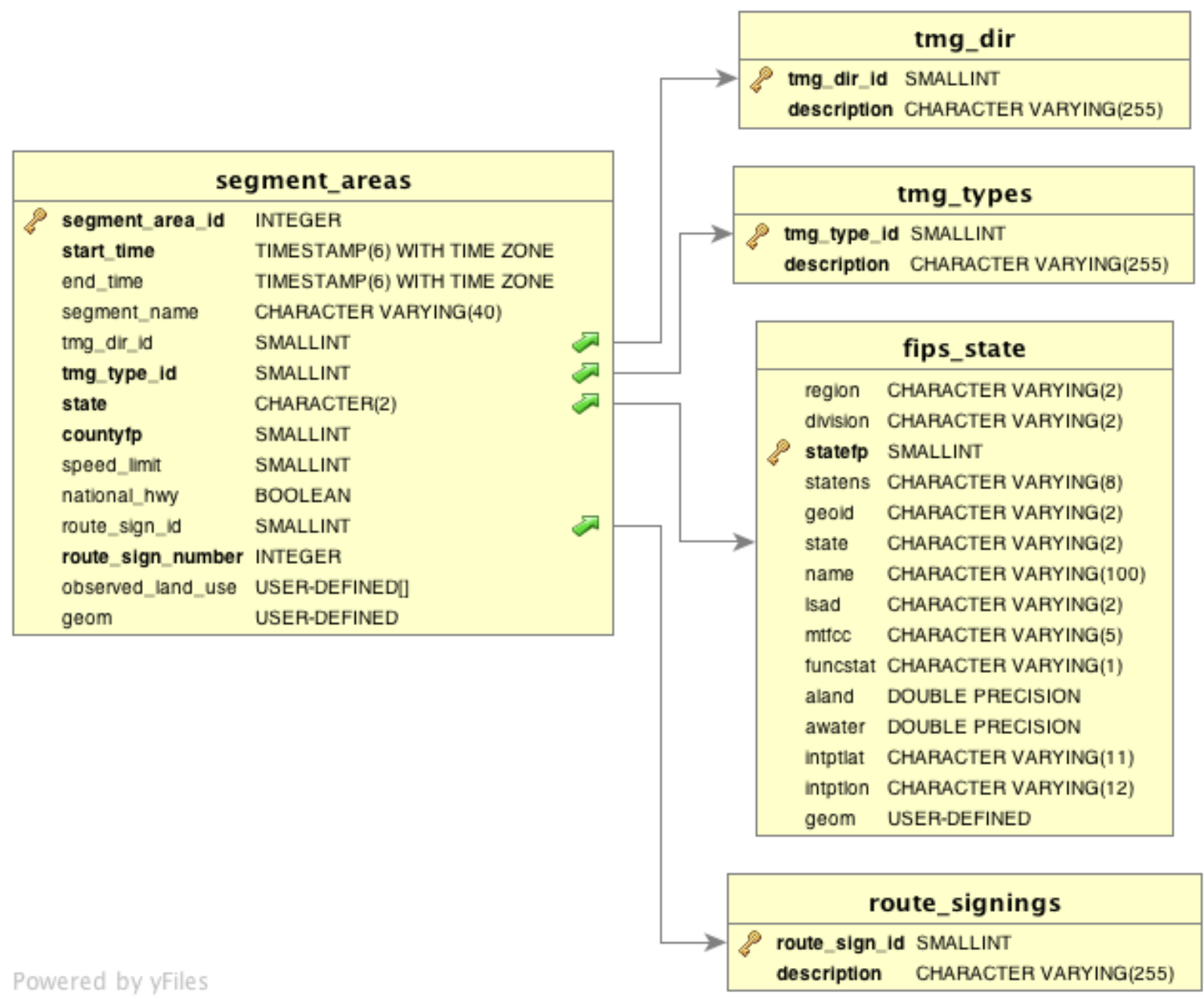




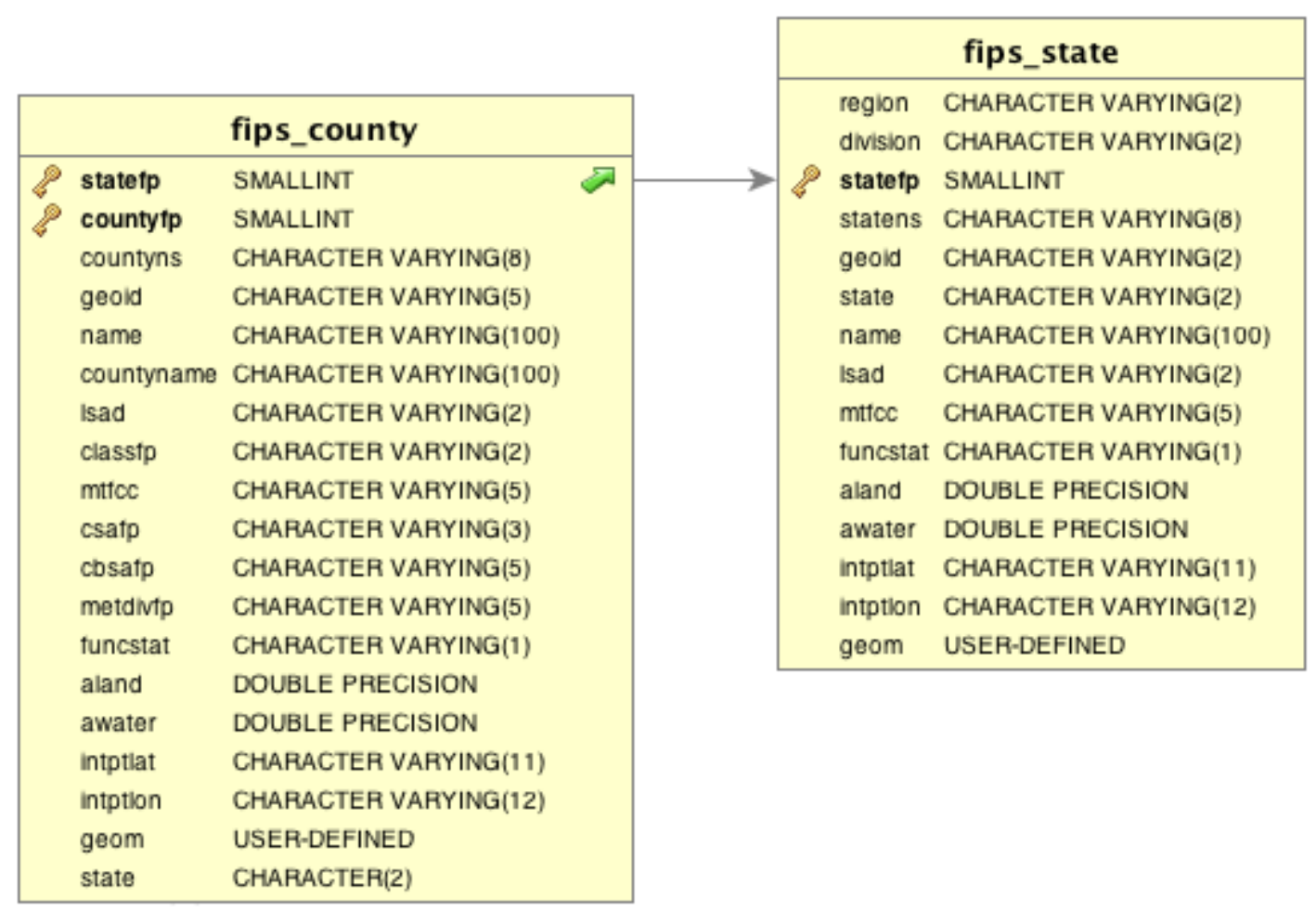




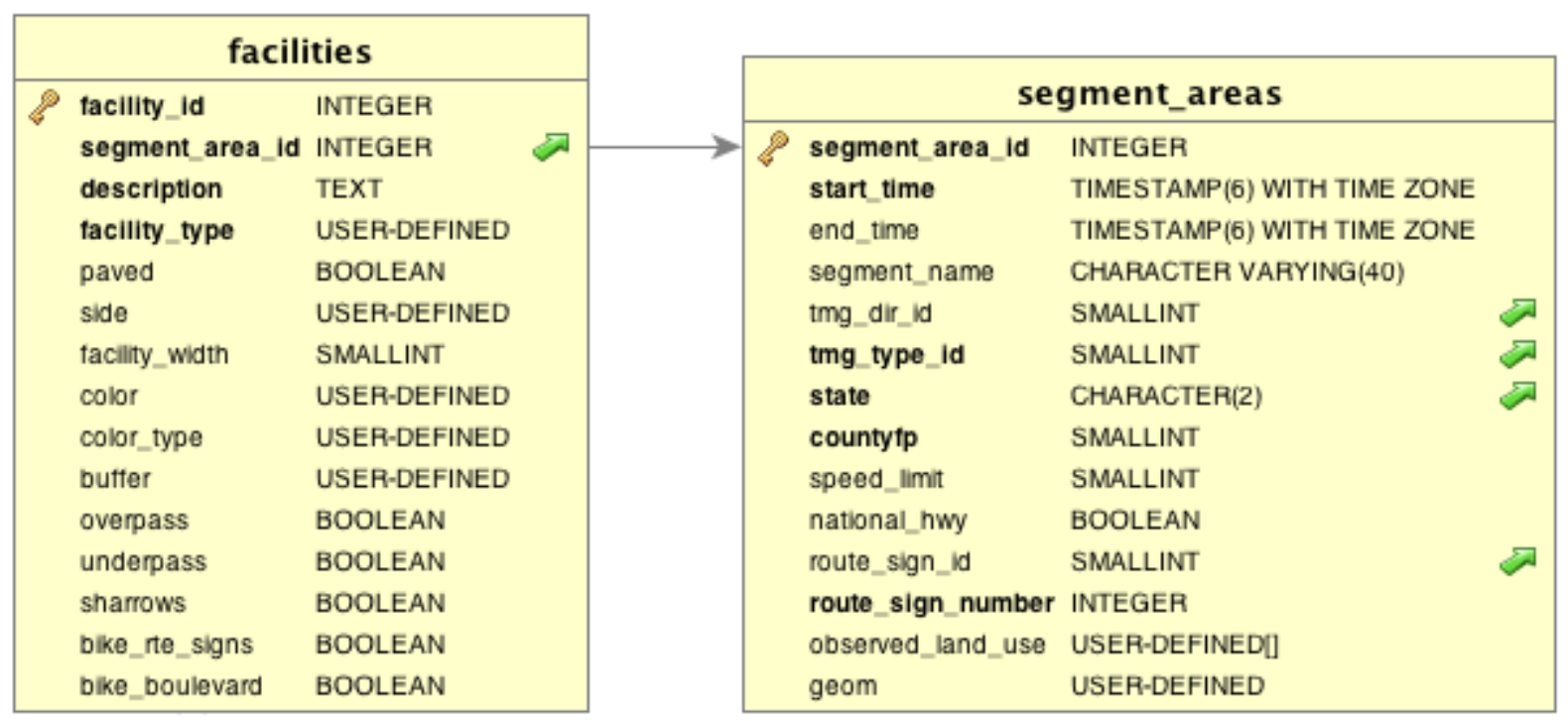

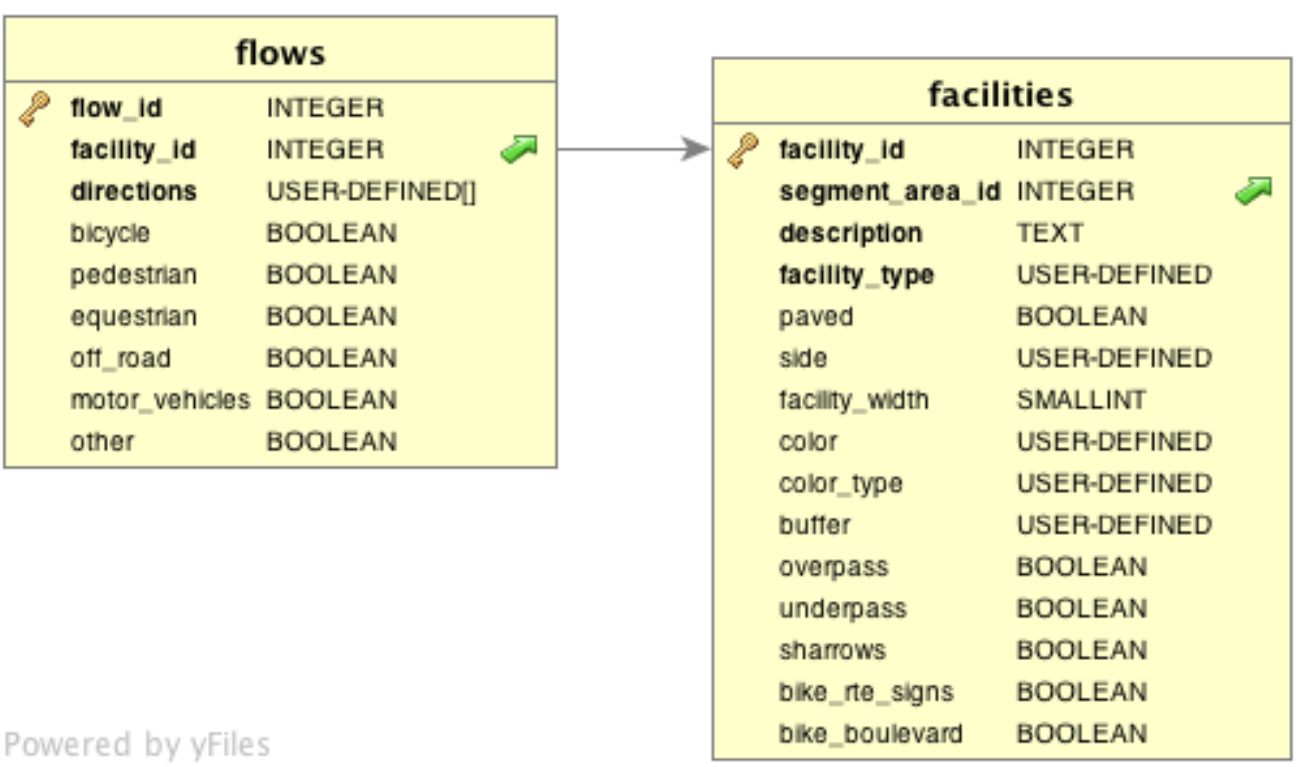




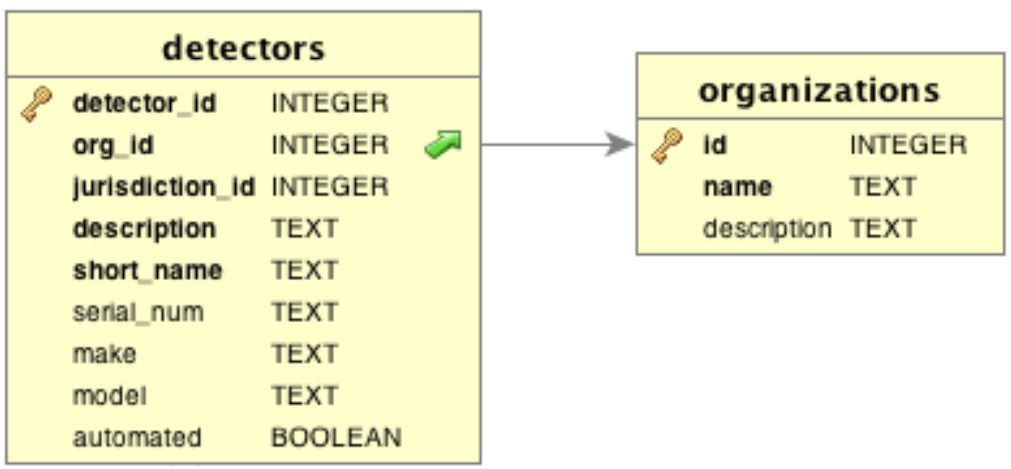

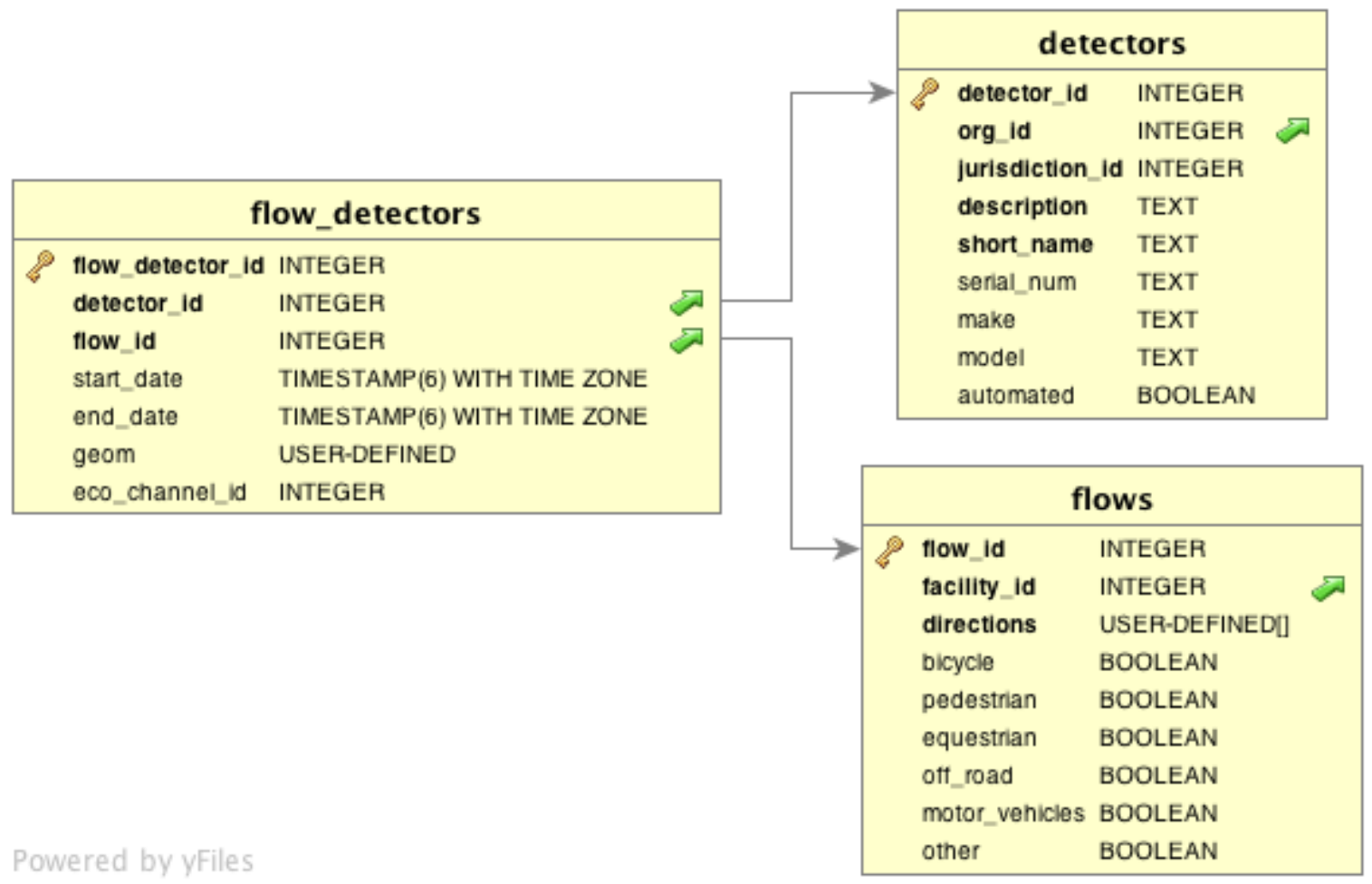




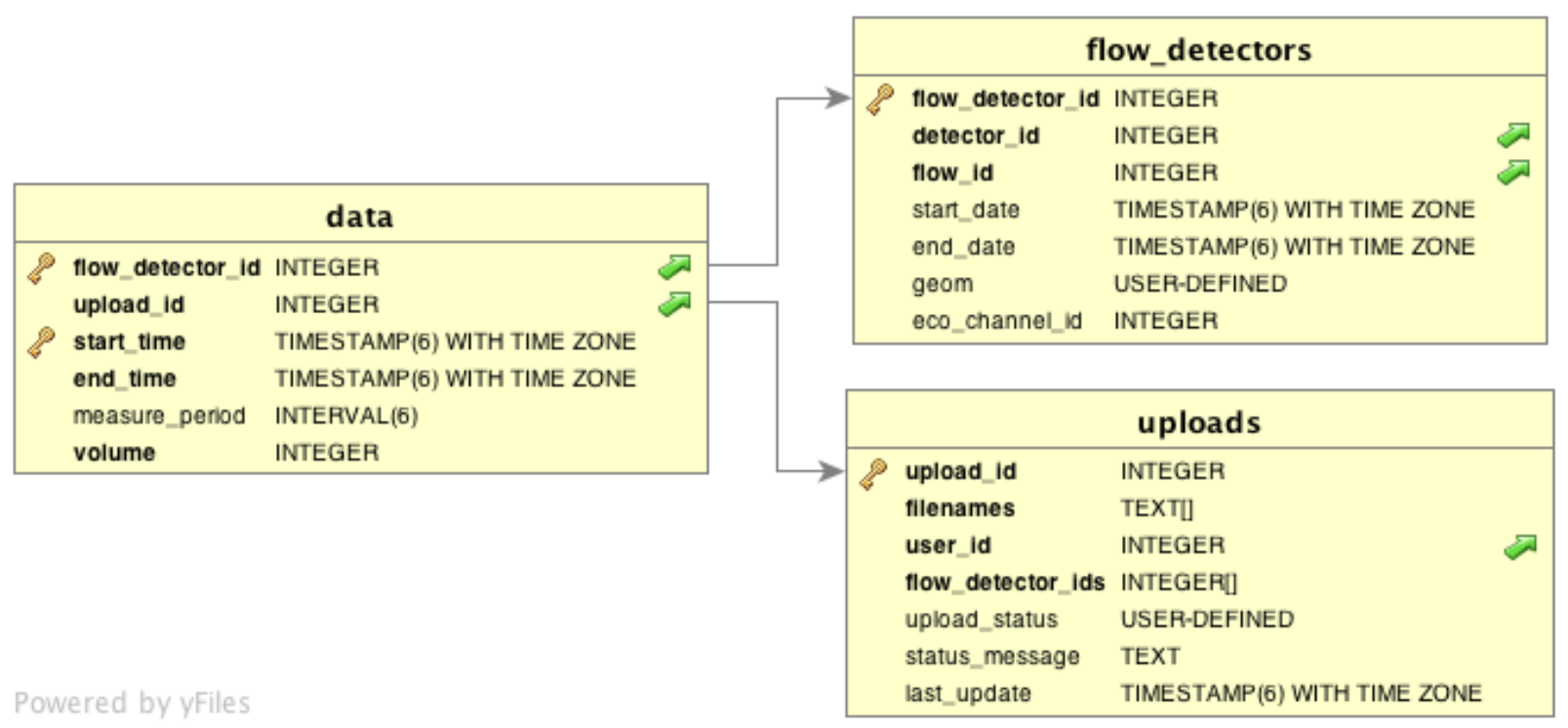




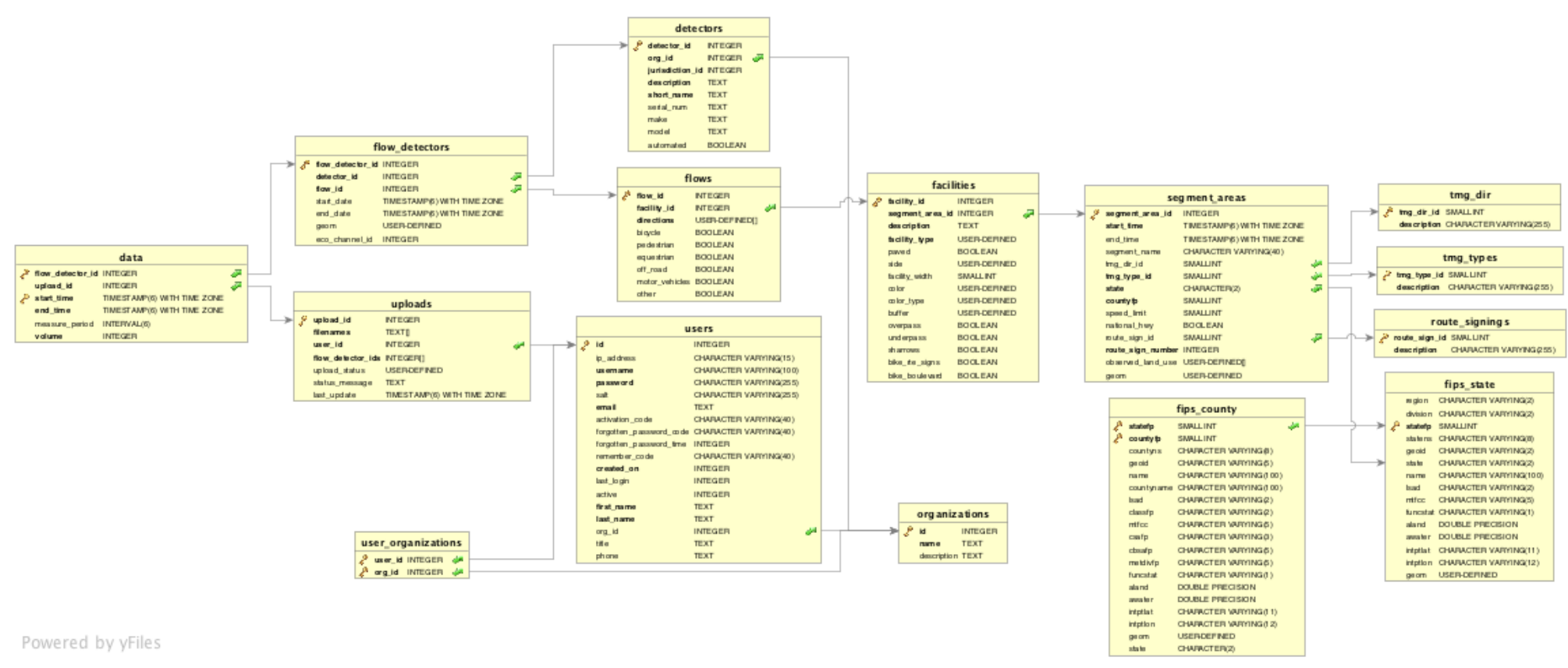




\subsection{EXAMPLES OF OTHER ONLINE NONMOTORIZED COUNT DATABASES}

\subsubsection{Review of Resources}

There are relatively few publicly owned, publicly available resources for bicycle and pedestrian count data. We reviewed the most prominent examples with which we are familiar. These represent some of the agencies that are more advanced in data sharing.

Delaware Valley Regional Planning Commission (DVRPC) Pedestrian and Bicycle Counts site provides information on weeklong bicycle and pedestrian counts conducted on street segments throughout greater Philadelphia. Users can view a map with points showing the locations of different counts, color-coded by mode, and click on points to see details on the data collected through that count. Figure 9.1 shows an example of the map and reports produced through the site. 


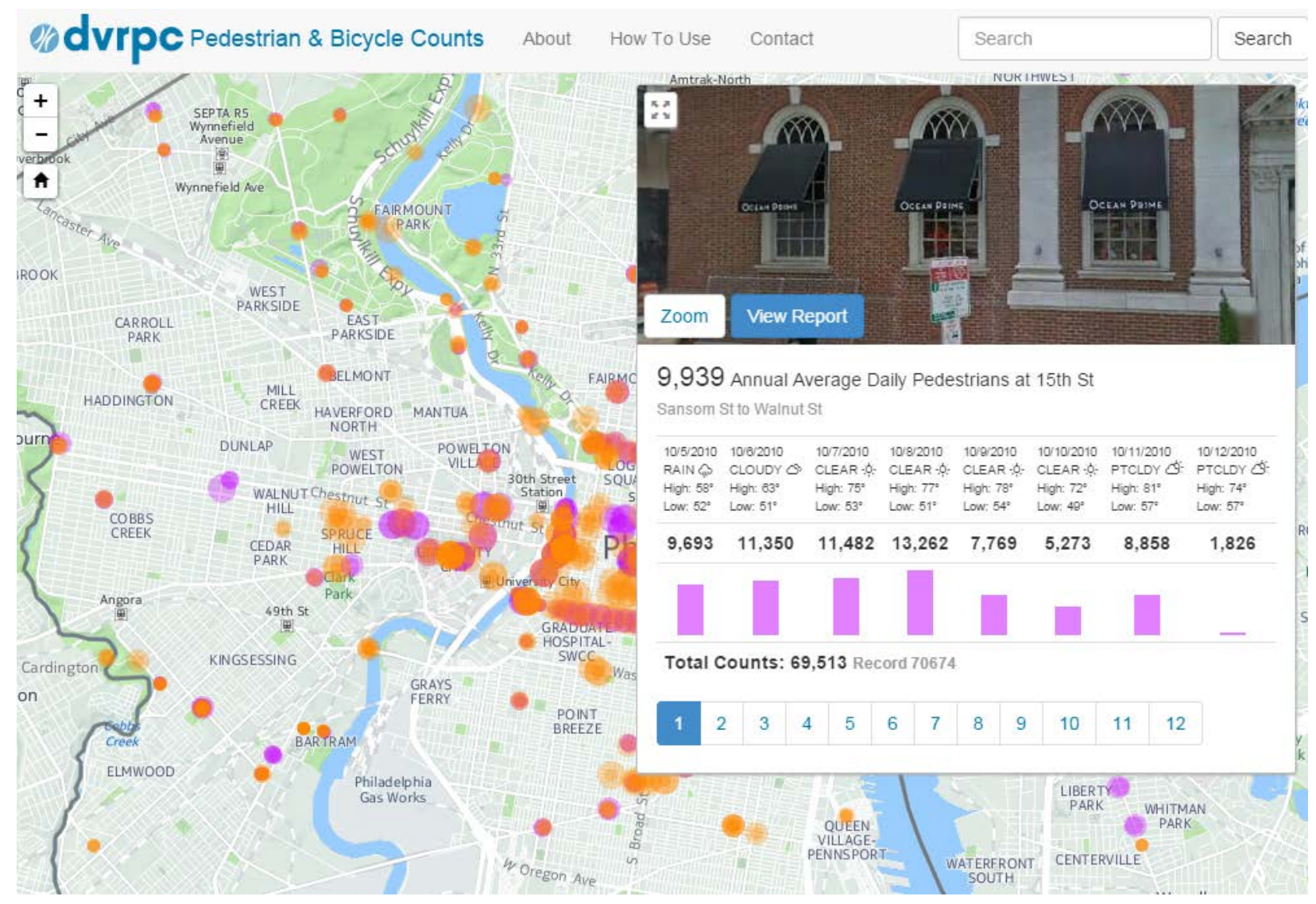

Figure 9.1 DVRPC Pedestrian and Bicycle Counts Website (DVRPC, 2014)

BikeArlington Bicycle and Pedestrian Counters Website. Bike Arlington, together with Arlington County in Virginia, hosts a site where count data from continuous pedestrian and bicycle counters are displayed. The site features the ability to both download and do simple analysis tasks including compare weather events and temperatures to count data. The site features a map of count sites and allows users to graph pedestrian data, filter it, and summarize the desired data (Figure 9-2 and Figure 9-3). 


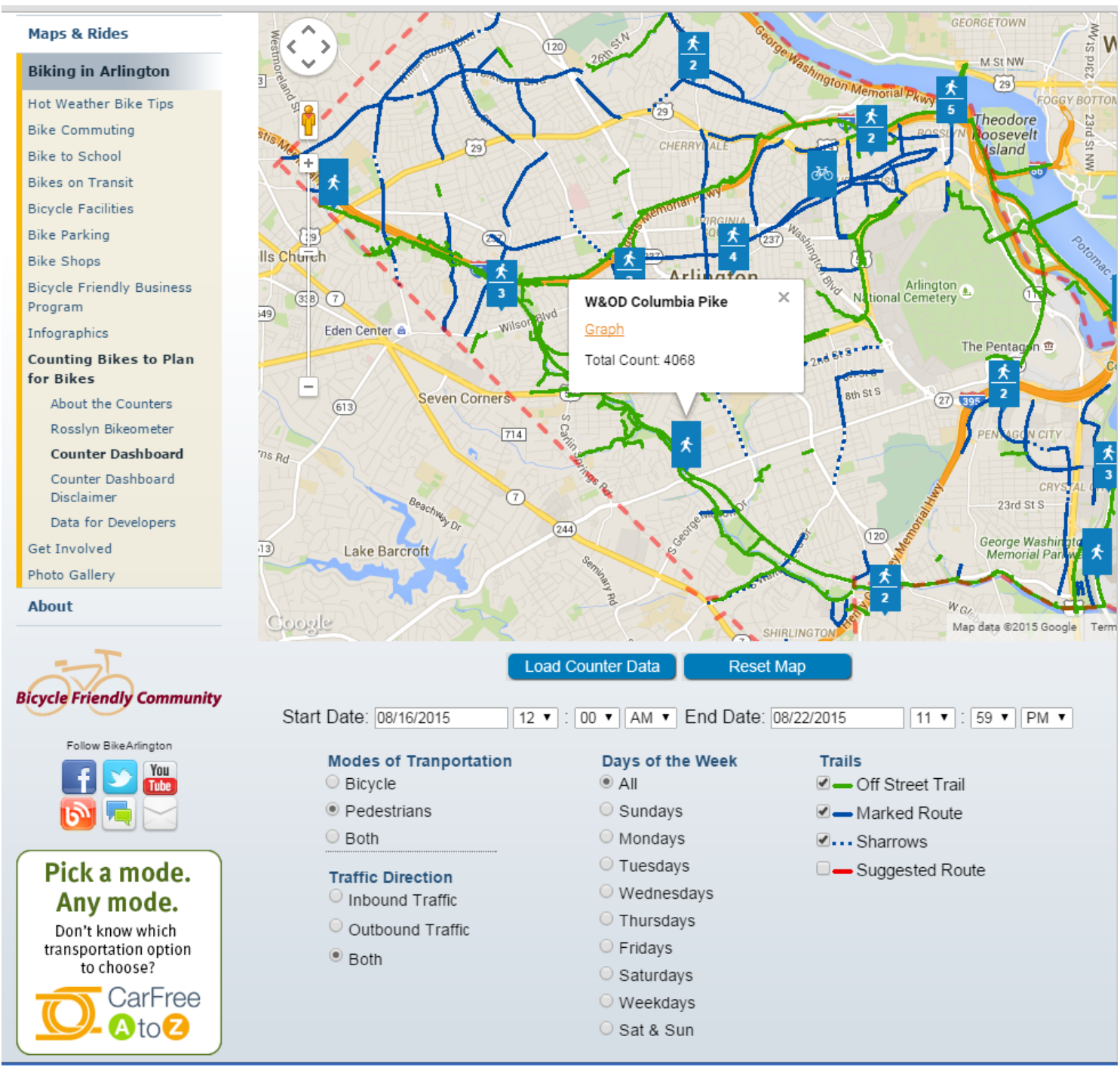

Figure 9.2 Map View from Bike Arlington Bicycle and Pedestrian Counters Website (Bike Arlington, 2014) 


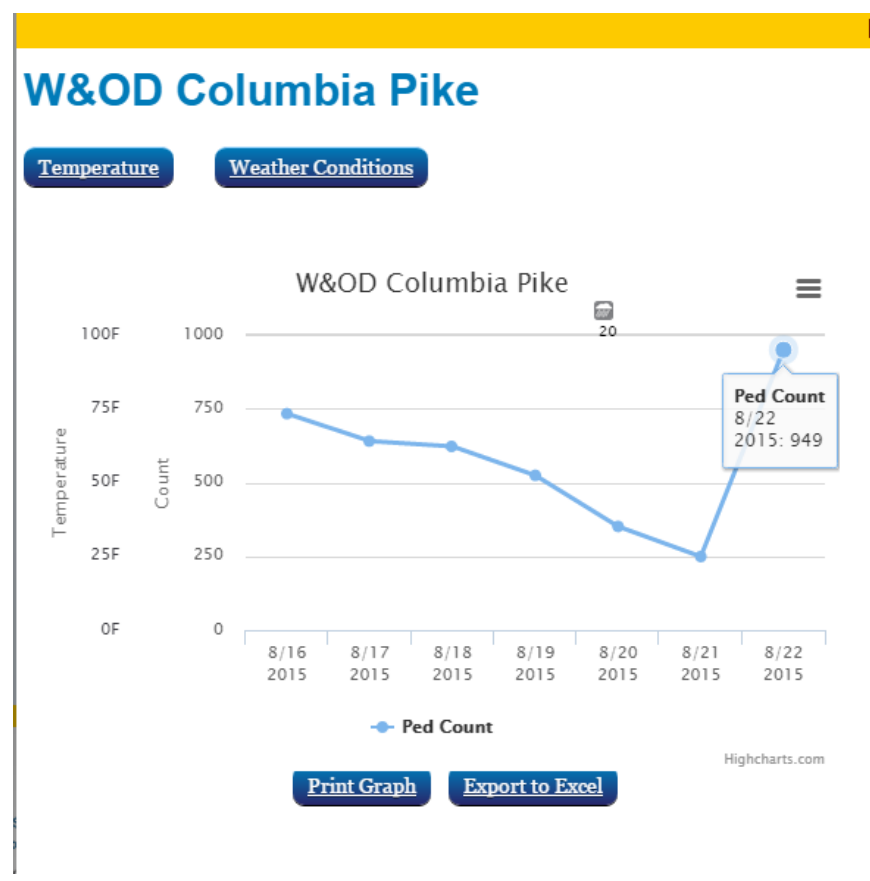

Figure 9.3 Data View from Bike Arlington Bicycle and Pedestrian Counters Website (Bike Arlington, 2014)

Southern California Association of Governments (SCAG) Bike Count Data Clearinghouse. The SCAG Bike Count Data Clearinghouse, implemented by UCLA, is designed primarily for manual count data, but data from automated counters can be entered. The site offers Los Angeles area governments the ability to upload data. While the site is focused on bicycle counts, pedestrian counts are being collected and will be supported in future versions. The site offers the ability to both upload and download data and shows the maximum count for each location (Huff and Brozen, 2014).

Travel Monitoring Analysis System (TMAS). While TMAS is not currently available to the public, it can be accessed by transportation professionals. While TMAS does not currently accept bicycle or pedestrian count data, the next version is expected to include the ability to upload TMG-formatted pedestrian and bicycle (nonmotorized) station and count data to the system. The system includes the ability to upload data, automate quality control (customized by site), report data, delete data, and export data as well as some analysis tools (FHWA, 2013). 


\subsection{USER GUIDE}

This user guide is a work in progress. We provide the guide in the pages to follow as a snapshot of the guidance provided to users as of the end of the first phase of work (Summer 2016). We expect that the user guide will continue to develop and improve as the archive itself continues to develop and improve.

\subsubsection{User Access and Authorization}

To access Bike-Ped Portal, a user account is required. To get an account, email Krista Nordback (nordback@pdx.edu) or Morgan Harvey (mharvey@pdx.edu).

Access to the demo site (bp-demo.its.pdx.edu) is also available. To gain access, email Krista Nordback or Morgan Harvey.

\subsubsection{Count Site Metadata}

To assist those who are creating metadata for each count site and to encourage data uniformity, the following user guide was created. The guide is housed in a living document which is updated as new situations are encountered by TREC's data wranglers who are adding data to Bike-Ped Portal. They are provided below as a snapshot of where the archive is now. Those wishing to use Bike-Ped Portal to add new sites should contact the Bike-Ped Portal Data Wrangler team for the latest guidance on metadata creation. The current head of this team is Michelle Watkins (mwatkins@pdx.edu). 


\section{Metadata fields for Bike-Ped Portal}

There are five categories of metadata used to describe the count data you've been collecting. When collecting information about each counted site, five categories of metadata input is accounted for:

- Segment Area

- Facility

- Flow

- Detector

- Flow Detector

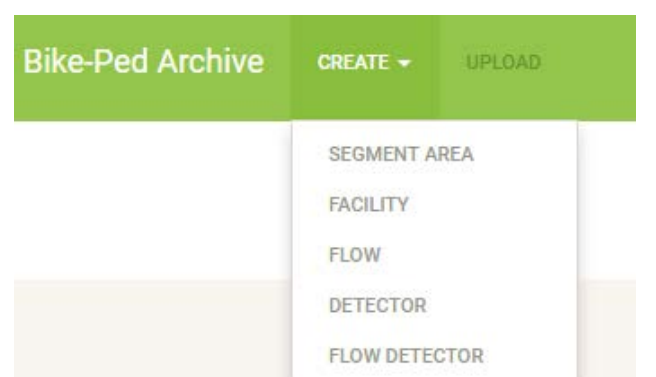

Each category of metadata should be entered into the database using the online user interface, in order, starting with the segment area, then each facility in the segment area, then each flow that is counted on the facilities, then the detectors that count the flows, and finally the flowdetector which links the traffic flow counted to the detector that is counting the flow. For example, below is a screenshot of the Segment Area form. The blue text fields are required inputs, and the black text fields are optional. 


\section{Segment Area Description}

The following questions apply to the segment area. A segment area is composed of all the facilities (e.g. traffic lanes, bike lanes, sidewalks, etc.) within the right-of-way along a defined stretch of road or path.

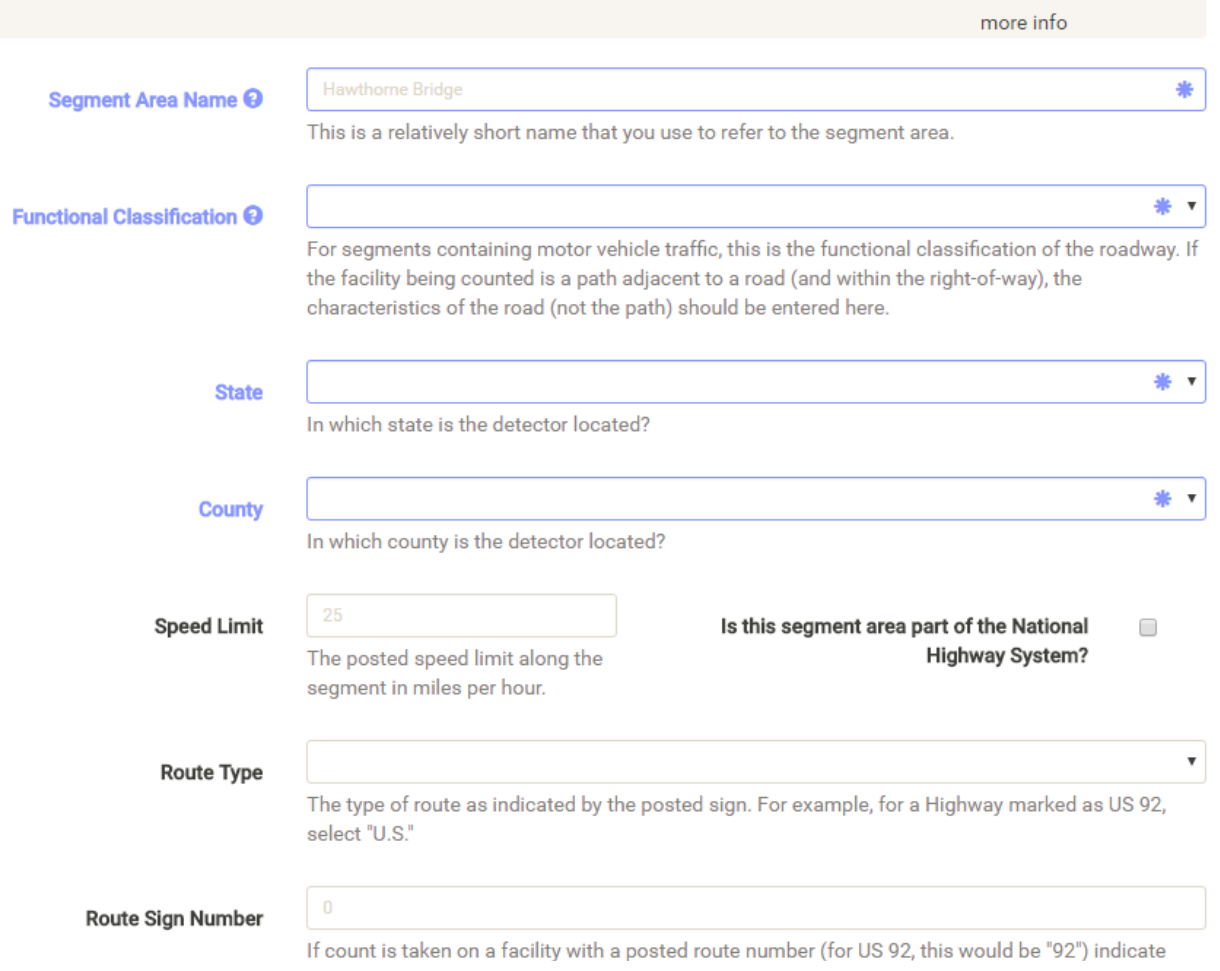

After completing each of the five categories, you will then be able to upload count data for each flow-detector. Uploaded data can be reviewed using the Download button for that Segment Area and the Flow associated.

It is best to separate Segment Areas and Flows as much as possible to allow a thorough look and understanding of the data.

These guidelines will review the five categories of metadata input into Bike-Ped Portal.

\section{Segment Area}

A Segment Area is composed of all facilities, detectors, flows along a roadway or path within proximity to a counting detector.

The Segment Area section includes the following fields: 


\begin{tabular}{|c|c|c|c|}
\hline Fields & Required & Optional & Field Options or Information \\
\hline Segment Area Name & & & $\begin{array}{l}\text { A relatively short name that you use to } \\
\text { refer to the segment area. } 40 \\
\text { characters maximum. }\end{array}$ \\
\hline Functional Classification & & & $\begin{array}{l}\text { - Interstate } \\
\text { - Principal Arterial - Other } \\
\text { - Freeways and Expressways } \\
\text { - Principal Arterial - Other } \\
\text { - Minor Arterial } \\
\text { - Major Collector } \\
\text { - Minor Collector } \\
\text { - Local } \\
\text { - Trail or Shared Use Path } \\
\text { - General Activity Count }\end{array}$ \\
\hline State & & & \\
\hline County & & & \\
\hline Speed Limit & & & \\
\hline Route Type & & & $\begin{array}{l}\text { - Not Signed } \\
\text { - Interstate } \\
\text { - U.S. } \\
\text { - State } \\
\text { - Off-Interstate Business Marker } \\
\text { - County } \\
\text { - Township } \\
\text { - Municipal }\end{array}$ \\
\hline Is this segment area paved? & & & \\
\hline Route Sign Number & & & $\begin{array}{l}\text { If count is taken on a facility with a } \\
\text { posted route number (for US } 92, \text { this } \\
\text { would be " } 92 ") \text {. Indicate that number. } \\
\text { Otherwise leave blank. }\end{array}$ \\
\hline Observed Land use & & & $\begin{array}{l}\text { - Residential } \\
\text { - Office } \\
\text { - Retail } \\
\text { - School } \\
\text { - University } \\
\text { - Industrial } \\
\text { - Agricultural } \\
\text { - Park } \\
\text { - } \text { Mixed Use }\end{array}$ \\
\hline
\end{tabular}




\begin{tabular}{|l|l|l|l|}
\hline & & & $\begin{array}{l}\text { : Water } \\
\text { : Bridge } \\
\bullet \text { Transit Center }\end{array}$ \\
\hline
\end{tabular}

\section{Segment Area Name}

- A short descriptor of the counted area that you use to refer to the Segment Area.

- Should not exceed 40 characters.

- If "Station Number" or "Location Number" is associated with the count site, please include that in the name or number of the Segment Area and Facility Description.

Accepted abbreviations for naming Segment Areas includes, but is not limited to:

- Greenway - Gwy

- Highway - Hwy

- Parkway - Pkwy

- Boulevard - Blvd

- Underpass - undrps

- Overpass - ovrps

- North(South,East, West) of - N/

\section{Choosing a Segment Area}

Keep in mind:

- A Segment Area extends as far down the road or pathway until a path user is able to change direction of their travel. It does not include intersections.

Let's take the Hawthorne Bridge as an example.

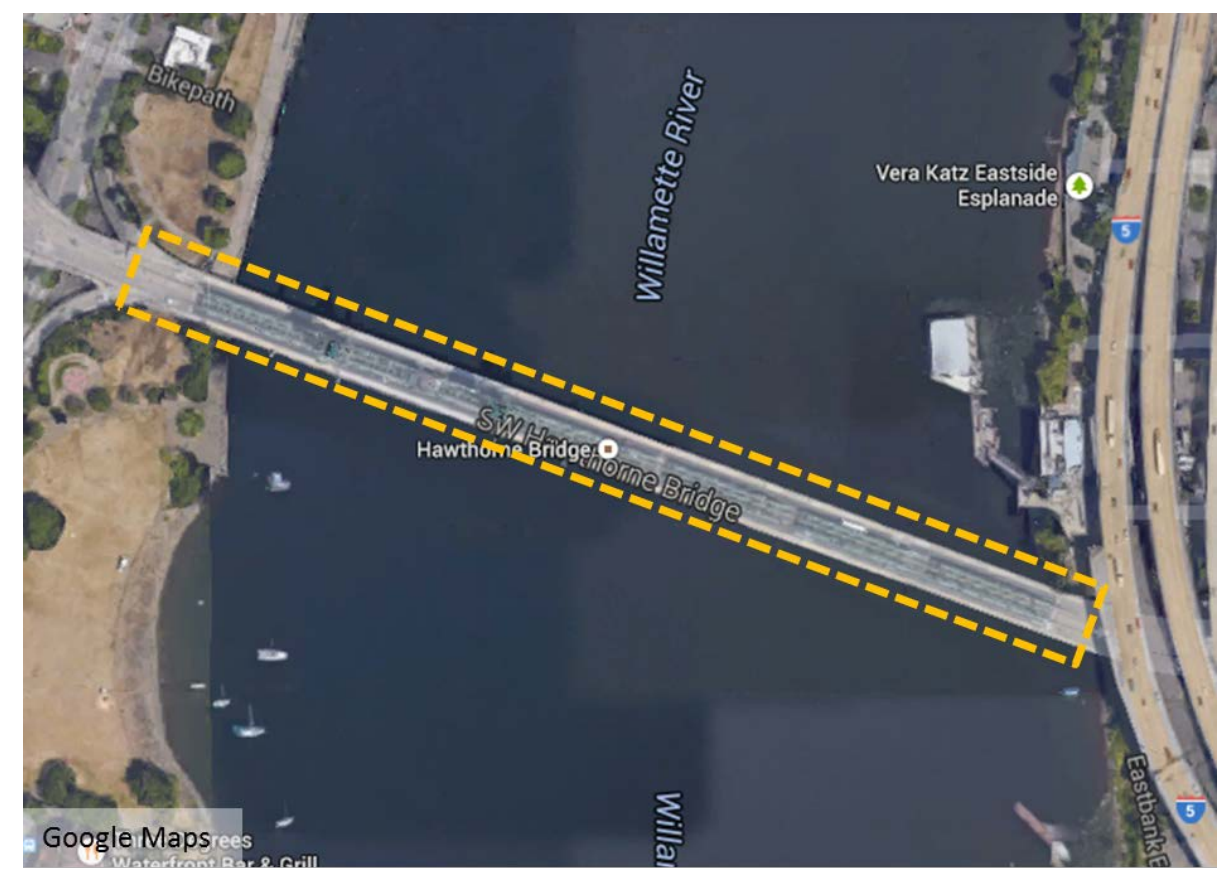


The Segment Area is boxed in the image above. The Segment Area Name would be "Hawthorne Bridge." This is because the cyclist-pedestrian cannot vear off the path when travelling over the Hawthorne Bridge until they have left the bridge, then the Segment Area will end also.

For a less straightforward situation, let's take the Boulder Creek Path in Boulder, Colorado as an example:

The detector device is located on Boulder Creek Path just east of Broadway Path. The section highlighted in orange would be considered the Segment Area because the path user cannot change their travelled path when in this Segment Area. Therefore, "Boulder Creek Path east of Broadway Path" would be considered the Segment Area.

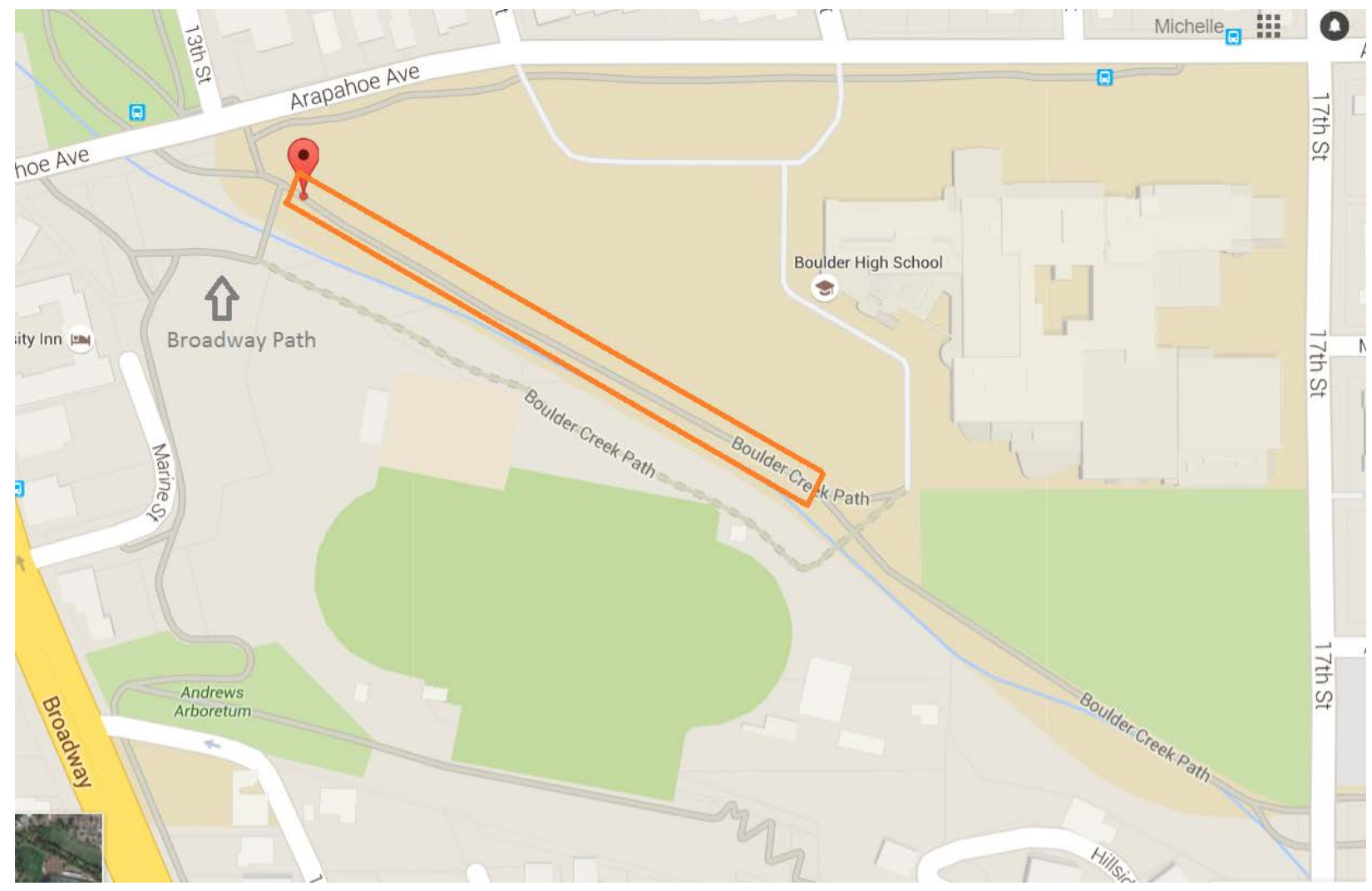

\section{Functional Classification}

Types of Functional Classifications are:

- Arterial roads connect interstates with collector roads or urban centers together, generally regulated by stoplights, somewhat limited with medians, physical distance, etc.

- Collector roads connect local roads to arterial roads, allow access to residential areas, sometimes have small commercial areas; if major/minor classification isn't specified, choose "minor collector".

- Local roads are smaller than collectors and can be residential, retail, backroads. 
- Path/Trails are in their own right-of-ways separate from any roadway.

- General Activity Count refers to areas like plazas or squares where there is no motorized traffic in an open area; includes golf courses and sports fields where direction is undifferentiated in open areas.

If the on-road facility (i.e., bike lane) is a pedestrian and/or bicycle overpass over a roadway or pedestrian and/or bicycle underpass under a roadway, the functional class is the functional class of the roadway. Other indicators such as speed limit would also be of the roadway. This differs from a Trail or Shared Use path which is not affiliated with the roadways classifications that it runs adjacent to.

Functional Classifications may be found by referring to the state's Department of Transportation website. A few examples are given below:

California

http://www.dot.ca.gov/hq/tsip/hseb/crs maps/

Colorado

http://dtdapps.coloradodot.info/staticdata/Downloads/StatewideMaps/func class.pdf

National Highway System

http://www.fhwa.dot.gov/planning/national highway system/nhs maps/

Portland, Oregon (Multnomah County)

http://www.oregon.gov/ODOT/TD/TDATA/gis/docs/citymaps/Portland.pdf

Portland-Mt.Tabor, Oregon (Multnomah County)

http://www.oregon.gov/ODOT/TD/TDATA/gis/docs/citymaps/Portland-Mount Tabor.pdf

Portland-Beaverton, Oregon (Washington County)

http://www.oregon.gov/ODOT/TD/TDATA/gis/docs/citymaps/Portland-Beaverton.pdf

Portland - Lake Oswego, Oregon (Clackamas County)

http://www.oregon.gov/ODOT/TD/TDATA/gis/docs/citymaps/Portland-Lake Oswego.pdf

Oregon

http://www.oregon.gov/ODOT/TD/TDATA/pages/gis/CityMaps.aspx

Texas

http://www.txdot.gov/apps/statewide mapping/StatewidePlanningMap.html

Virginia

http://www.arcgis.com/home/webmap/viewer.html?webmap=3eca6c9adb6649c988d98734f85b

$\underline{\text { addb }}$ 
Washington

http://www.wsdot.wa.gov/data/tools/geoportal/?config=functionalclass\&layers=Functional+Class

\section{Speed Limit-optional}

- If the pathway runs along a roadway, such as a sidewalk or bike lane, use the speed limit of the road

- No speed limit for Trails or Shared Use paths

\section{Route Type-optional}

- If the path runs along a highway, use the highway as the Route Type

- Refers to freeways, highways, interstates, etc.

- it's an overpass(or underpass) over a highway, input the route type for the highway over which it passes

- If a path is next to a highway or crosses it near the count locations, put the route type

- By default, use the road classification

\section{Route Sign Number-optional}

- If you put in a route type, you MUST put in a number

○ Example: I-5 -> Route Type "Interstate," Route Number "5"

- If a counted path is next to or crosses near a highway, put the number for that highway.

- If no number, put route type down as "Not signed"

\section{National Highway System}

- "includes the Interstate Highway System as well as other roads important to the nation's economy, defense, and mobility."

- Maps for each state can be viewed here: http://www.fhwa.dot.gov/planning/national highway system/nhs maps/

\section{Observed Land Use - optional}

Select all types of land use within one block of the Segment Area.

- Residential

- Retail

○ Includes green belts/green spaces bordered by residential areas

$\circ$ Anything you need to pay for, including gyms, libraries, post offices

- School

○ $\mathrm{K}-12$

- University

- Includes community colleges, two year and four year colleges, vocational schools

- Industrial

- Park

$$
\text { Manufacturing }
$$

- Public parks including public outdoor athletic facilities (disc golf, soccer fields) and scenic corridors, state parks, etc.

- Water 
- Creeks, rivers, lakes, oceans

\section{Facility}

This page asks about the facility's characteristics on which the count was collected. The facility, such as a sidewalk or bike lane, is within a Segment Area. Multiple facilities may exist within a single Segment Area

The Facility section includes:

\begin{tabular}{|c|c|c|c|}
\hline Fields & Required & Optional & Field Options \\
\hline State & & & \\
\hline County & & & \\
\hline Segment Area & & & \\
\hline Description & & & $\begin{array}{l}\text { Please provide a brief } \\
\text { description of the facility on } \\
\text { which the count was taken. } 40 \\
\text { characters maximum }\end{array}$ \\
\hline Facility Type & & & $\begin{array}{l}\text { - Roadway } \\
\text { - } \text { Path/trail } \\
\text { - } \text { Crowalk } \\
\text { - Cycle track } \\
\text { - } \text { Bike lane } \\
\text { - General activity count }\end{array}$ \\
\hline Paved & & & Is the facility paved? \\
\hline Side & & $\sqrt{ }$ & $\begin{array}{ll}\text { - } & \text { North } \\
\text { - } & \text { South } \\
\text { - } & \text { East } \\
\text { - } & \text { West } \\
\text { - } & \text { Northwest } \\
\text { - } & \text { Southwest } \\
\text { - } & \text { Northeast } \\
\text { - } & \text { Southeast } \\
\text { - } & \text { Median }\end{array}$ \\
\hline
\end{tabular}




\begin{tabular}{|c|c|c|}
\hline Facility Width & & $\begin{array}{l}0,1,2,3,4,5,6,7,8,9,10 \\
11,12,13,14+\end{array}$ \\
\hline Buffer & & $\begin{array}{ll}\text { - } & \text { None } \\
\text { - } & \text { Colored } \\
\text { - } & \text { Painted Stripe } \\
\text { - } & \text { Plexible Posts } \\
\text { - } & \text { Parking } \\
\text { - } & \text { Concrete Barrier } \\
\text { - Other Physical Barrier }\end{array}$ \\
\hline $\begin{array}{l}\text { Overpass/Underp } \\
\text { ass }\end{array}$ & & \\
\hline
\end{tabular}

\section{Facility Type Description}

This description allows 50 characters maximum to describe the type of path and its location relative to other elements within the Segment Area with surrounding areas. Tip: If using a spreadsheet to record metadata, format your Segment Area Name and Facility Description to be flagged if they exceed their allotted amount of characters. Select column $>$ Format $>$ Conditional Formatting...>Add new rule $>$ Custom Formula is $>$ LEN(B1:B10000) $>50>$ Formatting style (mark color of your choosing.)

Depending on the column used for creating Segment Area Name and Facility Descriptions, B1:B10000 will change. B, meaning column, and 1-10000 rows within said column.

Now, your entries will be highlighted if the Segment Area Name exceeds 40 characters or 50 characters for Facility Description. 


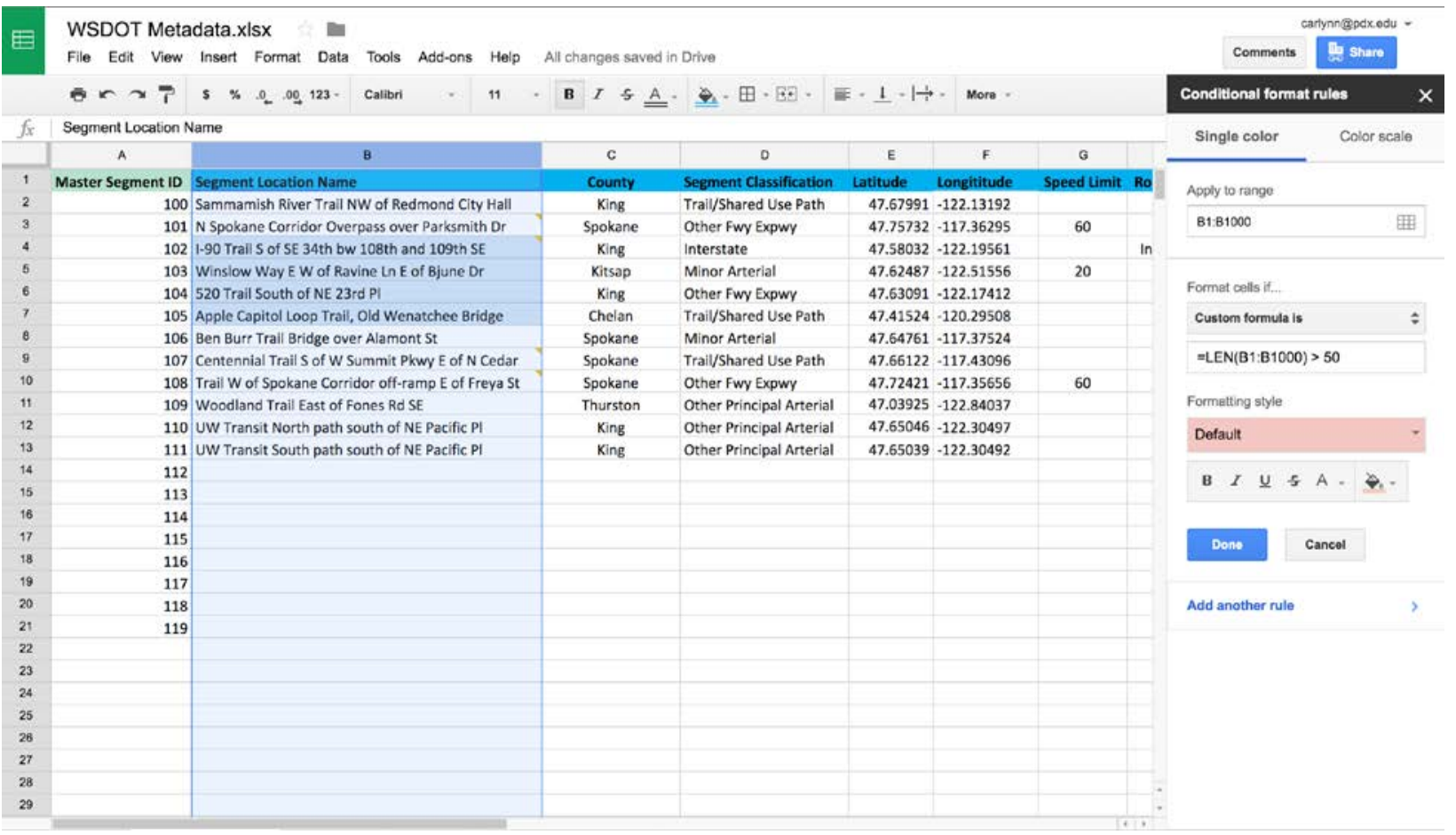

- For example:

- If the Segment Area includes two sidewalks on either side of a roadway with twolane traffic, three facilities exist. 


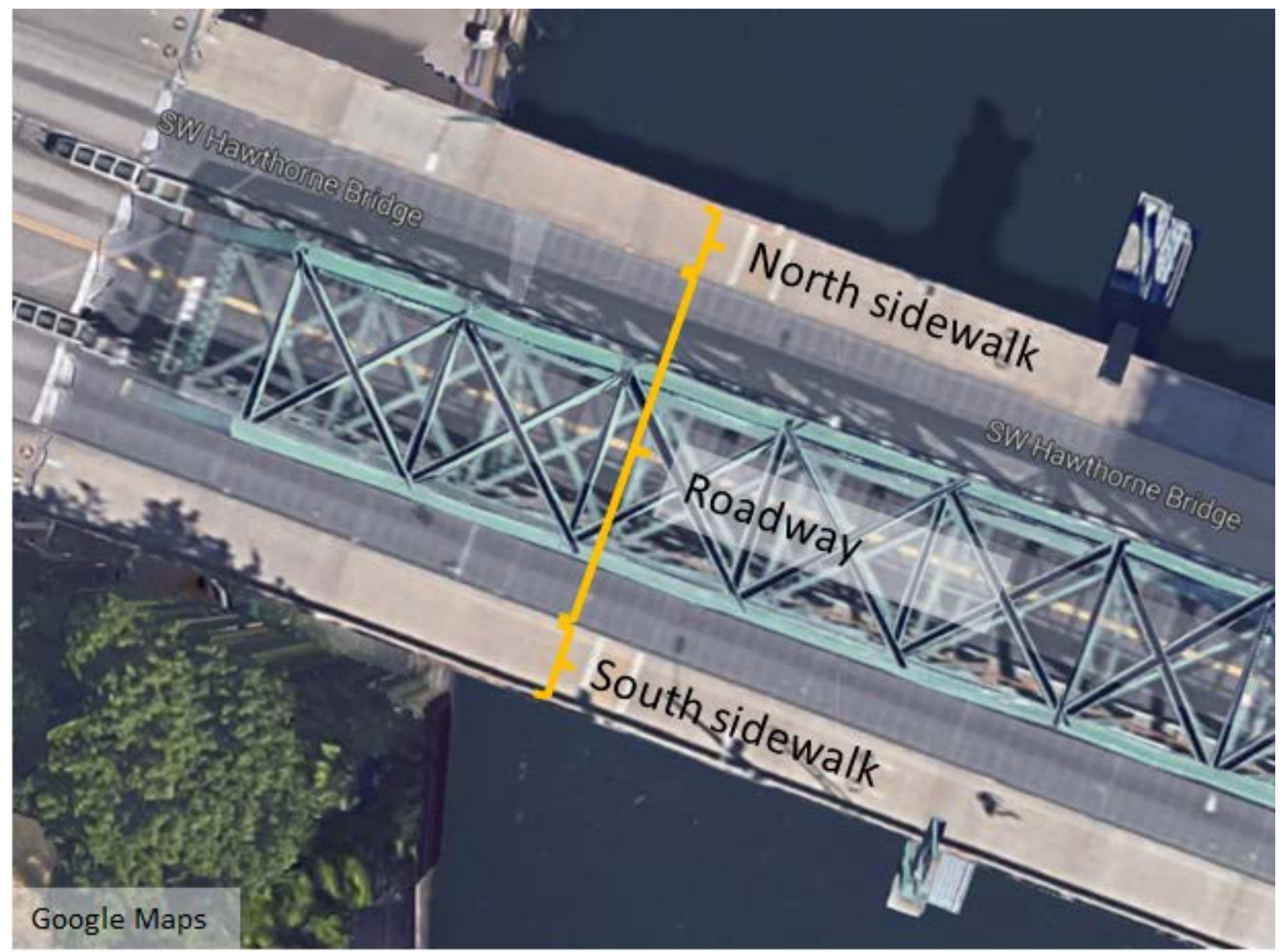

- Facilities would include

- "North sidewalk of Hawthorne Bridge"

- "South sidewalk of Hawthorne Bridge"

- "Roadway on Hawthorne Bridge"

\section{Facility Type}

- If the count includes some sidewalk riding, but is mostly on the roadway, use roadway for the facility. In the description, include that the count includes sidewalk riding.

- Cycle tracks are bike-only facilities separated by a vertical element (including parked cars, curbs, planters, flexible delineator posts, etc.) from motor vehicle traffic.

- Roadway shoulders are considered roadways unless there is a painted symbol of a bicyclist in the shoulder, in which case it would be a bike lane. If a shoulder and not a bike lane, classify as roadway and make a note of the shoulder in the description.

- When counts are on a roadway the entire roadway is the facility, not broken out by lanes. 
- If segment starts as one facility type but changes into another type on the same segment, the facility type is facility type where the detector is.

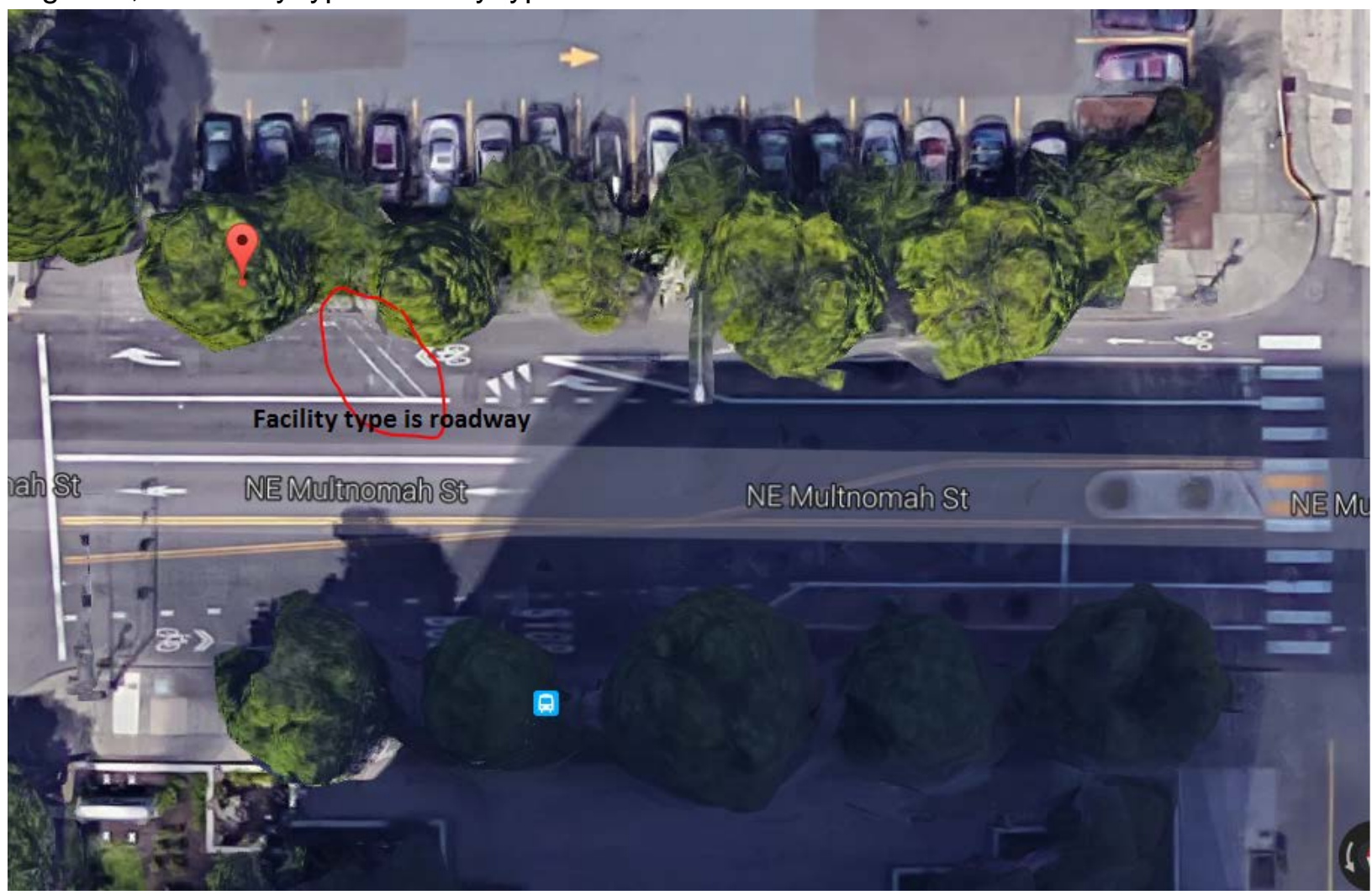

When "Roadway" is selected for Facility Type, the following fields appear:

- Sharrows -

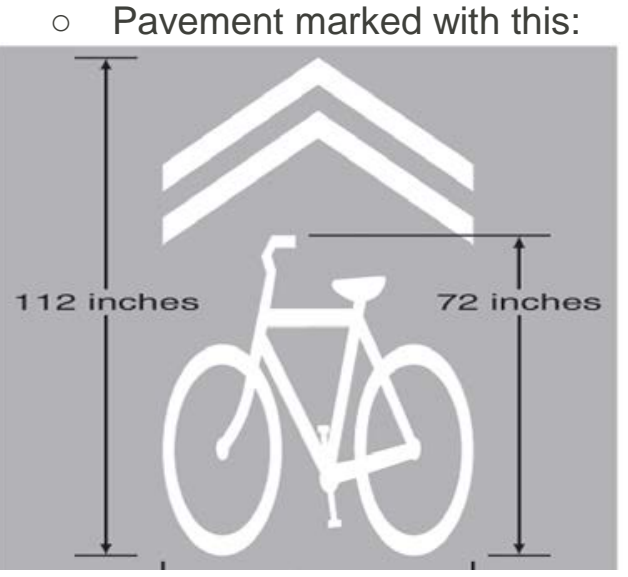

- Bike Route Signs

- Marked with a Bike Route sign as shown below 


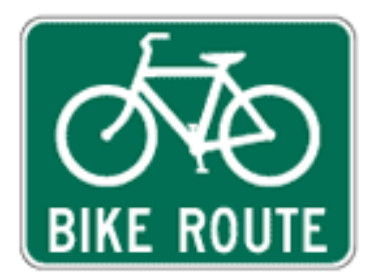

- Bike Boulevard

- A local road may be a bike boulevard if it is officially designated as such by the local transportation agency. Check on their web-sites for existing Bike Boulevards (also known as Neighborhood Greenways).

\section{Facility Width-optional}

- Facility width only applies to bike lanes, cycle tracks, sidewalks, crosswalks and paths. It does not apply to roadways or general activity counts.

- You can use Google Earth to measure Facility Width by zooming in and right clicking and selecting the "Measure" option.

\section{Buffer- optional}

Buffer is what's between the motor vehicle traffic and the bicycle traffic other than just a white line. A double line or a vertical separation between the road and the path is considered a buffer. This is usually only used in the case of cycle tracks, but sometimes applies to off-street paths.

\section{Color- optional}

- Refers to color of bike lane/cycle track

Flow

Direction of travel in a particular facility.

\begin{tabular}{|l|c|l|l|}
\hline Fields & Required & Optional & Field Options \\
\hline State & $\checkmark$ & & \\
\hline County & $\checkmark$ & & \\
\hline Segment Area & $\checkmark$ & & \\
& & & \\
\hline
\end{tabular}




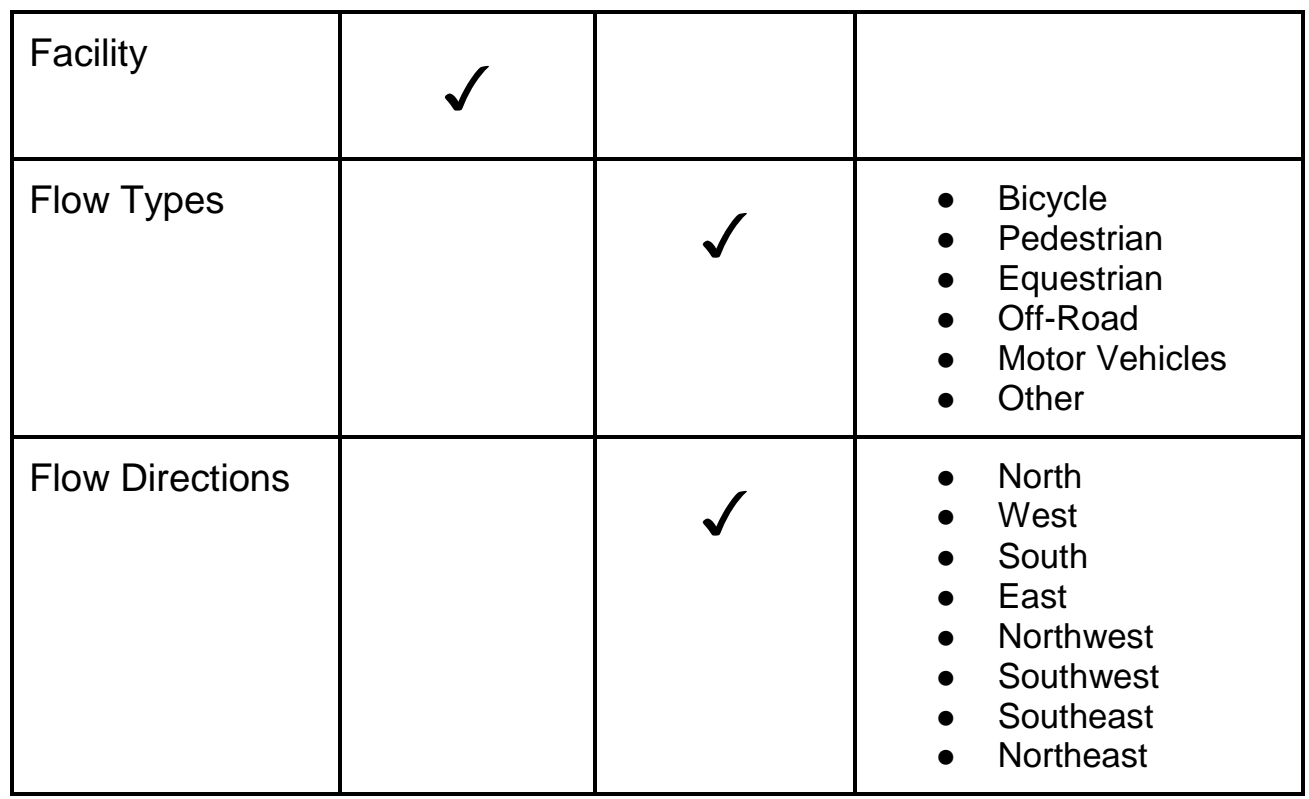

After selecting the State, County, Segment Area, and Facility you've created for your data, it is time to designate the flow of non-motorized traffic being counted. Note that you should only input flows for the traffic counted, not for all the road users who use the facility. If pedestrians are present but not counted, do not submit a Flow for them.

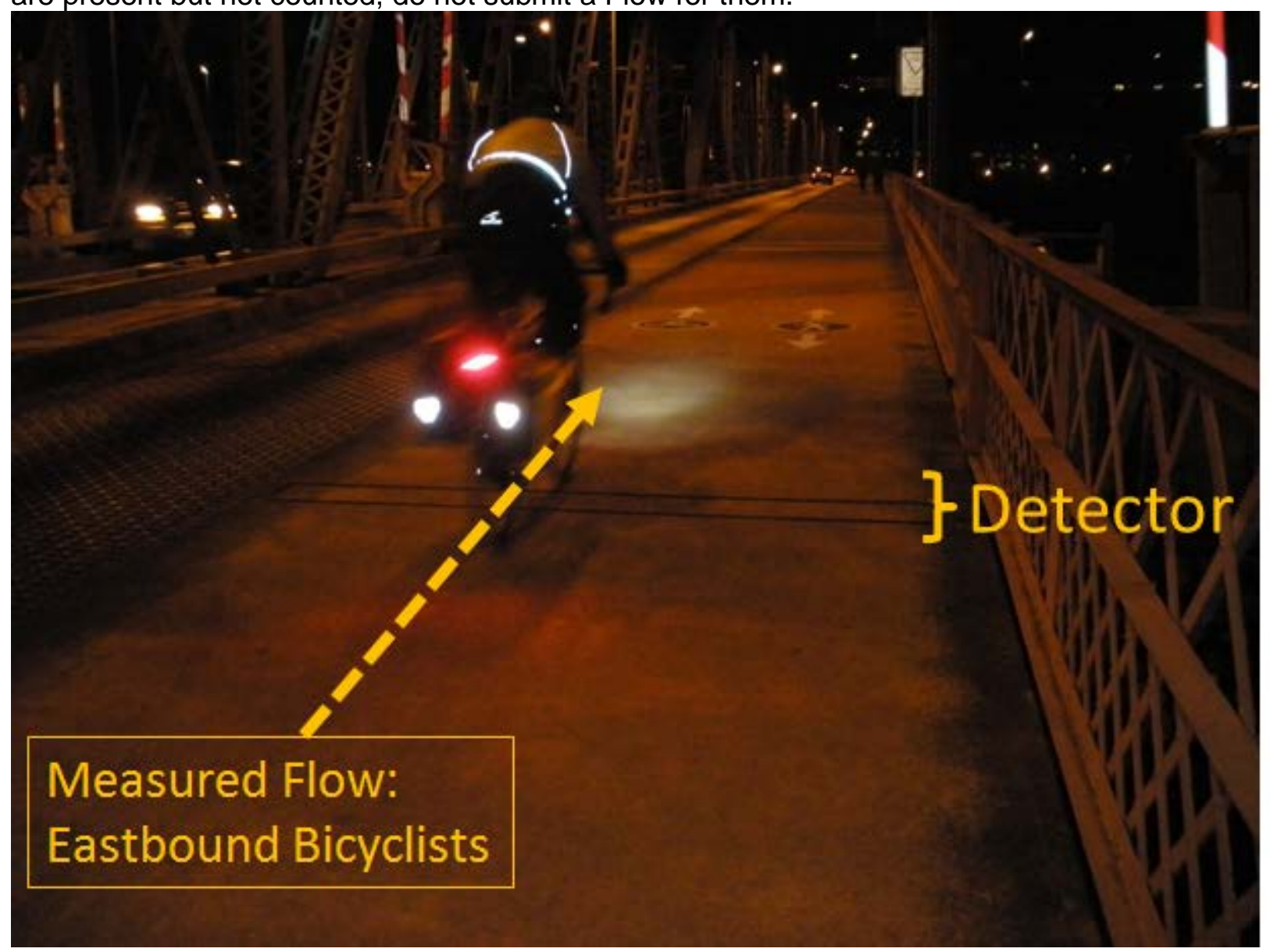


A Segment Area may have multiple modes, or flow types(i.e. Cyclists, pedestrians), and flow directions (i.e., northbound, eastbound) depending on how the data was collected. If data is separated by mode and/or direction, only choose one flowtype along with one direction for each submitted Flow.

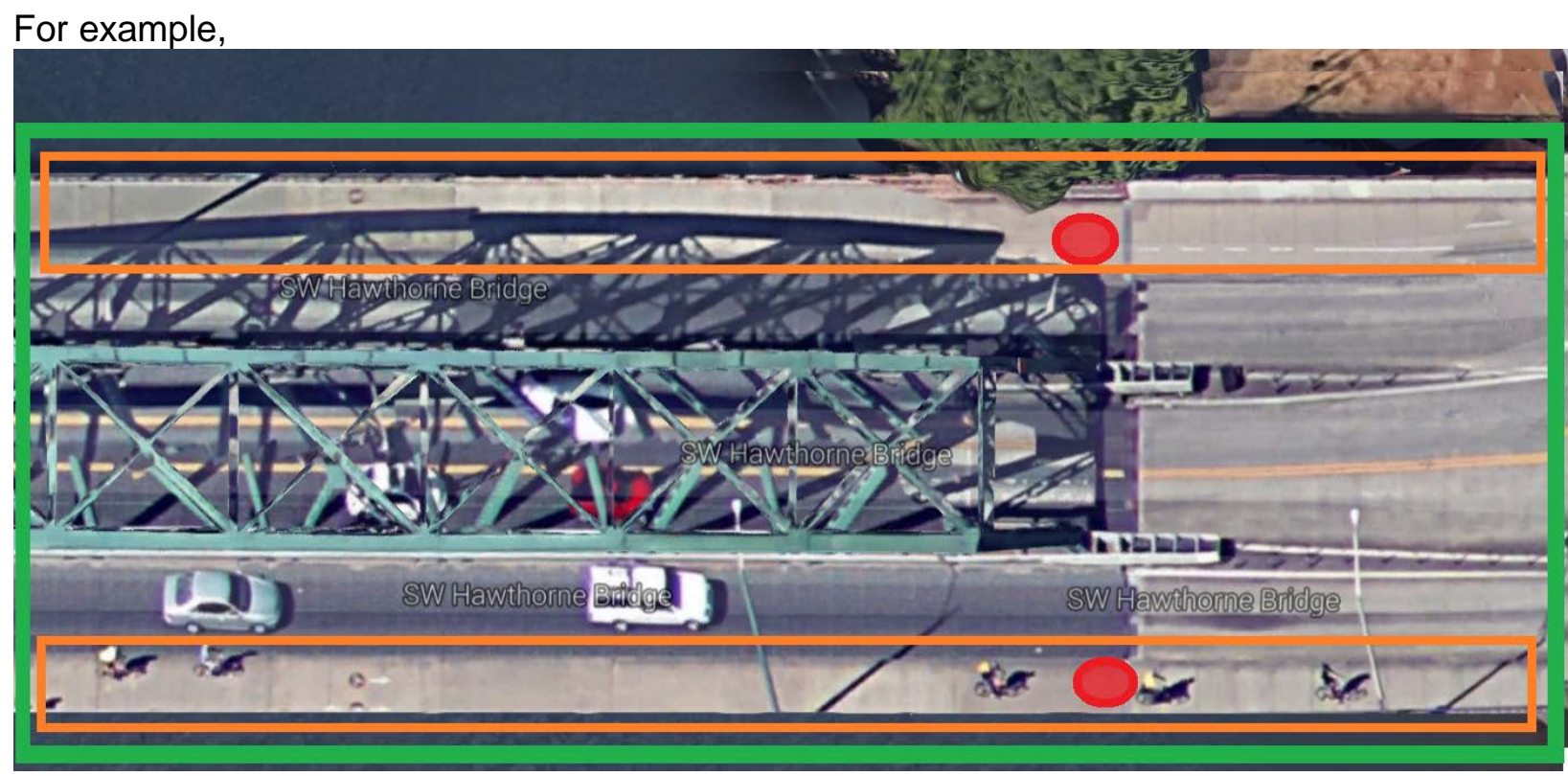

Segment Area: Hawthorne Bridge

Two Facilities: North sidewalk on Hawthorne Bridge South sidewalk on Hawthorne Bridge

- Two detectors, a detector for each facility

Flow Types: Flow directions are eastbound and westbound.

- For the north sidewalk, separate data was collected for cyclists travelling westbound AND pedestrians travelling westbound and eastbound. In other words, pedestrian counts were not distinguished by direction.

- On the south sidewalk, separate data was collected for cyclists travelling eastbound AND pedestrians travelling westbound and eastbound. Again, pedestrian counts were not distinguished by direction. 


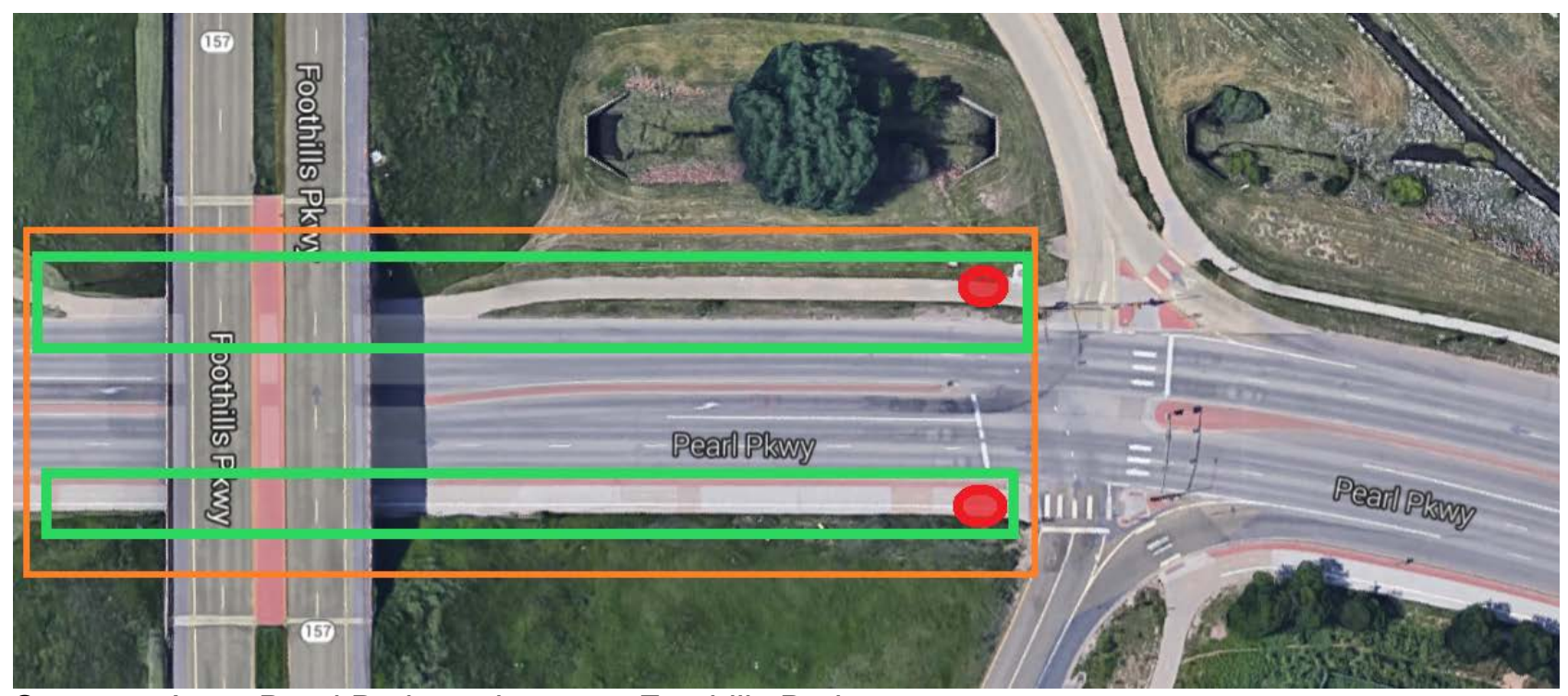

Segment Area: Pearl Parkway between Foothills Parkway ramps

Two facilities: North sidewalk between Foothills Parkway ramps

South sidewalk between Foothills Parkway ramps

- Two detectors, a detector for each facility

Flow Types: Flow directions are eastbound and westbound.

- For the north sidewalk, separate data was collected for cyclists travelling eastbound and cyclists travelling westbound.

- On the south sidewalk, data was not separated by direction for cyclists, therefore cyclists travelling eastbound and westbound.

\section{Inputting Flows and Flow Types into Bike-Ped Portal}

When inputting flows and flow types, select all options counted with detector device at that site. For example, if only bicyclists will be counted, only "Bicycle" should be selected as a Flow Type. If the detector will count both bicyclists and pedestrians (and cannot or will not distinguish between them), both "Bicycle" and "Pedestrian" should be selected as Flow Types. However, if the detector is able to distinguish bicyclists and pedestrians AND you intend to upload counts for each, THEN you should add independent flows for each type.

The same goes for direction. If only northbound traffic will be counted, only "Northbound" should be selected as a Flow Direction. If the detector will count both northbound and southbound traffic (and cannot or will not distinguish between them), both "Northbound" and "Southbound" should be selected as Flow Directions.

Here's an example:

Facility: Pearl Pkwy Path N side between Foothills Pkwy ramps

Flow Type: Bicycle

Flow Direction: West 


\section{Flow}

This is information about a specific type or types of measured activity along a path. For example, eastbound pedestrian traffic or combined southbound and northbound bicycle traffic.

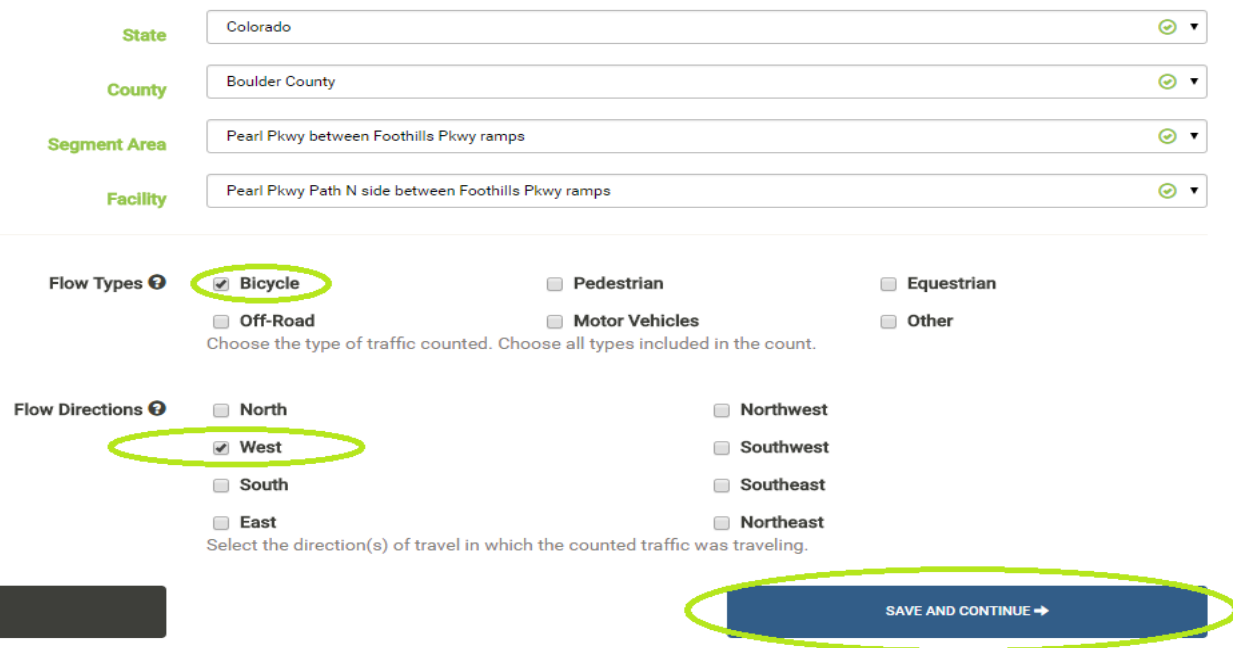

(c) BikePed Portal 2004-2016

Save and Continue.

Submit a new Flow form for the east direction.

Facility: Pearl Pkwy Path N side between Foothills Pkwy ramps 
Flow Type: Bicycle

Flow Direction: East

\section{Bike-Ped Archive}

\section{Flow}

This is information about a specific type or types of measured activity along a path. For example, eastbound pedestrian traffic or combined southbound and northbound bicycle traffic.

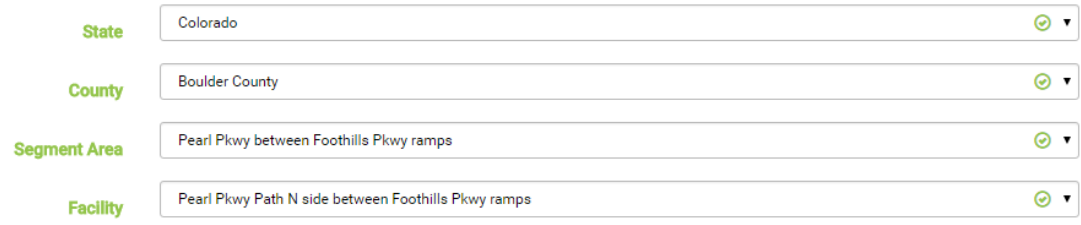

Flow Types 9

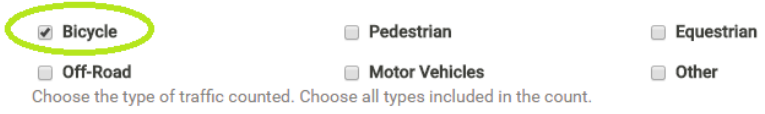

Flow Directions 9
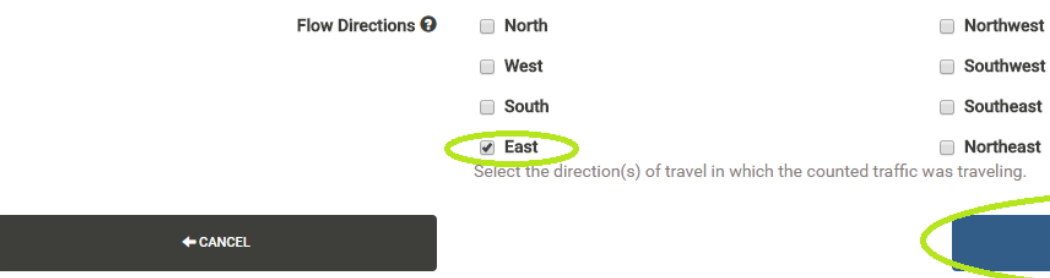

SAVE AND CONTINUE $\rightarrow$

Save and Continue

Submit a new Flow form form for the east and west direction data on the south sidewalk facility:

Facility: Pearl Pkwy Path S side between Foothills Pkwy ramps

Flow Type: Bicycle

Flow Direction: East, West

- Select all flow directions accounted for if data isn't separated by travel direction. 


\section{Flow}

This is information about a specific type or types of measured activity along a path. For example, eastbound pedestrian traffic or combined southbound and northbound bicycle traffic.
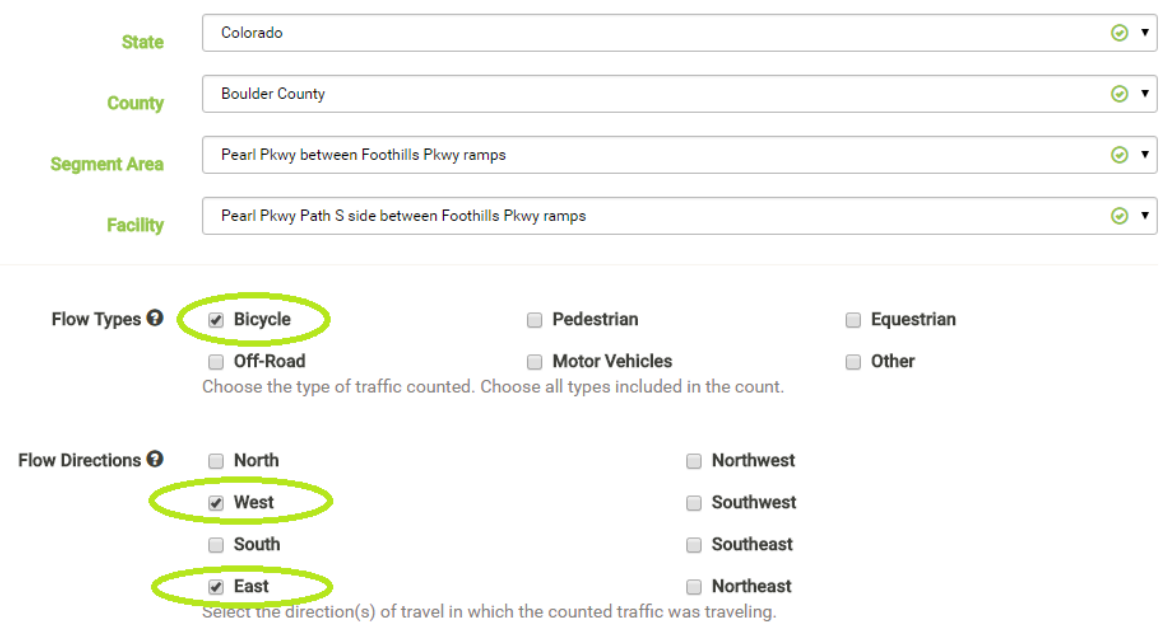

\section{Detector}

Counts are taken with a detector device. Multiple flows can be detected by one single detector within a certain facility of a segment area. 


\section{Dashboard}

\begin{tabular}{llll} 
My Detectors & & & \\
\hline Description & $\begin{array}{l}\text { Serial } \\
\text { Number }\end{array}$ & Make & Model \\
\hline $\begin{array}{l}\text { The Greatest Test Detector. Our only detector. } \\
\text { It's great. }\end{array}$ & GTD- & $\begin{array}{l}\text { Counting Machines } \\
\text { International }\end{array}$ & CountMaster \\
\hline
\end{tabular}

All Flows

\begin{tabular}{llllllll} 
State & County & $\begin{array}{l}\text { Segment } \\
\text { Name }\end{array}$ & Segment Type & Facility & $\begin{array}{l}\text { Facility } \\
\text { Type }\end{array}$ & Directions & Download \\
\hline Oregon & $\begin{array}{l}\text { Multnomah } \\
\text { County }\end{array}$ & $\begin{array}{l}\text { Hawthorne } \\
\text { Bridge }\end{array}$ & $\begin{array}{l}\text { Principal Arterial } \\
\text { - Other }\end{array}$ & $\begin{array}{l}\text { North } \\
\text { Sidewalk }\end{array}$ & sidewalk & $\{$ E $\}$ & Download \\
Oregon & $\begin{array}{l}\text { Multnomah } \\
\text { County }\end{array}$ & $\begin{array}{l}\text { Hawthorne } \\
\text { Bridge }\end{array}$ & $\begin{array}{l}\text { Principal Arterial } \\
\text { - Other }\end{array}$ & $\begin{array}{l}\text { North } \\
\text { Sidewalk }\end{array}$ & sidewalk & $\{$ W $\}$ & Download \\
Oregon & $\begin{array}{l}\text { Multnomah } \\
\text { County }\end{array}$ & $\begin{array}{l}\text { Hawthorne } \\
\text { Bridge }\end{array}$ & $\begin{array}{l}\text { Principal Arterial } \\
\text { - Other }\end{array}$ & $\begin{array}{l}\text { North } \\
\text { Sidewalk }\end{array}$ & sidewalk & $\{$ W,E $\}$ & Download
\end{tabular}

\begin{tabular}{|l|l|l|l|}
\hline Fields & Required & Optional & Field Options or Information \\
\hline Organization & $\checkmark$ & & \\
\hline Jurisdiction & $\checkmark$ & & \\
\hline Description & $\checkmark$ & & $\begin{array}{l}\text { An internal reference number or other short } \\
\text { description for this device. }\end{array}$ \\
\hline Short name & & & $\begin{array}{l}\text { The manufacturer's serial number. Optional } \\
\text { but highly recommended. If unknown, write } \\
\text { "Unknown" along with identifier. }\end{array}$ \\
\hline Serial Number & & & $\begin{array}{l}\text { The manufacturer of the counting } \\
\text { device.Optional but highly recommended. If } \\
\text { unknown, write "Unknown." No identifier } \\
\text { needed. }\end{array}$ \\
\hline Make & & & \\
\hline
\end{tabular}




\begin{tabular}{|l|l|l|l|}
\hline Model & $\sqrt{ }$ & $\begin{array}{l}\text { The counting device model name.Optional } \\
\text { but highly recommended. If unknown, write } \\
\text { "Unknown." No identifier needed. }\end{array}$ \\
\hline
\end{tabular}

Sometimes serial number, make, or model will be unknown. "Unknown" may be used for these fields, but should also include more information such as the city name or detector identifier in one of these fields, i.e. "Unknown-Portland" for Serial Number.

Here is a non-exhaustive list of different detector makes and models.

\begin{tabular}{|c|c|c|}
\hline Correct makes & Correct models & Description \\
\hline Eco-Counter & ZELT & inductive loop \\
\hline Eco-Counter & TUBE & tube \\
\hline Eco-Counter & MULTI & $\begin{array}{l}\text { combination of } \\
\text { loop and } \\
\text { infrared }\end{array}$ \\
\hline Eco-Counter & MULTI Nature & $\begin{array}{l}\text { Combination of } \\
\text { ZELT/PYRO }\end{array}$ \\
\hline Eco-Counter & MULTI Urban & \\
\hline Eco-Counter & PYRO & $\begin{array}{l}\text { Passive } \\
\text { infrared }\end{array}$ \\
\hline Eco-Counter & CITIX-IR & $\begin{array}{l}\text { Overhead } \\
\text { passive infrared }\end{array}$ \\
\hline Eco-Counter & SLAB & pressure plate \\
\hline Eco-Counter & Eco-totem & $\begin{array}{l}\text { Zelt with real- } \\
\text { time display }\end{array}$ \\
\hline TRAFX & $\begin{array}{l}\text { Infrared Trail } \\
\text { Counter }\end{array}$ & \\
\hline Jamar & TRAX Cycles Plus & \\
\hline GTT & Canoga & \\
\hline TimeMark & Gamma & \\
\hline Diamond & TT6 & \\
\hline Reno A\&E & C-1100 B & \\
\hline Reno A\&E & C-1101 B & \\
\hline EDI & LM222 & \\
\hline MetroCount & MC 5600 & \\
\hline Trail Master & TM1550 & \\
\hline FLIR & & \\
\hline
\end{tabular}

If it is a manual counter:

- Description: Manual Counter 
- Short name, Serial Number, Make, and Model are all the First and Last name of the counter

- If the Manual Counter is not known simply put: "unknown" under all the Short name, Serial Number, Make, and Model

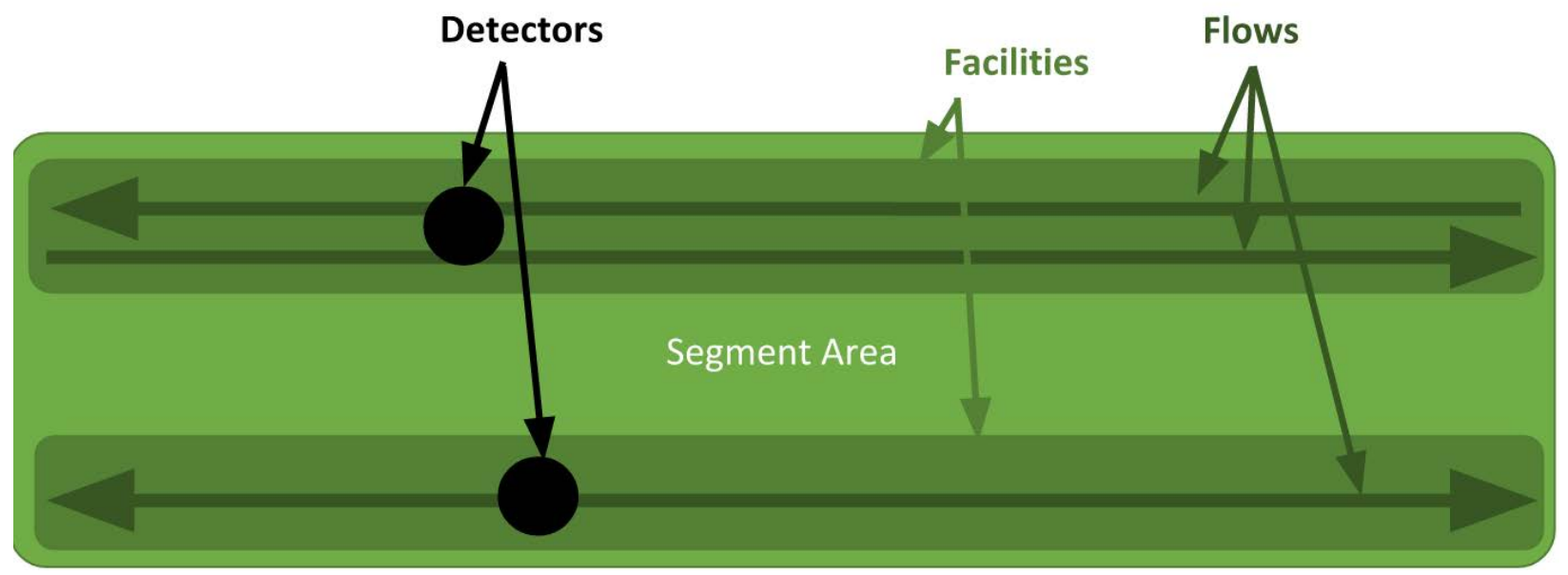

\section{Flow Detector}

Locating your detector on a map.

After selecting the Organization affiliated with your Segment Area (i.e., The City of Portland), the list of Detectors will appear along with the following:

- State

- County

- Segment Area

- Flow Direction

- Latitude and Longitude

Using Google Earth, you may find the detector by manually hunting, zooming and scrolling. Take the coordinates of your detector and use this to input for Latitude and Longitude in BikePed Portal.

Congratulations! You've completed the metadata input for your count site.

You will be directed to the Data Upload page where you will asked for the following fields affiliated with your count data.

- Organization

- Detector

- Flow

You can then choose to Add File.

By selecting this, an upload window will appear, allowing you to browse your computer for the data files. You can also click-and-drag the data files to the Bike-Ped Portal page for upload. 
Only .csv files are accepted for upload into Bike-Ped Portal.

When you are ready to upload, simply Start Upload to begin! You can upload multiple files at one time or drag and drop files into the upload user interface if you'd like.

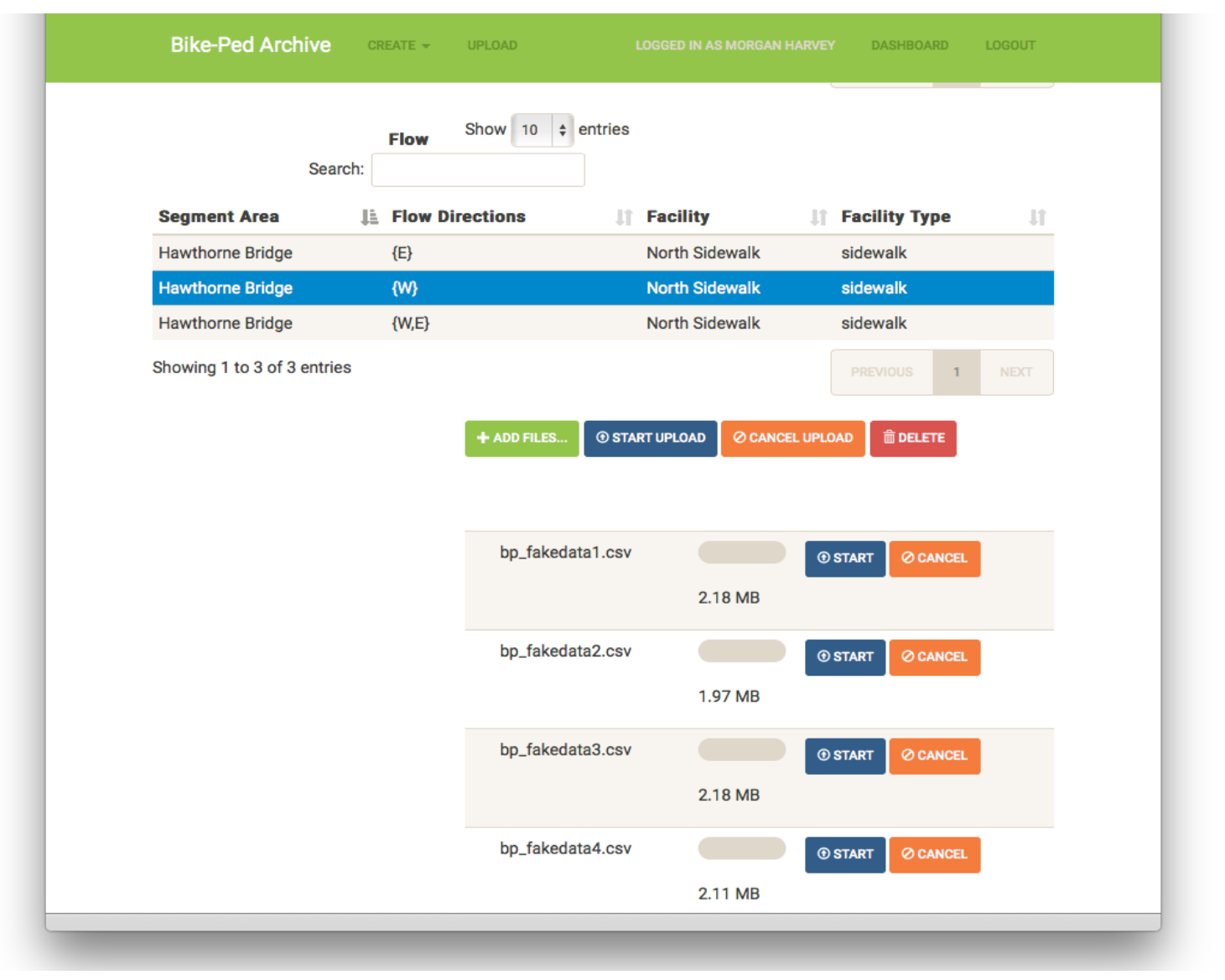

\section{Data Upload}

To upload data, the data must be properly formatted as listed in the "How To Format Your Data" guide below. Some important factors to consider:

- The data time-stamps should not overlap already uploaded data in the archive for that Segment Area's facility's flow.

- Each count record must be on a separate line.

- The count data cannot be left blank.

- The file should not contain blank rows or columns. 


\section{How to Format Your Data}

\section{Interpreting the csv file (opened in Notepad)}

Top three lines are for REFERENCE ONLY
The "start time" is the start time for the time
period during which count occurred. The header
must contain the words "start" and "time"
separated by an underscore, space, or nothing. Start
time must be in the following format:
YYYY-MM-DD HH:MM:SS

\section{Document Name}

This is completely up to you, the user, but we suggest that documents be labeled with some indication of what detector or station it is, some indication of the facility, and flow of traffic. For example, "Hawthorne_bike_NE.csv" indicates the location name (Hawthorne), the traffic flow counted (bike), the facility $(\bar{N})$, and direction of travel $(E)$.

Rules for document, or file, names:

- The filename must contain only letters, numbers and underscores.

- $\quad$ No spaces or special characters $\left(\$, /,-,{ }^{\wedge} \ldots\right)$.

- The file must end in *.csv.

- Don't use names longer than 200 characters. 


\section{Reference Lines}

Each file begins with three reference rows which are completely up to the user. Helpful information regarding segment area, flow types, flow directions, date range of data collected can be included in these first three rows.

Rules for Reference Lines:

- There is a limit of 1024 characters per line.

- These can be any text. It will be saved in the archive with the record of the upload.

- These lines are for reference only.

NOTE: The count will be linked to the Count Descriptor selected during the web upload process. The Reference lines are NOT used to link the count to a location or detector.

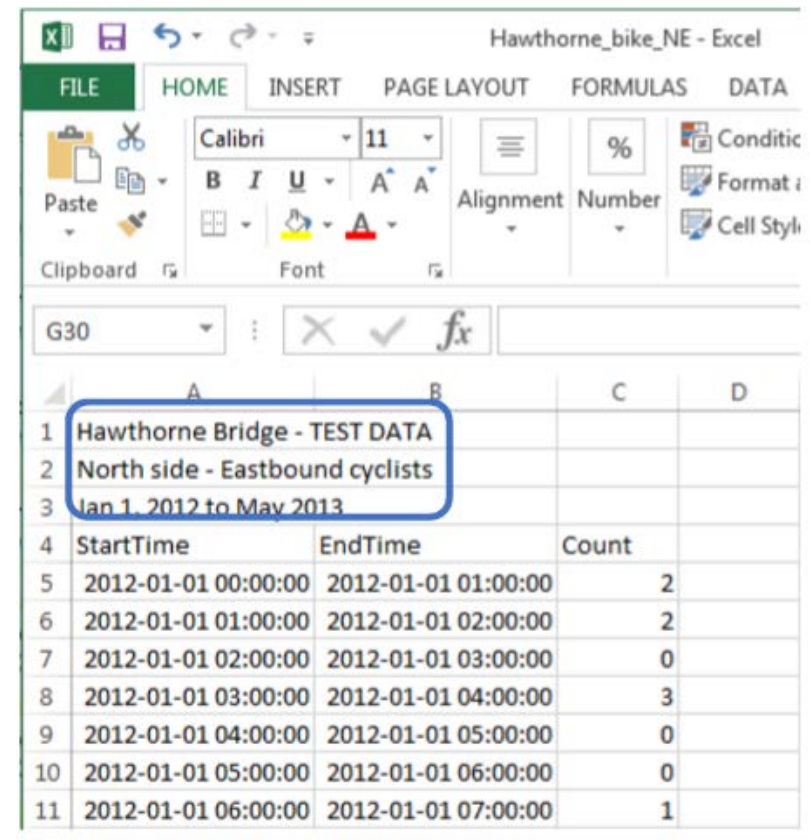

\section{Header Line}

The fourth row is the header line which must consist of one of the options below:

a)

\begin{tabular}{c|c|c|c|}
\hline 4 & A & B & C \\
\hline 1 & & & \\
\hline 2 & & & \\
\hline 3 & & & \\
\hline 4 & starttime endtime & count \\
\hline 5 & & &
\end{tabular}

b) 5

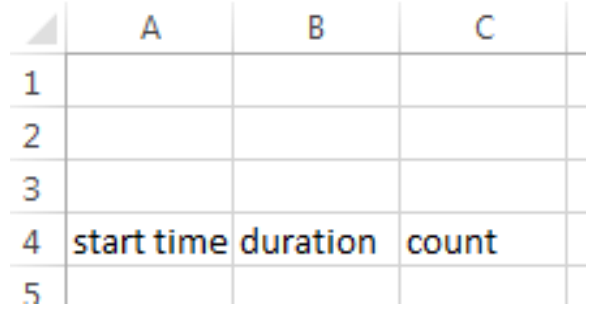

NOTE: The upload script must find these rows in order to properly upload the data. Ensure the 
data in the second column matches the format of the second column header.

- These headers are not case-sensitive.

\section{First Column - Start Time}

The first column of the count record is the start date and time of the count.

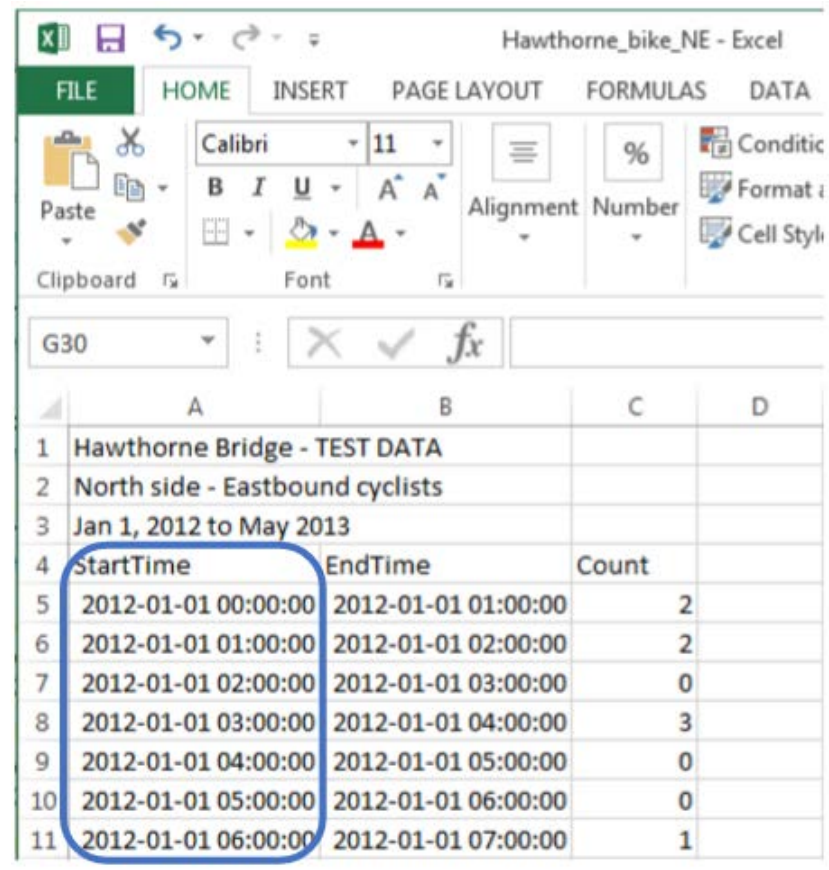

Required format is in 24-hour format:

YYYY-MM-DD HH:MM:SS

Converting Timestamps to the Accepted Format:

To convert your Start-Time column:

1) Select the relevant cells (column $A$ in this case)

2) Right click for options $>$ Format Cells

3) Copy and Paste "YYYY-MM-DD HH:MM:SS" (without quotes) into the text - box "Type:"

4) Select "OK" 


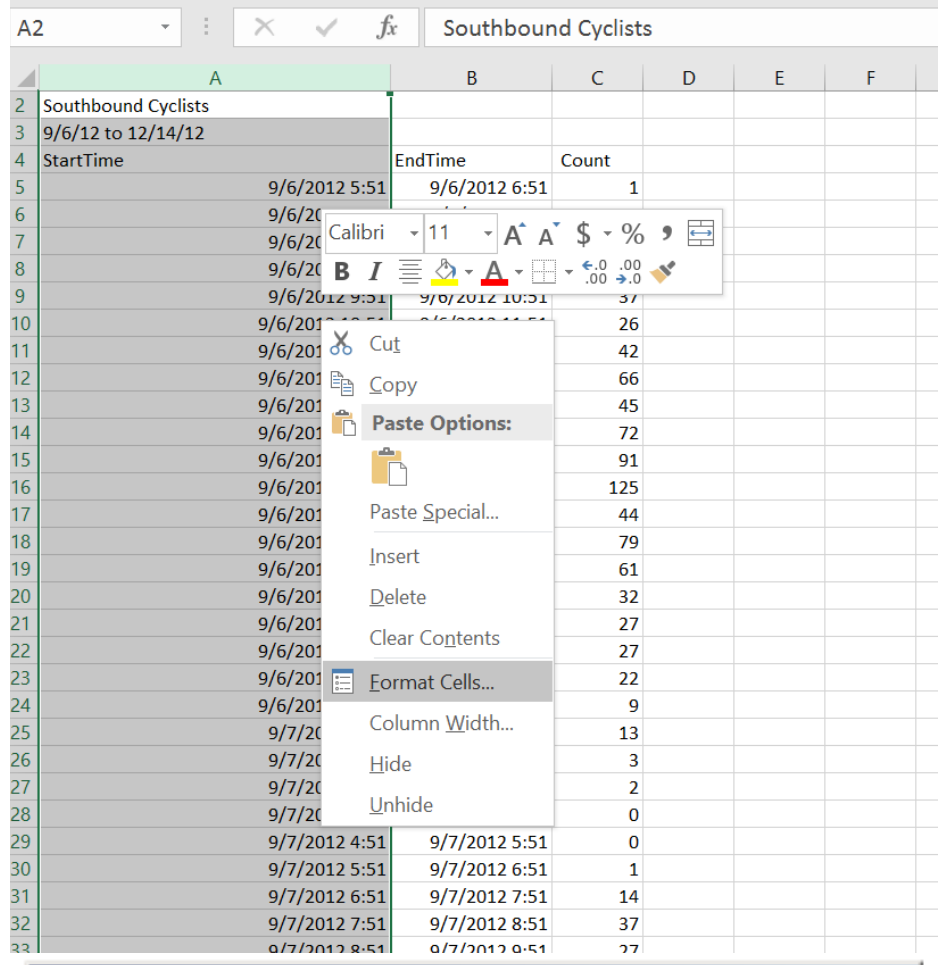

Format Cells $\quad$ ?|x

Number $\mid$ Alignment $\mid$ Font | Border | Fill | Protection

Sategory:

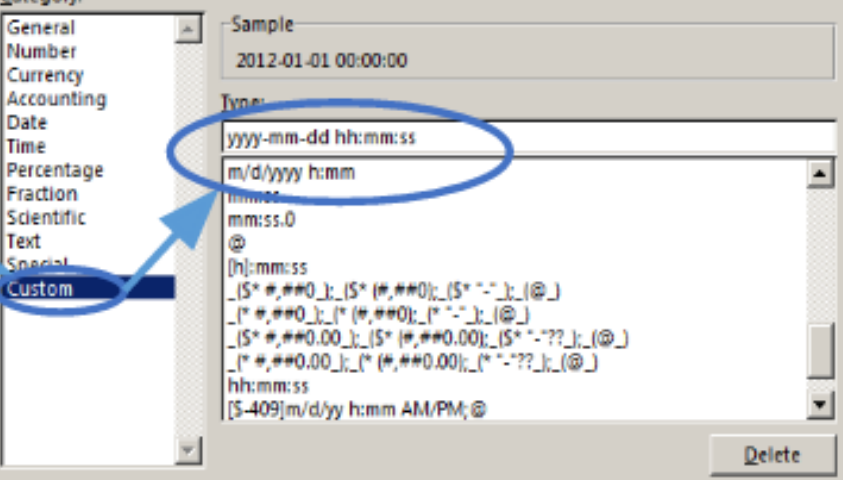

Type the number format code, using one of the existing codes as a starting point. 


\section{Second Column - End Time or Duration}

The second column may either be

(a) the end date-time of the count in YYYY-MM-DD HH:MM:SS format (refer to Converting Timestamps to the Accepted Format):

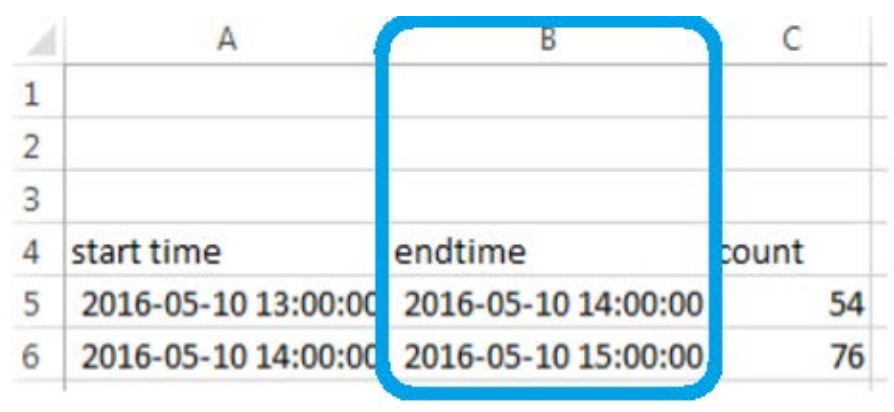

or (b) the duration of the count in hh:mm:ss time format:

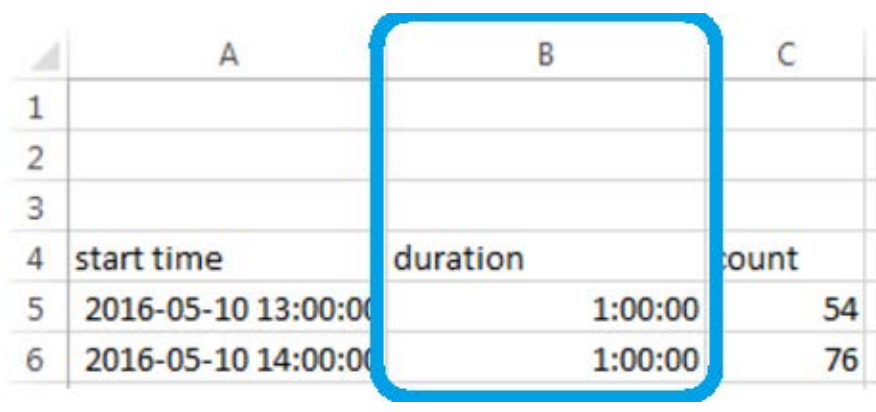

\section{Computing Duration}

Duration is the length of the time period during which counts occurred. For example, if 25 cyclists were counted between 5:30 PM and 6:00 PM, the duration would be 00:30:00.

If you only have start times counts in your file, duration can be calculated in Excel by subtracting the Date-Time in the following row from the Date-Time in the current row as shown below.

CAUTION: If daylight saving time is during the time period or if there are time gaps in the data, this approach can result in erroneous durations. If the count period for a file is consistent throughout, it is better to simply copy and past the standard duration down the column, rather than compute it. 


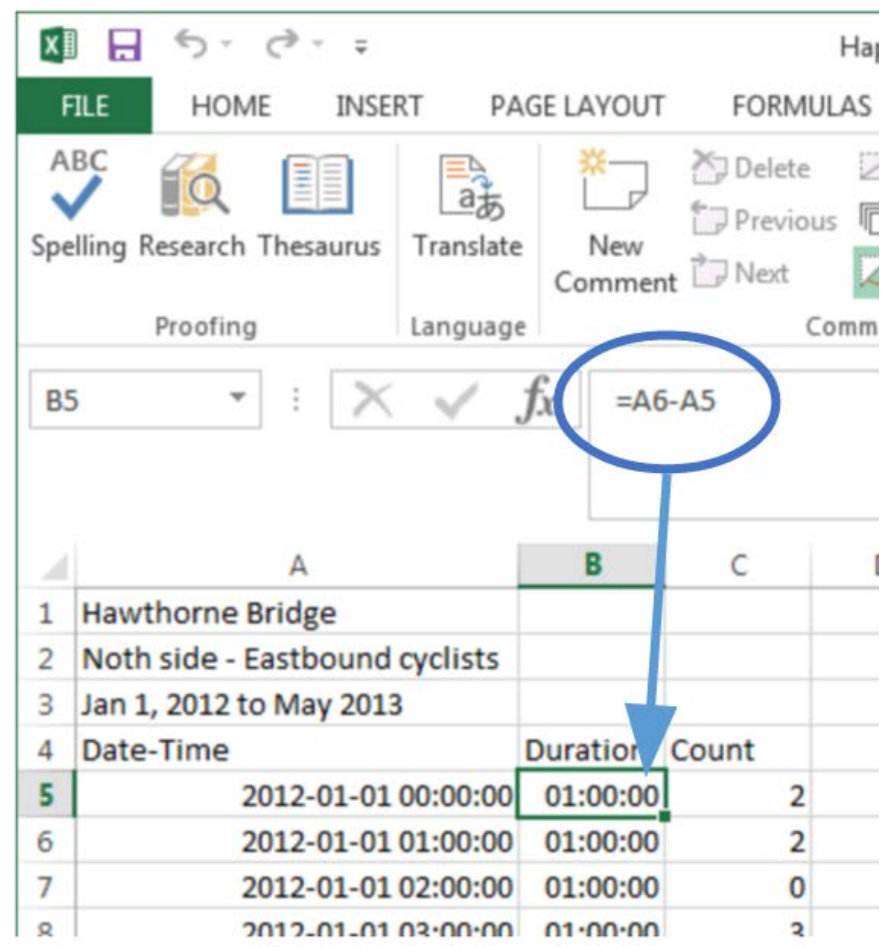

\section{Third Column - Count}

The third column is the Count column. Each row of the Count column represent the value of the count. If any blank counts exist, the file will not be accepted into Bike-Ped Portal. Help in finding blank rows or columns may be found in the Data Uploading Troubleshoot Guide.

\section{The Upload Process}

Using the Upload category, select Organization, Detector, and Flow for your data. Find the data file you want to upload by selecting Add File... or click-and-drag files onto the Bike-Ped Portal Upload page. Multiple files may be uploaded at one time.

Once the file successfully uploads, a graph of the data is provided to confirm to the user that the data was properly added to the database. Uploading data is not quick and the user should be patient as checks are made to ensure the file is properly formatted. If there is an error, an error message should appear in a red message box describing the problem.

A successful upload 


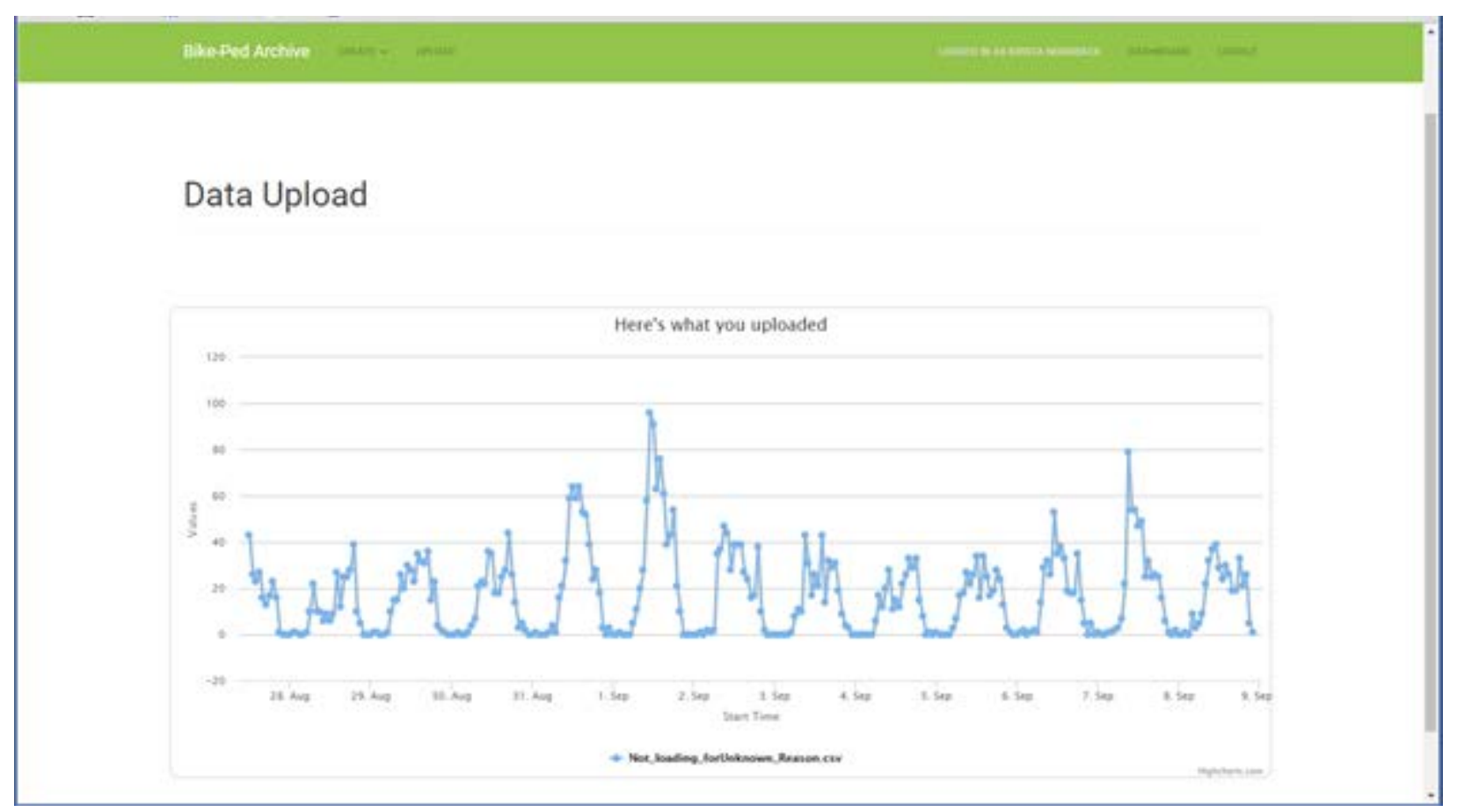

An unsuccessful upload: An error occurred while partitioning the data. Try checking for overlapping timestamps, incorrect headers, daylight savings time was not accounted for, or blank rows or columns.

Data Upload

\section{Data Uploading Troubleshoot Guide}


Issues may occur when attempting to upload. Be aware of the following instances that may prevent your data from uploading, and refer to this troubleshooting guide if problems occur when upload. Contact for further assistance if issues persist.

1. Blank rows or columns

2. Incorrect heading format

3. Duplicate values

4. Daylight Savings time is not accounted for

5. Multiple commas at the end of each of row

6. File size is too large

\section{Finding blank cells}

Blank cells are not allowed in the data portion of the spreadsheet (first 3 columns, starting with row 4).
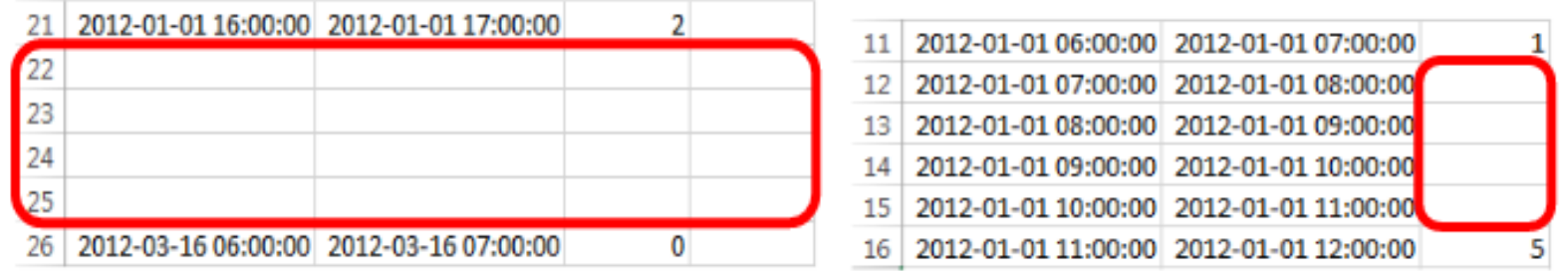

1) Using Excel, open the .csv file.

2) Select the columns of which you want to search for blank cells.

3) Go to Home $>$ Editing $>$ Find \& Select $>$ Go To Special...>Blanks

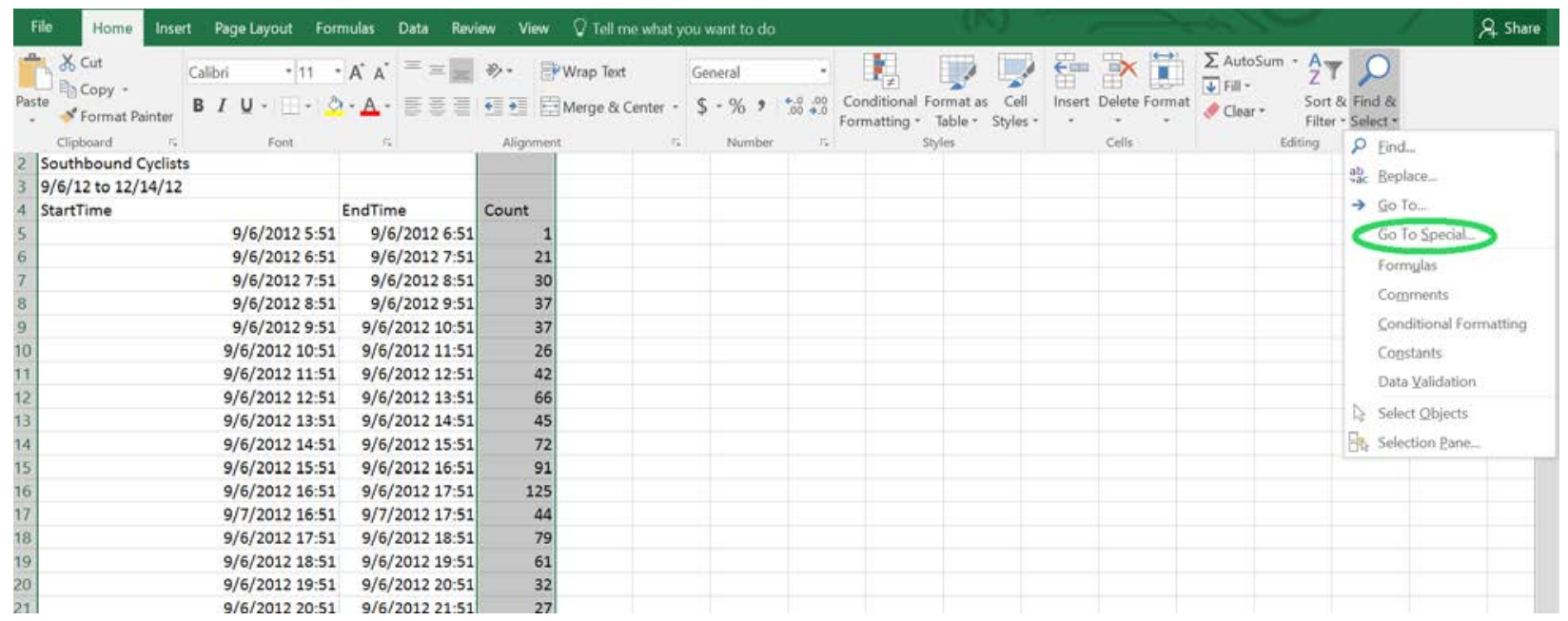

\section{Accepted heading formats}

The header on the fourth line can be either of the following, wth start time as the header of the first column, duration of the second, and count as the third. 
start time, duration,count start time,endtime,count

This is not sensitive to capitalization so "Start Time" and "start time" are equally valid. The words may be separated by a space, underscore, hyphen or no space.

\section{Duplicate values}

\section{Method 1:}

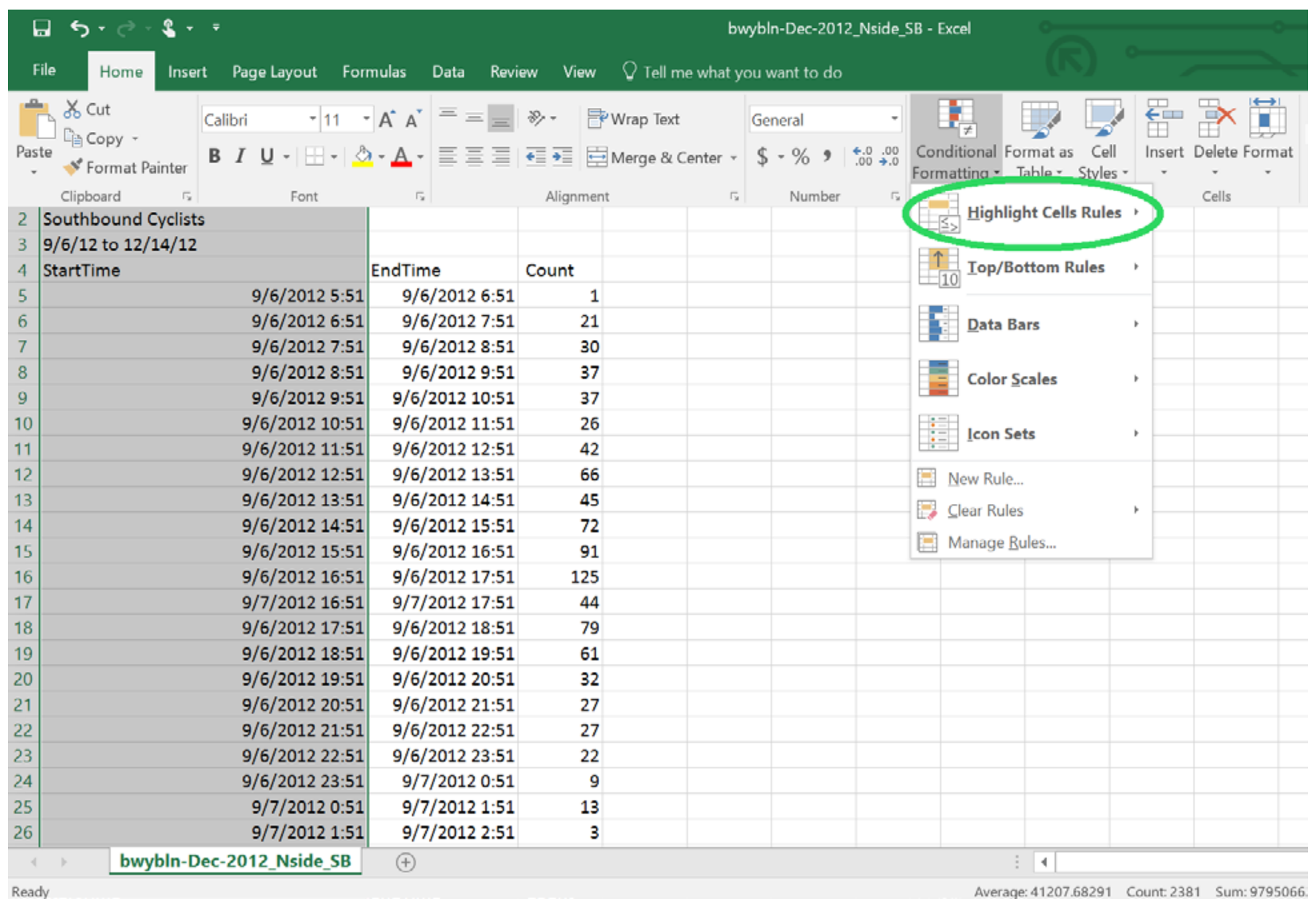

1) Select the columns of which you want to search for repeating time-stamps and dates.

2) Go to Home > Styles $>$ Conditional Formatting $>$ Highlight Cells Rules $>$ Duplicate Values

3) A prompt box will appear with the following message:

Format Cells that Contain: Duplicate values with....

4) Select Duplicate in the dropdown menu and your highlight option of your choice. 


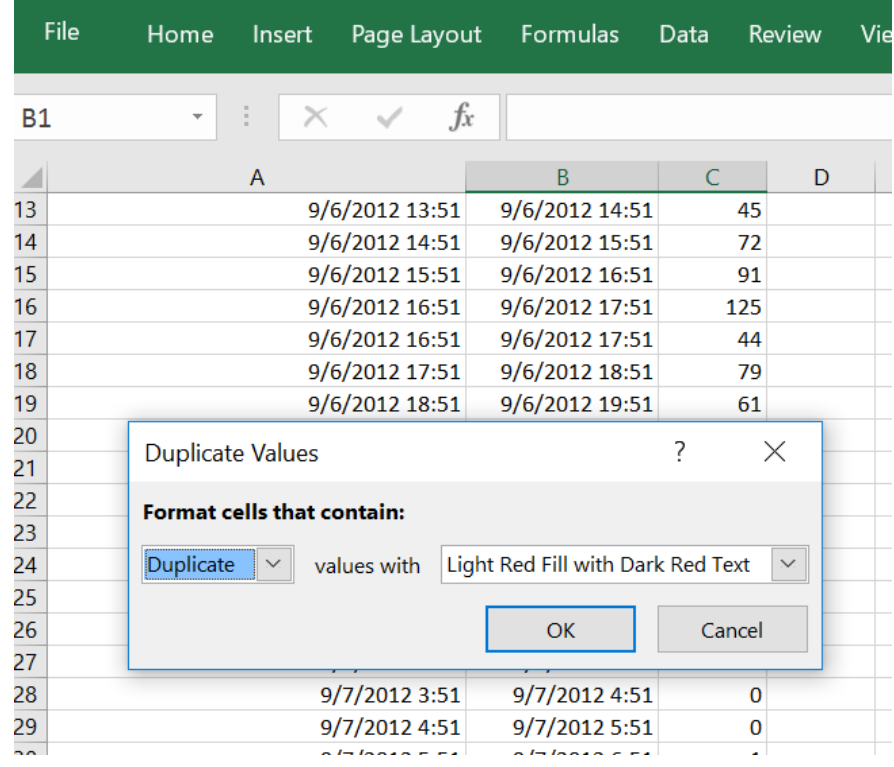

Duplicate values in your data will appear highlighted. Scroll through the file to find all duplicate values that have been detected.

\begin{tabular}{|r|r|r|r|}
\hline 90 & $9 / 9 / 201217: 51$ & $9 / 9 / 2012 ~ 18: 51$ & 24 \\
\hline 91 & $9 / 9 / 201218: 51$ & $9 / 9 / 201219: 51$ & 14 \\
\hline 92 & $9 / 9 / 201219: 51$ & $9 / 9 / 201220: 51$ & 21 \\
\hline 93 & $9 / 9 / 201220: 51$ & $9 / 9 / 201221: 51$ & 12 \\
\hline 95 & $9 / 9 / 201221: 51$ & $9 / 9 / 201222: 51$ & 12 \\
\hline 96 & $9 / 9 / 201222: 51$ & $9 / 9 / 201223: 51$ & 7 \\
\hline 97 & $9 / 9 / 201223: 51$ & $9 / 10 / 20120: 51$ & 2 \\
\hline 98 & $9 / 10 / 20120: 51$ & $9 / 10 / 20121: 51$ & 3 \\
\hline 99 & $9 / 10 / 20121: 51$ & $9 / 10 / 20122: 51$ & 1 \\
\hline 100 & $9 / 10 / 20121: 51$ & $9 / 10 / 20122: 51$ & 1 \\
\hline 101 & $9 / 10 / 20122: 51$ & $9 / 10 / 20123: 51$ & 1 \\
\hline 102 & $9 / 10 / 20123: 51$ & $9 / 10 / 20124: 51$ & 0 \\
\hline 103 & $9 / 10 / 20124: 51$ & $9 / 10 / 20125: 51$ & 1 \\
\hline 105 & $9 / 10 / 20125: 51$ & $9 / 10 / 20126: 51$ & 2 \\
\hline 106 & $9 / 10 / 20126: 51$ & $9 / 10 / 2012 ~ 7: 51$ & 22 \\
\hline 107 & $9 / 10 / 20127: 51$ & $9 / 10 / 20128: 51$ & 35 \\
\hline & $9 / 10 / 20128: 51$ & $9 / 10 / 20129: 51$ & 29 \\
\hline
\end{tabular}

The counts should be the same for the repeated hour. If not, further investigation is required to decide which count should be taken.

Method 2:

Duplicate values can also be removed by navigating to the Data tab>Remove Duplications 


\begin{tabular}{|l|l|l|l|l|l|}
\hline Formulas Data & Review View & Tell me what you want to do \\
\hline
\end{tabular}

A Remove Duplicates dialog box will appear asking which columns to search for duplicate values. Do not select Column C since similar count values may exist from one hour to the next.

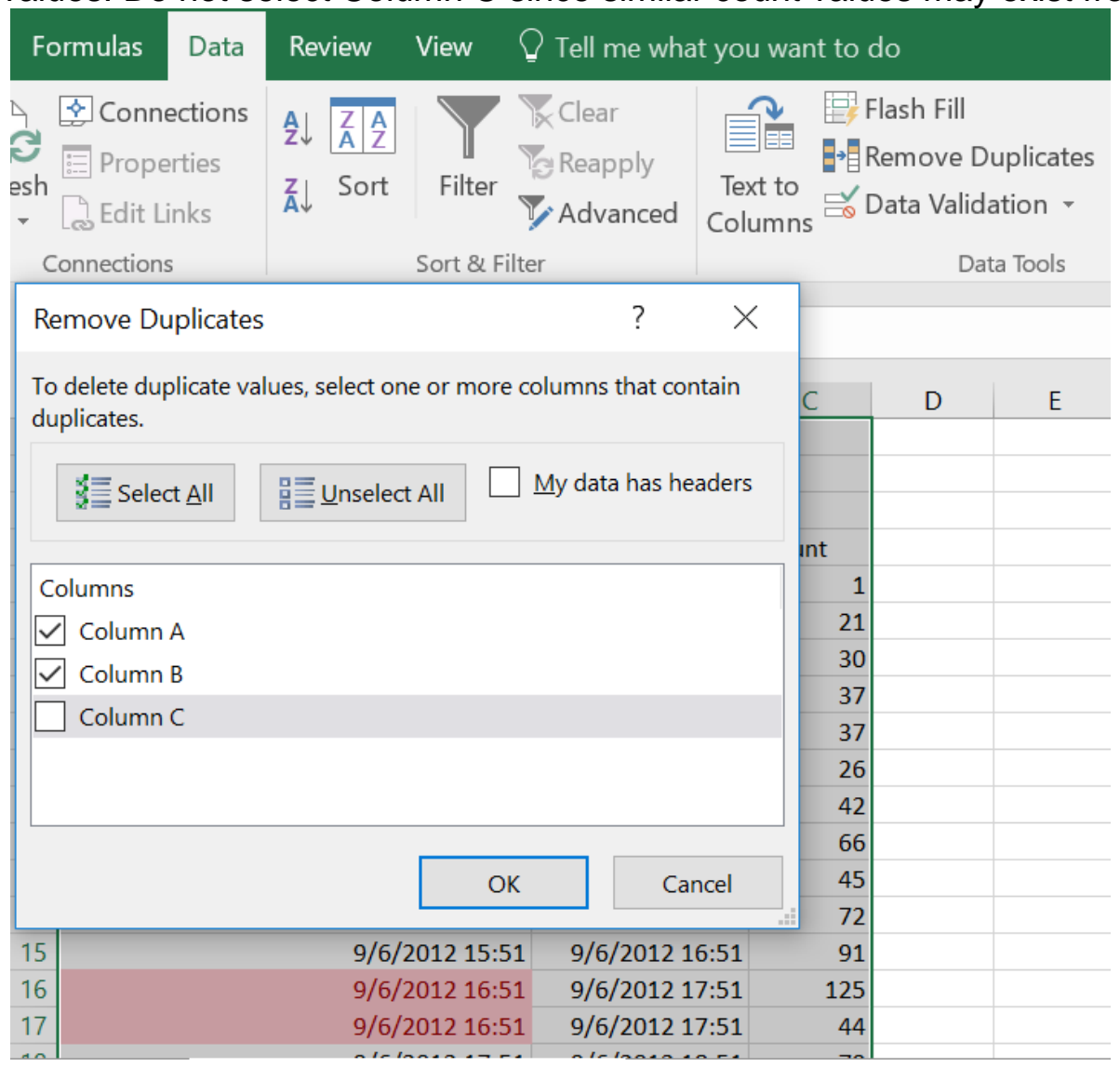




\section{Adjusting for Daylight Savings Time}

All timestamps must include time zone indicators. This can be done using the international standard ISO 8601, which looks like this: 2015-04-19T02:59:23-08:00.

If you are able to do so, format your timestamps in this way and daylight savings time will not be a problem.

If you are unable to format your timestamps in this way, then each timestamp will need to be adjusted to include a UTC timezone offset. Every year, two days of daylight savings time change occurs: one day in the springtime, an hour is skipped at 2 am and another day in the fall, an hour is repeated at 2 am.

\section{Adjusting for Daylights Savings Time by Case}

The detector that collected the data will determine if UTC time zone offset will change on these daylights savings days. Different detector manufacturers/models may adjust for daylight savings automatically (e.g, many EcoCounter models), while others may not at all (e.g., TRAFx Infrared Trail counters). Consider the following cases:

- If the detector's settings DO account for daylight savings (i.e., in the data if the timestamp skips one hour in the spring, and duplicates one hour in the fall), data will require adjustment using two UTC time zone offsets (i.e., for Portland, -08:00 is used at the end of each time stamp during standard time and -07:00 for daylight savings time)

$$
\begin{aligned}
& \text { 2010-03-14 00:00:00-08:00 }=8 \text { AM UTC time } \\
& \text { 2010-03-14 01:00:00-08:00 }=9 \text { AM UTC time } \\
& \text { 2010-03-14 03:00:00-07:00 }=10 \text { AM UTC time } \\
& \text { 2010-03-14 04:00:00-07:00 }=11 \text { AM UTC time } \\
& \text { 2010-03-14 05:00:00-07:00 }=12 \text { PM UTC time }
\end{aligned}
$$

- If the detector's settings DO NOT account for daylight savings (i.e., timestamps are continuous at the times of daylight savings time changes), data will only require a single UTC time zone offset.

$$
\begin{aligned}
& \text { 2010-03-14 00:00:00-08:00 }=8 \text { AM UTC time } \\
& \text { 2010-03-14 01:00:00-08:00 }=9 \text { AM UTC time } \\
& \text { 2010-03-14 02:00:00-08:00 = } 10 \text { AM UTC time } \\
& \text { 2010-03-14 03:00:00-08:00 }=11 \text { AM UTC time } \\
& \text { 2010-03-14 04:00:00-08:00 }=12 \text { PM UTC time }
\end{aligned}
$$

- If the detector stores each count in "PER VEHICLE" FORMAT, or each count as it's own unique event where duration of time isn't standard throughout the data, the counts must first be "binned" into a standard duration of time throughout the file (e.g., 15 min or $1 \mathrm{hr}$ bins using a Pivot Table in Excel). It is likely that there will be missing bins that will appear as data gaps. You will want to create a time series (see below for step-by-step instructions) for the entire data series that includes these missing bins and sets their corresponding counts to zero (since no counts were recorded during these times). However, be careful not to include real data gaps when creating the time series (e.g., gaps between shuttle files that do not overlap) because that will produce false zeroes. Then, a single UTC time zone offset is applied to each timestamp if no skipped hour/duplicated hour occurs. 


\section{Creating a Time Series}

1) In a new Excel spreadsheet, copy the DateTime in Column A and Total Count in Column C from Pivot Table data.

2) Convert DateTime to text in Column B and label the column "TEXTDateTime", keeping Count as Column C using this formula: B2=TEXT(A2,"yyyy-mm-dd hh:mm:ss")

3) Label Column D as "StartTime"

a) Copy/paste special as values cell $A 2$ into cell $D 2$

b) An one hour to D2 using this formula: $\mathrm{D} 3=\mathrm{D} 2+\mathrm{TIME}(1,0,0)$

c) Copy the formula down the column

d) Go to the bottom of the column. Continue copying the column down to complete the Time Series you need.

4) Label Column E as "Count"

a) Use VLOOKUP and IFERROR to look up the Count and insert 0 for missing StartTimes from Column A using the formula:

E2 =IFERROR(VLOOKUP(TEXT(D2,"yyyy-mm-dd hh:mm:ss"),\$B\$2:\$C\$value, 2,FALSE),0)

i) Adjust $\underline{C}$-value to the correct size of the table array for the VLOOKUP

b) Copy the formula down the column and confirm it worked correctly

5) Copy StartTime and Count (Columns D and E) to a new Excel Spreadsheet

\section{Adjusting Data using a Single UTC Time Zone Offset}

Choosing which UTC time zone offset to use throughout each data file, whether it is daylight savings or standard UTC timezone offset, will depend on the detector's manufacturer make and model. Check with the manufacturer to find which timezone the data is stored in.

1. Copy this formula into a blank field apart from the first three columns. Copy by typing it exactly how it is written below:

=TEXT(A5, “YYYY-MM-DD hh:mm:ss") \& “-07:00”

2. Click-and-drag the bottom right corner of the field to the end of the values, or Ctrl+Shift+Down then Ctrl+D to fill the fields.

3. Copy the column you've created to include time zone indicators and paste values into the time column you are adjusting (Column A or Column B).

4. Delete the column you've created apart from the first three columns.

The ending timestamp "-07:00" will depend on

a. If data is in Standard Time or Savings Time

b. The city where the counts were taken (Eastern time, Mountain time, Pacific time, etc.) 
For data files that skip an hour in the spring and duplicate an hour in the fall during daylight savings days, adjust data files by following these steps:

1. Create a new sheet in your data file spreadsheet and call it 'Daylight Savings Dates'.

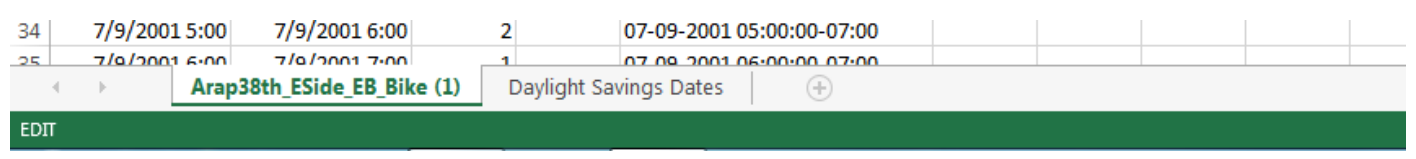

2. In the 'Daylight Savings Dates' sheet, copy and paste the values from this Daylight Savings Dates spreadsheet. The spreadsheet values should occupy columns A, B, and $\mathrm{C}$, similar to the image shown below:

\begin{tabular}{|c|c|c|c|}
\hline & A & B & C \\
\hline 1 & Year & Date & End \\
\hline 2 & 1998 & $4 / 5 / 982: 00$ & $10 / 25 / 982: 00$ \\
\hline 3 & 1999 & 4/4/99 2:00 & $10 / 31 / 992: 00$ \\
\hline 4 & 2000 & $4 / 2 / 002: 00$ & $10 / 29 / 002: 00$ \\
\hline 5 & 2001 & $4 / 1 / 012: 00$ & $10 / 28 / 012: 00$ \\
\hline 6 & 2002 & $4 / 7 / 022: 00$ & $10 / 27 / 022: 00$ \\
\hline 7 & 2003 & $4 / 6 / 032: 00$ & $10 / 26 / 032: 00$ \\
\hline 8 & 2004 & $4 / 4 / 042: 00$ & $10 / 31 / 042: 00$ \\
\hline 9 & 2005 & $4 / 3 / 052: 00$ & $10 / 30 / 052: 00$ \\
\hline 10 & 2006 & $4 / 2 / 062: 00$ & $10 / 29 / 062: 00$ \\
\hline 11 & 2007 & $3 / 11 / 07$ 2:00 & $11 / 4 / 07$ 2:00 \\
\hline 12 & 2008 & $3 / 9 / 082: 00$ & $11 / 2 / 082: 00$ \\
\hline 13 & 2009 & $3 / 8 / 092: 00$ & $11 / 1 / 092: 00$ \\
\hline 14 & 2010 & $3 / 14 / 102: 00$ & $11 / 7 / 102: 00$ \\
\hline 15 & 2011 & $3 / 13 / 112: 00$ & $11 / 6 / 112: 00$ \\
\hline 16 & 2012 & $3 / 11 / 122: 00$ & $11 / 4 / 122: 00$ \\
\hline 17 & 2013 & $3 / 10 / 132: 00$ & $11 / 3 / 132: 00$ \\
\hline 18 & 2014 & $3 / 9 / 142: 00$ & $11 / 2 / 142: 00$ \\
\hline 19 & 2015 & $3 / 8 / 152: 00$ & $11 / 1 / 152: 00$ \\
\hline 20 & 2016 & $3 / 13 / 162: 00$ & $11 / 6 / 162: 00$ \\
\hline
\end{tabular}

3. Return to Sheet\#1, your count data spreadsheet, and copy this formula into a blank field of a blank column apart from the rest of the data.

$=$ IF(AND(A5>=VLOOKUP(YEAR(A5),'Daylight Savings Dates'! \$A $\$$ 2:\$C20,2,FALSE),A5<VLOOKUP(YEAR(A5),'Daylight Savings Dates'!\$A 2:\$C\$20,3,FALSE)),TEXT(A5,"YYYY-MM-DD HH:MM:SS")\&"-07:00",TEXT(A5,"YYYY-MM-DD HH:MM:SS")\&"-08:00")

$>$ Note: The time zone indicators "-07:00" and "-08:00" will change according to which timezone the count data was taken. These specific indicators are used for Pacific Time time zone (Pacific Daylight Time and Pacific Standard time, respectively) for cities such as Portland, OR, Seattle, WA, Los Angeles, CA. Alter the above formula according to which UTC time zone indicator your count data was taken. 


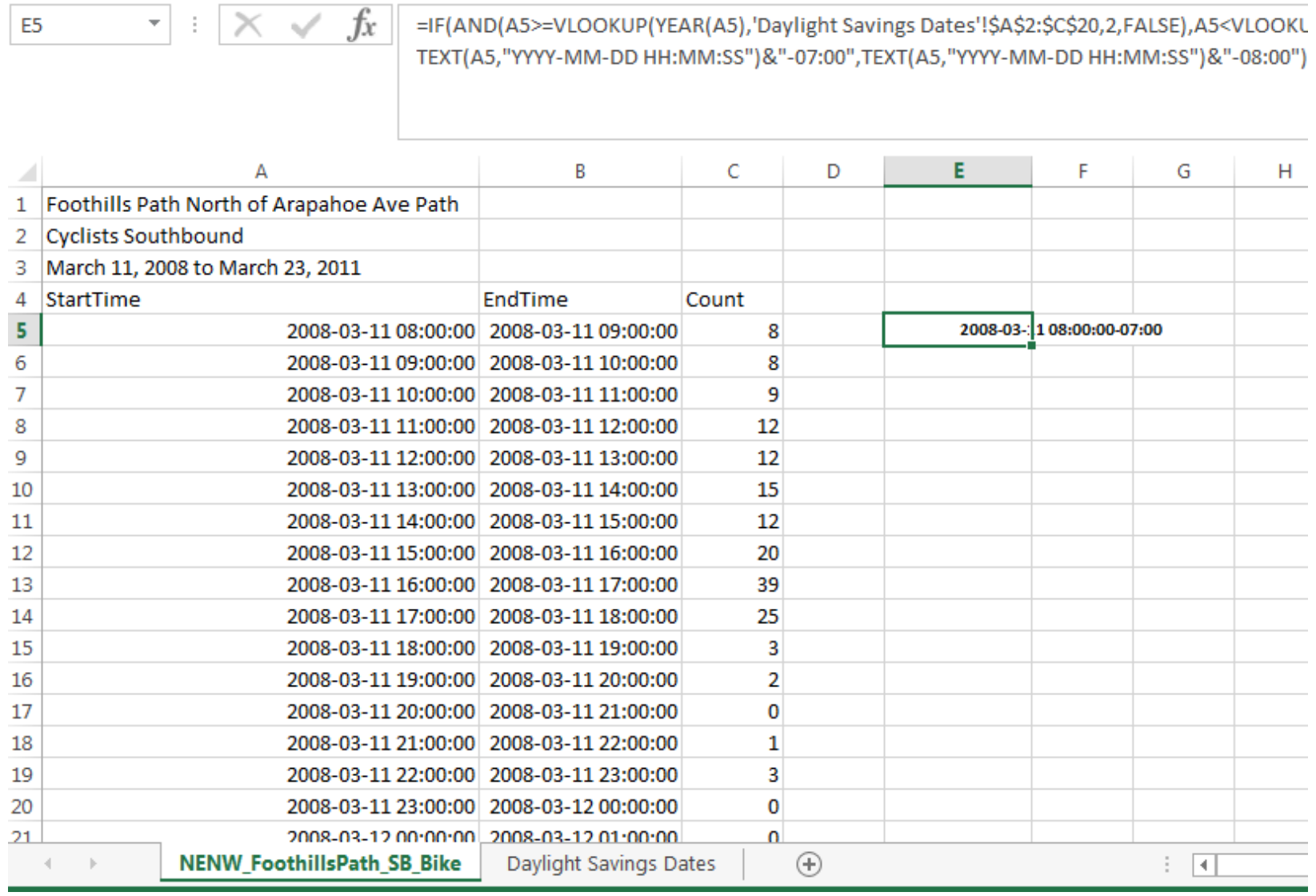

4. Double-click the lower right-hand corner of the field where you input the above formula. This will fill-in the rest of the column using the column A timestamps

If double-clicking the bottom-right corner doesn't work, navigate to the name box and input the range of fields for the column you chose to input the formula:

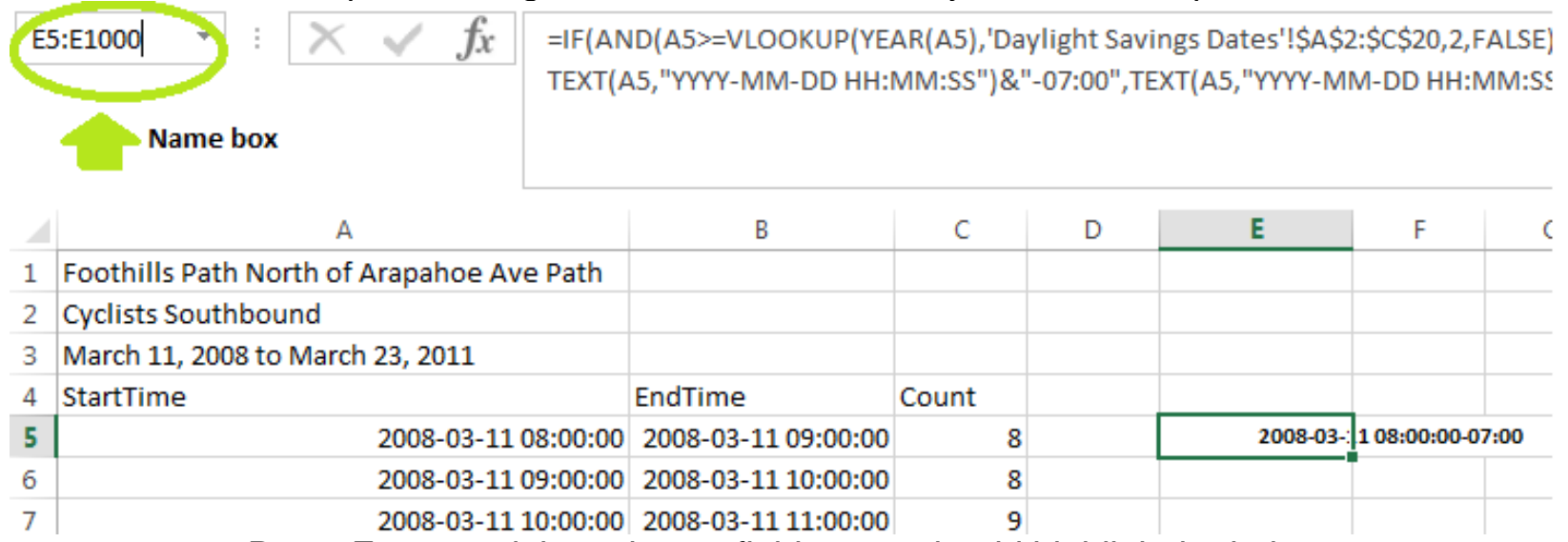

$>$ Press Enter, and the columns field range should highlight in dark grey: 


\begin{tabular}{|c|c|c|c|c|c|c|c|c|}
\hline 4 & & A & B & C & D & $\mathbf{E}$ & $\mathrm{F}$ & G \\
\hline 1 & Foothills $\mathrm{Pa}$ & th North of Arapahoe Ave Path & & & & & & \\
\hline 2 & Cyclists Sou & thbound & & & & & & \\
\hline 3 & March 11, 2 & 08 to March 23, 2011 & & & & & & \\
\hline 4 & StartTime & & EndTime & Count & & & & \\
\hline 5 & & 2008-03-11 08:00:00 & 2008-03-11 09:00:00 & 8 & & 2008-03- & $108: 00: 00-07: 0$ & \\
\hline 6 & & 2008-03-11 09:00:00 & 2008-03-11 10:00:00 & 8 & & & & \\
\hline 7 & & 2008-03-11 10:00:00 & 2008-03-11 11:00:00 & 9 & & & & \\
\hline 8 & & 2008-03-11 11:00:00 & 2008-03-11 12:00:00 & 12 & & & & \\
\hline 9 & & 2008-03-11 12:00:00 & 2008-03-11 13:00:00 & 12 & & & & \\
\hline 10 & & 2008-03-11 13:00:00 & 2008-03-11 14:00:00 & 15 & & & & \\
\hline 11 & & 2008-03-11 14:00:00 & 2008-03-11 15:00:00 & 12 & & & & \\
\hline 12 & & 2008-03-11 15:00:00 & 2008-03-11 16:00:00 & 20 & & & & \\
\hline 13 & & 2008-03-11 16:00:00 & 2008-03-11 17:00:00 & 39 & & & & \\
\hline 14 & & 2008-03-11 17:00:00 & 2008-03-11 18:00:00 & 25 & & & & \\
\hline 15 & & 2008-03-11 18:00:00 & 2008-03-11 19:00:00 & 3 & & & & \\
\hline 16 & & 2008-03-11 19:00:00 & 2008-03-11 20:00:00 & 2 & & & & \\
\hline 17 & & 2008-03-11 20:00:00 & 2008-03-11 21:00:00 & 0 & & & & \\
\hline 18 & & 2008-03-11 21:00:00 & 2008-03-11 22:00:00 & 1 & & & & \\
\hline 19 & & 2008-03-11 22:00:00 & 2008-03-11 23:00:00 & 3 & & & & \\
\hline 20 & & 2008-03-11 23:00:00 & 2008-03-12 00:00:00 & 0 & & & & \\
\hline 21 & & วกก:-กร-1 $12 n \cdot n n \cdot n n$ & 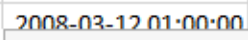 & $n$ & & & & \\
\hline & , & NENW_FoothillsPath_SB_Bike & Daylight Savings Da & & † & & & $\vdots$ \\
\hline
\end{tabular}

Press Ctrl $+\mathrm{D}$ and all fields should fill with the formula as defined in the first field of the column:

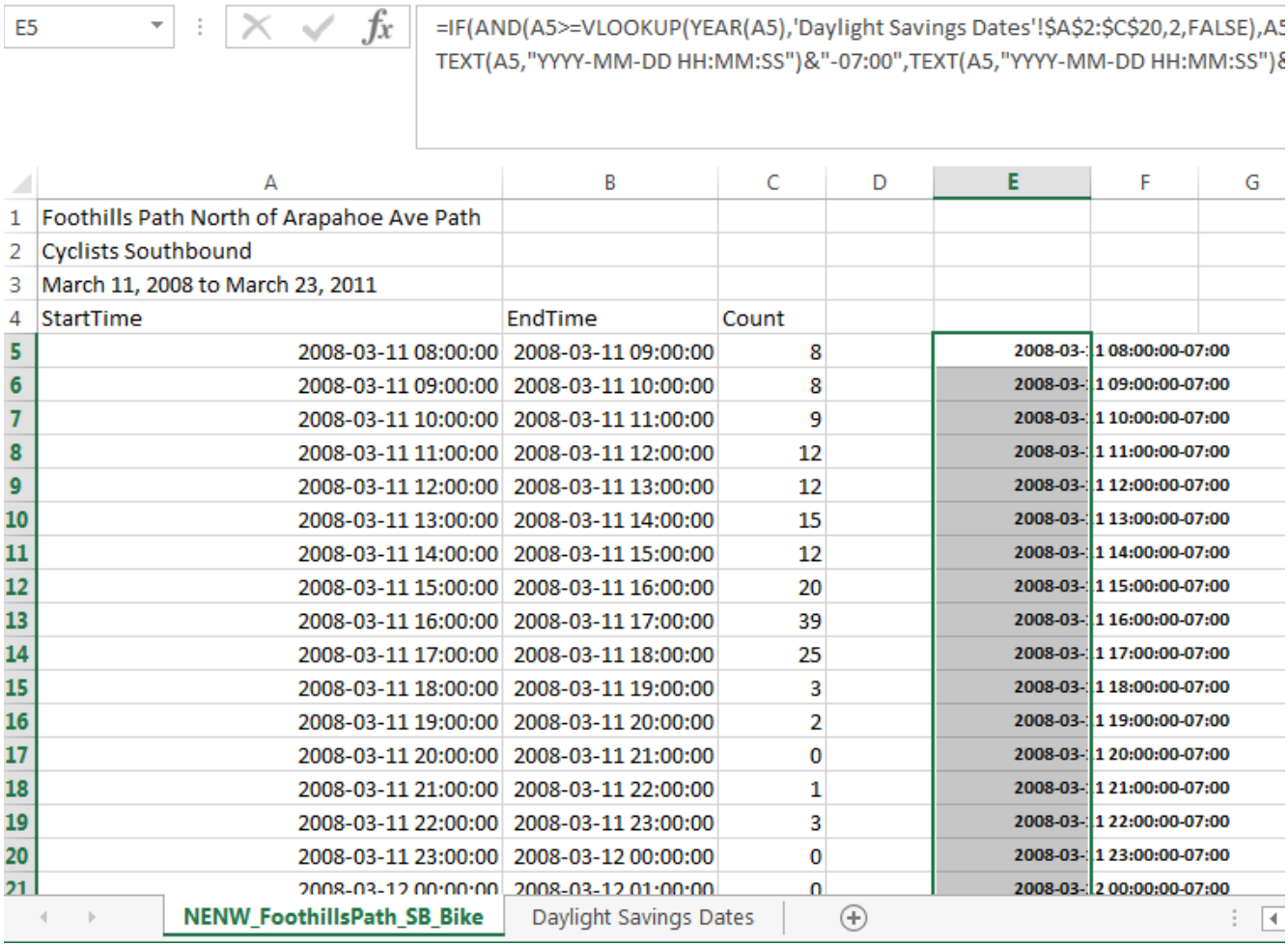

\section{Double check that at 2:00 AM on the day that time change occurs, the time zone indicator also changes.}




\begin{tabular}{|c|c|c|c|c|c|}
\hline 4 & A & B & $\mathrm{C}$ & D & E \\
\hline$i 458$ & 2009-03-07 11:00:00 & 2009-03-07 12:00:00 & 1 & & 2009-03-07 11:00:00-08:00 \\
\hline i459 & 2009-03-07 12:00:00 & 2009-03-07 13:00:00 & 0 & & 2009-03-07 12:00:00-08:00 \\
\hline$i 460$ & 2009-03-07 13:00:00 & 2009-03-07 14:00:00 & 0 & & 2009-03-07 13:00:00-08:00 \\
\hline 461 & 2009-03-07 14:00:00 & 2009-03-07 15:00:00 & 0 & & 2009-03-07 14:00:00-08:00 \\
\hline i462 & 2009-03-07 15:00:00 & 2009-03-07 16:00:00 & 0 & & 2009-03-07 15:00:00-08:00 \\
\hline$i 463$ & 2009-03-07 16:00:00 & 2009-03-07 17:00:00 & 0 & & 2009-03-07 16:00:00-08:00 \\
\hline$i 464$ & 2009-03-07 17:00:00 & 2009-03-07 18:00:00 & 0 & & 2009-03-07 17:00:00-08:00 \\
\hline$i 465$ & 2009-03-07 18:00:00 & 2009-03-07 19:00:00 & 0 & & 2009-03-07 18:00:00-08:00 \\
\hline$i 466$ & 2009-03-07 19:00:00 & 2009-03-07 20:00:00 & 0 & & 2009-03-07 19:00:00-08:00 \\
\hline 467 & 2009-03-07 20:00:00 & 2009-03-07 21:00:00 & 0 & & 2009-03-07 20:00:00-08:00 \\
\hline 4688 & 2009-03-07 21:00:00 & 2009-03-07 22:00:00 & 0 & & 2009-03-07 21:00:00-08:00 \\
\hline 469 & 2009-03-07 22:00:00 & 2009-03-07 23:00:00 & 0 & & 2009-03-07 22:00:00-08:00 \\
\hline$i 470$ & 2009-03-07 23:00:00 & 2009-03-08 00:00:00 & 0 & & 2009-03-07 23:00:00-08:00 \\
\hline i471 & 2009-03-08 00:00:00 & 2009-03-08 01:00:00 & 0 & & 2009-03-08 00:00:00-08:00 \\
\hline 4772 & 2009-03-08 01:00:00 & 2009-03-08 02:00:00 & 0 & & 2009-03-08 01:00:00-08:00 \\
\hline 473 & 2009-03-08 02:00:00 & 2009-03-08 03:00:00 & 0 & & 2009-03-08 02:00:00-07:00 \\
\hline 4474 & 2009-03-08 03:00:00 & 2009-03-08 04:00:00 & 0 & & 2009-03-08 03:00:00-07:00 \\
\hline i475 & 2009-03-08 04:00:00 & 2009-03-08 05:00:00 & 0 & & 2009-03-08 04:00:00-07:00 \\
\hline
\end{tabular}

6. Repeat Steps \#3-5 for EndTime column (if EndTime is used as opposed to Duration) by altering the formula in Step \#3, changing A5 values in the formula to B5.

\section{$=$ IF(AND(B5>=VLOOKUP(YEAR(B5),'Daylight Savings Dates'!\$A 2:\$C\$20,2,FALSE),B5<VLOOKUP(YEAR(B5),'Daylight Savings Dates'!\$A 2:\$C\$20,3,FALSE)),TEXT(B5,"YYYY-MM-DD HH:MM:SS")\&"-07:00",TEXT(B5,"YYYY-MM-DD HH:MM:SS")\&"-08:00")}

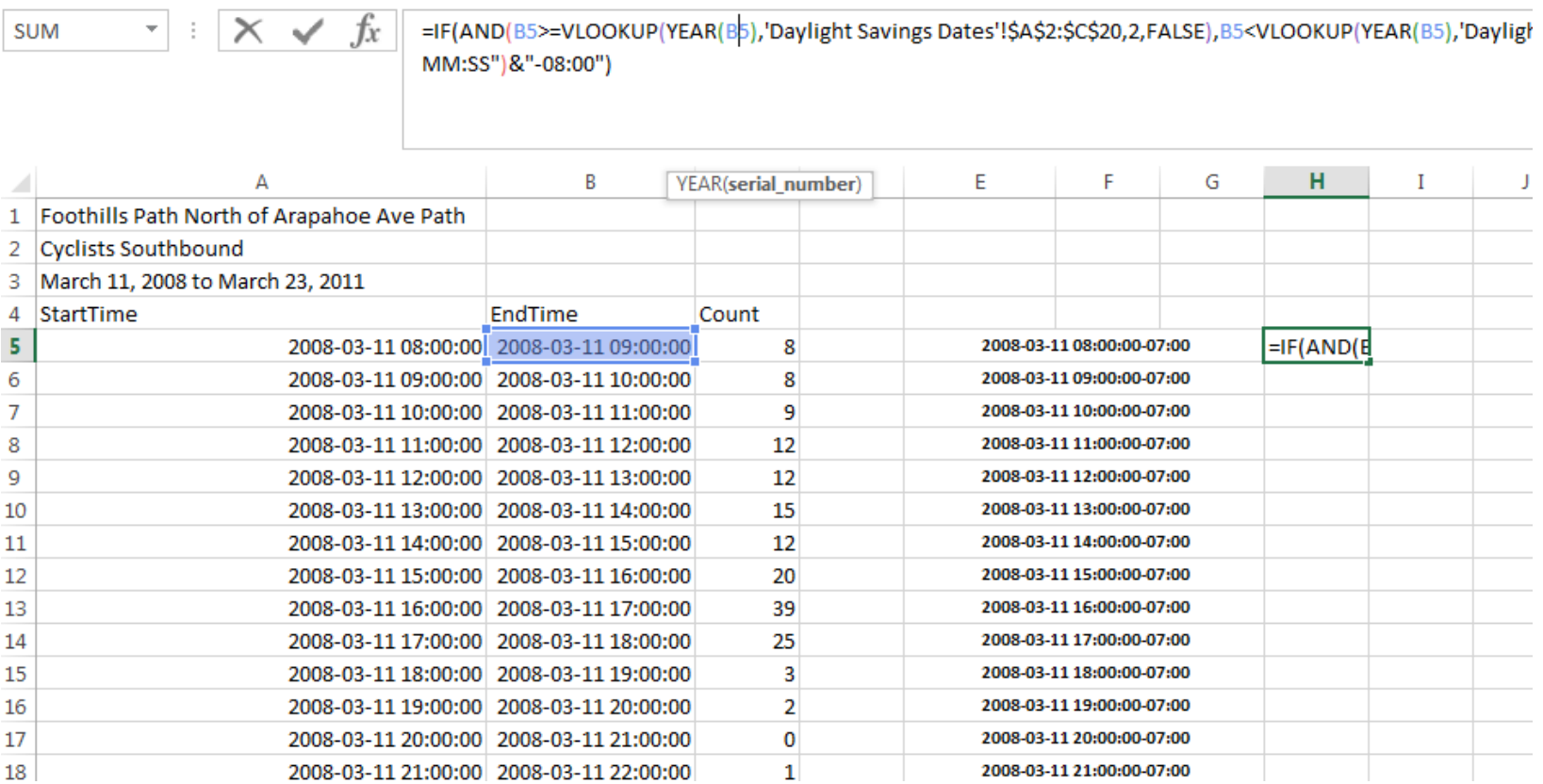

7. Copy and paste values of all new timestamps into columns $A$ and $B$ to replace the timestamps that don't have time zone indicators, to timestamps that do have time zone indicators. 
Calibri - 11 A A $\$$ - \%, 固

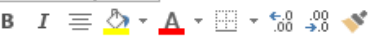

Foothills Path North of Arapahoe

Cyclists Southbound

March 11, 2008 to March 23, 2011

StartTime

2008-03-11 18:U0:00 LUU8-U3-11 19:00:00
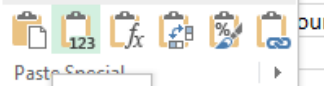

2008-03-11 20:00:00

2008-03-11 21:00:00

2008-03-11 22:00:00

2008-03-11 23:00:00

2008-03-12 00:00:00

2008-03-12 01:00:00

2008-03-12 02:00:00

2008-03-12 03:00:00

2008-03-12 04:00:00

2008-03-12 05:00:00

2008-03-12 06:00:00

2008-03-12 07:00:00

2008-03-12 08:00:00

2008-03-12 09:00:00

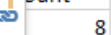

$\begin{array}{r}8 \\ \hline\end{array}$

8
9

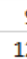

12
12

15

12
20

20
39

39

25
3

2

0

0
1

1

0

0
0
0

0
0

0

0
1

1

1
5

\begin{tabular}{l|l|l}
$E$ & $F$ & \\
\hline & & \\
\hline & \\
\hline $2008-03-$ & \\
\hline $108000000-07: 00$
\end{tabular}

2008-03-1 08:00:00-07:00 2008-03-1 09:00:00-07:00 2008-03-11 10:00:00-07:00 2008-03-11 11:00:00-07:00 2008-03-1 1 12:00:00-07:00 2008-03- 1 13:00:00-07:00 2008-03-\$1 14:00:00-07:00 2008-03-11 15:00:00-07:00 2008-03-1 16:00:00-07:00 2008-03-1 17:00:00-07:00 2008-03-1 18:00:00-07:00 2008-03-11 19:00:00-07:00 2008-03-11 20:00:00-07:00 2008-03-1 1 21:00:00-07:00 2008-03-1 22:00:00-07:00 2008-03-1 23:00:00-07:00 2008-03-12 00:00:00-07:00 2008-03-12 01:00:00-07:00 2008-03- 2 02:00:00-07:00 2008-03-2 03:00:00-07:00 2008-03-12 04:00:00-07:00 2008-03-12 05:00:00-07:00 2008-03-12 06:00:00-07:00 2008-03- 07:00:00-07:00 2008-03-i2 08:00:00-07:00
2008-03-11 09:00:00-07:00 2008-03-11 10:00:00-07:00 2008-03-11 11:00:00-07:00 2008-03-11 12:00:00-07:00 2008-03-11 13:00:00-07:00 2008-03-11 14:00:00-07:00 2008-03-11 15:00:00-07:00 2008-03-11 16:00:00-07:00 2008-03-11 17:00:00-07:00 2008-03-11 18:00:00-07:00 2008-03-11 19:00:00-07:00 2008-03-11 20:00:00-07:00 2008-03-11 21:00:00-07:00 2008-03-11 22:00:00-07:00 2008-03-11 23:00:00-07:00 2008-03-12 00:00:00-07:00 2008-03-12 01:00:00-07:00 2008-03-12 02:00:00-07:00 2008-03-12 03:00:00-07:00 2008-03-12 04:00:00-07:00 2008-03-12 05:00:00-07:00 2008-03-12 06:00:00-07:00 2008-03-12 07:00:00-07:00 2008-03-12 08:00:00-07:00 2008-03-12 09:00:00-07:00

8. Now columns A and B have time zone indicators tagged to the end of each timestamp Delete the columns used to generate the new timestamps from the formula, along with the 'Daylight Savings Dates' spreadsheet. Be sure to save your work and check for other data formatting requirements. Your file is now ready for upload into Bike-Ped Portal. 


\begin{tabular}{|c|c|c|c|c|c|c|c|c|c|}
\hline 4 & A & B & C & $\mathrm{D}$ & $\mathrm{E}$ & $\mathrm{F}$ & G & $\mathrm{H}$ & I \\
\hline 1 & Foothills Path North of Arapahoe Ave Path & & & & & & & & \\
\hline 2 & Cyclists Southbound & & & & & & & & \\
\hline 3 & March 11, 2008 to March 23, 2011 & & & & & & & & \\
\hline 4 & StartTime & EndTime & Count & & & & & & \\
\hline 5 & 2008-03-11 08:00:00-07:00 & 2008-03-11 09:00:00-07:00 & 8 & & \#VALUE! & & & \#VALUE! ! & \\
\hline 6 & |2008-03-11 09:00:00-07:00 & 2008-03-11 10:00:00-07:00 & 8 & 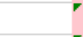 & \#VALUE! & & & \#VALUE! & \\
\hline 7 & 2008-03-11 10:00:00-07:00 & 2008-03-11 11:00:00-07:00 & 9 & 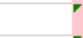 & \#VALUE: & & & \#VALUE! & \\
\hline 8 & 2008-03-11 11:00:00-07:00 & 2008-03-11 12:00:00-07:00 & 12 & 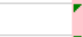 & \#VALUE: & & & \#VALUE! & \\
\hline 9 & 2008-03-11 12:00:00-07:00 & 2008-03-11 13:00:00-07:00 & 12 & 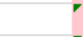 & \#VALUE: & & & \#VALUE! & \\
\hline 10 & 2008-03-11 13:00:00-07:00 & 2008-03-11 14:00:00-07:00 & 15 & r & \#VALUE! & & & \#VALUE! & \\
\hline 11 & 2008-03-11 14:00:00-07:00 & 2008-03-11 15:00:00-07:00 & 12 & 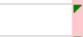 & \#VALUE! & & & \#VALUE! & \\
\hline 12 & $2008-03-11$ 15:00:00-07:00 & 2008-03-11 16:00:00-07:00 & 20 & & \#VALUE! & & & \#VALUE! & \\
\hline 13 & 2008-03-11 16:00:00-07:00 & $2008-03-11$ 17:00:00-07:00 & 39 & $\boldsymbol{r}$ & \#VALUE! & & & \#VALUE! & \\
\hline 14 & 2008-03-11 17:00:00-07:00 & 2008-03-11 18:00:00-07:00 & 25 & & \#VALUE! & & & \#VALUE! & \\
\hline 15 & $2008-03-1118: 00: 00-07: 00$ & $2008-03-11$ 19:00:00-07:00 & 3 & 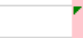 & \#VALUE! & & & \#VALUE! ! & \\
\hline 16 & 2008-03-11 19:00:00-07:00 & 2008-03-11 20:00:00-07:00 & 2 & & \#VALUE! & & & \#VALUE! & \\
\hline 17 & $2008-03-1120: 00: 00-07: 00$ & 2008-03-11 21:00:00-07:00 & 0 & $\checkmark$ & \#VALUE: & & & \#VALUE! ! & \\
\hline 18 & 2008-03-11 21:00:00-07:00 & 2008-03-11 22:00:00-07:00 & 1 & & \#VALUE! & & & \#VALUE! & \\
\hline 19 & 2008-03-11 22:00:00-07:00 & 2008-03-11 23:00:00-07:00 & 3 & 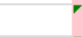 & \#VALUE! & & & \#VALUe! & \\
\hline 20 & 2008-03-11 23:00:00-07:00 & 2008-03-12 00:00:00-07:00 & 0 & & \#VALUE! & & & \#VALUE! & \\
\hline 21 & 2008-03-12 00:00:00-07:00 & 2008-03-12 01:00:00-07:00 & 0 & $r$ & \#VALUE! & & & \#VALUE! & \\
\hline 22 & 2008-03-12 01:00:00-07:00 & 2008-03-12 02:00:00-07:00 & 0 & $\checkmark$ & \#VALUE: & & & \#VALUE! & \\
\hline 23 & 2008-03-12 02:00:00-07:00 & 2008-03-12 03:00:00-07:00 & 0 & r & \#VALUE: & & & \#VALUE! & \\
\hline 24 & 2008-03-12 03:00:00-07:00 & 2008-03-12 04:00:00-07:00 & 0 & 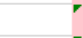 & \#VALUE! & & & \#VALUE! & \\
\hline 25 & 2008-03-12 04:00:00-07:00 & 2008-03-12 05:00:00-07:00 & 1 & r & \#VALUE! & & & \#VALUE! & \\
\hline 26 & 2008-03-12 05:00:00-07:00 & 2008-03-12 06:00:00-07:00 & 1 & 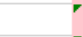 & \#VALUE! & & & \#VALUE! & \\
\hline 27 & 2008-03-12 06:00:00-07:00 & $2008-03-12$ 07:00:00-07:00 & 5 & & \#VALUE! & & & \#VALUE! & \\
\hline 28 & 2008-03-12 07:00:00-07:00 & 2008-03-12 08:00:00-07:00 & 13 & 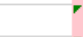 & \#VALUE! & & & \#VALUE! & \\
\hline 29 & 2008-03-12 08:00:00-07:00 & 2008-03-12 09:00:00-07:00 & 4 & & \#VALUE! & & & \#VALUE! & \\
\hline 30 & 2008-03-12 09:00:00-07:00 & $2008-03-12$ 10:00:00-07:00 & 6 & 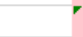 & \#VALUE! & & & \#VALUE! & \\
\hline 31 & 2008-03-12 10:00:00-07:00 & 2008-03-12 11:00:00-07:00 & 2 & & \#VALUE! & & & \#VALUE! & \\
\hline 32 & 2008-03-12 11:00:00-07:00 & $2008-03-12$ 12:00:00-07:00 & 8 & $\boldsymbol{r}$ & \#VALUE! & & & \#VALUE! & \\
\hline 33 & 2008-03-12 12:00:00-07:00 & 2008-03-12 13:00:00-07:00 & 5 & 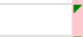 & \#VALUE! & & & \#VALUE! & \\
\hline 34 & $2008-03-12$ 13:00:00-07:00 & $2008-03-12$ 14:00:00-07:00 & 10 & r & \#VALUE: & & & \#VALUE! & \\
\hline 25 & 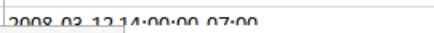 & 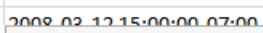 & 7 & 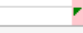 & \#MIUIEI & & & ? HNAMEI & \\
\hline & \begin{tabular}{l|l} 
& NENW_FoothillsPath_SB_Bike
\end{tabular} & Daylight Savings Dates & $\oplus$ & & & & & & \\
\hline
\end{tabular}

\section{Automatic Counters}

First, look up daylight savings time for the year of the data.

$\circ$ In the spring, there should be a gap (no data for 2:00 am on the day of daylight savings time, i.e. 1:00 AM, 3:00 AM). If there is a record for that time, delete the line if the count is zero. If the count is not zero, then add the counts for that time to the next hour.

$\circ$ In the fall, there should be two counts with the same date-time stamp (i.e., 2:00 AM, 2:00 AM). Add the two counts together, use this value for one of the date-time stamps and delete the other.

$\circ$ If there is no gap in the spring and no redundant data in the fall, we may have a problem. We need to make sure the counting device is actually adjusting for daylight savings time. Otherwise the summer counts might all be one hour off. Please check this with the detector manufacturer. 
5. One or more commas at the end of every line

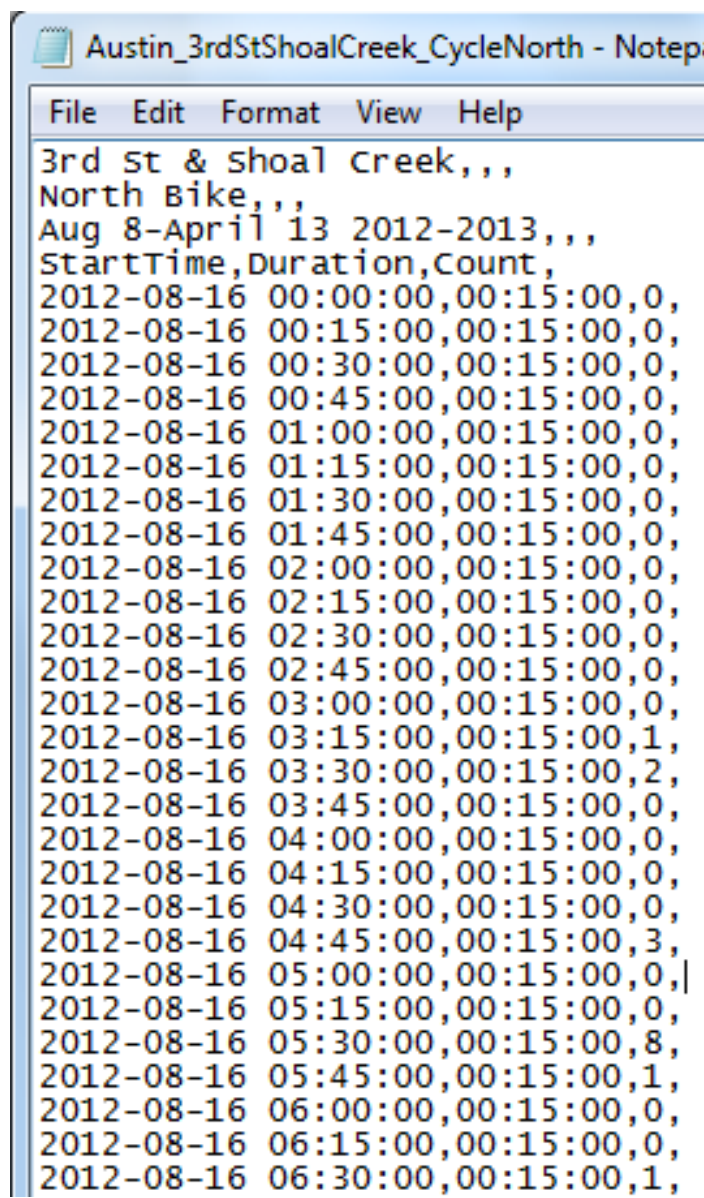

When opening a .csv file in Notepad after opening in Excel, commas may appear at the end of each line. This indicates a blank column. Reopen the file in Excel and delete the extra column(s) by selecting columns $\mathrm{D}$ and thereafter and Delete. The number of commas correspond with the number of blank columns. It is normal for the first three Reference Rows to have 2 commas after each line.

6. Data file is too large

Portal will not accept data files over about $20 \mathrm{MB}$ 
Transportation Research and Education Center

Portland State University

1900 S.W. Fourth Ave., Suite 175

Portland, OR 97201 